\title{
IntechOpen
}

\section{Dental Implantology and Biomaterial}

Edited by Mazen Ahmad Jawad Amin Almasri 



\section{DENTAL IMPLANTOLOGY AND BIOMATERIAL}

Edited by Mazen Ahmad Jawad Amin Almasri 
Dental Implantology and Biomaterial

http://dx.doi.org/10.5772/61473

Edited by Mazen Ahmad Jawad Amin Almasri

\section{Contributors}

Dalia Khalil, Bodil Lund, Margareta Hultin, Volkan Arisan, Mazen Ahmad Almasri, Federico Mussano, Tullio Genova, Luca Munaron, Maria Giulia Faga, Stefano Carossa, Nicola Mobilio, Francesco Mollica, Santo Catapano, Wen Lin Chai, Masfueh Razali, Wei Cheong Ngeow, Youssef Al Jabbari, Wolf-Dieter Mueller, Spiros Zinelis, Abdulaziz Al-Rasheed, Aleksa Markovic, Jaume Miranda-Rius, Eduard Lahor-Soler, Lluís Brunet-Llobet, David De Dios, Francesc Xavier Gil

\section{(c) The Editor(s) and the Author(s) 2016}

The moral rights of the and the author(s) have been asserted.

All rights to the book as a whole are reserved by INTECH. The book as a whole (compilation) cannot be reproduced, distributed or used for commercial or non-commercial purposes without INTECH's written permission.

Enquiries concerning the use of the book should be directed to INTECH rights and permissions department (permissions@intechopen.com).

Violations are liable to prosecution under the governing Copyright Law.

\section{(cc) BY}

Individual chapters of this publication are distributed under the terms of the Creative Commons Attribution 3.0 Unported License which permits commercial use, distribution and reproduction of the individual chapters, provided the original author(s) and source publication are appropriately acknowledged. If so indicated, certain images may not be included under the Creative Commons license. In such cases users will need to obtain permission from the license holder to reproduce the material. More details and guidelines concerning content reuse and adaptation can be foundat http://www.intechopen.com/copyright-policy.html.

\section{Notice}

Statements and opinions expressed in the chapters are these of the individual contributors and not necessarily those of the editors or publisher. No responsibility is accepted for the accuracy of information contained in the published chapters. The publisher assumes no responsibility for any damage or injury to persons or property arising out of the use of any materials, instructions, methods or ideas contained in the book.

First published in Croatia, 2016 by INTECH d.o.o.

eBook (PDF) Published by IN TECH d.o.o.

Place and year of publication of eBook (PDF): Rijeka, 2019.

IntechOpen is the global imprint of IN TECH d.o.o.

Printed in Croatia

Legal deposit, Croatia: National and University Library in Zagreb

Additional hard and PDF copies can be obtained from orders@intechopen.com

Dental Implantology and Biomaterial

Edited by Mazen Ahmad Jawad Amin Almasri

p. cm.

Print ISBN 978-953-51-2521-1

Online ISBN 978-953-51-2522-8

eBook (PDF) ISBN 978-953-51-7289-5 


\section{We are IntechOpen, the first native scientific \\ publisher of Open Access books}

$3,450+$

Open access books available
$110,000+$

International authors and editors

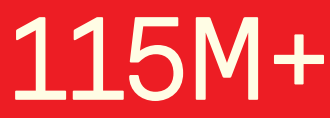

Downloads

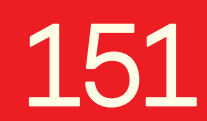

Countries delivered to

Our authors are among the

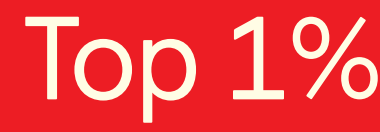

most cited scientists

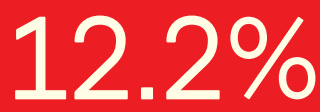

Contributors from top 500 universities

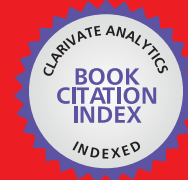

WEB OF SCIENCE ${ }^{\mathrm{TM}}$

Selection of our books indexed in the Book Citation Index in Web of Science ${ }^{\mathrm{TM}}$ Core Collection (BKCI)

Interested in publishing with us?

Contact book.department@intechopen.com

Numbers displayed above are based on latest data collected.

For more information visit www.intechopen.com







\section{Meet the editor}

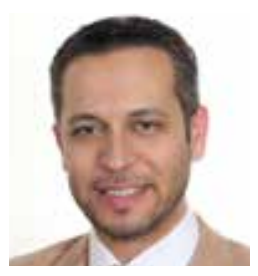

Dr. Mazen Ahmad Almasri is an Assistant Professor of Oral Maxillofacial Surgery at King Abdulaziz University (KAU), Faculty of Dentistry - Health Center (Jeddah, Saudi Arabia). He graduated from KAU with an honor degree back in 2002 and then went to McGill University Health Care Center (Montreal, Quebec, Canada) in 2005 for the training and education in the field of Oral

Maxillofacial Surgery, Reconstruction, and Dental Implantology, where he completed his residency training program, fellowship, and Masters of Dental Science degree in 2010. Subsequently, he succeeded to obtain the Canadian board of the Oral Maxillofacial Surgery specialty and became an active fellow of the Royal College of Dentist of Canada since 2009 (FRCDC 2009) as well as the American Board and becoming an active Diplomate of the American Board of Oral Maxillofacial Surgery since 2011 (Dipl. ABOMS, 2011). The inspiration of the "Clinician Scientist" vibe has been always an energy trigger for the McGillians' and the KAU's graduates, and hence he continued the line for advancing the clinical care as a surgeon in the hospital centers and office practice, as well as a researcher through the continuous publication of scientific papers, chapters, and textbooks. Furthermore, he is an active member of editorial and advisory editorial boards of a lot of international journals and publishing agencies directing the reviews and research contribution in the field. 



\section{Contents}

\section{Preface XI}

Section 1 Implant Clinical Managemet - Expectations and Reality 1

Chapter 1 Introductory Chapter : Dental Implantology, The Challenging Scenarios between Training, Resources, and Patients' Demands 3

Mazen Almasri

Chapter 2 Antibiotics in Implant Dentistry 19

Dalia Khalil, Bodil Lund and Margareta Hultin

Chapter 3 Dimension and Structures of Biological Seal of Peri-Implant Tissues 39

Wen Lin Chai, Masfueh Razali and Wei Cheong Ngeow

Section 2 The Applications of Ceramic Dental Implants 61

Chapter 4 Ceramic Biomaterials for Dental Implants: Current Use and Future Perspectives 63

Federico Mussano, Tullio Genova, Luca Munaron, Maria Giulia Faga and Stefano Carossa

Chapter 5 Ceramic Materials as an Alternative to Titanium for Dental Implant Fabrication 91

Mobilio Nicola, Mollica Francesco and Catapano Santo

Section 3 Implant Surface Treatment 107

Chapter 6 Treatments to Optimize Dental Implant Surface Topography and Enhance Cell Bioactivity 109

Jaume Miranda-Rius, Eduard Lahor-Soler, Lluís Brunet-Llobet, David de Dios and Francesc Xavier Gil 
Chapter 7 The Role of Hydrophilic Sandblasted Titanium and Laser Microgrooved Zirconia Surfaces in Dental Implant Treatment 129

Aleksa Markovic

Chapter 8 The Effects of Surface Roughening Techniques on Surface and Electrochemical Properties of Ti Implants 153

Youssef Al Jabbari, Wolf Dieter Mueller, Abdulaziz Al-Rasheed and Spiros Zinelis

Section 4 Non Autogenous Grafting Healing Pattern 169

Chapter 9 Biodegradation of Injectable Calcium Phosphate Bone Cements: A Dental Perspective 171

Volkan Arısan 


\section{Preface}

Dental implantology is a dynamic science that is evolving very fast. The current era of technology and social media has added more pressure to reach a superior quality in health care and cosmetics. As every aspect in life, a lot of challenges stood up to the mission. As a surgeon dealing with dental implants and facial reconstruction, almost on a daily basis, the challenging vibes are always there especially after a long consultation visit of a severely compromised case requiring multistep rehabilitation, ended up by receiving a shy patient's wish stating, "I can't wait for 6 months or so to complete the whole process". I honestly totally agree with the patient's wish, and I do feel that the science of dental implant has a lot to provide to our clients. And that is raising the question of "how can we make it better and faster" to meet every patient's expectation and social obligations at the current era of the twenty-first century.

Occasionally, practitioners in the field will try to be as idealistic as possible in all aspects of care, and usually that means more preparation, more surgical reconstruction, and hence more time on patients cost, however, such is considered totally unrealistic. Hence, the art of customizing a specific rehabilitation plan can be the secret to solve the predicament depending on science, tools, manpower, and the technology that can provide that plan.

To be able to do so, it is of prime importance to understand how wide is this specialty. It requires a lot of knowledge about the basics of healing biology, including bone, graft, soft tissue, and adding an external metallic or ceramic material into them and hoping for the complex to be in a stable well-being for lifetime. It can be as simple as placing a single implant in a well-prepared site and can get much more complicated once dealing with compromised sites or compromised health, such as trying to treat sick elderlies with significant tissue deficiency. A lot of texts have discussed the basics and beyond; however, still more are needed to keep up to the best expectations and outcomes in this comprehensive dental implant science.

When the clinical expertise is put together with evolving research and technology to improve the service, that is when updates in the field can be applicable. Hence, the book "Dental Implantology and Biomaterial" has gathered a special group of unique scientists from more than 10 countries, including Germany, Greece, Italy, Iran, Malaysia, Saudi Arabia, Serbia, Spain, Sweden, and Turkey, who discussed "hot" clinically applied correlated research topics in a single book to enrich the idea of a "focused updates" toward dental implantology, linking the involved specialties with scientific tips and tricks in the field. Clinicians, postgraduate residents, researchers, and students can find this book stimulating to improve their practice and initiate more research ideas in the subject. The beauty is about reducing the gap 
between the laboratory science and the clinical application, and that is what forms the main value of the book.

"Dental Implantology and Biomaterial" started with an introductory chapter discussing the clinically applied dental implant practice through a direct link to the main factors of success and failure. The chapter will discuss exciting challenging cases, technical maneuvers, and showing some complications. This chapter will be the door to discuss some solutions through current research topics that are modifying implant surfaces and improving the implant biological seal in relation with the soft tissue envelop, improving the implant surface, narrowing the diameter, or using a white implant surface material that can present valid solutions in demanding locations in the oral cavity such as the cosmetically challenging anterior maxilla.

Every implantologist will be dealing with the shortcomings of alveolar bone deficiency in different shapes and forms, in horizontal or/and vertical dimension. Although it is well known that autogenous grafting is usually the best, it might not be applicable based on the clinical scenario or patient's preference and hence, discussing an alternative such as nonautogenous calcium phosphate biodegradable products is useful. All the former can be compromised if the "bacterial load" factor is not considered in managing such cases and hence the relation and the application of antibiotics are thoroughly discussed as well.

As timing is always a prime topic of discussion with almost every patient seeking implant rehabilitation, the feasibility to put implants in full function is a point of continuous research. Although a lot of studies are using the primary stability path as an indicator for rehabilitation, it should be carefully approached. Improving the implant surface characters and using an objective method to check secondary stability such as the resonance frequency analysis is presented. However, the long-term relation with the soft tissue envelope is another challenge that should be linked with the success of the treatment provided.

It makes all the contributing authors and myself as an editor and contributor, proud to share an experience that I prefer calling "focused and diverse" in the wide field of "dental implantology". I hope that it can be a uniquely excellent reference to clinicians, trainees, and researchers in the field.

As life goes, missions will evolve surrounded by challenges that might help pursuing them or letting them go. Although, I am a big believer in positive and negative energy impacts; as an oral maxillofacial surgeon, I do believe as well in the power of utilizing those energies to the best paths ever. It does imitate a surgical challenge in the theatre that would urge cutting through, camouflaging, or just excising. Therefore, a positive surrounding will definitely boost up the energy, whereas a negative one should be forced with a spirit of refocusing and that is what a real training in oral maxillofacial surgery is all about and that is what we should be training our younger trainees to pursue for the future of education and health care. Hence, I am pleased to acknowledge all my friends, teachers, peers and colleagues whom I was lucky to have around in my life. Their presence has been always pleasant and supportive to me on the personal as well as the professional level; "You've been always an 'energy boost', God bless you all." My family members: "thank you dear Father Ahmad Jawad, mother Fatma, wife Najiah, and lovely children, for keeping up with my busy schedule and me." 
King Abdulaziz University, Faculty of Dentistry: All the faculty, administration, and staff with special gratitude to dear colleagues, teachers, and friends:

Abdulghani Mira, Motaz Ghulman, Ali Alghamdi, Yaser Alkhiari, Fahad Alsulaimani, Ali Habib, Zuhair Al Morshed, Ahmad Alyamani, Amr Bayoumi, Ahmad Jan, Maisa Alsubaie, Basem Jamal, Mohammad Alghamdi, Mohammad Shah, Wael Elias, Hosam Baeshen, Moath Attar, Samar Alagi, Abeer Alnowaiser, Mohammad Khalil, Ibrahim Yamani, Lina Ashi, AbdulElah Binmahfoz, Osama Qutob, Loai Alsofi, Mohammad Huwait, Khalid Merdad, Dina Altayeb and Ayman Johar

And a special gratitude to the following personnel at the administration section: Mr. Fouad Abdulmajed, Abboud Mohammad, Khalid Alshehri, Rajallah Alsulami, and Farid Alzahrani.

McGill University: Timothy Head (RIP), Jocelyn Feine, Richard Emery, Michele Elhakim, Antoine Chehadi, Deborah Iera, Julia Pompura, Paul Allison, Mark Shenouda, Alex Dostie, Aldo Camarda, and Dennis Kalloyannis.

The Saudi Board of Oral and Maxillofacial Surgery (The Saudi Commission of Health specialties): Colleagues and friends whom I had an honored chance to operate, educate, and research with: Abdulla Al-Etel, Mohammad Alkindi, Khalid Almutairi, Abdulrahman Alosaimi, Abdulsalam Aljabbab, Sulaiman Alruwaili, Raed Shata, Fahad Aljayar, Bader Aljandan, Emtenan Abdulmajed, and Ebtesam Aljerb.

King Khalid University: Ibrahim Alshahrani, Mohammad Alfarsi, Yousef Algarni, Saad Alqahtani, Adel Mostafa, Ashraf Gebreel, Abdulnaser Sulaiman, Khalid Bdair, Zahir Kota, Kamran Bokhari, Abdulbagi Mostafa, and Ghatafan Alnohaily (RIP), and Mohammad Dallak.

Dentalia Specialty Clinic: Ahmad Halawani, Wassim Saati, Zainab Saati, Jowdat Jamulddin, Nada Jamaluddin, Hasan Shaikh, Hasan Kathiri, Ahmad Hani, Wahid Mohammad, and the amazing coordinators: Rana Anjum, Hanan Beyan, Mohammad Saafan, Rawan Almalki, Morooj Masriya, Eman Tolba, and Moneera Alsulaimani

And finally, I would like to acknowledge the support of the InTech publishing agency members: Ana Simcic, Romina Rovan, Iva Lipovic, and Ana Pantar. Thank you for being patient and supportive throughout the project.

Mazen Ahmad Almasri, BDS, MSc, FRCD(C), Dipl. ABOMS Consultant of Oral Maxillofacial Surgery/Reconstruction and Implantology Assistant Professor, Department of Oral Maxillofacial Surgery Faculty of Dentistry, King AbdulAziz University Jeddah, Saudi Arabia 

Section 1

Implant Clinical Managemet - Expectations and Reality 

Chapter 1

\title{
Introductory Chapter : Dental Implantology, The Challenging Scenarios between Training, Resources, and Patients' Demands
}

\author{
Mazen Almasri \\ Additional information is available at the end of the chapter \\ http://dx.doi.org/10.5772/63834
}

\section{Introduction}

Dental implant is a dynamic science that practitioners are relying on for oral rehabilitation. Due to the higher success rate, dental care is turning more and more toward using implantbased oral prosthetics. However, the drawbacks are still of concern in this field due to errors occasionally encountered among practitioners with improper training, weak knowledge, or underestimating the case difficulty. Those errors can accumulate at each phase during the process of planning, taking records, interpreting data, surgical intervention, prosthetic rehabilitation, and finally the maintenance program. Furthermore, the misleading marketing messages that can introduce novel tools or ideas if not handled carefully especially by junior or nonspecialist practitioners. What adds more to the complexity of this aspect is what I like calling the "case requirement," (CR) which is not a secret neither a mysterious side in the field, it is just being forgotten occasionally. "Case requirement" is indicating another dimension to the field of rehabilitation based on the applicability factor, patient's preference, and demands that are becoming sophisticated more and more in the 21st century [1]. As the rhythm of life is moving faster, communication is following and hence the patients' outcome demands, to be faster and precise.

In this chapter, we are aiming to introduce the textbook to readers in the field of oral maxillofacial rehabilitation through cases of special challenges that might face practitioners in the field. The consideration of the $\mathrm{CR}$ aspect and the anticipation of future research will enlighten possible solutions and pitfall tactics. Yes, we are trying to be as idealistic as we can; nonetheless, we will always be facing factors that might modify our intervention. The trick is to find this perfect customized management plan [2]. 
Hence, the dynamic advancement in the field is taking place on different levels that are important for any implantologist to comprehend, at the clinical, micro, and nano levels. The implant surface characteristics, the implant soft tissue interface, alveolar bone reconstruction, the involvement of micro-organisms, the indications of antibiotics in implant surgery, osseointegration, cellular attachments, and the advancement of implant designs are all areas of important research topics nowadays that are going to be explored in the book hoping to present more options for future care.

It is well known that training in the dental implant field usually starts with the basics of planning, starting from case interview, examination, investigational images, analyzing the data, considering case requirement, finalizing the rehabilitation plan, dental extraction, alveolar reconstruction, implant surgical installment, prosthetic rehabilitation options, patient cooperation, and establishing a recall schedule. It is unfortunate that a lot of training programs are focusing mainly on the technicalities including implant placement and prosthetic restoration while forgetting the importance of the scientific background in applying the clinical practice. And it causes a dilemma via producing graduates who are not able to connect the basic science, research, clinical application, and the future potential to improve the field. Therefore, it is not uncommon that during residents teaching, rounds, and board exams, candidates might show technicality excellence without knowing the justification, and hence, reaching into a block when facing a challenge in a case, a complication, or an examination question.

The technical advancement in dental and medical care is continuously improving and producing ideas; however, still a lot of doubts that one day technology might replace a human surgeon to operate on another human solely. The reason behind that doubt is the simple existence of human race that will always show variable clinical conditions that can never be the same and might differ on three major categories, patient's, operator's, and material's pertinent factors.

\section{Patient-related factors}

These are defined as factors mainly pertinent to the patient him/herself that include and not limited to the medical background, anxiety, allergy, smoke history, anatomical variations, implant site local challenges, local bone type, local topography, and the personal preference. The patient preferences can be limitless, which include a demand in implant type, surgical intervention, grafting technicality, prosthetic end result, and the mostly challenging the time frame demand. The reason that time frame is very challenging, as it is mainly affected by the body's healing power, which some time can never add much except of waiting few more weeks [3]. However, research shows promising results by modifying the implant surface itself, as will be discussed in the forthcoming chapters. On the patient's level, the use of stem cells, growth factors, and systemic drugs to improve osseointegration is being experimented to improve the healing power $[3,4]$. 


\subsection{Surgical site alveolar deficiency}

Surgical site evaluation to identify vertical or horizontal deficiency has been an area of continuous challenge to implantologist [5]. The techniques of management are beyond the scope of this chapter, but the importance of mastering more techniques to manage such challenges is an area that should be considered while training. Not to mention that not all cases would accept manipulating their jaws in a way to reconstruct it back to its original. And hence, the necessity to formulate boundaries in the practice according to what can be done for a patient or what has to be compromised (Figures 1-5).

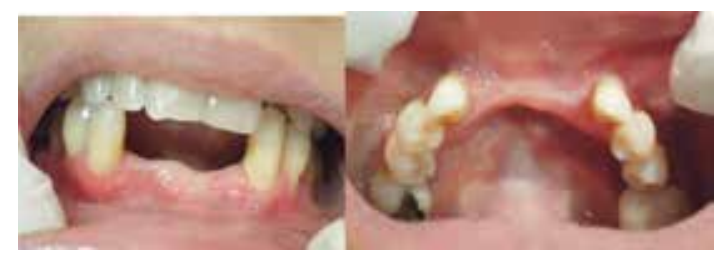

Figure 1. Intraoral clinical images showing bone deficiency at the vertical and horizontal levels leading to minimal gingival recession pertinent to the lower canine teeth.

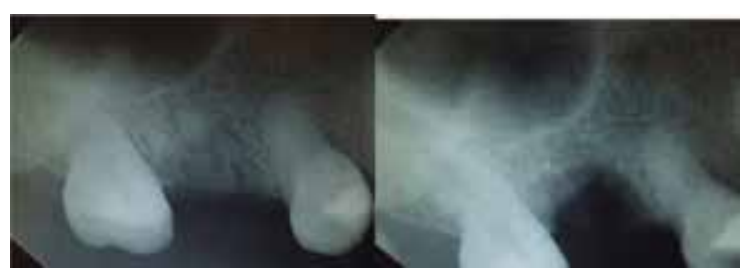

Figure 2. A periapical radiograph showing remaining roots of a previously attempted dental extraction performed in another practice few months ago. The patient was upset and demanding dental implant treatment on site without delay. Therefore, after thorough discussion on the operative procedure, risks, benefits, alternatives and modification plan, careful manipulation of the surgical site was exercised to remove the buried roots aiming to preserve the surrounding bone structure otherwise placing an implant immediately can be aborted and switching the procedure to alveolar bone grafting only will take place. However, the extraction was performed successfully with preservation of the buccal plate and confirming the socket dimension area with the periapical radiograph on the right side.

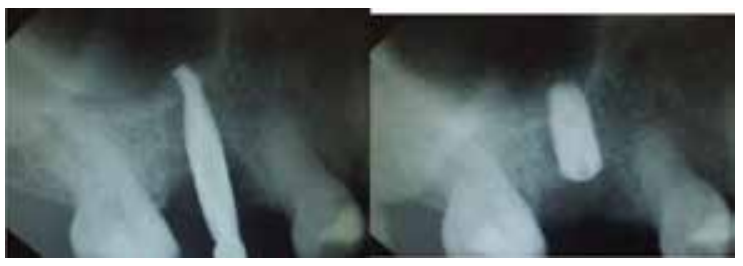

Figure 3. The surgical site was carefully prepared and the implant osteotomy was performed aiming at bone conservation and immediate implant placement that was accomplished successfully with good primary stability achieved at the apical portion at the sinus cortical boundary. 

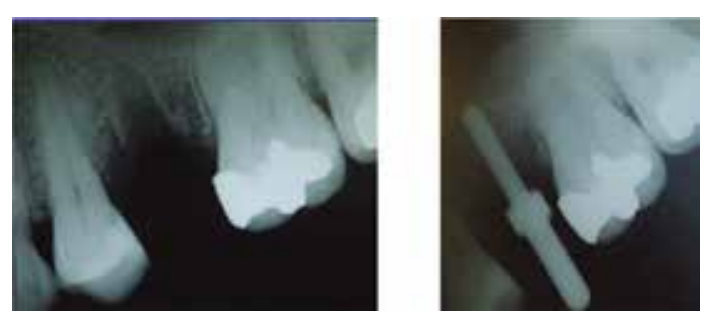

Figure 4. A radiograph of a 50-year-old patient showing limited vertical bone height to place dental implant. The patient was offered a sinus lift procedure and was not a choice of preference to the patient. The option of short implant insertion was discussed including risks, benefits and alternatives, and it was more appealing to the patient. The figure on the right shows the pin guide indicating the length and parallelism.

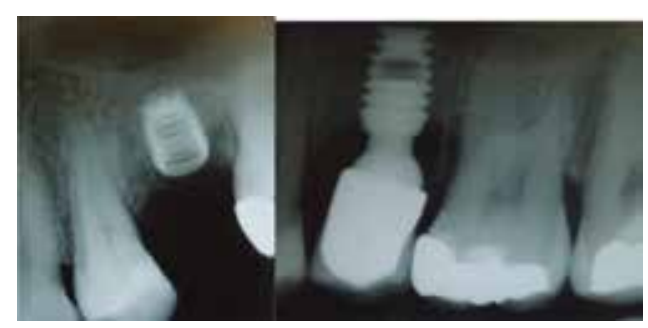

Figure 5. A periapical radiograph showing the short implant in situ and the crown placed in favorable status. The restoration and functional result were satisfying to the patient and achieved the "case requirement" demands.

\subsection{Local blood supply deficiency}

The era of osseointegration is based on the viable existence of an implant and bone interface. The former is anatomically defined via a viable osseous region containing adequate blood perforates to facilitate the implant-bone relation. Sometimes, missing to identify cortical areas of poor blood perforates, especially in older patients, can be the reason behind the success or failure. The following cases show examples of local compromise (Figures 6-9).

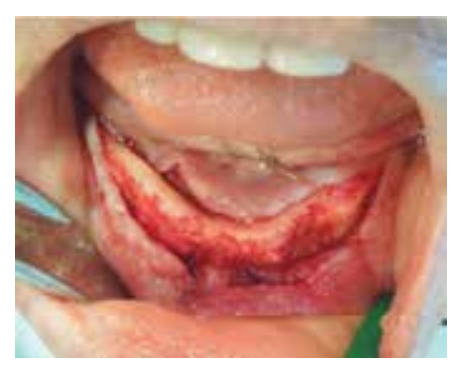

Figure 6. A 75-year-old female patient who was known to be diabetic that is controlled and followed by an endocrinologist. The clinical image shows alveolar bone local limited blood supply at the crestal level when compared to the buccal plate perforates. It has to be carefully considered when planning osteotomies for implant placement. 


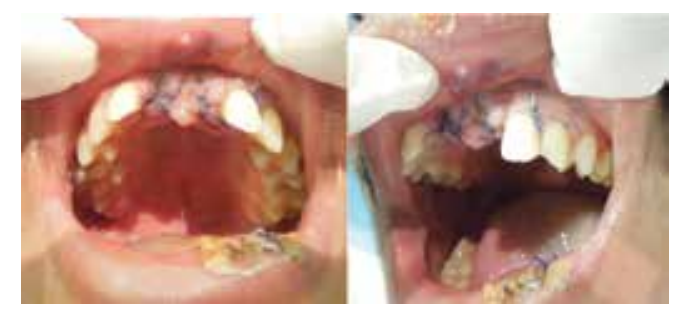

Figure 7. A 19-year-old male patient went through road traffic accident leading to avulsion of the anterior central incisors, dentoalveolar fracture, and a minimally displaced left lateral incisor. The primary care was undergone at the emergency department as localized dentoalveolar reduction and lateral incisor reduction with wire splinting. The patients presented to the clinic 3 days after the accident are concerned about the rehabilitation of the anterior maxilla. This scenario might lead to significant post-trauma alveolar bone loss and gingival deformity if not planned carefully for dental implant-based rehabilitation.

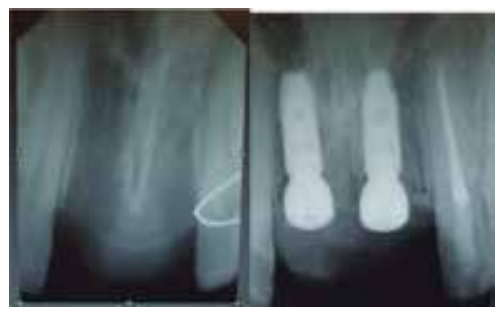

Figure 8. Periapical radiographs showing the central incisors intact socket status, and the implants were placed 10 weeks after the accident to minimize the bone resorption trauma effect especially at the buccal plate aspect. The dental implants were placed carefully aiming at keeping sufficient hard and soft tissue for future cosmetic rehabilitation in addition to buccal plate augmentation. The radiograph on the right shows the preservation of the vertical height of the interimplant site to help supporting the interdental papilla later on.



Figure 9. The radiograph shows a favorable crown coping and favorable interimplant bone level as being counted for the future support to interdental papilla, avoiding black triangles in the anterior maxilla, a dangerous cosmetic region. 


\section{Operator-related factors}

The operator's factors include the expertise, training background, operator's capabilities, personal interest to introduce new techniques, knowledge of data interpretation, the presence of a supporting team, and the talent to adjust with the challenging case requirement. As much as it is fair to all patients, as much being part of the code of ethics at any area of practice around the world, the capabilities of practice must be clearly disclosed. An example of the surgical specialties is oral and maxillofacial surgery (OMS or OMFS) that is a practice of intensive training in the oral, facial, head, and neck regions that would share continuous interventional skills at the maxillomandibular complex. It can include major interventions or millimeter cosmetic part of care. OMFS intensive training around the area usually produces practitioners of crucial sense when it comes to estimating details of blind maneuvers, osteotomy direction, depth gauging, tactile dexterity to length and width, tactile sense to osteotomy structure of nature, and confidence in managing perisinus structures and jaw components [5]. As more specialties are sharing the implant part of health care practice, it is important to consider such reality in managing cases of special challenges, systemically as well as locally. Especially those implant survival studies show variable success outcomes depending on the specialty of practice [6-8]. Nonetheless, the interspecialty consultation to manage a case is what matters to clients seeking dental implants. The multispecialty consultations and teamwork practice will always provide the best care possible.

\subsection{Narrow dental implant}

In locations of limited mesiodistal width, the ability to place an implant can be jeopardized by a lot of factors, such as the flap design, root angulation, coronal tilting, alveolar bone dimension, and operator's clinical skills to place an implant usually via one or two drilling sequences only, which can leave no room for corrections neither over preparation of osteotomy sites (Figures 10-12).

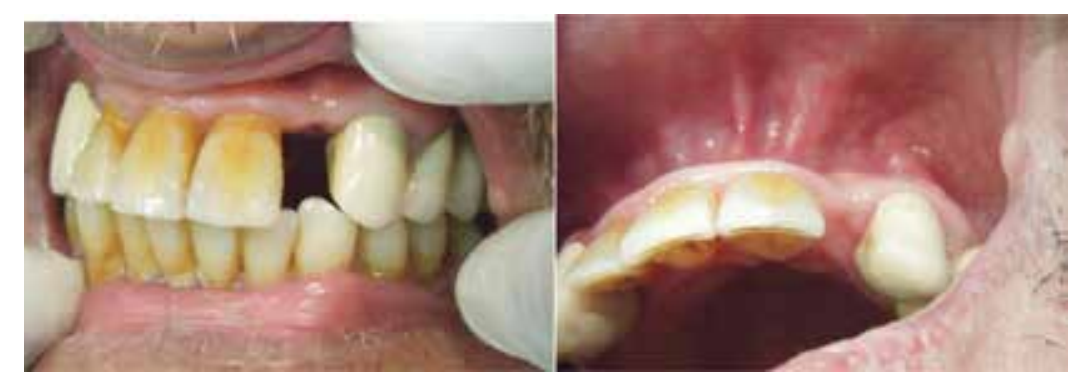

Figure 10. A clinical image showing a challenging narrow location of missing left lateral incisor. The patient is 70 years old and asking for implant-based rehabilitation. The plan was to place a narrow implant in the area with minor odontoplasty to plan for cosmetically pleasant maxillary lateral incisor. This area constitutes part of the cosmetically challenging region, the anterior maxilla. 


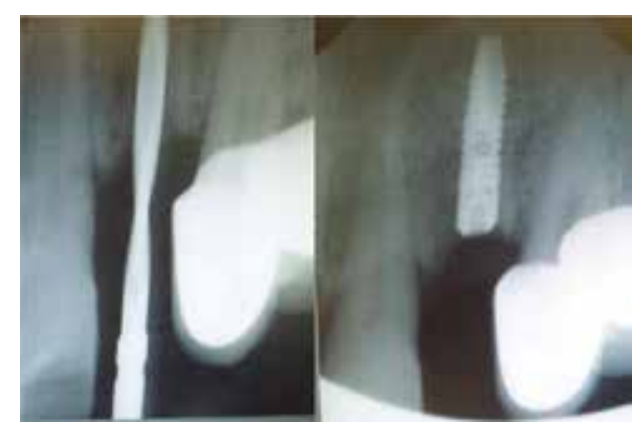

Figure 11. A flap was raised to carefully prepare the narrow implant site as a single osteotomy attempt is usually valid for such cases with limited opportunity to redirect. Hence, a flapless procedure is discouraged in such cases. The clinical picture on the right shows favorable position for future rehabilitation based on the case requirement.



Figure 12. An intraoperative pin direction X-ray indicating the limited space and favorable inclination for drilling in correlation with the intraoperative clinical setting. The aforementioned counts are necessary to adjust location and direction on the first attempt. The postoperative radiograph on the right shows the implant position in accordance with the plan in the three dimensions, apicocoronal and mesiodistal. The clinical correlation is of prime importance to adjust all the dimensions including the buccolingual dimension as presented in Figure 11.

\subsection{The challenge of onlay bone grafting}

The science of onlay bone grafting is evolving rapidly to match up the challenges that are facing the surgeons in the field or oral implantology and reconstruction. It is well known that inlay defect bone fill is much more predictable than onlay defects [9-11]. The technique of application and the materials used are variable, including allogenic, alloplastic, bone morphogenetic proteins, and xenograft graft materials. Not to mention the time factor of managing extraction sockets in either immediate or late phase to prepare implant placement [12-14]. The operators have to have the ability to properly select the best reconstructing 
technique in each case separately and to avoid limited techniques to do so. The cases will always be different as introduced in the following cases (Figures 13-15).

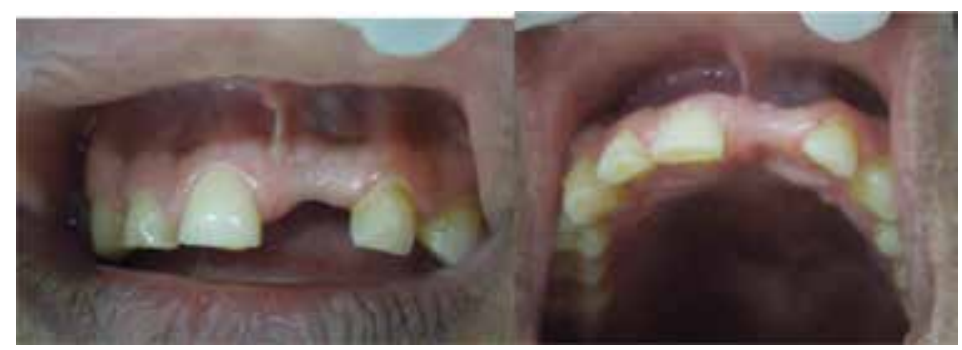

Figure 13. A 33-year-old male patient presented with missing left central incisor for more than 6 years secondary to trauma. The clinical examination and investigatory cone beam CT scan images were suggesting the possibility of having an alveolar bone space for implant placement with simultaneous grafting.

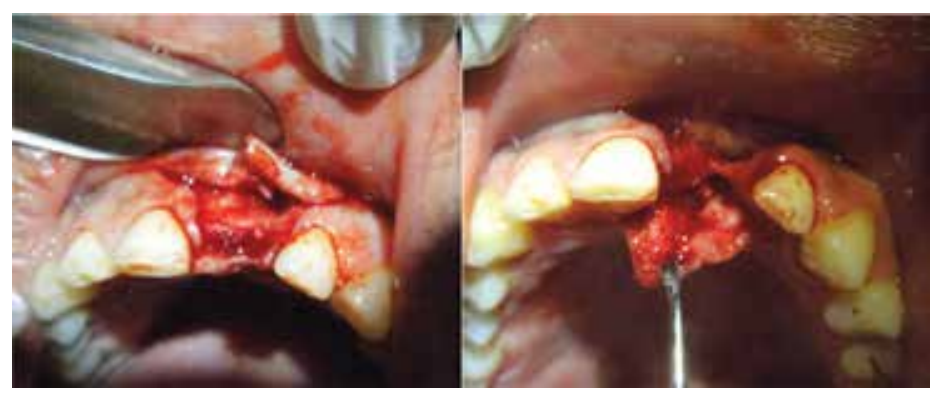

Figure 14. A clinical intraoperative image of the previous case showing the flap raised and indicating an extremely poor alveolar bone horizontal width that prohibits the implant placement and switch the procedure to a local grafting using particulate allogenic graft with calcium sulfate carrier to improve the consistency and bulk.

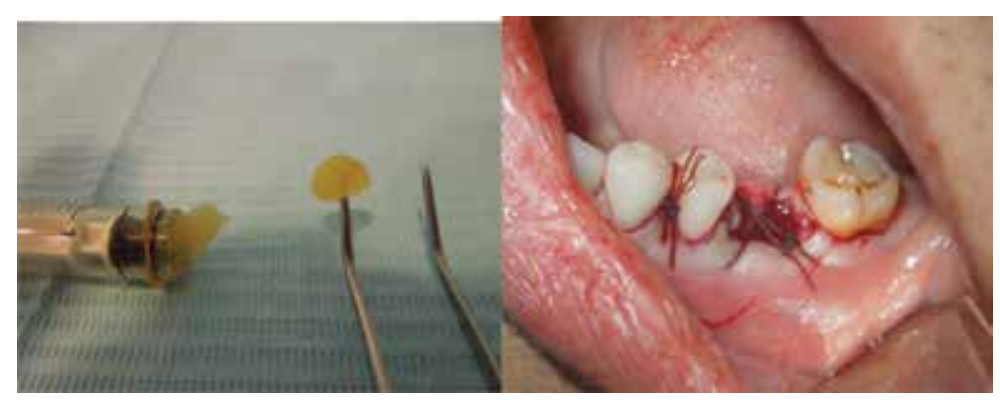

Figure 15. A clinical picture showing a putty-like bone graft that can be molded and sustain acceptable consistency and bulk for alveolar bone reconstruction. The picture on the right shows the location postgrafting that did not require any membranes to be placed due to the consistency of the material and the carrier barrier [11,12]. The option of either using bone mophogenic protein delivered via carriers or using a graft contained in an alloplastic membrane cover is amenable for onlay or inlay alveolar defects reconstruction $[13,14]$. 


\section{Material-related factors}

When it comes to the material's factors, it includes the implant surface type, length, diameter, internal design, external design, laboratory capabilities, managing challenges, images capabilities, surgical stents, radiographic imaging, cone beam CT scanning (CBCT), and finally, the proficiency to manage the time factor.

It is not uncommon these days to observe cases being treated while omitting the role of case planning in the laboratory and mocking future results. The former is much critical when planning a case going through comprehensive care including orthodontics management. The controversy of completing the dental alignment before implant insertion is advocated in order to avoid any misplacement of the dental implant [15]. Proponents claim the loss of alveolar bone by the time of completing the orthodontic care couple of years later that warrants more challenging reconstruction, grafting, implant insertion, and delaying the rehabilitation care, not to mention the cumulative cost. Proper planning and inter specialty consultations can provide better results and can always manage such cases either way (Figures 16-18).



Figure 16. The planning of implant insertion while performing orthodontic treatment is an issue of discussion. It has the advantage of utilizing the bone while in favorable width and height better than waiting for the prolonged time of orthodontic treatment that will lead to significant alveolar bone resorption and hence a future challenge of implant placement, root exposure, not to mention the further delay in oral rehabilitation [15]. This can only be applied in selected cases based on careful planning.

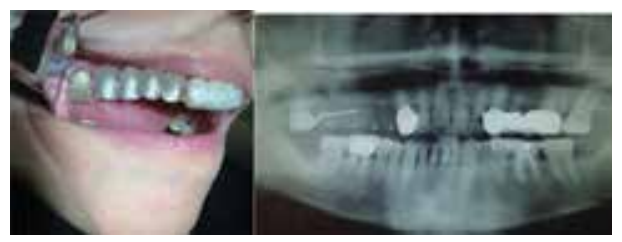

Figure 17. This case was planned for multiple dental implants in the upper right maxillary region using surgical stent that was reviewed in the lab by the prosthetic team. The stent was used in the presence of the right wisdom tooth helping in precise stability of the stent in localizing the future implant sites, AKA, tooth-supported surgical guide, that is considered more precise compared to the other two types of surgical guides, the mucosa-supported and the bone-supported surgical guides. However, the wisdom tooth will be extracted once the objective is achieved intraoperatively [16]. 


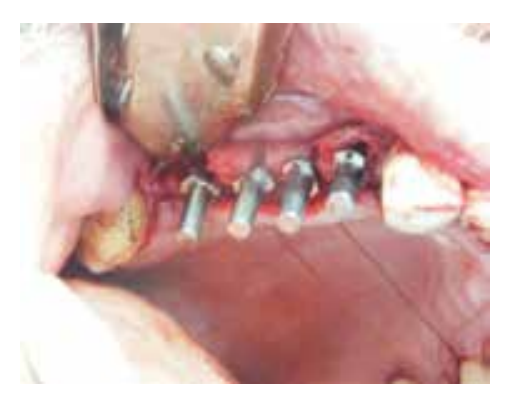

Figure 18. The implant locations were precisely identified using pin guides with clinical relevance to carefully place the implants in this limited site from buccopalatal dimension. The right maxillary wisdom tooth (third molar) was extracted at that point. The buccal plate deficiency reconstruction was considered at earlier stage in addition to the expected inlay defect post third molar removal [17].

\subsection{Dental wax-up and surgical stent fabrication}

The dental wax-up is a necessary tool used to plan dental implant treatment. It is not only used for estimating the exact location and size of an implant, it is used as well to plan orthodontic movement and future grafting sites $[16,17]$. The application of the conventional laboratory surgical stent or CBCT-based stent might lead to the same result. The comprehension of the best utilization and avoiding possible errors are the factors that matter. Hence, interspecialty consultation at the primary visits would save time and interventions from the surgical point of view. As more time elapsed, the more bone loss, and the more challenging alveolar reconstruction and implant care.

\subsection{Cone beam scan application in dental implant therapy}

Part of the advancement in dental implantology care is represented by the use of cone beam $\mathrm{CT}$ scan (CBCT). Although not all cases might require CBCT image-based planning, the significance does exist among specific cases where the three-dimensional orientation is the key to success $[16,18]$. Hence, it requires knowledge and skills for analyzing the images and supporting the clinical correlation (Figures 19-21).

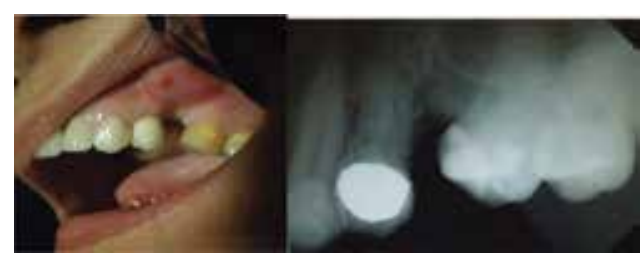

Figure 19. A 42-year-old female patient presented with a missing left second premolar that is challenged horizontally by crown tilting and pneumatized maxillary sinus. The radiographic image shows the shadow of maxillary sinus pneumatization leaving limited alveolar height, radiographically. Therefore, CBCT scan was carried out and showed an overimposed sinus floor distopalatally with an extraction socket space barely limited for an implant placement without sinus lifting. The case review, risks, benefits, and alternatives were discussed and consented to proceed. 


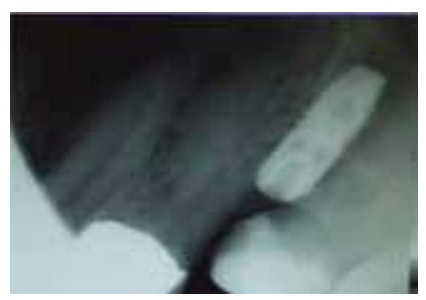

Figure 20. The surgical site was exposed and the previous socket space was identified and carefully followed to place the implant in situ. The evaluation of the osteotomy site confirmed intact edges without sinus violation, and hence, the implant was inserted. The postoperative periapical radiograph can be deceiving to the position of the implant as it shows a superimposition on the sinus floor and close proximity to neighboring teeth which was double confirmed clinically and using a postoperative CBCT scan (see Figure 21).

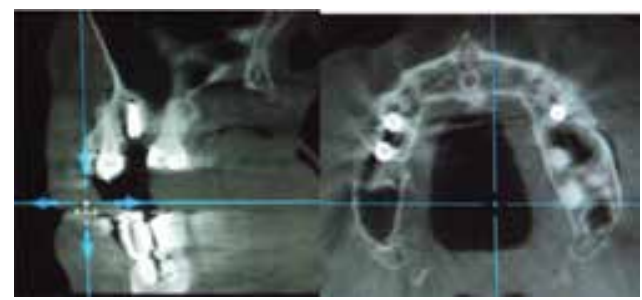

Figure 21. A postoperative CBCT scan shows the previous case of proper implant location that is not violating the sinus or dental structures as confirmed by parasagittal and axial views.

It can be noticed that all the former categories, such as the patient's, operator's, and material's, are linked to all the implant cases, in this chapter, forthcoming chapters, and possibly all over the world. Improving the service, survival, time factor, esthetics, and final results are the factors that result in success. And that is the involvement of current research to improve the implant therapy. Hence, cases are not going to be the same, and the difficulty levels will always dictate the methodology of intervention.

\section{Challenges of implant training vs. iatrogenic issues}

Just like anything in life, improper training will lead to disasters. The current observation of awkward complications is presented due to the jeopardized weekend diplomas, nonaccredited training programs, downgrading the training duration, and mixing the specialties of care. The phenomena of picturing dental implantology as a practice of placing a pin in the bone and then sticking a crown on top is putting this field in a lot of danger, not to mention the marketing twists in using medical terminologies such as flapless, sutureless, graftless, painless, harmless, and so on. The former will send false massages to the community, the students, and general practitioners. It is imperative to communicate evidence-based clinical application when it comes to health care science. The importance of basic science, the comprehension of variable 
methods of practice, and the advent of current technology will add up to the training products and will never facilitate shortcuts.

The last section of this chapter will be showing few examples of cases that could have been carried out in a better way. I had the chance to view these cases as consultations showing up as early as a month postimplant placement and up to two years postinsertion. All practitioners in the field would have cases that are not proud of, facing difficult cases, or probably incorrect choice at one time or another. The purpose of sharing some of these cases is for educating the target readers, to prophylactically avoid some of these pitfalls, and to introduce the current era of implant care discussed in the next chapters.

Managing challenges are areas of special concerns in the field of dental implants. It can be found secondary to any shortcomings of what were mentioned earlier, such as patient's, operator's, and material's. A deficiency in one aspect might lead to transferring a challenge into an actual complication [19]. Novel practitioners might be surprised with the power of handedness tendency even if all aspects of care were taken, still the vision of placing that implant in three dimensions can be deceiving and requires a plateau of proper training to gain accuracy (Figures 22 and 23).

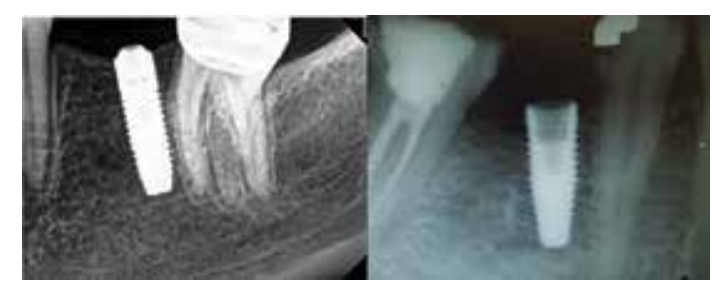

Figure 22. A radiograph showing dental implant with unfavorable positioning, tilting, and improper apicocoronal seating. It will lead to a challenging restoration with diverged emergence profile angle, AKA, "a tomato on a stick."

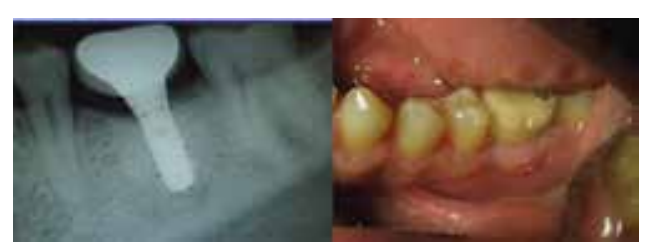

Figure 23. A periapical radiograph showing an implant not seated deep enough apicocoronally, leading to extremely diverged emergence profile, AKA, "a tomato on a stick." The 42-year-old patient presented as an emergency visit complaining of tenderness at the implant of mandibular left molar site attempted in a different practice about a year ago. The patient stated that the pain is repeatedly eliciting providing the fact of changing the crown few times. The diverged emergence profile formed a "housing" curve to collect food debris leading to subgingival abscess infection as seen on the right clinical picture. The patient underwent an emergency intervention of conservative incision and drainage of the purulent discharge, copious irrigation, antibiotic prescription, and analgesics until deciding for a definitive care.

In other situations, underestimating the necessity of proper planning to calculate the implant space available for future prosthetic rehabilitation can lead to bizarre outcomes (Figures 24 
and 25). Hence, even if the care is going to take place through the conventional laboratory waxup and surgical stent fabrication or through the soft-wear simulation programs, the result will be the same, and the surgeon is still in charge when deciding to place those implants in place or not [16]. The practitioner should comprehend that any data gathered will only be an additive item aiming to assist in placing the implant onsite, whereas the surgeon is the only person in charge at the intraoperative stage to place those implants, review the data again, modify the plan, or abort the procedure [18,19] (Figure 26).

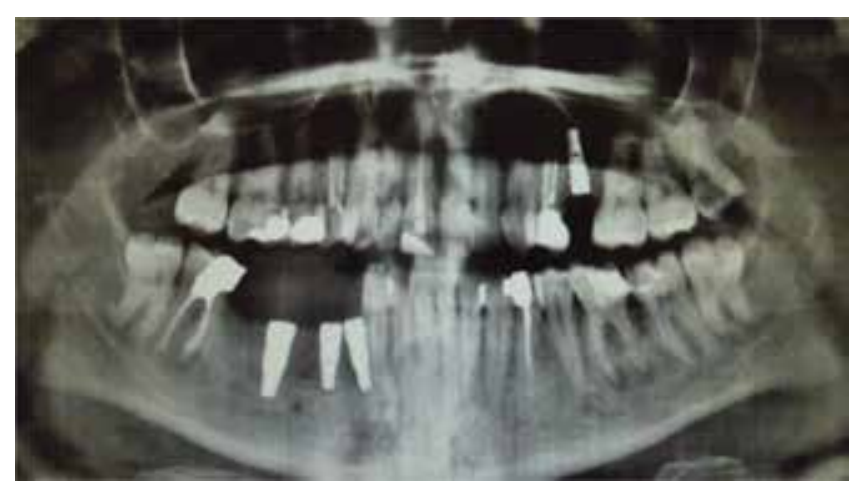

Figure 24. A panoramic radiograph showing three implants placed at the right mandible region. The implants are placed at improper locations pertinent to each other, surrounding structure, future rehabilitation, and opposing occlusion. Not using proper surgical stent to guide the future rehabilitation plan might lead to such devastating results.

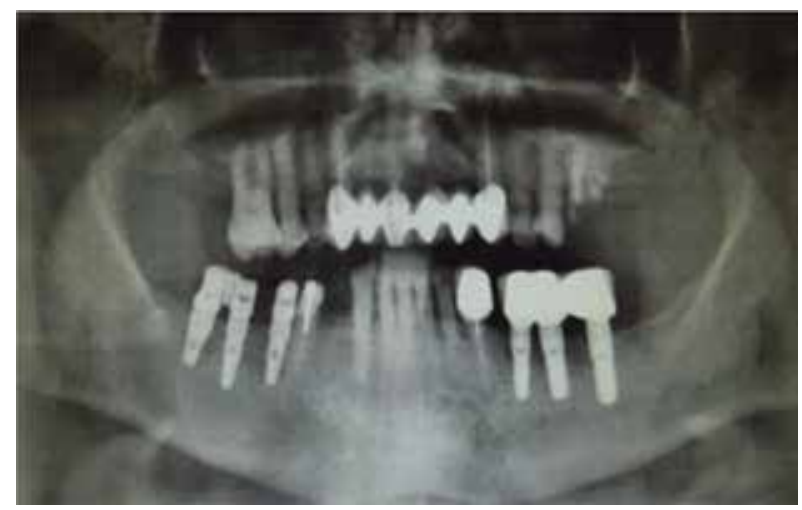

Figure 25. A panoramic radiograph showing three implants placed at the right mandible posterior region. The three implants were placed at a location where a single posterior implant might suffice. Poor planning, careless intervention, or untrained practitioner will lead to such horrifying outcomes and unnecessary expenses. The improper relation and the close proximity to the neighboring right premolar will jeopardize the implant itself. As the premolar sounds to be poorly treated, and hence it will be a source of infection or extraction. Either will be placing the extremely close implant in jeopardy. The most distal implant is placed at a negative functional zone; hence, it has no role in the rehabilitation plan not to mention the unnecessary surgery and cost. Therefore, the general rehabilitation plan of the maxillomandibular complex does require careful revision especially considering the existence of poor prognostic teeth in both arches [18,19]. 


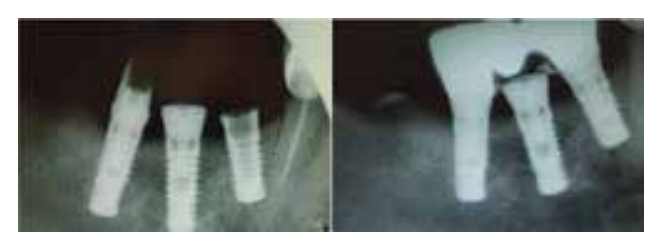

Figure 26. A periapical radiograph showing three implants next to each other with improper relation pertinent to future rehabilitation and as a relation to the neighboring tooth structure. The result showed leaving the implant in the middle in a sleeping status with questionable outcomes, indicating an unnecessary surgical intervention and cost [19].

\title{
6. Conclusion
}

As the dental implantology science is growing very fast, the demand to perfectionism is becoming more challenging. The obstacles of grafting techniques, faster osseointegration, completing cases faster than what used to be, and perfectionism in cosmetic results all play partial role in the current era of implant therapy. Obstacles are still configured in the form of questionable training, nonevidence-based applications, and limitless case requirement demands. Hence, there is the need to consider reviewing the actual capabilities of training programs, stabilizing the basics among trainees, probing the application of new tactics as per the evidence-based recommendations, potentiating research projects in the field of oral maxillofacial surgery, rehabilitation, and dental implantology. Last but not the least, advocating the transparency of more outcome-related studies in different programs and practices is necessary in order to identify what more can be carried out to improve the dental implantology health care.

\section{Author details}

\author{
Mazen Almasri
}

Address all correspondence to: mazen_ajm@yahoo.com

King Abdulaziz University, Faculty of Dentistry, Department of Oral Maxillofacial Surgery Position, Saudi Arabia

\section{References}

[1] Schlee M, and Esposito M (2009) Aesthetic and patient preference using a bone substitute to preserve extraction sockets under pontics. A cross-sectional survey. Eur J Oral Implantol. 2(3):209-217. 
[2] Barber HD, Betts NJ (1993) Rehabilitation of maxillofacial trauma patients with dental implants. Implant Dent. 2(3):191-193.

[3] Steiner GG, Francis W, Burrell R, Kallet MP, Steiner DM, Macias R (2008) The healing socket and socket regeneration. Compend Contin Educ Dent. 29(2):114-116.

[4] Sonick M, Hwang D (2007) Tooth extraction-an opportunity for site preservation. Contemp Esthetics. 11(2):38-43.

[5] Smith LP, Ng M, Grubor D, Chandu A (2009) Outcomes of dental implants placed in a surgical training programme. Aust Dent J. 54:361-367.

[6] Da Silva JD, Kazimirof J, Papas A, Curro F, et al (2014). Outcomes of implants and restorations placed in general dental practices: a restorative study by the Practitioners Engaged in Applied Research and Learning (PEARL) Network. J Am Dent Assoc. 145(7):704-713.

[7] Almasri M (2013) Does immediate reconstruction of lost buccal plate reduces the chances of implant surface exposure after crown placement? J Surg Sci. 4:110-113.

[8] Present S, Levine RA (2010). Single maxillary tooth restoration. Inside Dent. 6(1):58-66.

[9] Aghaloo TL, Moy PK (2007) Which hard tissue augmentation techniques are the most successful in furnishing bony support for implant placement? Int J Oral Maxillofac Implants. 22(Suppl.):49-70.

[10] Almasri M, Camarda A, Hugo C, Fairuz C, Dorismond S (2002) Preservation of posterior mandible extraction site with allogenic demineralized FDMB and CS graft binder before eventual implant placement. J Can Dent Assoc.:78-79.

[11] Peter K (2004) Alveolar ridge reconstruction with preprosthetic surgery: a precursor to site preservation following extraction of natural dentition. Oral Maxillofac Surg Clin N Am. 16(1):1-7.

[12] Iasella J, Greenwell H, Miller H, Drisko C, Bohra A, Scheetz J. (2003) Ridge preservation with free-dried bone allograft and a collagen membrane compared to extraction alone for implant site development: a clinical and histologic study in humans. J Periodontol. 74:990-999.

[13] Almasri M, Altalibi M (2010) Efficacy of reconstruction alveolar bone using an alloplastic HA TCP graft under biodegradable chambers. Br J OMFS. 49(6):469-473.

[14] Bae HW, Zhao L, Kanim LE, Delamarter RB, Dawson EG (2006) Intervariability and intravariability of bone morphogenetic proteins in commercially available demineralized bone matrix products. Spine J. 31(12):1299-1306.

[15] Massoud S, Sayed AG (2012) Determination of orthodontic tooth movement and tissue reaction following DFDB allograft grafting intervention. Dent Res J. 9(2):203-208. 
[16] Manikandan R, et al (2013) Implant surgical guide: from the past to the present. J Pharm Bioallied Sci. 5(1):S98-S102.

[17] Gosain AK, Liansheng S, Paul R, Amarante MT, Nagy PG, Wilson CR, et al (2205) A 1 year study of osteoinduction in hydroxyapatite-derived biomaterials in an adult sheep model: III. Comparison with autogenous bone graft for facial augmentation. Plast Recons Surg. 116:1044-1052.

[18] Almasri M, Elhakim M (2012) Fracture of the anterior segment of the atrophic mandible related to dental implants. Int J OMFS 41(5):646-649.

[19] Su-Gwan Kim (2011). Clinical Complications of Dental Implants, Implant Dentistry A Rapidly Evolving Practice, Prof. Ilser Turkyilmaz (Ed.), InTech, DOI: 10.5772/17262. Available from: http://www.intechopen.com/books/implant-dentistry-a-rapidlyevolving-practice/clinical-complications-of-dental-implants 
Chapter 2

\title{
Antibiotics in Implant Dentistry
}

\author{
Dalia Khalil, Bodil Lund and Margareta Hultin \\ Additional information is available at the end of the chapter \\ http://dx.doi.org/10.5772/62681
}

\begin{abstract}
Antibiotics have been recommended either as an extended treatment for several days or as a single antibiotic prophylaxis dose since the development of dental implant osseointegration technique in the 1970s. It is also performed as part of surgical protocol during the peri-operative phase in the treatment of peri-implantitis. To date, there is a lack of scientific evidence regarding the additive effect of antibiotics in the treatment of dental implant. This has thus left the clinician with inconclusive recommendations, leading to increase antibiotic prescription. With this increase, the development of antibiotic resistance is becoming a threat to modern healthcare that requires revisiting of current indications and implementation of rational treatment strategies. Therefore, more studies are needed to assess the benefit of antibiotic prescription and whether it is safe to refrain from its use.
\end{abstract}

Keywords: Dental implant failure, dental implant surgery, antibiotic prophylaxis, treatment of peri-implantitis, selection of antibiotic resistance

\section{Introduction}

Since the introduction of dental implants as treatment for missing teeth, systemically administered antibiotics have been used to prevent and treat implant failure. In conjunction with implant placement, antibiotics have been recommended either as extended treatment or shortterm prophylaxis during the peri-operative period. In the treatment of peri-implantitis, the majority of surgical flap protocols described in the literature also include administration of systemic antibiotics in the peri-operative phase.

Today, antibiotic resistance is the largest threat to modern healthcare where many treatment options, including advanced surgical interventions, require access to effective antibiotics [1]. 
Therefore, original or consensus-based recommendations, such as the use of antibiotics in implant dentistry, are being reevaluated. Previous policies of prescribing antibiotics, until it is proven safe to refrain from their use, are today considered an outdated option in otherwise healthy patients. Currently, the potential risk of using antibiotics must be weighed against possible benefits for individual patients when undergoing dental implant treatment.

A dental implant is a titanium device anchored and integrated into the jawbone. Osseointegrated dental implants have been an established treatment modality for replacing missing teeth since the beginning of the 1970s [2]. A substantial number of studies using long-term follow-ups have shown successful results for patients with partially and completely edentulous jaws [3-8]. Survival rates of $90-100 \%$ of inserted implants have been reported in several longitudinal studies during follow-ups of up to 20 years later [4,9-14]. Despite the high success rate of dental implants, failures do occur.

Biological implant failures may be categorized into early failures, that is, failure to achieve osseointegration due to surgical trauma, infection, lack of primary stability [15], or late failures, that is, failure to maintain the achieved osseointegration, due to occlusal overload, periimplantitis, or both [15]. Implant failure is an outcome that may require implant removal [15].

\section{Prophylactic use of antibiotics during surgery}

\subsection{Peri-operative antibiotic treatment and extended prophylaxis}

The empirically based tradition of using a peri-operative systemically administered prescription of antibiotics originates from the introduction of the treatment method by PI Brånemark and collaborators [2] during the 1970s. The original implant placement protocol recommended the use of antibiotic treatment during the initial phase of healing, for up to 10 days, to prevent postoperative infection and early implant failure [16, 17]. A two-staged surgical protocol for implant placement was initially introduced to further prevent infection [18]. The rationale for prescribing the extended antibiotic prophylaxis was, at the time of introduction, based on empiric medical/orthopedic considerations. Today, one has to remember that one of the key factors in making the method successful was the addition of a tissue preserving surgical technique. This technique minimized the risk of bacterial contamination during surgery, which at the time included the extended use of systemic antibiotic treatment.

It has been shown that bacterial contamination during implant insertion may be one of the major reasons for early implant failure [19]. Oral implant surgical procedures are often graded as class II surgical procedures (clean-contaminated surgery) [20, 21]. Clean-contaminated surgery has a local infection rate of $10-15 \%$ (Figure 1). However, the incidence of infection can be reduced to $1 \%$ or less with proper surgical technique and the use of prophylactic antibiotics $[20,21]$. Conversely, prophylactic antibiotics can never make up for poor surgical technique and hygienic measures. However, during the past decade, due to the emergence of bacterial antibiotic resistance, the recommendation of extended prophylactic antibiotic treatment has been challenged. Scientific evidence from various surgical fields including placement of dental 
implants shows no benefit of antibiotic prophylaxis beyond the day of surgery in uncomplicated routine cases [22-25]. Therefore, this extended antibiotic treatment is now increasingly being replaced by a single-dose antibiotic prophylaxis.

Surgical Wound Classification in Relation to Occurrence of Microbial Contamination and the Corresponding Infection Rates

\author{
-Class 1: Clean $(<2 \%)$ \\ Elective, nontraumatic surgery, no transection of the respiratory, gastrointestinal, \\ and urinary tracts. \\ -Class 2: Clean-Contaminated (10\%-15\%) \\ Elective surgery entering the respiratory, gastrointestinal, and urinary tracts. No \\ significant bacterial contamination. \\ -Class 3: Contaminated (20\%-30\%) \\ Fresh traumatic injuries, gross spillage from gastrointestinal, and urinary tracts. \\ -Class 4: Dirty/Infected (50\%) \\ Established clinical infection, or a traumatic injury for more than 8 hours old. \\ Perforation of respiratory, gastrointestinal, and urinary tracts.
}

Figure 1. Surgical wound infection classification and the estimated percentage risk for postoperative infections [20, 21].

\title{
2.2. Short-term, single-dose antibiotic prophylaxis
}

There are several clinical studies [26-36] summarized in systematic reviews showing that the use of prophylactic antibiotics during dental implant insertion reduces the risk of implant failure [22,37]. However, this finding has recently been questioned [38, 39]. For example, none of the randomized controlled studies included in a recent meta-analysis [38] showed a statistically significant beneficial effect of antibiotic prophylaxis on their own [27, 30, 31, 40, $41]$, although the beneficial effect could not be excluded in complex or compromised patients $[38,42]$. Therefore, this issue remains a controversial subject under constant revision, and recommendations based on sound scientific evidence are still lacking. Despite this, the routine use of antibiotics during implant placement continues to be common among the majority of dentists in most countries [43-45]. These results today have thus left the clinician with inconclusive recommendations. However, it should also be kept in mind that there are several factors in addition to the use of prophylactic antibiotics during implant placement that can affect implant success rates, such as implant systems, duration of surgery, the number of implants placed, as well as surgical skills [29]. 


\section{The use of antibiotics for the treatment of peri-implant infection}

When a dental implant is inserted into the oral cavity, it provides a new and physically different surface for the colonization of microorganisms. The development of this new biofilm is a process strongly resembling biofilm formation on natural teeth [46-51]. The colonization of microorganisms on this new surface has been shown to start within hours after insertion, with a microflora already resident in the oral cavity $[52,53]$.

Peri-implantitis was initially defined as "a site-specific infection with many features in common with chronic adult periodontitis" [54] and/or as "an inflammatory, bacterial-driven destruction of the implant supporting tissues" [55]. Both definitions imply that bacteria may play a crucial role in the initiation and progression of peri-implantitis. With time varying from months to years, the implant microflora has shown to become more complex if soft tissue inflammation and pocket formation develop around a dental implant (i.e., clinical signs of periimplantitis) [56].

Studies have shown that when comparing clinically healthy peri-implant sites to sites with peri-implantitis, a transition in microflora composition can be seen [57, 58]. A shift from predominantly nonmotile, aerobic, and facultative anaerobic bacteria to a biofilm with a high proportion of gram-negative, motile, anaerobic bacteria has occurred [59, 60]. Moreover, residual teeth (not edentulous or partially edentulous) and clinical condition (periodontally healthy teeth or persisting ongoing periodontitis with residual probing) have been shown to influence the development of the subgingival microflora around dental implants [61, 62]. In partially edentulous patients, the adjacent teeth play a role in the periodontal pathogen colonization [63-65]. Accumulation of a microbial biofilm on the implant surface promotes an inflammatory response in the peri-implant mucosa, resulting in peri-implant mucositis. This is characterized as a reversible inflammation of the soft tissues, with reddening, swelling, and bleeding on probing [66-68]. Persistence of inflammation may result in the loss of peri-implant supporting tissues which is defined as peri-implantitis [42, 54, 55, 68]. Peri-implantitis appears to be associated with a similar microflora as that found in chronic periodontitis such as Porphyromonas gingivalis, Tannerella forsythia, and Aggregatibacter actinomycetemcomitans [6973]. However, compared with periodontitis, some bacteria, which are not part of the typical periodontopathic microbiota, have been found in peri-implantitis lesions such as staphylococci, enteric rods, and Candida [74, 75].

Peri-implantitis has become a prevalent, notable disease, affecting a substantial number of patients [76]. However, a recent review indicates a wide variation in the incidence and prevalence of peri-implantitis [76]. This variation is most likely due to patient/case selection, diagnostic criteria used, and varying time of follow-up. Tomasi and Derks [76] in a recent review stated that the prevalence of peri-implantitis varies between 8.9 and $47 \%$ of implants. In 2012, the EAO Consensus Conference stated that peri-implantitis occurred in one of five patients within 5 years following implant placement [77].

Treatment of peri-implantitis is directed towards removing the biofilm, resolving the inflammation, and arresting the progression of bone loss. Various protocols have been suggested as 
a method for achieving this [78]. The primary objective was to alter the microbiota and induce the host immune system to eliminate putative pathogens [79]. Mechanical debridement and disinfection of implant surfaces are directed to remove the oral biofilm and perio-pathogenic microbes to a certain extent [80]. Indeed, the surface characteristics and the screw-shaped configuration of most current implants may influence the resolution of the inflammation in the surrounding tissues [79]. Conventional mechanical therapies currently used in the treatment of periodontitis may therefore be difficult to apply around dental implants [79].

It is therefore difficult to treat peri-implantitis, and the outcome may not be predictable [68]. To date, there is no standard protocol for the treatment of peri-implantitis. A nonsurgical treatment alone appears to be insufficient in resolving peri-implantitis lesions and is less successful in arresting disease recurrence in long-term follow-up [68, 81].

Surgical treatment of peri-implantitis allows better access for the removal of granulation tissue and decontamination of exposed implant surfaces [68]. Since the etiology of peri-implantitis is similar to periodontitis, the anti-infective protocol used with periodontitis has been adopted in the treatment of peri-implantitis. In the treatment of aggressive periodontitis, the use of adjunctive systematic antibiotics (amoxicillin and metronidazole) has shown an additional effect. The combination of amoxicillin and metronidazole has the potential to decrease a wide range of oral bacteria usually associated with peri-implantitis [82]. Studies including surgical treatment of peri-implantitis in combination with the use of amoxicillin (500 $\mathrm{mg}$ ) and metronidazole $(400 \mathrm{mg})$ for 7 days have shown a $58 \%$ success rate for implants with machined surfaces $[83,84]$. However, in a majority of prospective clinical studies, the parallel effect of several procedures has been evaluated simultaneously [83-86]. These procedures include access flap procedures as well as reconstructive/regenerative procedures. Regardless of surgical technique, adjunctive treatment of systemically administered antibiotics has been used. Therefore, the knowledge of a single specific intervention, such as the adjunctive use of systematic antibiotic, is still limited [87, 88].

In a recent RCT including 100 patients, surgical treatment of peri-implantitis was performed with or without adjunctive systemic antibiotics [89]. The results of this study showed that the use of adjunctive systematic antibiotics combined with surgical treatment of peri-implantitis had a limited significant effect on implant success. However, there is an increase in the probability of treatment success of implants with a modified surface, but not at implants with a nonmodified/smooth surface [89]. The overall implant treatment success after a 1-year follow-up was $45 \%$ [89]. As presented in the scientific literature to date and concluded in a consensus from 2012 at the 8th European Workshop in Periodontology [88], the adjunctive use of systemic antibiotics on treatment outcome is still limited in the treatment of peri-implantitis.

\section{Antibiotic delivery route with dental implants}

The use of oral antibiotics is one of the most common approaches in treating bacterial infections. Antibiotics can be delivered either systemically or by direct placement into the pocket around the dental implant. Each method of delivery has specific advantages and disadvantages. However, based on clinical and microbiological evidence, the type of microorganisms 
responsible for the infection is treated on a presumptive basis, founded on probabilistic reasoning [90]. A wide range of antibiotic compounds and dose regiments is presented in the literature. Ideally, antibiotic treatment duration should include the shortest efficient cycle for preventing both clinical and microbiological relapse [91]. However, this short cycle should ideally have certain characteristics such as rapid onset of action; bactericidal activity; lack of propensity to promote resistant mutants; ease of invasion into tissues; activity against nondividing bacteria; unaffected by adverse infection conditions (low $\mathrm{pH}$, presence of pus, etc.); administration at an optimal dose; and an optimal and convenient dosing regimen [92].

\subsection{Local use of antibiotics}

Local delivery facilitates the application of antimicrobial agents at levels that cannot be reached by the systemic route. However, these levels need to be maintained at a high local concentration for a long period of time, and the agents should reach the entire affected area, that is, the base of the pocket, in order to be efficient. This type of delivery varies from simple pocket irrigation and specifically placed drug-containing ointments and gels, to sophisticated tools for sustained release of antibacterial agents. However, it is unlikely that mouth rinse or supragingival irrigation could predictably deliver an agent to the deeper parts of the defect because the crevicular fluid rapidly washes out agents from the pockets [93, 94]. Nevertheless, there is a low incidence of side effects with locally applied antibiotics. The use of local antibiotics as an adjunctive in the treatment of peri-implantitis has shown no or limited effect on the reduction of periodontal pocket depth and gain in clinical attachment level $[95,96]$. This lack of significant clinical additive effects of local antibiotic supplement is may be due to inadequate exposure of the subgingival bacteria to the compound.

\subsection{Systematic use of antibiotics}

Systemic use of antibiotics is commonly recommended when the targeted bacteria are more widely spread, which is beyond the site of initial infection. The periodontal bacteria may be found throughout the whole oral cavity including on non-dental sites such as the dorsum of the tongue or tonsillary crypts [97-103]. However, this colonization of perio-pathogens at various oral ecological niches is not to be regarded as a systemic infection and does not call for systemic antimicrobial treatment. The drawback of systematic administration is the high rate of drug dissemination throughout the body, where only a small portion reaching the subgingival microflora in the periodontal pocket [104]. Moreover, adverse drug reactions are of greater concern. Systemic antibiotics should never be applied as compensation for inadequate oral hygiene.

\section{Antibiotic compounds commonly used in implant dentistry}

Antibiotic compounds can be classified in a number of different ways: (a) by their origin (natural, semisynthetic or synthetic drugs); (b) by their mode of antibacterial activity as bacteriostatic (growth inhibiting), or bacteriocidal (drugs kill the bacteria); (c) by antibacterial 
spectrum (broad-spectrum or narrow-spectrum), or (d) by their cellular mechanism of action, for example:

i. Cell wall inhibitors, such as the beta-lactam antibiotics penicillin and carbapenem

ii. Inhibitors of nucleic acid synthesis, such as quinolones and metronidazole, which inhibit DNA synthesis, and rifampincin which inhibits RNA synthesis

iii. Protein synthesis inhibitors, such as tetracycline and clindamycin

iv. Anti-metabolites, such as the sulfa drugs

v. Antibiotics that can damage the cell membrane, such as polymyxin B and daptomycin

\begin{tabular}{|c|c|c|c|c|}
\hline & Amoxicillin & Clindamycin & Metronidazole & Penicillin-V \\
\hline \multirow{7}{*}{ Spectrum } & Streptococcus & Streptococcus & Peptostreptococcus & Streptococcus \\
\hline & Peptostreptococcus & Staphylococcus & Clostridium & Peptostreptococcus \\
\hline & Actinomyces & Bacteroids & Bacteroids & Actinomyces \\
\hline & Fusobacterium & Fusobacterium & Prophyromonas & Fusobacterium \\
\hline & Capnocytophaga & Prevotella & Prevotella & Capnocytophaga \\
\hline & & Anaerobic cocci & Fusobacterium & \\
\hline & & & Capnocytophaga & \\
\hline Effect & Time dependent & $\begin{array}{l}\text { Concentration } \\
\text { dependent }\end{array}$ & $\begin{array}{l}\text { Concentration } \\
\text { dependent }\end{array}$ & Time dependent \\
\hline \multicolumn{5}{|l|}{ Pharmacokinetic } \\
\hline Absorption (p.o.) & $90 \%$ & $90 \%$ & $>95 \%$ & $50 \%$ \\
\hline $\mathrm{T}^{1} / 2$ & $\sim 1 \mathrm{~h}$ & $\sim 2,5 \mathrm{~h}$ & $\sim 8 \mathrm{~h}$ & $\sim 30 \mathrm{~min}$ \\
\hline Solubility & Water & Fat & Fat & Water \\
\hline Excretion & Urine & Gall bladder, feces, urine & $\begin{array}{l}\text { Urine and } \\
\text { gall bladder }\end{array}$ & Urine \\
\hline $\begin{array}{l}\text { Common side } \\
\text { effect }\end{array}$ & $\begin{array}{l}\text { Vomiting, diarrhea, } \\
\text { nausea, exanthema } \\
(5 \%)\end{array}$ & $\begin{array}{l}\text { Vomiting, diarrhea, } \\
\text { nausea } \\
(8 \%)\end{array}$ & $\begin{array}{l}\text { Gastrointestinal } \\
\text { upset, metallic } \\
\text { taste } \\
(5-10 \%)\end{array}$ & $\begin{array}{l}\text { Diarrhea, nausea } \\
(5 \%)\end{array}$ \\
\hline \multicolumn{5}{|l|}{ Ecological effect } \\
\hline Oral & ++ & +++ & ++ & ++ \\
\hline Gastrointestinal & ++ & +++ & + & + \\
\hline
\end{tabular}

P.O. peroral; $\mathrm{T}^{1 / 2}$ half time; + mild/no effect; ++ moderate effect; +++ severe effect.

Table 1. Summary of characteristics of the most common antibiotic compounds used in implant dentistry.

Although there are numerous antimicrobial agents available, only a limited number of systemic antibiotics such as amoxicillin; phenoxymethylpenicillin (PcV); clindamycin; 
metronidazole; and the combination of amoxicillin and metronidazole have been widely used in the implant dentistry field (Table 1).

\subsection{Amoxicillin}

Amoxicillin is derived from one of the oldest antibiotics, penicillin, which was discovered in 1928 by Alexander Fleming. It is a broad-spectrum antibiotic compound commonly used during invasive dental procedures as it shows a good and predictable absorption and bioavailability [106]. It has a bactericidal activity against gram-positive and gram-negative microorganisms. In addition, it is active against several members of the oral commensal microflora, such as viridans streptococci, and is thus expected to reduce the risk of local and systemic infection after dental procedures. The molecular structure of amoxicillin includes a $\beta$-lactam ring that may be cleaved by bacterial enzymes.

The combination of amoxicillin and clavulanic acid, the beta-lactamase inhibitors, is used to treat infections with $\beta$-lactamase producing bacteria. This combination results in an antibiotic with a broader spectrum of action and restored efficacy against amoxicillin-resistant bacteria, which produce $\beta$-lactamase.

\subsection{Penicillin-V}

Penicillin-V is a widely used antibiotic in dentistry and possesses several beneficial characteristics. It achieves peak serum levels within $30 \mathrm{~min}$, and persistent, detectable levels for up to $4 \mathrm{~h}$ after administration [106]. It has a bactericidal action with a narrow microbial spectrum, and it is highly effective against most Streptococcus species and oral anaerobes [106]. Penicillin$\mathrm{V}$ is recommended as the drug of choice for the treatment of dental infections in Scandinavian countries. However, it is seldom used outside Scandinavia mainly because it is not available for purchase in many countries. The wide use of penicillin- $\mathrm{V}$ instead of broad-spectrum compounds is considered to be an important factor contributing to the low rates of antibiotic resistance seen in Scandinavian countries.

\subsection{Metronidazole}

Metronidazole has a unique bactericidal effect against anaerobic bacteria. It is a narrowspectrum antibiotic, which minimizes the risk of opportunistic pathogens among commensal microbiota and reduces the risk of developing a resistant species. There is no known allergic or hypersensitivity reactions to metronidazole, and it has limited side effects which are generally tolerable, transient, or reversible [107].

\subsection{Clindamycin}

Clindamycin is a broad-spectrum compound active against oral anaerobic and aerobic bacteria, such as streptococci and staphylococci, although its use in dentistry is recommended mainly in patients with a penicillin allergy [106]. It is bacteriostatic in normal concentrations and has good bone penetration [91]. Because of its broad-spectrum effect, it gives significant 
and long-term effects on the protective resident microflora and is associated with the development of Clostridium difficile gastroenteritis [108, 109].

\subsection{Antibiotic combination therapy}

Peri-implant subgingival microbiota contains several putative periodontopathic species with different antimicrobial susceptibility. Therefore, antibiotic combination may be useful because of its wider spectrum of activity compared with a single agent. Combination drug therapy may reduce the possibility of developing bacterial resistance due to antimicrobial spectrum overlap, or it may be combined in a synergetic way when targeting organisms, allowing the dose of a single agent to be lowered [110]. However, such combinations may lead to increased adverse reactions. Recently, the combination of metronidazole and amoxicillin has become a popular treatment modality for many dentists and researchers.

\section{Consequences of antibiotic treatment}

No antibacterial drug is completely nontoxic, and its use carries accompanying risks, which has to balance the benefits and risks of its use before prescribing. The most common side-effects are gastrointestinal, ranging in severity from frequent self-limiting gastrointestinal upset to rare life-threatening pseudomembranous colitis. Other relatively common adverse effects are hypersensitivity reactions ranging from mild to life-threatening anaphylactic reactions [110]. However, the majority of these reactions are mild and limited to a rash or skin lesions in the head or neck region. Another negative impact of the over prescription of antibiotics is the cost to the healthcare system. A survey performed in USA suggested that while the cost of antibiotic prophylaxis is low to the individual, the potential cost to the healthcare system may be well over \$150 million annually [111].

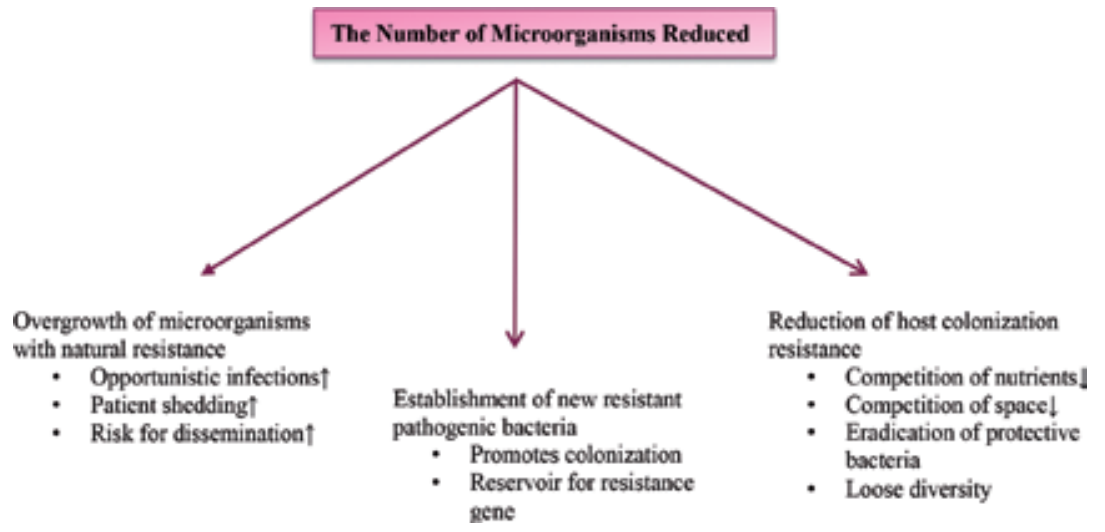

Figure 2. The effect of antibiotic treatment on the ecology of the normal microflora [112-114]. 
It is well known that the administration of antimicrobial agents causes a disturbance in the oropharyngeal and intestinal microflora, which is considered to be important for health maintenance. This disturbance is not only due to the spectrum of agents, but also to their degree of absorption, route of elimination, possible enzymatic inactivation and/or binding to human fluids and intestinal material [112]. Individual variations in normal microflora further determines the ecological outcome of antimicrobial therapy [112]. Selective pressure by the administration of antibiotics will decrease the number of microorganisms in the oral cavity. Consequently, this leads to a disturbance in human microbial ecology as shown in Figure 2 [112-114].

Antibiotic resistance has become a global growing health problem. The golden age of antibiotic therapy is now coming to an end as stated in 2014 by WHO [115]. However, some researcher believes that we are already in the pre-antibiotic era. The Global Economic Forum reported that the development of antibiotic resistance has major societal risks and increases both morbidity and mortality of affected individuals $[115,116]$. Each year there are thousands of deaths, and millions of dollars spent on healthcare costs due to resistant infections [117]. Therefore, a restrictive approach towards using antibiotics is mandatory in order to limit the development of microbial antibiotic resistance and avoid the risk of unwanted systemic effects of antibiotics for the treated individual.

\section{Future prospective and knowledge gap}

The prescription of antibiotics in medical practice needs to be addressed globally, particularly in the dental field, including dental implant procedures [29]. In fact, there is a decrease in surgical infection rate incidence even without the use of antibiotics, yet there is still an increase in antibiotic prescriptions [118]. There are a lot of factors influencing the prescription of antibiotics by healthcare practitioners including patients request, gap in knowledge and practitioner's education. Indeed, considering the serious situation regarding emerging and quickly disseminating antibiotic resistance there is no justification for prescription antibiotics without medical indication [29].

Within the literature, there is a lack of scientific evidence showing the additive effect of antibiotics, either prophylactic or therapeutic, in the treatment of dental implant. However, with the demands on restrictive antibiotic policy more studies are needed to assess the benefit of antibiotic prescription and the safety to refrain from its use. In order to restrict antibiotic use to fields where it has unquestioned medical value, it is important to investigate the need for antibiotics. Therefore, additional RCTs with larger sample sizes and longer follow-up period are needed to determine the role of antibiotic prophylaxis during implant insertion to prevent early implant failure in both uncomplicated/straight forward and complicated cases. Furthermore, different type of complicated cases such as immediate insertion into extraction site, bone augmentation procedures, full jaw surgery and implant surgery in the medically compromised patient, may pose a variable risk of postoperative infection and should therefore be studied separately. In the treatment of peri-implantitis, there is a critical need for double- 
blinded placebo-controlled randomized clinical trials to demonstrate the efficacy of adjunctive use of systemically delivered antibiotics [80]. Furthermore, more studies are needed to evaluate antibiotic prescriptions from the societal and cost-effective perspectives, not just from the healthcare perspective.

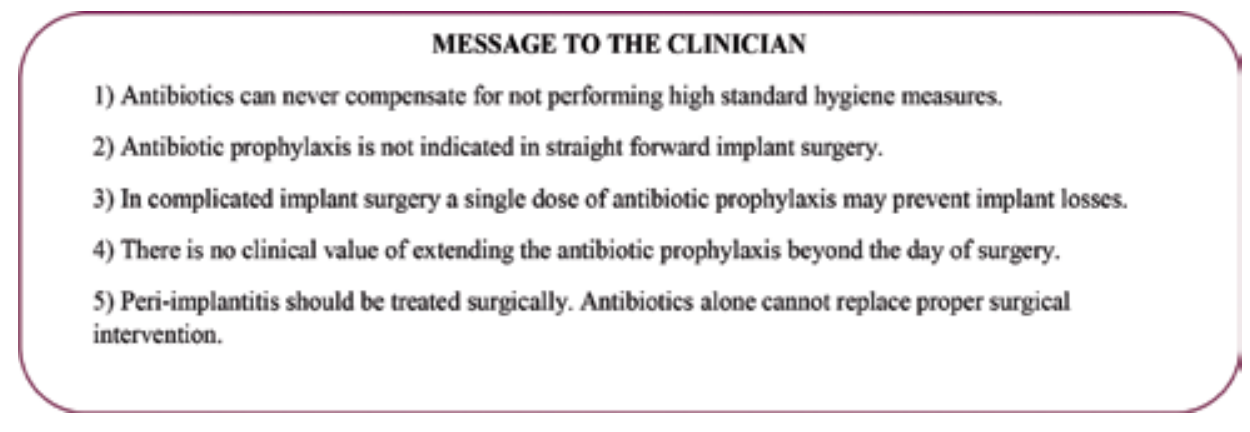

Figure 3. Tips for the clinician regarding antibiotic prescription in implant dentistry.

Finally, there is a need for recommendations to limit and optimize the utilization of antibiotics in the dental implant field. This recommendation may result in a more sustainable antibiotic usage, preventing the risk of infection, which in turn can improve the results of a surgical intervention, reduce the risk of resistant bacterial strains developing, reduce the total use of antibiotics, and possibly reduce the cost of care [119]. Based on available evidence some summarized suggested advices to the clinician are presented in Figure 3.

\section{Author details}

Dalia Khali1 ${ }^{1 *}$, Bodil Lund ${ }^{2,3}$ and Margareta Hultin ${ }^{1}$

*Address all correspondence to: Dalia.Khalil@ki.se

1 Department of Dental Medicine, Division of Periodontology, Karolinska Institutet, Huddinge, Sweden

2 Department of Dental Medicine, Division of Orofacial Diagnostics and Surgery, Karolinska Institutet, Huddinge, Sweden

3 Department of Oral and Maxillofacial Surgery, Karolinska University Hospital, Stockholm, Sweden 


\section{References}

[1] Davies J, Davies D. Origins and evolution of antibiotic resistance. Microbiol Mol Biol Rev. 2010;74(3):417-33.

[2] Branemark PI, Hansson BO, Adell R, Breine U, Lindstrom J, Hallen O, . Osseointegrated implants in the treatment of the edentulous jaw. Experience from a 10-year period. Scand J Plast Reconstr Surg Suppl. 1977;16:1-132.

[3] Simonis P, Dufour T, Tenenbaum H. Long-term implant survival and success: A 1016-year follow-up of non-submerged dental implants. Clin Oral Implants Res. 2010;21(7):772-7.

[4] Buser D, Janner SF, Wittneben JG, Bragger U, Ramseier CA, Salvi GE. 10-year survival and success rates of 511 titanium implants with a sandblasted and acid-etched surface: A retrospective study in 303 partially edentulous patients. Clin Implant Dent Relat Res. 2012;14(6):839-51.

[5] Ekelund JA, Lindquist LW, Carlsson GE, Jemt T. Implant treatment in the edentulous mandible: A prospective study on Branemark system implants over more than 20 years. Int J Prosthodont. 2003;16(6):602-8.

[6] Pjetursson BE, Tan K, Lang NP, Bragger U, Egger M, Zwahlen M. A systematic review of the survival and complication rates of fixed partial dentures (FPDs) after an observation period of at least 5 years. Clin Oral Implants Res. 2004;15(6):667-76.

[7] Jemt T, Johansson J. Implant treatment in the edentulous maxillae: A 15-year followup study on 76 consecutive patients provided with fixed prostheses. Clin Implant Dent Relat Res. 2006;8(2):61-9.

[8] Lindquist L, Carlsson G, Jemt T. A prospective 15-year follow-up study of mandibular fixed prostheses supported by osseointegrated implants. Clinical results and marginal bone loss. Clin Oral Implants Res. 1996;7(4):329-36.

[9] Daubert DM, Weinstein BF, Bordin S, Leroux BG, Flemmig TF. Prevalence and predictive factors for peri-implant disease and implant failure: A cross-sectional analysis. J Periodontol. 2015;86(3):337-347.

[10] Van Velzen FJ, Ofec R, Schulten EA, Ten Bruggenkate CM. 10-year survival rate and the incidence of peri-implant disease of 374 titanium dental implants with a SLA surface: A prospective cohort study in 177 fully and partially edentulous patients. Clin Oral Implants Res. 2015;26(10):1121-1128.

[11] Cehreli MC, Uysal S, Akca K. Marginal bone level changes and prosthetic maintenance of mandibular overdentures supported by 2 implants: A 5-year randomized clinical trial. Clin Implant Dent Relat Res. 2010;12(2):114-21.

[12] Jungner $M$, Lundqvist $P$, Lundgren S. A retrospective comparison of oxidized and turned implants with respect to implant survival, marginal bone level and peri-implant 
soft tissue conditions after at least 5 years in function. Clin Implant Dent Relat Res. 2014;16(2):230-7.

[13] Malo P, de Araujo Nobre M, Lopes A, Ferro A, Moss S. Extramaxillary surgical technique: Clinical outcome of 352 patients rehabilitated with 747 zygomatic implants with a follow-up between 6 months and 7 years. Clin Implant Dent Relat Res. 2015;17(S1):e153-e162.

[14] Ravald N, Dahlgren S, Teiwik A, Grondahl K. Long-term evaluation of Astra Tech and Branemark implants in patients treated with full-arch bridges. Results after 12-15 years. Clin Oral Implants Res. 2013;24(10):1144-51.

[15] Sakka S, Baroudi K, Nassani MZ. Factors associated with early and late failure of dental implants. J Investig Clin Dent. 2012;3(4):258-61.

[16] Adell R, Lekholm U, Branemark PI, Lindhe J, Rockler B, Eriksson B, . Marginal tissue reactions at osseointegrated titanium fixtures. Swed Dent J Suppl. 1985;28:175-81.

[17] Waddell T, Rotstein O. Antimicrobial prophylaxis in surgery. Committee on Antimicrobial Agents, Canadian Infectious Disease Society. CMAJ. 1994;151(7):925.

[18] Adell R, Lekholm U, Rockler B, Brånemark P, Lindhe J, Eriksson B, . Marginal tissue reactions at osseointegrated titanium fixtures:(I). A 3-year longitudinal prospective study. Int J Oral Maxillofac Surg. 1986;15(1):39-52.

[19] Charalampakis G, Leonhardt A, Rabe P, Dahlen G. Clinical and microbiological characteristics of peri-implantitis cases: A retrospective multicentre study. Clin Oral Implants Res. 2012;23(9):1045-54.

[20] Olson M, O'Connor M, Schwartz ML. Surgical wound infections. A 5-year prospective study of 20,193 wounds at the Minneapolis VA Medical Center. Ann Surg. 1984;199(3): 253-9.

[21] Peterson LJ. Antibiotic prophylaxis against wound infections in oral and maxillofacial surgery. J Oral Maxillofac Surg. 1990;48(6):617-20.

[22] Esposito M, Grusovin MG, Worthington HV. Interventions for replacing missing teeth: Antibiotics at dental implant placement to prevent complications. Cochrane database of systematic reviews (Online). 2013;7:CD004152.

[23] Trampuz A, Zimmerli W. Antimicrobial agents in orthopaedic surgery. Drugs. 2006;66(8):1089-106.

[24] Townley WA, Baluch N, Bagher S, Maass SW, O'Neill A, Zhong T, . A single preoperative antibiotic dose is as effective as continued antibiotic prophylaxis in implantbased breast reconstruction: A matched cohort study. J Plast Reconstr Aesthet Surg. 2015;68(5):673-8. 
[25] Arduino PG, Tirone F, Schiorlin E, Esposito M. Single preoperative dose of prophylactic amoxicillin versus a 2-day postoperative course in dental implant surgery: A two centre randomised controlled trial. Eur J Oral Implantol. 2015;8(2):143-149.

[26] Abu-Ta'a M, Quirynen M, Teughels W, van Steenberghe D. Asepsis during periodontal surgery involving oral implants and the usefulness of peri-operative antibiotics: A prospective, randomized, controlled clinical trial. J Clin Periodontol. 2008;35(1):58-63.

[27] Anitua E, Aguirre JJ, Gorosabel A, Barrio P, Errazquin JM, Roman P, . A multicentre placebo-controlled randomised clinical trial of antibiotic prophylaxis for placement of single dental implants. Eur J Oral Implantol. 2009;2(4):283-92.

[28] Caiazzo A, Casavecchia P, Barone A, Brugnami F. A pilot study to determine the effectiveness of different amoxicillin regimens in implant surgery. J Oral Implantol. 2011;37(6):691-6.

[29] Nolan R, Kemmoona M, Polyzois I, Claffey N. The influence of prophylactic antibiotic administration on post-operative morbidity in dental implant surgery. A prospective double blind randomized controlled clinical trial. Clin Oral Implants Res. 2014;25(2): 252-9.

[30] Esposito M, Cannizzaro G, Bozzoli P, Consolo U, Felice P, Ferri V, . Efficacy of prophylactic antibiotics for dental implants: A multicentre placebo-controlled randomised clinical trial. Eur J Oral Implantol. 2008;1(1):23-31.

[31] Esposito M, Cannizzaro G, Bozzoli P, Checchi L, Ferri V, Landriani S, . Effectiveness of prophylactic antibiotics at placement of dental implants: A pragmatic multicentre placebocontrolled randomised clinical trial. Eur J Oral Implantol. 2010;3(2):135-43.

[32] Dent CD, Olson JW, Farish SE, Bellome J, Casino AJ, Morris HF, . The influence of preoperative antibiotics on success of endosseous implants up to and including stage II surgery: A study of 2,641 implants. J Oral Maxillofac Surg. 1997;55(12 Suppl. 5):19_ 24.

[33] Gynther GW, Köndell PÅ, Moberg L-E, Heimdahl A. Dental implant installation without antibiotic prophylaxis. Oral Surg Oral Med Oral Pathol Oral Radiol Endodontol. 1998;85(5):509-11.

[34] Binahmed A, Stoykewych A, Peterson L. Single preoperative dose versus long-term prophylactic antibiotic regimens in dental implant surgery. Int J Oral Maxillofac Implants. 2005;20(1):115.

[35] Hossein K, Dahlin C, Bengt A. Influence of different prophylactic antibiotic regimens on implant survival rate: A retrospective clinical study. Clin Implant Dent Relat Res. 2005;7(1):32-5.

[36] Laskin DM, Dent CD, Morris HF, Ochi S, Olson JW. The influence of preoperative antibiotics on success of endosseous implants at 36 months. Ann Periodontol. 2000;5(1): 166-74. 
[37] Sharaf B, Jandali-Rifai M, Susarla SM, Dodson TB. Do perioperative antibiotics decrease implant failure? J Oral Maxillofac Surg. 2011;69(9):2345-50.

[38] Lund B, Hultin M, Tranaeus S, Naimi-Akbar A, Klinge B. Complex systematic review -Perioperative antibiotics in conjunction with dental implant placement. Clin Oral Implants Res. 2015;26(S11):1-14.

[39] Chrcanovic BR, Albrektsson T, Wennerberg A. Prophylactic antibiotic regimen and dental implant failure: A meta-analysis. J Oral Rehabil. 2014;41(12):941-56.

[40] Tan WC, Ong M, Han J, Mattheos N, Pjetursson BE, Tsai AY, . Effect of systemic antibiotics on clinical and patient-reported outcomes of implant therapy - A multicenter randomized controlled clinical trial. Clin Oral Implants Res. 2014;25(2):185-93.

[41] El-Kholey KE. Efficacy of two antibiotic regimens in the reduction of early dental implant failure: A pilot study. Int J Oral Maxillofac Surg. 2014;43(4):487-90.

[42] Klinge B, Flemming T, Cosyn J, De Bruyn H, Eisner BM, Hultin M, . The patient undergoing implant therapy. Summary and consensus statements. The 4th EAO Consensus Conference 2015. Clin Oral Implants Res. 2015;26:64-7.

[43] Khalil D, Hultin M, Andersson Fred L, Parkbring Olsson N, Lund B. Antibiotic prescription patterns among Swedish dentists working with dental implant surgery: Adherence to recommendations. Clin Oral Implants Res. 2015;26(9):1064-9.

[44] Ireland RS, Palmer NO, Lindenmeyer A, Mills N. An investigation of antibiotic prophylaxis in implant practice in the UK. Br Dent J. 2012;213(8):E14.

[45] Datta R, Grewal Y, Batth JS, Singh A. Current trend of antimicrobial prescription for oral implant surgery among dentists in India. J Maxillofac Oral Surg. 2014;13(4):503-7.

[46] Mombelli A, Lang NP. The diagnosis and treatment of peri-implantitis. Periodontol 2000. 1998;17(1):63-76.

[47] Mombelli A, Marxer M, Gaberthüel T, Grander U, Lang NP. The microbiota of osseointegrated implants in patients with a history of periodontal disease. J Clin Periodontol. 1995;22(2):124-30.

[48] Mombelli A, Mericske-ster R. Microbiological features of stable osseointegrated implants used as abutments for overdentures. Clin Oral Implants Res. 1990;1(1):1-7.

[49] Salvi GE, Fürst MM, Lang NP, Persson GR. One-year bacterial colonization patterns of Staphylococcus aureus and other bacteria at implants and adjacent teeth. Clin Oral Implants Res. 2008;19(3):242-8.

[50] Sbordone L, Barone A, Ciaglia RN, Ramaglia L, Iacono VJ. Longitudinal study of dental implants in a periodontally compromised population. J Periodontol. 1999;70(11):13229 . 
[51] van Winkelhoff AJ, Wolf JW. Actinobacillus actinomycetemcomitans-associated periimplantitis in an edentulous patient. A case report. J Clin Periodontol. 2000;27(7):5315 .

[52] Furst MM, Salvi GE, Lang NP, Persson GR. Bacterial colonization immediately after installation on oral titanium implants. Clin Oral Implants Res. 2007;18(4):501-8.

[53] Leonhardt A, Olsson J, Dahlen G. Bacterial colonization on titanium, hydroxyapatite, and amalgam surfaces in vivo. J Dent Res. 1995;74(9):1607-12.

[54] Mombelli A, Oosten M, Schürch E, Lang N. The microbiota associated with successful or failing osseointegrated titanium implants. Oral Microbiol Immunol. 1987;2(4):14551.

[55] Tonetti M. Peri-implantitis: Biological considerations. J Parodontol. 1996;15:269-84.

[56] Socransky SS, Haffajee AD, Cugini MA, Smith C, Kent RLJr. Microbial complexes in subgingival plaque. J Clin Periodontol. 1998;25(2):134-44.

[57] Lang NP, Bragger U, Walther D, Beamer B, Kornman KS. Ligature-induced periimplant infection in cynomolgus monkeys. I. Clinical and radiographic findings. Clin Oral Implants Res. 1993;4(1):2-11.

[58] Leonhardt A, Renvert S, Dahlen G. Microbial findings at failing implants. Clin Oral Implants Res. 1999;10(5):339-45.

[59] Covani U, Marconcini S, Crespi R, Barone A. Bacterial plaque colonization around dental implant surfaces. Implant Dent. 2006;15(3):298-304.

[60] Leonhardt A, Adolfsson B, Lekholm U, Wikstrom M, Dahlen G. A longitudinal microbiological study on osseointegrated titanium implants in partially edentulous patients. Clin Oral Implants Res. 1993;4(3):113-20.

[61] Saaby M, Karring E, Schou S, Isidor F. Factors influencing severity of peri-implantitis. Clin Oral Implants Res. 2016;27(1):7-12.

[62] Free Inquiry in Creative Sociology, Renvert S, Quirynen M. Risk indicators for periimplantitis. A narrative review. Clin Oral Implants Res. 2015;26(S11):15-44.

[63] Hultin M, Bostrom L, Gustafsson A. Neutrophil response and microbiological findings around teeth and dental implants. J Periodontol. 1998;69(12):1413-8.

[64] Apse P, Ellen RP, Overall CM, Zarb GA. Microbiota and crevicular fluid collagenase activity in the osseointegrated dental implant sulcus: A comparison of sites in edentulous and partially edentulous patients. J Periodontal Res. 1989;24(2):96-105.

[65] Nakou M, Mikx F, Oosterwaal P, Kruijsen J. Early microbial colonization of permucosal implants in edentulous patients. J Dent Res. 1987;66(11):1654-7. 
[66] Khammissa RA, Feller L, Meyerov R, Lemmer J. Peri-implant mucositis and periimplantitis: Clinical and histopathological characteristics and treatment. SADJ. 2012;67(3):122, 4-6.

[67] Wilson V. An insight into peri-implantitis: A systematic literature review. Prim Dent J. 2013;2(2):69-73.

[68] Lindhe J, Meyle J, Group DoEWoP. Peri-implant diseases: Consensus report of the sixth European workshop on periodontology. J Clin Periodontol. 2008;35(8 Suppl.):282-5.

[69] Alcoforado G, Rams T, Feik D, Slots J. Microbial aspects of failing osseointegrated dental implants in humans. J Parodontol. 1991;10(1):11-8.

[70] Augthun M, Conrads G. Microbial findings of deep peri-implant bone defects. Int J Oral Maxillofac Implants. 1996;12(1):106-12.

[71] Listgarten MA, Lai C-H. Comparative microbiological characteristics of failing implants and periodontally diseased teeth. J Periodontol. 1999;70(4):431-7.

[72] Rosenberg E, Torosian J, Slots J. Microbial differences in 2 clinically distinct types of failures of osseointegrated implants. Clin Oral Implants Res. 1991;2(3):135-44.

[73] Salcetti JM, Moriarty JD, Cooper LF, Smith FW, Collins JG, Socransky SS, . The clinical, microbial, and host response characteristics of the failing implant. Int J Oral Maxillofac Implants. 1996;12(1):32-42.

[74] Smeets R, Henningsen A, Jung O, Heiland M, Hammacher C, Stein JM. Definition, etiology, prevention and treatment of peri-implantitis-A review. Head Face Med. 2014;10:34.

[75] Salvi GE, Furst MM, Lang NP, Persson GR. One-year bacterial colonization patterns of Staphylococcus aureus and other bacteria at implants and adjacent teeth. Clin Oral Implants Res. 2008;19(3):242-8.

[76] Tomasi C, Derks J. Clinical research of peri-implant diseases-Quality of reporting, case definitions and methods to study incidence, prevalence and risk factors of periimplant diseases. J Clin Periodontol. 2012;39(Suppl. 12):207-23.

[77] Klinge B, Meyle J, Working G. Peri-implant tissue destruction. The Third EAO Consensus Conference 2012. Clin Oral Implants Res. 2012;23(Suppl. 6):108-10.

[78] Heitz-Mayfield LJ. Diagnosis and management of peri-implant diseases. Aust Dent J. 2008;53(Suppl. 1):S43-8.

[79] Renvert S, Polyzois I, Persson GR. Treatment modalities for peri-implant mucositis and peri-implantitis. Am J Dent. 2013;26(6):313-8.

[80] Javed F, AlGhamdi AST, Ahmed A, Mikami T, Ahmed HB, Tenenbaum HC. Clinical efficacy of antibiotics in the treatment of peri-implantitis. Int Dent J. 2013;63(4):169-76. 
[81] Renvert S, Roos-Jansaker AM, Claffey N. Non-surgical treatment of peri-implant mucositis and peri-implantitis: A literature review. J Clin Periodontol. 2008;35(8 Suppl.):305-15.

[82] Mombelli A, Decaillet F. The characteristics of biofilms in peri-implant disease. J Clin Periodontol. 2011;38(Suppl. 11):203-13.

[83] Heitz-Mayfield LJ, Salvi GE, Mombelli A, Faddy M, Lang NP, Implant Complication Research G. Anti-infective surgical therapy of peri-implantitis. A 12-month prospective clinical study. Clin Oral Implants Res. 2012;23(2):205-10.

[84] Leonhardt A, Dahlen G, Renvert S. Five-year clinical, microbiological, and radiological outcome following treatment of peri-implantitis in man. J Periodontol. 2003;74(10): 1415-22.

[85] Roos-Jansaker AM, Persson GR, Lindahl C, Renvert S. Surgical treatment of periimplantitis using a bone substitute with or without a resorbable membrane: A 5-year follow-up. J Clin Periodontol. 2014;41(11):1108-14.

[86] Matarasso S, Iorio Siciliano V, Aglietta M, Andreuccetti G, Salvi GE. Clinical and radiographic outcomes of a combined resective and regenerative approach in the treatment of peri-implantitis: A prospective case series. Clin Oral Implants Res. 2014;25(7):761-767.

[87] Javed F, Alghamdi AS, Ahmed A, Mikami T, Ahmed HB, Tenenbaum HC. Clinical efficacy of antibiotics in the treatment of peri-implantitis. Int Dent J. 2013;63(4):169-76.

[88] Sanz M, Chapple IL, Working Group 4 of the VEWoP. Clinical research on peri-implant diseases: Consensus report of Working Group 4. J Clin Periodontol. 2012;39(Suppl. 12): 202-6.

[89] Carcuac O, Derks J, Charalampakis G, Abrahamsson I, Wennstrom J, Berglundh T. Adjunctive systemic and local antimicrobial therapy in the surgical treatment of periimplantitis: A randomized controlled clinical trial. J Dent Res. 2016;95(1):50-57.

[90] Ferraz AV, Aranguren AI. Principios de terapéutica antimicrobiana. MedicinePrograma de Formación Médica Continuada Acreditado. 2006;9(49):3196-203.

[91] Oberoi SS, Dhingra C, Sharma G, Sardana D. Antibiotics in dental practice: How justified are we. Int Dent J. 2015;65(1):4-10.

[92] Rubinstein E. Short antibiotic treatment courses or how short is short? Int J Antimicrob Agents. 2007;30:76-9.

[93] Eakle WS, Ford C, Boyd RL. Depth of penetration in periodontal pockets with oral irrigation. J Clin Periodontol. 1986;13(1):39-44.

[94] Pitcher GR, Newman HN, Strahan JD. Access to subgingival plaque by disclosing agents using mouthrinsing and direct irrigation. J Clin Periodontol. 1980;7(4):300-8. 
[95] Tang Z, Cao C, Sha Y, Lin Y, Wang X. Effects of non-surgical treatment modalities on peri-implantitis. Chin J Stomatol. 2002;37(3):173-5.

[96] Renvert S, Lessem J, Dahlén G, Lindahl C, Svensson M. Topical minocycline microspheres versus topical chlorhexidine gel as an adjunct to mechanical debridement of incipient peri-implant infections: A randomized clinical trial. J Clin Periodontol. 2006;33(5):362-9.

[97] Zambon J, Reynolds H, Slots J. Black-pigmented Bacteroides spp. in the human oral cavity. Infect Immun. 1981;32(1):198-203.

[98] Winkelhoff A, Velden U, Clement M, Graaff J. Intra-oral distribution of black-pigmented Bacteroides species in periodontitis patients. Oral Microbiol Immunol. 1988;3(2):835 .

[99] Müller HP, Lange DE, Müller RF. Failure of adjunctive minocycline-HCI to eliminate oral Actinobacillus actinomycetemcomitans. J Clin Periodontol. 1993;20(7):498-504.

[100] Müller HP, Eickhoíz P, Heinecke A, Pohl S, Müller R, Lange D. Simultaneous isolation of Actinobacillus actinomycetemcomitans from subgingival and extracrevicular locations of the mouth. J Clin Periodontol. 1995;22(5):413-9.

[101] Pavičič MJAMP, van Winkelhoff AJ, Douqué NH, Steures RWR, de Graaff J. Microbiological and clinical effects of metronidazole and amoxicillin in Actinobacillus actinomycetemcomitans associated periodontitis. J Clin Periodontol. 1994;21(2):107-12.

[102] Mombelli A, Gmür R, Gobbi C, Lang NP. Actinobacillus actinomycetemcomitans in adult periodontitis. I. Topographic distribution before and after treatment. J Periodontol. 1994;65(9):820-6.

[103] Mombelli A, McNabb H, Lang NP. Black-pigmenting Gram-negative bacteria in periodontal disease. I. Topographic distribution in the human dentition*. J Periodontal Res. 1991;26(4):301-7.

[104] Slots J, Rams TE. Antibiotics in periodontal therapy: Advantages and disadvantages. J Clin Periodontol. 1990;17(s1):479-93.

[105] Lund B, Skoog G, Götrick B, Blomgren J, Snygg-Martin U. Antibiotika för systemiskt bruk. (Article in Swedish). 2014(ÅRG 106:NR 4).

[106] Resnik RR, Misch C. Prophylactic antibiotic regimens in oral implantology: Rationale and protocol. Implant Dent. 2008;17(2):142-50.

[107] Stranz M, Bradley W. Metronidazole (Flagyl IV, Searle). Drug Intell Clin Pharm. 1981;15(11):838-46.

[108] Jernberg C, Löfmark S, Edlund C, Jansson JK. Long-term impacts of antibiotic exposure on the human intestinal microbiota. Microbiology. 2010;156(11):3216-23. 
[109] Lindgren M, Löfmark S, Edlund C, Huovinen P, Jalava J. Prolonged impact of a oneweek course of clindamycin on Enterococcus spp. in human normal microbiota. Scand J Infect Dis. 2009;41(3):215-9.

[110] Granowitz EV, Brown RB. Antibiotic adverse reactions and drug interactions. Crit Care Clin. 2008;24(2):421-42, xi.

[111] Lockhart PB, Blizzard J, Maslow AL, Brennan MT, Sasser H, Carew J. Drug cost implications for antibiotic prophylaxis for dental procedures. Oral Surg Oral Med Oral Pathol Oral Radiol Endodontol. 2013;115(3):345-53.

[112] Sullivan A, Edlund C, Nord CE. Effect of antimicrobial agents on the ecological balance of human microflora. Lancet Infect Dis. 2001;1(2):101-14.

[113] Nord CE. Studies on the ecological impact of antibiotics. Eur J Clin Microbiol Infect Dis. 1990;9(7):517-8.

[114] Van der Waaij D, Nord CE. Development and persistence of multi-resistance to antibiotics in bacteria; an analysis and a new approach to this urgent problem. Int J Antimicrob Agents. 2000;16(3):191-7.

[115] Huddleston JR. Horizontal gene transfer in the human gastrointestinal tract: Potential spread of antibiotic resistance genes. Infect Drug Resist. 2014;7:167-76.

[116] weforum. Global Risks, 9th Ed. Available from: http://www3weforumorg/docs/ WEF_GlobalRisks_Report_2014pdf. 2014.

[117] O'Neill J. Antimicrobial Resistance: Tackling a Crisis for the Health and Wealth of Nations. 2014.

[118] Powell CA, Mealey BL, Deas DE, McDonnell HT, Moritz AJ. Post-surgical infections: Prevalence associated with various periodontal surgical procedures. J Periodontol. 2005;76(3):329-33.

[119] Antibiotic Prophylaxis for Surgical Procedures, Summary and Conclusions. SBU report no: 200. 2010. 
Chapter 3

\title{
Dimension and Structures of Biological Seal of Peri- Implant Tissues
}

\author{
Wen Lin Chai, Masfueh Razali and \\ Wei Cheong Ngeow
}

Additional information is available at the end of the chapter

http://dx.doi.org/10.5772/63950

\begin{abstract}
Over the years, improved understanding of the nature of bone-implant interface is among the important contributors to the success of osseointegration in modern dental implantology. The focus has since shifted to the assessment of the soft tissue-implant interface to better understand the mechanism of biological seal in the transmucosal region. The importance of peri-implant mucosal region lies in the need to establish a tight seal that isolates implant and the bone from the oral environment via epithelial and connective tissue attachment, thus preventing ingrowth of bacterial plaque. Many factors may influence the soft tissue attachment at this peri-implant interface. In this chapter, the dimension of peri-implant tissues and the factors affecting the biological seal, namely surface topography and physicochemical properties, are discussed. The review also looks into the impact of the type of materials and surface modifications of dental implant, all of which may influence the formation of biological seal of soft tissue around the dental implant.
\end{abstract}

Keywords: implant-soft tissue interface, biological seal, peri-implant tissues, surface topography, three-dimensional oral mucosal model

\section{Introduction}

The success of dental implant in the oral cavity depends on direct bone-implant surface contact as well as the soft tissue attachment surrounding the implant abutment (and dental implant), which the latter acts as biological seal against external oral environment. Much of the attentions in the early dental implant studies were given to the bone-to-titanium interface. 
These studies range from clinical [1, 2] to molecular levels [3], and from animal model [4, 5] to human biopsies $[6,7]$. In all studies, the bone appears to be in direct contact with implant without the presence of any connective tissue or fibrous tissue encapsulating the implant.

The extensive and well-established researches on bone-implant interface have led to the wide acceptance of the concept of osseointegration. Presently, more focuses are placed on understanding and improving the implant-soft tissue interface. The biological seal of the soft tissueimplant interface is created by epithelium and connective tissue. The presence of keratinized mucosa surrounding an implant is thought to be one of the important factors in maintaining peri-implant soft tissue health. Moreover, materials and surface topography of implant abutment materials may also influence the biological seal formed at the implant-soft tissue interface. The available data from animal studies and emerging information from human investigations suggest that different material with different surface energy and enhanced surface topography is associated with increased soft tissue-to-implant contact $[8,9]$. The nature of soft tissue-implant against normal periodontium is compared in the subsequent paragraph. By understanding the tissue around transmucosal region, the factors influencing this biological seal will be better appreciated.

\section{Peri-implant tissue}

The periodontium is known as a tooth-supporting structure while the peri-implant mucosa is the structure and function of the mucosa that surrounds the abutment of a dental implant. Clinically, both tooth and prosthesis of the dental implant will emerge from the gingival tissue with tight gingival cuff. Figure 1 features the clinical pictures of healing abutment in situ and the appearance of peri-implant mucosa following removal of the healing abutment. The mucosa surrounding the dental implant formed tight gingival cuff consists of epithelium and connective tissues established during healing after the surgery. Many studies provide information on similarities and differences between peri-implant soft tissue and tissue at the dento-gingival junction. The similarities and differences of both periodontium and periimplant mucosa are depicted in Table 1.
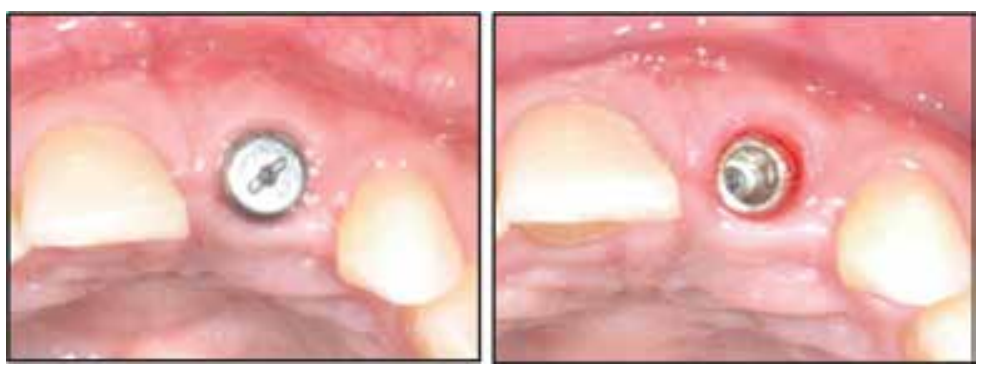

Figure 1. The clinical pictures of healing abutment in situ and mucosa at the implant neck. (Courtesy of Dr. Masfueh Razali). 


\begin{tabular}{|c|c|c|}
\hline Features & Periodontium & Peri-implant tissue \\
\hline $\begin{array}{l}\text { Gingival sulcus } \\
\text { depth }\end{array}$ & Shallow & $\begin{array}{l}\text { Dependent upon abutment length and restoration } \\
\text { margin }\end{array}$ \\
\hline $\begin{array}{l}\text { Junctional } \\
\text { epithelium }\end{array}$ & Hemidesmosome attachment to enamel & Hemidesmosome attachment on titanium $[10,11]$ \\
\hline Gingival fibres & $\begin{array}{l}\text { Complex array of fibres, some inserted } \\
\text { into cementum above crestal bone, } \\
\text { and onto periosteum }\end{array}$ & $\begin{array}{l}\text { - Lack of fibres insertion on implant surface } \\
\text {-Fibres orientated longitudinally, parallel or } \\
\text { circumferential to the long axis of the implant [12] }\end{array}$ \\
\hline $\begin{array}{l}\text { Connective tissue } \\
\text { attachment }\end{array}$ & $\begin{array}{l}\text { Well-organised collagen fibre } \\
\text { bundles, running perpendicular } \\
\text { to root cementum }\end{array}$ & $\begin{array}{l}\text { - A scar-like structure that is rich in collagen but } \\
\text { deficient in fibroblasts and vascular systems }[13,14]\end{array}$ \\
\hline Blood supply & $\begin{array}{l}\text { Numerous vasculatures from periodontal } \\
\text { ligament space and gingival connective } \\
\text { tissue which formed anastomoses }\end{array}$ & $\begin{array}{l}\text { Fewer capillaries compared to tissue surrounding tooth. } \\
\text { [14-16] }\end{array}$ \\
\hline Biologic width & $\mathrm{JE}=0.97 \mathrm{~mm}, \mathrm{CT}=1.07 \mathrm{~mm}$ & $\mathrm{JE}=1.88 \mathrm{~mm}$ (average), $\mathrm{CT}=1.05 \mathrm{~mm}[12]$ \\
\hline
\end{tabular}

Table 1. Comparison of periodontium and peri-implant tissue.

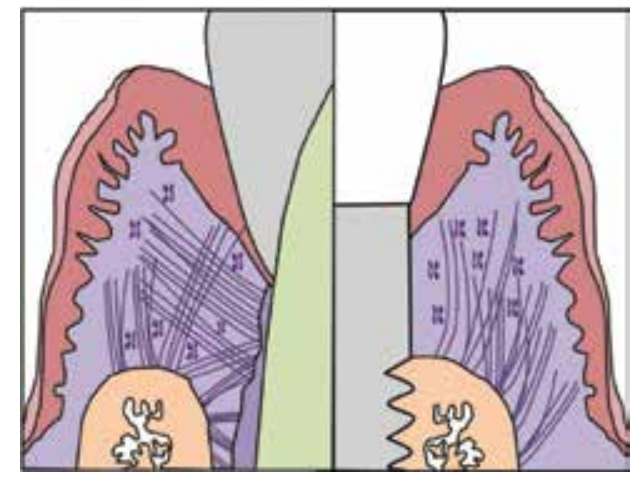

Figure 2. A schematic drawing of similarities and differences between dentogingival tissue and peri-implant mucosa (Prepared by Dr. Masfueh Razali).

Macroscopically, a tooth-supporting structure comprises the gingiva, connective tissues and periodontal ligament, which connects tooth to bone via cementum. There are three types of gingival epithelium covering the underlying connective tissue of a tooth. These are junctional epithelium, which provides the contact between the gingiva and the tooth; sulcular epithelium, which faces the tooth surfaces without any contact being made with the tooth surface; and lastly, oral epithelium, which faces the oral cavity. The oral epithelium is a keratinized, stratified squamous epithelium. The junctional epithelium, which is structurally different, is formed from the reduced enamel epithelium during tooth eruption and from dividing basal cells of the oral epithelium. The junctional epithelium forms a collar around the tooth and is about $2 \mathrm{~mm}$ high and $100 \mu \mathrm{m}$ thick. It is composed of only two cell layers, namely a basal layer 
and a supra basal layer. The inner cells of the junctional epithelium form and maintain a tight seal against the tooth surface. The connective tissue is composed of gingival fibres, which runs in many directions, from tooth and/or bone to gingival tissues. Similarly, the supporting structures of dental implant also consist of gingival epithelium and connective tissue attachment but without periodontal ligament. The epithelial part resembles the junctional epithelium around natural teeth $[10,12,18,19]$. The features of both normal periodontium surrounding teeth and peri-implant tissue are illustrated in Figure 2.

Generally, the macroscopic and microscopic features of peri-implant mucosa are almost similar to the tooth-supporting tissue (at the dento-gingival junction) with few exceptions.

1. The junctional epithelium: the junctional epithelium faces the implant smooth surfaces or abutment of an implant is less thick, and consists of only a few cell layers especially at the apical region.

2. Biologic width: both consist of junctional epithelium and connective tissue attachment, but the junctional epithelium of an implant is longer $[10,14,17]$ than that around teeth. Variation in height of these two attachments is noted between human and animal studies.

3. The gingival fibres connecting the periosteum to bone run parallel to the long axis of the implant, as compared with those around a tooth, where the gingival fibres consists of complexes arrays running from many direction including from tooth to gingival tissues, some of which perpendicular to the tooth. There were also fibres running circumferentially as shown by [15]. The arrangement of the fibres is schematically illustrated in Figure 2. The histological sections of transmucosal region of peri-implant soft tissue are shown in Figure 3. Note that there was a cell-free area adjacent to implant, and fibres appear running parallel to long axis of implant.

4. No periodontal ligament-bone is present.

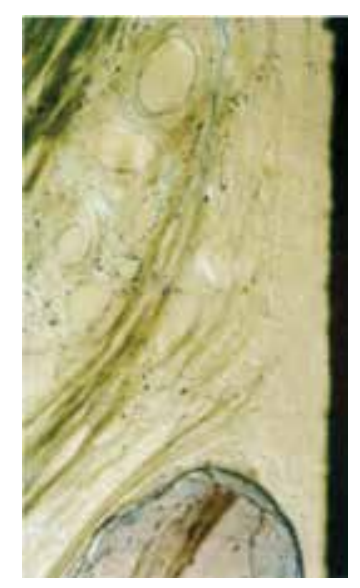

Figure 3. Transmucosal region of peri-implant mucosa demonstrating fibres of gingival connective tissue, no attachment of fibres on implant surface. (Reproduced with permission from [15]) 
So far, the structure, dimensions and the composition of gingival and implant transmucosal regions have been investigated by many researchers. These include early animal models studies in dogs $[10,11,14]$ and in human $[20,21]$. From those studies, a few conclusions have been made which included:

1. On average, the attachment between mucosa and a titanium implant comprises junctional epithelium about 1.4-2.9 mm high, and a connective tissue zone approximately 0.7-2.6 mm high $[10,12]$

2. The periodontium and peri-implant mucosa have common characteristics, but they differ in terms of composition of the connective tissue, the alignment of the collagen fibre bundles and the distribution of vascular structures apical to the junctional epithelium. The connective tissue-implant interface commonly consists of a non-infiltrated, densely structured, collagen-rich connective tissue. It can be divided into two zones: outer zone (located beneath the junctional epithelium) and inner zone (positioned above the bone crestal and in direct contact with implant surface) [14]

A qualitative analysis of the subepithelial connective tissue showed a cell-rich, wellvascularized outer zone with fibres running in many different directions and a poorly vascularized inner zone consisting of numerous dense collagen fibres running close to the implant surface, predominantly in a parallel direction [14, 15, 22]. The inner zone is in direct contact with the implant/abutment surface and is $50-100 \mathrm{~mm}$ thick. It is rich in fibres, with few scattered fibroblasts that appear to be in close contact with the transmucosal component. The peri-implant mucosa generally resembles and is recognized as a scar tissue, exhibiting an impaired resistance towards bacterial colonization [13, 16]. As a consequence, the connective tissue adhesion at implant has a poor mechanical resistance as compared to that of natural teeth.

As suggested by some studies mentioned earlier, the biological seal of the peri-implant tissue formed by both epithelial and connective tissue attachments is weak and poor in mechanical resistance $[13,16]$. Hence, this area is subjected to increased risk of peri-implant diseases, as the bacterial assault begins in this area. It is important to understand the nature of both attachments as it may lead to an enhancement this biological seal. Various models been used to evaluate the implant-soft tissue interface. These models are reviewed in the next section.

\section{Evaluation of implant-soft tissue response}

The soft tissue interface especially the structure of collagen fibre bundles received more attention over the past 10 years with studies that include animal models such as dogs [10-12, $14]$ and monkeys $[23,24]$ and human $[25,26]$ used to explore the structure and dimension of soft tissue-implant interface. Recently, Chai and co-workers [18] have ventured upon the use of three-dimensional oral mucosal models by using the tissue engineering technology to investigate the nature of the peri-implant biological seal. 


\subsection{Implant-soft tissue interface models}

The advantages and disadvantages of each implant-soft tissue interface study models are described in the next section. These models were developed in order to enhance our understanding of the soft tissue response on various materials with different surface topography and to establish best methods to evaluate the biological seal of peri-implant tissue. Generally, an in vitro study using monolayer cell culture model is conducted to assess the cytotoxicity of the cells and quickly observe cell activities and behaviour towards new dental implant materials. Histomorphometric analysis of en bloc tissue consisting of both soft tissue and implant body is the best method to demonstrate the presence of epithelial and connective tissue attachment at the soft tissue-implant interface. Yet, due to limited opportunity to obtain histological section from human, animal models were developed.

\subsubsection{In vitro studies}

Presently, in vitro testing is performed as a prerequisite to in vivo evaluation. However, the in vitro techniques do not reflect the clinical situation and the progress in our understanding of extra- and intracellular processes that occur in connective tissue attachment. Thus, the data cannot be extrapolated into clinical applications. Nevertheless, the study involving monolayer cells is by far the most popular and easy-to-conduct study although more sensitive in vitro evaluations are now available. The cell shape, activities and response can be evaluated morphometrically via immunocytochemical staining [27], or by analysis using scanning electron [28, 29] or fluorescent [30,31] miscroscopies. Additionally, the gene and protein expressions for cell adhesion and attachment can also be carried out [27, 32, 33]. Most studies used primary human gingival [29,32,34] and periodontal [35] fibroblasts as a cell model, which are cultured directly onto the dental implant materials surface. Keratinocytes are also frequently used $[27,36,37]$. Compared to fibroblasts, keratinocytes by far is most difficult to culture. Cochran et al. [35] compared the behaviour of periodontal and gingival fibroblast as well as keratinocytes towards the titanium with different surface textures. They found that human fibroblast and epithelial cell attachment and proliferation are significantly affected by surface characteristics of titanium. Of three cell types, gingival fibroblasts appeared to attach best, followed by periodontal ligament fibroblasts and epithelial cells. Both types of fibroblasts grow and proliferate well on both rough and smooth titanium surfaces compared to epithelial cells once they are attached to the surface [35]. Other study found a significant decrease in the number of gingival fibroblasts on rough titanium (Ti) surfaces compared with smooth polished Ti surfaces [30,34]. On the other hand, Oates et al. [32] found that the fibroblasts adhesion and attachment are enhanced in rougher surface than smooth surface, in contrast to other findings [33] where focal adhesion kinases were immunogold labelled. In a different study using ceramic, fibroblasts attached more on the milled ceramic and appeared to follow the direction of the fine irregularities on the surface [38]. Nevertheless, most common finding of those studies is that cells were oriented in a parallel order along the grooves of the machined surface but arranged randomly when in contact with a rough surface. Hence, the in vitro models appear to be able to provide an insight and could be used to guide specific cell attachment or 
specific material with surface characteristics for in vivo models. Animal models are the most common in vivo models carried out compared to human studies.

\subsubsection{Animal models}

Studies using animals as in vivo models for evaluation of soft tissue response around dental implant have been extensively conducted and are well documented. In animal models, the histological section of peri-implant tissue was made possible, which becomes the gold standard for the implant-soft tissue interface analysis. While dogs models such as the beagle $[8,14]$ being the most common animal of choice, monkeys $[23,39]$ and minipigs [40] were also used to demonstrate the presence of epithelial and connective tissue attachment around transmucosal region of dental implants histologically.

The experiments in animals demonstrated that the dimension of the mucosal attachment to implants was similar to the gingival attachment at teeth and was composed of an epithelial portion about 1.5-2 $\mathrm{mm}$ long and a cell-rich connective tissue portion close to the implant that was about 1-1.5 mm high [10]. Animal models were also used to evaluate the soft tissue response towards different abutment materials. Abrahamsson et al. [11] investigated the influence of abutment material on the location and the quality of the attachment that occurred between the peri-implant mucosa and the implant. They found no proper attachment formed at the abutment level made of gold alloy and porcelain when compared to those made of titanium and ceramic. In addition, similar finding was noted by Welander et al. [41] when titanium, zirconia and $\mathrm{Au} / \mathrm{Pt}$ alloy were used. The tissue around abutment made from titanium and zirconia was stable; meanwhile, an apical migration of epithelium was noted on $\mathrm{Au} / \mathrm{Pt}$ alloy. In another study, Abrahamsson et al. [42] demonstrated that the soft tissue attachment that formed at implants made of commercially pure titanium (c.p. titanium) was not influenced by the roughness of the titanium surface.

Among many, dogs have been the most common animal of choice. This is possibly due to easy access with regard to clinical examinations and oral hygiene procedures of the dogs. It must be noted that non-human primates bear more resemblence to human anatomy and histology than any other animal, thus may offer a higher degree of relevance to human. Nevertheless, the results from animal experiments should always be carefully interpreted since the healing response and immuno-reaction in animals might not be similar to human, so the data might not be comparable. A given sequence of soft tissue integration to implants in a dog may not correspond exactly to an expected outcome in humans. The differences in tissue response during healing between human-human subjects may sometimes become more pronounced between different human to human subjects than between animals and humans. Moreover, the healing response in animals is also less predictable compared to human. In the light of evidence-based dentistry, the result from animal studies should be interpreted cautiously. Additionally, animal studies are also bound to ethical considerations, where study design and calculation of sample size of animals in experiments are to be carried out with caution. Essentially, to have more clinical validity, human randomized control trials should be carried out to obtain more information on the peri-implant tissues. 


\subsubsection{Human studies}

The composition of the connective tissue interface towards implants was studied in both animal experiments and human biopsy materials. While human studies are very limited due to ethical issues, the evidence of epithelial and connective tissue attachment around periimplant regions are obtained mostly from failed implant [43], autopsy[44, 45] or clinical studies $[1,46]$, where the presence of connective tissue attachment on these studies is still difficult to demonstrate. Most of the human studies that have been carried out were clinical studies in which the traditional periodontal parameters were used for monitoring the soft tissue responses around dental implants intra-orally. According to clinical studies that involve the marginal bone levels, we can conclude that bone level is stable as it implies that the soft tissue integration has not migrated apically [1,46,47]. Liljenberg et al. [48] in their study of soft tissue biopsies of edentulous ridge mucosa and peri-implant mucosa revealed that the composition of both tissues were nearly identical in terms of collagen, cells and vascular structures. The peri-implant mucosa harboured a junctional epithelium that contained significantly enhanced numbers of different inflammatory cells infiltration. On the other hand, Piatelli et al. [44] found that there was no inflammatory infiltrate in epithelium or connective tissue in human autopsy biopsies of titanium dental implants. It is also interesting to note that the collagen fibres in the coronal part were parallel to implant surface while in the apical region the fibres were in a perpendicular fashion was found. Additionally, Glauser et al. [49] used both hard and soft tissue biopsies of mini titanium implants with different surface characteristics to demonstrate the establishment of junctional epithelium attachment to the implant surfaces. They noted that collagen fibres and the fibroblasts were oriented parallel to the implant surface. The oxidized and acid-etched implants revealed less epithelial downgrowth and longer connective tissue than machined implants [49]. As for different types of materials, Vigolo et al. [46] assessed the peri-implant mucosa around abutments made of gold alloy and titanium and found no difference between the two types of abutments with regard to peri-implant marginal bone level and soft tissue parameters. Meanwhile, Nevins et al. [26] using en bloc biopsy demonstrated intimate contact of junctional epithelium cells to implant surface and connective tissue with functionally oriented collagen fibres running towards the implant surface designed with LaserLok microchannels. Nonetheless, it is unethical to remove implant in order to attain en bloc tissue for histological analyses in human, and data from autopsy did not necessarily represent the ultrastructural nature of the peri-implant interface. In addition, not all animal experiments can be replicated in human samples due to cost and ethical considerations. For this reason, the investigation of peri-implant interface for improvement of connective tissue attachment is rather difficult to conduct in human. Thus, the need of development of different models for histological analyses may be essential.

\subsubsection{Three-dimensional oral tissue engineering}

As the opportunity to undertake human studies is limited, many studies that evaluated the peri-implant interface were carried out using animal models. With advances in knowledge on tissue regeneration, tissue-engineered oral mucosal equivalents (three-dimensional oral mucosal model, 3D OMM) have been developed for clinical applications and also for con- 
ducting in vitro studies on biocompatibility, mucosal irritation, disease and other basic oral biological phenomena such as for grafting of oral mucosal defects [50,51]. The 3D OMM consists of both epithelium and connective tissue layers, grown in the laboratory using collagen membrane as the scaffold. Therefore, evaluation of cell-cell interaction between epithelium, connective tissue and implant surface using 3D OMM is possible and could become an alternative method to study the nature of peri-implant interface. The use of 3D OMM will permit histological preparation and histomorphometric analysis of the interface. With the modification of culture technique, Chai et al. [18] have constructed 3D OMM and have demonstrated the presence of peri-implant tissue with features that mimicked those seen in vivo when tested with titanium. Chai and co-workers [19] further developed the 3D OMM and succeeded in obtaining formed peri-implant-like-epithelium (PILE) on the polished, machined, sand-blasted and TiUnite titanium surfaces. Using the 3D OMM, ultrastructural investigation of the soft tissue-implant interface with transmission electron microscopy (TEM) is also possible. It is also interesting to note that the presence of hemidesmosome-like structure as an epithelial attachment to the material surface is shown using this model (Figure 4). Moreover, the biological seal of peri-implant tissue can also be demonstrated quantitatively with 3D OMM $[52,53]$. This can be carried out via assessment of penetrative behaviour of radioisotope material through the 3D OMM model [52]. Alternatively, the biological seal of peri-implant can also be assessed through the measurement of degree formed by pocket or non-pocket epithelial attachment at the oral mucosal model-material interface [18, 53]. Although only limited study is available on the use of 3D OMM for evaluating the peri-implant interface, this model appears to have a more promising prospect than the monolayer cell culture model. This model is a useful method to evaluate the soft tissue response prior to investigation with an animal model.
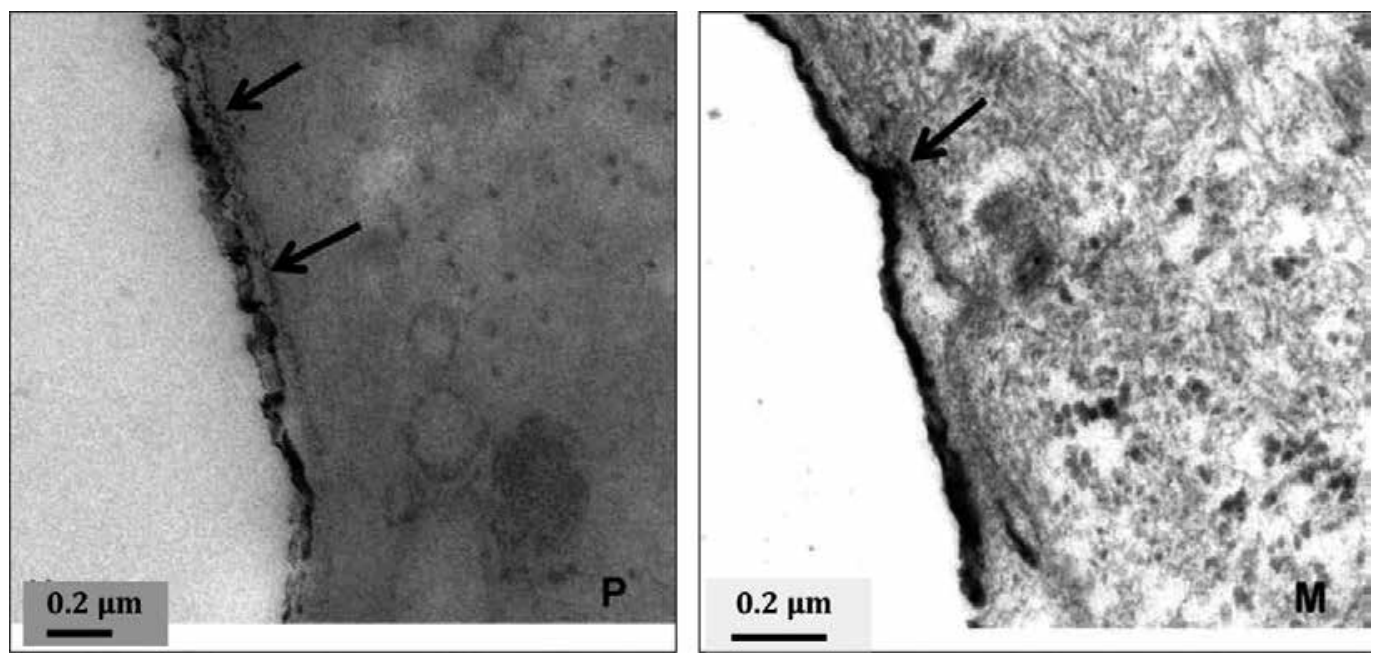

Figure 4. Hemidesmosome-like structures (black arrows) formed from 3D OMM and specimens (Ti). $\mathrm{P}=$ polished and $\mathrm{M}=$ machined surfaces. (Reproduced with permission from [19]). 


\subsection{Analyses of the soft tissue-implant interface}

The soft-tissue implant interface can be investigated through histomorphometric and histologic analyses. Of both, the preparation for latter analysis is very difficult to carry out especially if the implant is attached to the tissue. The histological studies also allow identification of specific protein markers expressed by any of the tissue or cells in response to dental implants. The histological sections can then be analysed under different types of microscopies. Among the known microscopic analyses for assessing the peri-implant interface are light microscopy (LM), scanning electron microscopy (SEM), confocal laser scanning microscopy (CLSM), focus ion beam (FIB) and transmission electron microscopy (TEM). Similar to SEM, CLSM allows assessment of peri-implant interface and cell-cell interaction without the need of histological processing as for light microscopy. With these two, direct visualization of implant-soft tissue interface is possible with appropriate preparation for each microscopy. The tissue or specimens can also be fluorescently labelled for the identification of adhesion molecules or cells and examined under CLSM [43]. While the use of 3D oral mucosal model with implant material intact may allow direct examination of the connective tissue attachment, the method to prepare the specimen still remains challenging and technically demanding. More studies in term of optimization of certain promising technique such as FIB for TEM analysis must be explored in order to obtain the ultrastructural nature of the implant-soft tissue interface.

\section{Factors influencing biological seal of implant-soft tissue interface}

The existence and function of biologic width around dental implant are well documented in animal and human histological studies. Any factors affecting soft tissue reaction around dental implant might also affect the biologic width, thus the biologic seal of the peri-implant region. As mentioned earlier in the text, the nature and health of soft tissue surrounding an implant may be influenced by many factors. The presence of keratinized mucosa surrounding an implant is thought to influence the dimension of biological seal [54]. Moreover, the attachment of epithelial and connective tissues may also be influenced by material properties and surface modifications of implant abutment materials. Within the context of this chapter, how soft tissue responds to material and surface modification of implant/implant abutment is only discussed briefly.

\subsection{Bulk of materials}

Material properties appear to affect the attachment formed by epithelial tissue. Most often, titanium is the material used for dental implants and abutments, and is therefore the most extensive and widely studied material. Commercially pure titanium (Grade 2 and Grade 4 ) is commonly used in the fabrication of dental implants and implants abutments. Recently, zirconia is gaining more popular and seems to be a suitable implant material because of its excellence aesthetics, mechanical properties and biocompatibility. The presence of zirconia in dentistry is now being embraced, with the manufacturers promoting the esthetic, biomechanical and biological qualities of the material. Despite the extensive literature in the field of 
osseointegration of zirconia $[39,55]$, the response of soft tissue towards zirconia is starting to gain attention from many researchers [9, 11, 40,41]. In animal experiments, Abrahamsson et al. [11] showed that an epithelial downgrowth occurred and migrated towards the implant neck and associated bone loss which was noted around the abutments of gold and gold alloys fused with dental ceramics, as compared to abutments made of pure titanium and aluminium oxide $\left(\mathrm{Al}_{2} \mathrm{O}_{11}\right)$ ceramics where peri-implant cuff of about $3.5 \mathrm{~mm}$ width was noted to be present. Kohal et al. [39] also reported a satisfactory soft-tissue formation on both titanium and zirconium oxide $(\mathrm{ZrO} 2)$ surfaces, without evidence of perpendicular fibres on the monkey model. Likewise, another study showed that the soft-tissue dimension at $\mathrm{Ti}$ and $\mathrm{ZrO} 2$ abutments remained stable after 5 months of healing, meanwhile at gold/platinum alloys abutment sites, an apical shift of the barrier epithelium and marginal bone loss occurred [41]. In contrast, a human clinical study conducted by Vigolo et al. [46] revealed no significant differences regarding peri-implant bone loss and soft-tissue level when abutments of titanium and gold alloy were used with cemented single implant crown. Similarly, Linkevicius and Apse [56] in their systematic review concluded that available data failed to give evidence that titanium abutments are better at maintaining stable peri-implant tissues as compared to gold, aluminium oxide and zirconium oxide abutments. The performance of zirconia vs titanium abutments over long term is yet to be available. Recently, Zembic et al. [57] has published a 5-year comparison of the clinical performance of both titanium and zirconia abutments, and they found no statistically and clinically relevant difference between the survival rates, and technical and biological complication of these two abutment types.

\subsection{Surface modifications}

Surface modifications of titanium dental implants or implant abutment are performed to improve the biological, chemical and mechanical properties of implants. Over the years, specific surface properties such as topography, structure, chemistry, surface charge and wettability have been investigated to help enhance the soft tissue attachment. Commonly, the surface modification can be broadly classified into modification of physical properties of the surface or chemical properties of the surface. In the subsequent paragraphs, the surface modifications of titanium dental implant/abutment are divided into surface topography and surface/chemical composition of the material. The surface topography of the implant can be altered in many ways. However, the methods of surface modifications of dental implant are not discussed since they are not within the scope of this chapter.

\subsubsection{Surface topography}

Different materials exhibit different surface energy. The differences in surface free energy may reflect their wettability characteristics. The higher the hydrophilicity of the material, the better adhesion of the cells thus enhancing the attachment formed by these cells [58]. Improving the surface texture with various techniques, thus altering the surface chemistry also enhances the wettability of certain material. Modification of surface texture will create different surface topography of dental implant material including abutment materials. Analysis of surface topography can be obtained from scanning profilometer (Figure 5) or SEM (Figure 6) in which 
the surface details can be visualized three dimensionally. The definition of surface roughness of dental implant has been proposed by Albrektsson and Wennerberg $[59,60]$. This definition can be used for study of osseointegration or implant-soft tissue interface. Accordingly, the characterization of surface topography is shown in Table 2. The values of Sa were determined by optical interferometry using Gaussian filters. There is a need to emphasize that Table 2 shows a summary of several studies cited in this chapter.

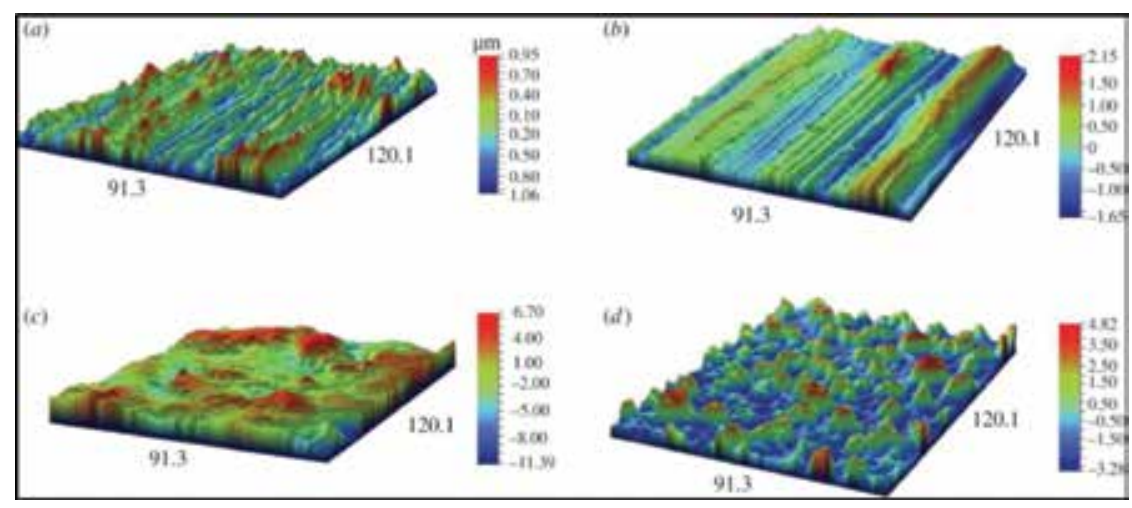

Figure 5. A light interferometry micrograph showing the surface topography of the four types of Ti surfaces. (a) Polished, (b) machined, (c) sandblasted, and (d) TiUnite. Scale bar: (a) 21.06-0.95 mm, (b) 21.65-2.15 mm, (c) 211.39-6.70 $\mathrm{mm},(\mathrm{d}) 23.28-4.82 \mathrm{~mm}$. (Reproduced with permission from [52]).

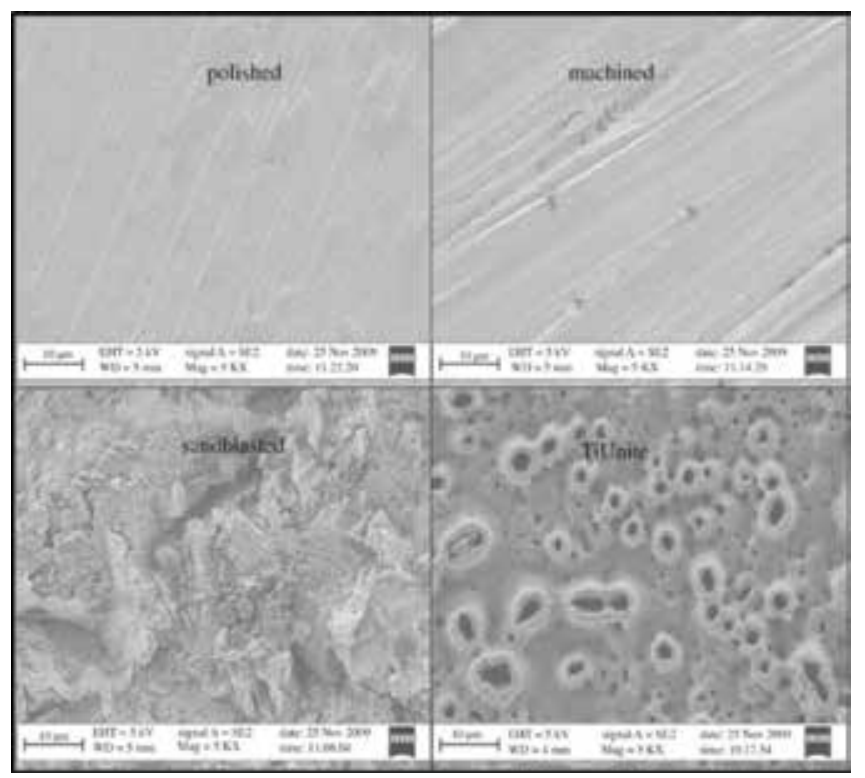

Figure 6. Scanning electron micrographs of the four types of Ti surface topographies.(Reproduced with permission from [52]). 


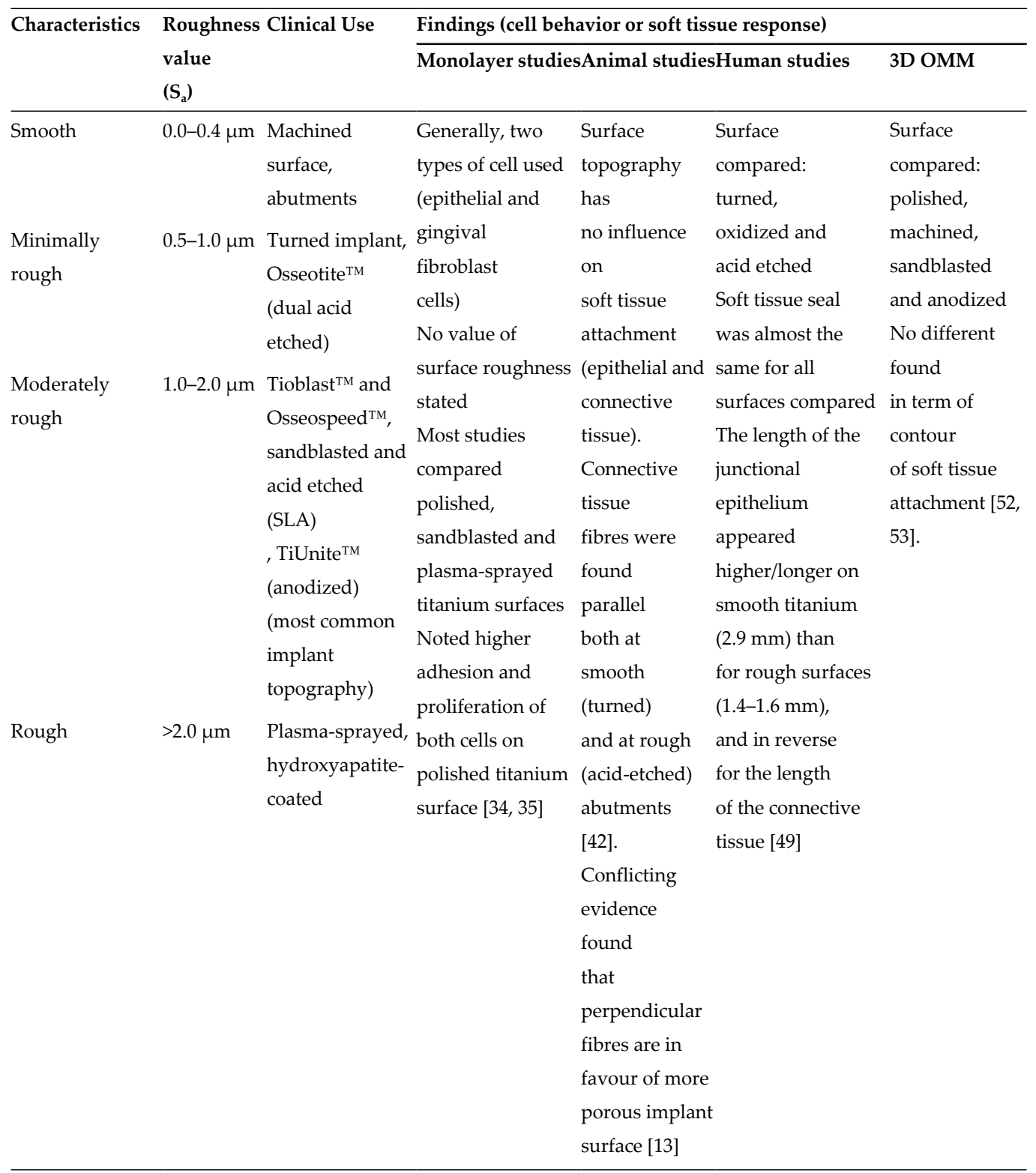

Table 2. Implant surface roughness.

Surface texture is known to influence epithelial cells and fibroblast attachment, although there is no complete agreement in the literature on the exact effect. One report found no significant differences concerning soft tissue reactions between roughed or smoothed surface implant [13], whereas Cochran et al. [35] found that smooth surfaces were more favourable for epithelial cell proliferation, as the fibroblasts appear to attach and proliferate better on rough surfaces. Simion et al. [61] reported that epithelial cells adhered and spread better on metallic 
surfaces than on ceramic surfaces with well-organized focal contacts and pre-hemidesmosomes found on metallic surfaces, but not on porcelain and aluminium oxide.

Brunete and Chehroudi [62] in their review have suggested that the micro-fabricated grooved surfaces are able to inhibit epithelial downgrowth on implants depending on the dimension of the grooves in vitro. Similarly, fibroblasts also exhibit contact guidance on grooved surfaces, although its shape in vitro differs from that found in vivo. Delgado-Ruiz and co-workers [63] noted that micro-grooved surfaces were able to induce transverse collagen fibre formation, thus supporting two studies [26, 64]. It is also important to include a study by Nevins et al. [26] who demonstrated that soft tissue in humans is attached mechanically by perpendicular collagen fibre bundles on a micro-grooved pulsed laser surface.

\subsubsection{Surface composition}

Over the years, many strategies have been explored to improve the biological seal of periimplant tissue by changing the surface chemistry of dental implants and implant abutments. The surface chemistry of the materials may be altered by biological modification, or by changing the chemical composition of the materials. As for biological modifications, methods of surface modification available include adding or coating with biomimetic/bioactive substances such as fibronection or intergrin onto the surface with the aim of promoting cellular adhesion and controlling cell behaviour. Fibronectin is a glycoprotein present on cell surfaces, found in connective tissues, basement membranes, and extracellular fluids, and is known to play a role in cell-to-cell and cell-to-substrate adhesion and enhances gingival fibroblast attachment. It is interesting to note that epithelial cells and fibroblasts have different affinities for adhesive proteins of the extracellular matrix. Dean et al [65] noted that higher number of fibroblasts bound to fibronection coated implant surface than epithelial cells, while gingival epithelial cell binding on implant surface coated with laminin was higher in number than fibroblasts [66,67]. Collagen Type 1 was also used to modify surface chemistry as it was found to improve initial fibroblasts attachment [68].

The chemistry of material surfaces can also be altered by using element such as calcium or magnesium coating. Hydrothermal treatment of titanium with $\mathrm{CaCl}_{2}$ or $\mathrm{MgCl}_{2}$ was found to enhance initial attachment of epithelial and fibroblasts cells, and may increase the quality of the soft tissue seal around dental implant [69]. In addition, surface chemistry of materials may also inadvertently altered by the presence of impurities, surface contamination and saliva. A clean surface has a high surface free energy, while a contaminated one has a lower surface energy.

\section{Conclusion}

There is some controversy on the possible attachment of connective tissue fibres to implant, but current studies indicate the presence of a parallel orientation with no insertion of periimplant connective tissue fibres. This difference in connective tissue attachment may affect the peri-implant tissue's susceptibility to disease. The gold standard for evaluating the connective 
tissue and epithelial attachment is assessing the histological section using various modes of processing, staining and analyses. The 3D OMM mimicking the oral tissue is a promising technique to be considered for evaluating the connective tissue attachment, yet the processing of the tissue/implant block is still similar to the tissue block obtained from animal/human. The reaction of cells on biomaterials is affected by the surface topography and surface physicochemistry of the materials. Various studies have shown that materials and surface modification of dental implants influence cell behaviour and interaction. Some of documented data were limited to cell response on the monolayer cell culture model and animal histological studies. Therefore, it is recommended that randomised controlled clinical trials are to be performed to determine the effects of dental implant materials and surface modifications on the peri-implant tissues.

\section{Author details}

Wen Lin Chai ${ }^{1}$, Masfueh Razali ${ }^{*}$ and Wei Cheong Ngeow ${ }^{3}$

*Address all correspondence to: masfuah_razali@yahoo.com

1 Department of Restorative Dentistry, Faculty of Dentistry, University of Malaya, Kuala Lumpur, Malaysia

2 Department of Periodontology, Faculty of Dentistry, Universiti Kebangsaan Malaysia (UKM), Jalan Raja Muda Abdul Aziz, Kuala Lumpur, Malaysia

3 Department of Oro-Maxillofacial Surgical \& Medical Sciences, Faculty of Dentistry, University of Malaya, Kuala Lumpur, Malaysia

\section{References}

[1] Lindquist L, Carlsson G, Jemt T. A prospective 15-year follow-up study of mandibular fixed prostheses supported by osseointegrated implants. Clinical results and marginal bone loss. Clinical Oral Implants Research. 1996;7(4):329-36.

[2] Ericsson I, Nilner K, Klinge B, Glantz PO. Radiographical and histological characteristics of submerged and nonsubmerged titanium implants. An experimental study in the Labrador dog. Clinical Oral Implants Research. 1996;7(1):20-6.

[3] Linder L, Albrektsson T, Branemark P-I, Hansson H-A, Ivarsson B, Jonsson U, et al. Electron microscopic analysis of the bone-titanium interface. Acta Orthopaedica Scandinavica. 1983;54(1):45-52. 
[4] Parr GR, Steflik DE, Sisk AL. Histomorphometric and histologic observations of bone healing around immediate implants in dogs. International Journal of Oral \& Maxillofacial Implants. 1993;8(5):534-540.

[5] Romanos GE, Toh CG, Siar CH, Wicht H, Yacoob H, Nentwig G-H. Bone-implant interface around titanium implants under different loading conditions: a histomorphometrical analysis in the Macaca fascicularis monkey. Journal of Periodontology. 2003;74(10):1483-90.

[6] Albrektsson T, Eriksson A, Friberg B, Lekholm U, Lindahl L, Nevins M, et al. Histologic investigations on 33 retrieved Nobelpharma implants. Clinical Materials. 1993;12(1):19.

[7] Wilson Jr TG, Schenk R, Buser D, Cochran D. Implants placed in immediate extraction sites: A report of histologic and histometric analyses of human biopsies. International Journal of Oral \& Maxillofacial Implants. 1998;13(3):333-341.

[8] Schwarz F, Ferrari D, Herten M, Mihatovic I, Wieland M, Sager M, et al. Effects of surface hydrophilicity and microtopography on early stages of soft and hard tissue integration at non-submerged titanium implants: An immunohistochemical study in dogs. Journal of Periodontology. 2007;78(11):2171-84.

[9] Becker K, Mihatovic I, Golubovic V, Schwarz F. Impact of abutment material and dis-/ re-connection on soft and hard tissue changes at implants with platform-switching. Journal of Clinical Periodontology. 2012;39(8):774-80.

[10] Berglundh T, Lindhe J, Ericsson I, Marinello CP, Liljenberg B, Thomsen P. The soft tissue barrier at implants and teeth. Clinical Oral Implants Research. 1991;2:81-90.

[11] Abrahamsson I, Berglundh T, Glantz P, Lindhe J. The mucosal attachment at different abutments. An experimental study in dogs. Journal of Clinical Periodontology. 1998;25(9):721-7.

[12] Cochran DL, Hermann JS, Schenk RK, Higginbottom FL, Buser D. Biologic width around titanium implants. A histometric analysis of the implanto-gingival junction around unloaded and loaded nonsubmerged implants in the canine mandible. Journal of Periodontology. 1997;68(2):186-97.

[13] Buser D, Weber HP, Donath K, Fiorellini JP, Paquette DW, Williams RC. Soft tissue reactions to non-submerged unloaded titanium implants in beagle dogs. Journal of Periodontology. 1992;63(3):225-35.

[14] Moon IS, Berglundh T, Abrahamsson I, Linder E, Lindhe J. The barrier between the keratinized mucosa and the dental implant. An experimental study in the dog. Journal of Clinical Periodontology. 1999;26:658-63.

[15] Weber H-P, Cochran DL. The soft tissue response to osseointegrated dental implants. Journal of Prosthetic Dentistry. 1998;79(1):79-89. 
[16] Berglundh T, Lindhe J, Jonsson K, Ericsson I. The topography of the vascular systems in the periodontal and peri-implant tissues in the dog. Journal of Clinical Periodontology. 1994;21(3):189-93.

[17] Gargiulo AW, Wentz FM, Orban B. Dimensions and relations of the dentogingival junction in humans. Journal of Periodontology. 1961;32(3):261-7.

[18] Chai WL, Moharamzadeh K, Brook IM, Emanuelsson L, Palmquist A, van Noort R. Development of a novel model for the investigation of implant-soft tissue interface. Journal of Periodontology. 2010;81(8):1187-95.

[19] Chai WL, Brook IM, Emanuelsson L, Palmquist A, van Noort R, Moharamzadeh K. Ultrastructural analysis of implant-soft tissue interface on a three dimensional tissueengineered oral mucosal model. Journal of Biomedical Materials Research Part A. 2011;100(2):269-77.

[20] Lang N, Wetzel A, Stich H, Caffesse R. Histologic probe penetration in healthy and inflamed peri-implant tissues. Clinical Oral Implants Research. 1994;5(4):191-201.

[21] Kan JY, Rungcharassaeng K, Umezu K, Kois JC. Dimensions of peri-implant mucosa: An evaluation of maxillary anterior single implants in humans. Journal of Periodontology. 2003;74(4):557-62.

[22] Abrahamsson I, Berglundh T, Wennström J, Lindhe J. The peri-implant hard and soft tissues at different implant systems. A comparative study in the dog. Clinical Oral Implants Research. 1996;7(3):212-9.

[23] Siar CH, Toh CG, Romanos G, Swaminathan D, Ong AH, Yaacob H, et al. Peri-implant soft tissue integration of immediately loaded implants in the posterior macaque mandible: a histomorphometric study. Journal of Periodontology. 2003;74(5):571-8.

[24] Kawahara H, Kawahara D, Mimura Y, Takashima Y, Ong JL. Morphologic studies on the biologic seal of titanium dental implants. Report II. In vivo study on the defending mechanism of epithelial adhesions/attachment against invasive factors. International Journal of Oral \& Maxillofacial Implants. 1998;13(4):465-73.

[25] Schierano G, Ramieri G, Cortese M, Aimetti M, Preti G. Organization of the connective tissue barrier around long-term loaded implant abutments in man. Clinical Oral Implants Research. 2002;13(5):460-4.

[26] Nevins M, Nevins ML, Camelo M, Boyesen JL, Kim DM. Human histologic evidence of a connective tissue attachment to a dental implant. International Journal of Periodontics \& Restorative Dentistry. 2008;28(2):111-21.

[27] An N, Rausch-fan X, Wieland M, Matejka M, Andrukhov O, Schedle A. Initial attachment, subsequent cell proliferation/viability and gene expression of epithelial cells related to attachment and wound healing in response to different titanium surfaces. Dental Materials. 2012;28(12):1207-14. 
[28] Mustafa K, Lopez BS, Hultenby K, Wennerberg A, Arvidson K. Attachment and proliferation of human oral fibroblasts to titanium surfaces blasted with $\mathrm{TiO} 2$ particles. A scanning electron microscopic and histomorphometric analysis. Clinical Oral Implants Research. 1998;9(3):195-207.

[29] Guida L, Oliva A, Basile MA, Giordanoo M, Nastri L, Annunziata M. Human gingival fibroblast functions are stimulated by oxidized nano-structured titanium surfaces. Journal of Dentistry. 2013;41:900-7.

[30] Furuhashi A, Ayukawa Y, Atsuta I, Okawachi H, Koyano K. The difference of fibroblast behavior on titanium substrata with different surface characteristics. Odontology. 2012;100(2):199-205.

[31] Dorkhan M, Yücel-Lindberg T, Hall J, Svensäter G, Davies JR. Adherence of human oral keratinocytes and gingival fibroblasts to nano-structured titanium surfaces. BMC Oral Health. 2014;14(1):1-9.

[32] Oates TW, Maller SC, West J, Steffensen B. Human gingival fibroblast integrin subunit expression on titanium implant surfaces. Journal of Periodontology. 2005;76(10):174350.

[33] Größner-Schreiber B, Herzog M, Hedderich J, Dück A, Hannig M, Griepentrog M. Focal adhesion contact formation by fibroblasts cultured on surface-modified dental implants: An in vitro study. Clinical Oral Implants Research. 2006;17(6):736-45.

[34] Hormia M, Könönen M. Immunolocalization of fibronectin and vitronectin receptors in human gingival fibroblasts spreading on titanium surfaces. Journal of Periodontal Research. 1994;29(2):146-52.

[35] Cochran DL, Simpson J, Weber HP, Buser D. Attachment and growth of periodontal cells on smooth and rough titanium. International Journal of Oral \& Maxillofacial Implants. 1994;9(3):289-97.

[36] Gould TR, Brunette DM, Westbury L. The attachment mechanism of epithelial cells to titanium in vitro. Journal of Periodontal Research. 1981;16(6):611-6.

[37] Kimura Y, Matsuzaka K, Yoshinari M, Inoue T. Initial attachment of human oral keratinocytes cultured on zirconia or titanium. Dental Materials Journal. 2012;31(3): 346-53.

[38] Mustafa K, Odén A, Wennerberg A, Hultenby K, Arvidson K. The influence of surface topography of ceramic abutments on the attachment and proliferation of human oral fibroblasts. Biomaterials. 2005;26(4):373-81.

[39] Kohal RJ, Weng D, Bächle M, Strub JR. Loaded custom-made zirconia and titanium implants show similar osseointegration: An animal experiment. Journal of Periodontology. 2004;75(9):1262-8. 
[40] Liñares A, Muñoz F, Permuy M, Dard M, Blanco J. Soft tissue histomorphology at implants with a transmucosal modified surface. A study in minipigs. Clinical Oral Implants Research. 2015;26(9):996-1005.

[41] Welander M, Abrahamsson I, Berglundh T. The mucosal barrier at implant abutments of different materials. Clinical Oral Implants Research. 2008;19(7):635-41.

[42] Abrahamsson I, Zitzmann NU, Berglundh T, Linder E, Wennerberg A, Lindhe J. The mucosal attachment to titanium implants with different surface characteristics: An experimental study in dogs. Journal of Clinical Periodontology. 2002;29:448-55.

[43] Baschong W, Suetterlin R, Hefti A, Schiel H. Confocal laser scanning microscopy and scanning electron microscopy of tissue Ti-implant interfaces. Micron. 2001;32(1):33-41.

[44] Piattelli A, Scarano A, Piattelli M, Bertolai R, Panzoni E. Histologic aspects of the bone and soft tissues surrounding three titanium non-submerged plasma-sprayed implants retrieved at autopsy: A case report. Journal of Periodontology. 1997;68(7):694-700.

[45] Romanos GE, Traini T, Johansson CB, Piattelli A. Biologic width and morphologic characteristics of soft tissues around immediately loaded implants: studies performed on human autopsy specimens. Journal of periodontology. 2010;81(1):70-8.

[46] Vigolo P, Givani A, Majzoub Z, Cordioli G. A 4-year prospective study to assess periimplant hard and soft tissues adjacent to titanium versus gold-alloy abutments in cemented single implant crowns. Journal of Prosthodontics. 2006;15(4):250-6.

[47] Glauser R, Sailer I, Wohlwend A, Studer S, Schibli M, Schärer P. Experimental zirconia abutments for implant-supported single-tooth restorations in esthetically demanding regions: 4-year results of a prospective clinical study. International Journal of Prosthodontics. 2004;17(3):285-90.

[48] Liljenberg B, Gualini F, Berglundh T, Tonetti M, Lindhe J. Some characteristics of the ridge mucosa before and after implant installation. A prospective study in humans. Journal of Clinical Periodontology. 1996;23(11):1008-13.

[49] Glauser R, Schüpbach P, Gottlow J, Hämmerle CH. Peri-implant soft tissue barrier at experimental one-piece mini-implants with different surface topography in humans: A light-microscopic overview and histometric analysis. Clinical Implant Dentistry and Related Research. 2005;7(s1):s44-s51.

[50] Moharamzadeh K, Brook IM, Scutt AM, Thornhill MH, Van Noort R. Mucotoxicity of dental composite resins on a tissue-engineered human oral mucosal model. Journal of Dentistry. 2008;36(5):331-6.

[51] Moharamzadeh K, Franklin KL, Brook IM, van Noort R. Biologic assessment of antiseptic mouthwashes using a three-dimensional human oral mucosal model. Journal of Periodontology. 2009;80(5):769-75. 
[52] Chai WL, Brook IM, Palmquist A, van Noort R, Moharamzadeh K. The biological seal of the implant-soft tissue interface evaluated in a tissue-engineered oral mucosal model. Journal of Royal Society Interface. 2012;9(77):3528-38.

[53] Chai WL, Moharamzadeh K, van Noort R, Emanuelsson L, Palmquist A, Brook IM. Contour analysis of an implant-soft tissue interface. Journal of Periodontal Research. 2013;48(5):663-70.

[54] Berglundh T, Lindhe J. Dimension of the periimplant mucosa. Biological width revisited. Journal of Clinical Periodontology. 1996;23(10):971-3.

[55] Gahlert M, Gudehus T, Eichhorn S, Steinhauser E, Kniha H, Erhardt W. Biomechanical and histomorphometric comparison between zirconia implants with varying surface textures and a titanium implant in the maxilla of miniature pigs. Clinical Oral Implants Research. 2007;18(5):662-8.

[56] Linkevicius T, Apse P. Influence of abutment material on stability of peri-implant tissues: A systematic review. International Journal of Oral \& Maxillofacial Implants. 2008;23(3):449-56.

[57] Zembic A, Bösch A, Jung RE, Hämmerle $\mathrm{CH}$, Sailer I. Five-year results of a randomized controlled clinical trial comparing zirconia and titanium abutments supporting singleimplant crowns in canine and posterior regions. Clinical Oral Implants Research. 2013;24(4):384-90.

[58] Ponsonnet L, Reybier K, Jaffrezic N, Comte V, Lagneau C, Lissac M, et al. Relationship between surface properties (roughness, wettability) of titanium and titanium alloys and cell behaviour. Materials Science and Engineering: C. 2003;23(4):551-60.

[59] Albrektsson T, Wennerberg A. Oral implant surfaces: Part 1 - review focusing on topographic and chemical properties of different surfaces and in vivo responses to them. International Journal of Prosthodontics. 2004;17(5):536-43.

[60] Albrektsson T, Wennerberg A. Oral implant surfaces: Part 2 - review focusing on clinical knowledge of different surfaces. International Journal of Prosthodontics. 2004;17(5):544-64.

[61] Simion M, Baldoni M, Rossi P. A study on the attachment of human gingival cell structures to oral implant materials. The International journal of prosthodontics. 1990;4(6):543-7.

[62] Brunette D, Chehroudi B. The effects of the surface topography of micromachined titanium substrata on cell behavior in vitro and in vivo. Journal of Biomechanical Engineering. 1999;121(1):49-57.

[63] Delgado-Ruiz RA, Abboud M, Romanos G, Aguilar-Salvatierra A, Gomez-Moreno G, Calvo-Guirado JL. Peri-implant bone organization surrounding zirconia-microgrooved surfaces circularly polarized light and confocal laser scanning microscopy study. Clinical Oral Implants Research. 2015;26(11):1328-37. 
[64] Nevins M, Kim DM, Jun S-H, Guze K, Schupbach P, Nevins ML. Histologic evidence of a connective tissue attachment to laser microgrooved abutments: A canine study. International Journal of Periodontics \& Restorative Dentistry. 2010;30(3):245-55.

[65] Dean III JW, Culbertson KC, D'Angelo AM. Fibronectin and laminin enhance gingival cell attachment to dental implant surfaces in vitro. International Journal of Oral \& Maxillofacial Implants. 1995;10(6):721-8.

[66] Atsuta I, Yamaza T, Yoshinari M, Goto T, Kido MA, Kagiya T, et al. Ultrastructural localization of laminin-5 (gamma2 chain) in the rat peri-implant oral mucosa around a titanium-dental implant by immuno-electron microscopy. Biomaterials. 2005;26:62807.

[67] Werner S, Huck O, Frisch B, Vautier D, Elkaim R, Voegel J-C, et al. The effect of microstructured surfaces and laminin-derived peptide coatings on soft tissue interactions with titanium dental implants. Biomaterials. 2009;30(12):2291-301.

[68] Nagai M, Hayakawa T, Fukatsu A, Yamamoto M, Fukumoto M, Nagahama F, et al. In vitro study of collagen coating of titanium implants for initial cell attachment. Dental Materials Journal. 2002;21(3):250-60.

[69] Okawachi H, Ayukawa Y, Atsuta I, Furuhashi A, Sakaguchi M, Yamane K, et al. Effect of titanium surface calcium and magnesium on adhesive activity of epithelial-like cells and fibroblasts. Biointerphases. 2012;7(1):27. 



\section{Section 2}

The Applications of Ceramic Dental Implants 

Chapter 4

\title{
Ceramic Biomaterials for Dental Implants: Current Use and Future Perspectives
}

\author{
Federico Mussano, Tullio Genova, Luca Munaron, \\ Maria Giulia Faga and Stefano Carossa
}

Additional information is available at the end of the chapter

http://dx.doi.org/10.5772/62701

\begin{abstract}
Although titanium implants have the longest traceable record of predictable clinical performance and by far the widest diffusion in the market, some drawbacks have been recently pointed out. Titanium is not a completely bioinert material, since it may elicit allergenic reactions and is capable to diffuse not only within the adjacent tissues, which is proven by the elevated concentrations found in peri-implant bone and regional lymph nodes, but also systemically. Ceramic materials for oral application have been used for 40 years. Presently, the material of choice is yttria-stabilized tetragonal zirconia, which presents excellent mechanical and tribological properties together with biocompatibility. Concerns remain about the long-term durability of the material, owing to the report of in vivo failures that were caused by the low-temperature degradation of zirconia. To address this issue, research has developed improved oxide-based materials such as alumina-zirconia composites along with non-oxidic ceramics such as silicon nitride.

The proposed book chapter deals with the above-mentioned improved ceramic materials, based on both scientific literature and the authors' direct experience. Particular emphasis is given to the major achievements attained so far in terms of the biological response supported by the interface. Original in vitro data regarding alumina-toughened zirconia (ATZ), zirconia-toughened alumina (ZTA), and silicon nitride $\left(\mathrm{Si}_{3} \mathrm{~N}_{4}\right)$ samples with differentsurfacemodificationsareshown. Accuratesurfacecharacterization wasachieved recurring to scanning electron microscopy, non-contact optical profilometry. Protein adsorption on the surface was determined. A mouse pre-osteoblastic cell line, that is MC3T3-E1, was used to examine cellular adhesion and morphology. Viability and proliferation rate of MC3T3-E1 cells were assessed with proper chemiluminescent kits. Cell differentiation was obtained in terms of calcium deposition within the extracellular matrix and quantification of keynote osteogenic markers. Data were analyzed by GraphPad Prism6. For the first time, the behavior of osteoblasts cultured on ATZ and ZTA that underwenta patented hydrothermal treatment was reported. Also, twodifferent surfaces of $\mathrm{Si}_{3} \mathrm{~N}_{4}$ were compared. MC3T3-E1 cells could properly spread in all the
\end{abstract}


experimental conditions tested. The proliferation rate was consistent with that expected for biocompatible materials. Hydrothermally treated ATZ samples and $\mathrm{Si}_{3} \mathrm{~N}_{4}$ rough surfaces were capable to enhance the osteogenesis in vitro. The biological responses induced in MC3T3 cells were correlated with the surface features. Immediately after seeded, osteoblasts are known to interact with their substrate via integrins that bind to the proteins adsorbed on the biomaterial surface. The interface effect was discussed in light of the literature. The most recent publications suggest that research aims at investigating the effects of surface modifications dictating the chemical characteristics and the nano-/micro-topography that are paramount modulators of the biological response.

Keywords: surface roughness, dental implants, ceramic materials, surface modifications, interface

\section{Introduction}

Modern oral implantology has been based on titanium since the research line originated by Brånemark's first discovery and subsequent experiments [1]. Titanium implants have the longest traceable record of predictable clinical performance with a cumulative success rate of $98.8 \%$ for 15 years [2]. High biocompatibility, favorable tissue response and adequate strength and corrosion resistance rendered titanium implants widely diffused in the market. The number of dental implant brands grew from 45 systems in 1988 [3] to 600 systems produced by 146 manufacturers in 2008 [4]. Currently, worldwide, there are more than 350 dental implant manufacturers producing an estimate of 1600 different systems, $98 \%$ of which are titanium implants. Titanium, however, is no longer considered a completely bioinert material, instead it might be an allergen as reported by several studies [5-8]. Elevated titanium concentrations have been found in the vicinity of oral implants [8], in regional lymph nodes [9], serum and urine [10], which is potentially hazardous to human body. Besides these issues, some dental patients are metal-phobic and demand to be treated solely with metal-free dental implants [11].

Only recently, truly viable alternative materials were proposed to titanium, although the first ceramics for oral applications dated back to the 1970s. Historically, indeed, high-density, highpurity aluminum oxide (alumina) was chosen for dental implant manufacturing, as it combined excellent corrosion resistance, good bio-compatibility, high wear resistance, and high strength. Despite these promising features, the material was brittle and prone to fracture under unfavorable load. Thus, the positive preclinical and clinical outcomes of the first studies could not prevent alumina implant systems to be withdrawn from the market [12]. Research and manufacturing technology have greatly improved the offer of bio-ceramics, thanks to the introduction of yttria-partially stabilized tetragonal zirconia polycrystals (Y-TZP), whilst a possible future use of alumina zirconia composites and silicon nitride-titanium nitride composites may further expand the offer of reliable devices on the market. Three distinct sections of the present chapter are dedicated to each of these materials. Specifically, the literature regarding zirconia was thoroughly revised in Section 2, whilst some novel data of our group are exposed and discussed in light of and along with previous work as for alumina 
zirconia composites (Section 3) and silicon nitride-titanium nitride non-oxidic ceramics (Section 4).

\section{Yttria-partially stabilized tetragonal zirconia polycrystals (Y-TZP)}

\subsection{Material features}

Zirconia $\left(\mathrm{ZrO}_{2}\right)$ is a crystalline dioxide of zirconium: as thoroughly reviewed elsewhere [12], unalloyed zirconia can assume three crystallographic forms depending on the temperature, at ambient pressure. At room temperature and upon heating up to $1170^{\circ} \mathrm{C}$, the symmetry is monoclinic (P21/c). The structure becomes tetragonal (P42/nmc) between 1170 and $2370^{\circ} \mathrm{C}$ and cubic (Fm3m) above $2370^{\circ} \mathrm{C}$ and up to the melting point [13]. Upon cooling at $\sim 950^{\circ} \mathrm{C}$, during the transformation from the tetragonal $(\mathrm{t})$ phase to the monoclinic $(\mathrm{m})$ phase, a substantial increase in volume ( $4.5 \%$ ) occurs, which is sufficient to lead to catastrophic failure. By alloying pure zirconia with stabilizers such as calcium oxide $(\mathrm{CaO})$, magnesium oxide $(\mathrm{MgO})$, yttrium oxide $\left(\mathrm{Y}_{2} \mathrm{O}_{3}\right)$, or cerium oxide $\left(\mathrm{CeO}_{2}\right)$, the tetragonal structure is maintained, even at room temperature, and the stress-induced $\mathrm{t} \rightarrow \mathrm{m}$ transformation is controlled, efficiently arresting crack propagation [14, 15]. Indeed, when a crack develops, tetragonal grains convert immediately to monoclinic form. The propagation of the crack develops sufficient stress within the tetragonal structure to transform also the grains around the crack to stable monoclinic form. Thus, the expansion volume of zirconium dioxide crystals produces compressive stress around the crack and prevents further propagation of crack [16-18]. This mechanism is known as transformation toughening and is influenced by temperature, vapor, particle size, micro- and macrostructure, and concentration of stabilizing oxides [19].

Yttria-stabilized zirconia (Y-TZP) [20] is endowed with excellent mechanical, and tribological properties together with biocompatibility and rightly represent a good choice for preparing dental implants. As yttria decreases the driving force of the t-m transformation [21, 22], biomedical grade zirconia are usually stabilized with $3 \mathrm{~mol} \%$ yttria $\left(\mathrm{Y}_{2} \mathrm{O}_{3}\right)$ (hence 3Y-TZP) [16]. The salient mechanical properties of $\mathrm{Y}$-TZP are reported in Table 1, but it is noteworthy that the Weibull modulus is strongly dependent on the type of surface finish and the processing conditions [23].

Notwithstanding the excellent mechanical properties of Y-TZP [19, 24], recent reports of in vivo failures [25-27] have questioned the long-term stability of the material. The low-temperature degradation (LTD) of zirconia [22, 28-31], also known as aging process, plays here a fundamental role. Involving the $t \rightarrow m$ transformation, LTD can be favored, even at room temperature, by the penetration of water radicals into zirconia lattice, thus leading to the formation of tensile stresses in zirconia surfaces. The activation barrier for the transformation is lowered, and the phase transition is promoted. The main consequences of this aging process include surface degradation with grain pullout, microcracking, and strength degradation. As reported by Cattani-Lorente et al. [32] also, Young's modulus and hardness of Y-TZP bars were reduced by $30 \%$, when they were subjected to hydrothermal cycling. The increase of mono- 
clinic-tetragonal phase ratio was associated with microcracking and resulted responsible for the decline in mechanical parameters [32].

To control the aging phenomenon, several factors can be taken into account: from the obvious use of stabilizers to the modulation of residual stress [33]. Likewise, adjusting crystal size and removing impurities during manufacturing was proposed with the same anti-aging scope [34]. Interestingly, surface finishing could affect the aging kinetics of 3Y-TZP, according to Deville et al. [35]. More precisely, rough polishing produced a compressive surface stress layer beneficial for the aging resistance, whilst smooth polishing lead preferential transformation nucleation around scratches, due to elastic/plastic damage tensile residual stresses.

In an extensive review of his, Jerome Chevalier concluded that "although in the 1990s, 3Y-TZP ceramics were considered very promising materials for biomedical applications, long-term follow-up is needed to address the critical problem of aging in vivo. Moreover, most zirconia implants were processed at a time when aging was not yet fully understood. Methods to assess a priori the aging sensitivity of a given zirconia ceramic have been developed and should lead to safer implants. In the meantime, new zirconia or zirconia-based materials that overcome the major drawback of the standard 3Y-TZP are now available" [22].

\subsection{Manufacturing methods}

Hot isostatic press (HIP) is the most common method used for preparing zirconia dental implant. By subjecting encapsulated powder, or sintered yet porous parts, to inert gas at isostatic pressure at a high temperature, HIPing is deemed an excellent method to obtain highdensity homogenous products [36]. HIPing enables the application of an equally distributed pressure in all directions resulting in greater material uniformity and higher strength [2]. HIPing of Y-TZP enhances the strength, eliminates fracture sources such as pores, and reduces the aging phenomenon [37]. The preparation entails many steps as summarized in Figure 1. Briefly, Y-TZP blocks are presintered at temperatures below $1500^{\circ} \mathrm{C}$ to reach a density of at least $95 \%$ of the theoretical density. Hot isostatic pressing (HIP) is applied to the blocks at temperatures between 1400 and $1500^{\circ} \mathrm{C}$ under high pressure. A HIP cycle after sintering is recommended to achieve a full density close to the theoretical values $\left(\mathrm{d}=6.1 \mathrm{~g} / \mathrm{cm}^{3}=100 \%\right.$ dense). Since HIPing changes the color of Y-TZP into dark-grey, a heat treatment in air is usually performed to restore the material whiteness by oxidation, prior to be machined using a specially designed milling system. Because of the high hardness of fully sintered Y-TZP, the milling system is to be particularly robust [38-40].

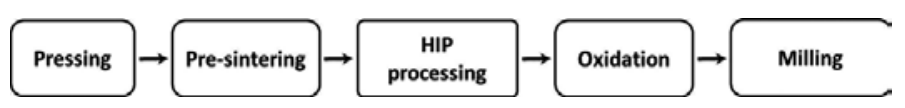

Figure 1. Manufacturing process for Y-ZPT.

The relatively recent and yet pervasive introduction of computer-aided design/computeraided manufacturing (CAD/CAM) technology has provided dentistry with an alternative to HIPing [42]. Usually, dental CAD/CAM systems recur to partly sintered yttria-stabilized 
tetragonal zirconia polycrystal (Y-TZP) blanks. The use of this partly sintered state of the YTZP ceramic renders the milling process faster and reduces the tools wear, compared to systems employing densely sintered blanks (HIP process). Of course, the final sintering shrinkage must be taken into account during the CAD phase by enlarging the shapes before milling, whilst this compensation is not necessary with the HIPed Y-TZP blanks that are directly ground to the desired dimensions [5]. The salient mechanical properties of Y-TZP subjected to the two manufacturing work-flow described above are compared in the following [43] table (Table 1), along with pressed and sintered polycrystalline $\alpha$-alumina.

\begin{tabular}{llll}
\hline & HIPed Y-TZP & $\begin{array}{l}\text { Pressure-less } \\
\text { sintered Y-TZP }\end{array}$ & $\begin{array}{l}\text { Pressed and sintered } \\
\text { polycrystalline } \alpha \text {-alumina }\end{array}$ \\
\hline Density (g/cm $)$ & 6.1 & 6 & 4 \\
Microhardness (Vickers) & $1000-1300$ & $1000-1200$ & 2300 \\
Young's modulus (GPa) & 200 & 200 & 420 \\
Bending strength (MPa) & 1200 & 800 & 500 \\
Toughness KIC (MPa m ${ }^{1 / 2}$ ) & $9-10$ & $9-10$ & 4 \\
\hline
\end{tabular}

Table 1. Values refer to Duraccio et al. [12].

\subsection{Biological properties}

In vitro experiments on different cell lines, in vivo studies on animals and clinical studies on humans supported the safety and the high level of biocompatibility of zirconia. In a preliminary in vitro investigation [44], one-piece zirconia implants were proven to possibly fulfill the biomechanical requirements for anterior teeth restoration. In addition, the mean fracture strength of zirconia implants was investigated after chewing simulation and it was found to be within the limits of clinical acceptance. However, the preparation of a one-piece zirconia implant prior to prosthetic finalization may significantly compromise fracture strength. Therefore, long-term clinical data were deemed necessary before one-piece zirconia implants could be recommended for clinical practice [45]. For the same reason, two-piece zirconia implants were considered clinically inadequate due to the increased risk of fracture at the implant head level [46].

Evidence from in vitro studies on osteoblasts supported the possible favorable response of zirconia ceramics in vivo [47,48]. When implanted in bone or soft tissues, these materials could elicit no inflammatory reactions, nor fibrous encapsulation, according to Hisbergues et al. [41]. Interestingly, Scarano et al. [49] reported the osseointegration of unloaded zirconia implants inserted in rabbit bones without any signs of inflammation or mobility. The possible role of surface roughness was investigated by comparing the removal torque of machined zirconia implants to roughened ones [50]. Notably, the roughened implants performed better than the smooth ones and behaved similarly to the oxidized titanium implants used as control. Loaded zirconia implants were studied and compared to titanium implants by Kohal and co-workers [51], who could find no significant difference in the osseointegration level between the two 
groups. Akagwa et al. [52] reported a similar bone to implant interlock in loaded and unloaded zirconia implants, but a crestal bone loss higher around the former group. In favor of the clinical use of Zirconia, it must be cited its maintenance of bending strength of over $700 \mathrm{MPa}$ after immersion in $95^{\circ} \mathrm{C}$ saline solution for over 3 years [53]. Furthermore, zirconia blanks did not show any significant mechanical detriment even after being embedded in the medullary cavity of the tibia of rabbits for 30 months.

Scarce are the clinical studies dedicated to the long-term performance of zirconia implants. The short follow-up period and the often small sample size hinder their quality of evidence, so that Andreiotelli and coauthors [29] could only include three retrospective cohort studies on one-piece zirconia dental implants in their systematic review, reaching in total 231 patients and 416 implants. The studies by Mellinghoff et al. [54] and Oliva et al. [55] investigated, respectively, 189 and 100 zirconia implants and estimated 1-year survival rates of 93 and 98\%. Almost all of the failures occurred during the healing phase, as only one implant failed after prosthetic reconstruction due to fracture. Lambrich and Iglhaut [56] observed 127 zirconia and 234 titanium implants for a mean period of 21.4 months. Notably, in this study, the survival rate of zirconia implants was similar to that of titanium in the mandible (Y-TZP $=98.4 \%$ vs. Ti $=97.2 \%)$, whilst differed considerably in the maxilla $(\mathrm{Ti}=98.4 \%$ vs. $\mathrm{Y}-\mathrm{TZP}=84.4 \%)$. Again, all failures occurred during the healing phase owing to increased implant mobility. These findings are consistent with the paper by Depprich et al. [57], where the survival rate of zirconia implants obtained from 17 clinical studies was between 74 and $98 \%$ after $12-56$ months. Payer et al. [58] followed up for 2 years 19 immediately loaded zirconia implants, reporting a 95\% survival rate, as determined clinically and radiographically. These results are in accordance with Oliva et al. [59] who determined the same survival rate at 5 years in 371 patients who received 831 one-piece zirconia implants. Kohal et al. [60] found that immediately restored one-piece zirconia implants have 1-year cumulative survival rate comparable to titanium counterparts. In conclusion, the clinical data currently available for Y-TZP implants may not be sufficient to recommend their routine clinical use. Zirconia, however, may have the potential to be a successful implant material, although this is as yet not fully supported by present investigations and further good-quality research is needed.

\section{Zirconia-toughened alumina (ZTA) and alumina-toughened zirconia}

\section{(AZT)}

\subsection{Background}

The demand of structural ceramics has led to an increased interest in Alumina-Zirconia composites for biomedical [21,61] and dental implant application [62, 63]. Two composite materials can be prepared: $\mathrm{ZrO}_{2}$ reinforced with alumina particles, which is denominated alumina toughened zirconia (ATZ), and $\mathrm{Al}_{2} \mathrm{O}_{3}$ reinforced with zirconia particles, which is known as zirconia-toughened alumina (ZTA). Thus, higher fracture values can be reached if compared with the monophase ceramics [64] (Table 2). 


\begin{tabular}{lll}
\hline & ATZ & ZTA \\
\hline Hardness (GPa) & $15.3 \pm 0.9$ & $21.3 \pm 1.5$ \\
Young's modulus (GPa) & $245 \pm 9$ & $363 \pm 5$ \\
Bending strength (MPa) & $633 \pm 127$ & $441 \pm 24$ \\
Toughness KIC (MPa m $\left.{ }^{1 / 2}\right)$ & $7.1 \pm 0.1$ & $3.9 \pm 0.05$ \\
\hline
\end{tabular}

Table 2. Physical and mechanical properties of ATZ and ZTA data are extracted from Faga et al. [85].

These composites benefit from combining the characteristics of Alumina, namely the high hardness and stiffness, with the superior strength and toughness of Zirconia, which improves remarkably the resistance to crack growth [65]. In addition, alumina increases the hydrothermal stability of tetragonal Zirconia phase $[65,66]$, owing mainly to the formation of a stiff matrix capable to keep the Zirconia particles in a metastable tetragonal state [67], thus acting as mechanical stabilizer. The only commercially used ATZ oral implant was tested both statically and dynamically for its fracture resistance in different simulated oral conditions with satisfying results [68].

The main features of the aforementioned implant are reported in the following table (Table 3).

\begin{tabular}{ll}
\hline & ATZ \\
\hline Density $\left(\mathrm{g} / \mathrm{cm}^{3}\right)$ & 5.5 \\
Average grain size $(\mu \mathrm{m})$ & $<0.5$ \\
Microhardness (Vickers) & $1000-1200$ \\
Young's modulus (GPa) & 220 \\
Bending strength (MPa) & 2000 \\
Toughness KIC $\left(\mathrm{MPa} \mathrm{m} \mathbf{m}^{1 / 2}\right)$ & 8 \\
\hline
\end{tabular}

Table 3. Physical and mechanical properties of ATZ values refer to Spies et al. (2015) - [68]

Very recently, a complete powder injection molding process was developed to fabricate cylindrical ZTA parts recurring to a binder system made of high-density polyethylene, paraffin wax, and stearic acid. The effects of sintering temperature on shrinkage, relative density, and hardness of the sintered part were taken into account and proved the technology suitable for the production of ZTA parts with sufficient mechanical properties [69]. However, ATZ and ZTA are usually produced through the classic workflows described above for Y-TZP (see Section 2.2).

The favorable mechanical features and the biological safety of different ZTA and ATZ composites have been the object of several studies in the last years [64, 70-78]. Whilst ATZ materials show increased mechanical stability [79] and improved aging resistance versus $\mathrm{Y}$ TZP, still they exhibit a certain degree of aging [79]. ZTA materials display much better aging resistance than both monolithic Y-TZP and ATZ $[21,79,80]$. In a recent work by our research 
group, both ATZ and ZTA were functionalized with two laminins as a preliminary investigation for improving soft tissue healing around implants. The simple adsorption of these two different isoforms was sufficient to induce some of the most important cell kinases in the epithelial cells grown on the surface of the two Alumina-Zirconia composites, supporting the possible advantages of these materials in dental implantology [81]. On this basis, we further studied the behavior of ATZ dental implants treated with a patented hydrothermal process, comparing them to a clinical use titanium surface in a minipig model. Bone healing was assessed through histology and mRNA expression at different time points $(8,14,28$, and 56 days). The most interesting outcome was a statistically significant higher percentage of newly formed bone along ATZ implants, at 56 days, suggesting that the tested material proved to be a promising candidate among the possible ceramic dental implants [82]. Interestingly, by comparing the bone-to-implant contact of moderately roughened ATZ implants $(\mathrm{Sa}=1.51 \mu \mathrm{m})$ to an anodized titanium standard $(\mathrm{Sa}=1.31 \mu \mathrm{m})$ in Sprague-Dawley rats, Kohal et al. [83] found that titanium greatly $(58 \% / 75 \%)$ outperformed the ceramic implant $(24 \% / 41 \%)$ after a healing period of 14 and 28 days. In addition, at the same time points, the mechanical interlock measured as push-in values increased from 20 to $39 \mathrm{~N}$ for titanium and from 10 to $25 \mathrm{~N}$ for ATZ. Although the moderately roughened ATZ implants were well accepted in rat bone, their osseointegration process seemed to proceed more slowly than that of anodized titanium.

However, the concerns raised in light of the in vivo data reported by Kohal et al. [51] seemed not to be completely consistent with the promising outcomes of the clinical study conducted by the same research group. Indeed, the cumulative survival rate $(94.2 \%)$ of one-piece ATZ implants immediately restored with partial fixed prostheses was comparable to that of the loaded titanium implants, in a human clinical trial involving 40 patients after 3 years of observation. In addition to the marginal bone loss $(0.79 \mathrm{~mm})$, several soft tissue parameters and patient-reported outcome measures were evaluated suggesting the potential of ATZ for clinical utilization [84]. Notwithstanding the clinical use, little information is still available about the ideal surface treatment that a ceramic dental implant should receive. To better understand whether roughness or hydroxyapatite precipitation capability were more likely to be efficient in terms of surface modifications, we designed a simple in vitro pilot study.

\subsection{Material and methods}

\subsubsection{Sample preparation}

Two high purity, ready-to-press powders were used to produce the $\mathrm{ATZ}\left(\mathrm{ZrO}_{2}-20 \mathrm{wt} \% \mathrm{Al}_{2} \mathrm{O}_{3}\right.$, TZ-3Y20AB, Tosoh, Japan) and ZTA $\left(\mathrm{Al}_{2} \mathrm{O}_{3}-16 \mathrm{wt} \% \mathrm{ZrO}_{2}\right.$, Taimicron, Taimei, Japan) samples. As reported elsewhere [85], specimens were prepared through linear pressuring at $80 \mathrm{MPa}$ followed by cold isostatic pressing at $200 \mathrm{MPa}$. The process parameters for sintering were as follows: heating up to $700^{\circ} \mathrm{C}$ at a rate of $50^{\circ} \mathrm{C} / \mathrm{h}$, followed by a 2-h dwell; heating up to $1500^{\circ} \mathrm{C}$ at a rate of $100^{\circ} \mathrm{C} / \mathrm{h}$, followed by a 2-h dwell. The resulting fully dense materials were $12-\mathrm{mm}$ disks with thickness ranging between 4 and $5 \mathrm{~mm}$.

As reported in the diagram below, both ATZ and ZTA discs were either mirror polished with diamond suspension in ethanol with decreasing granulometry to the final surface roughness 
of $<1$ micron. Also as-fired samples were used to evaluate the influence of the surface roughness on the biological response. Subsequently, the samples were either bioactivated with phosphoric acid under hydrothermal conditions (patent numbers: TO2012A000029 and PCT/ IB2013/050425) or left untreated (Figure 2).
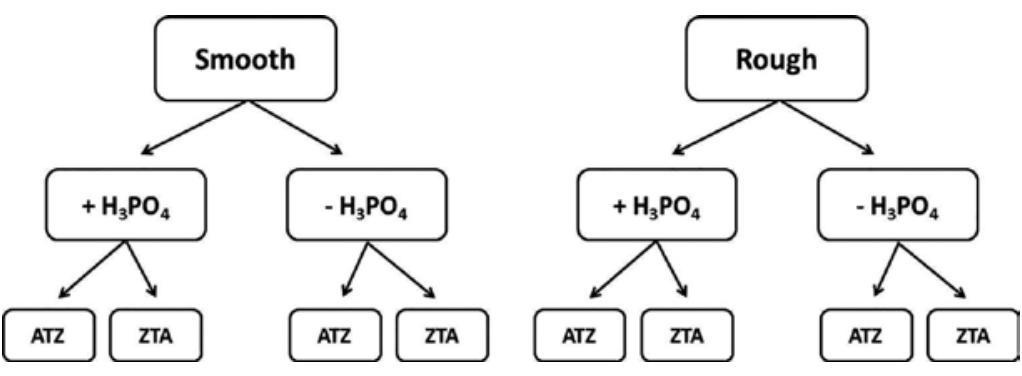

Figure 2. Schematic representation of samples treatments.

\subsubsection{Surface characterization}

Microstructure was studied by means of a scanning electron microscope Zeiss EVO 50 with energy dispersion spectroscopy analyzer for elemental composition detection. Surface roughness was measured with a non-contact profilometer, Talysurf CCI 3000A. The tests were performed in an air-conditioned laboratory, where temperature is kept at $20^{\circ} \mathrm{C}$, on a representative surface of $90 \mu^{2}$. To quantify the amount of protein adsorbed, fetal bovine serum (FBS) was diluted in phosphate-buffered saline (PBS) at a concentration of $2 \%$ and was used to incubate the samples at $37^{\circ} \mathrm{C}$ for $30 \mathrm{~min}$. After two wash in PBS, the adsorbed protein was eluted from the disks using Tris Triton buffer (10 mM Tris ( $\mathrm{pH} 7.4), 100 \mathrm{mM} \mathrm{NaCl}, 1 \mathrm{mM}$ EDTA, $1 \mathrm{mM}$ EGTA, $1 \%$ Triton X-100, 10\% Glycerol, and 0.1\% SDS) for $10 \mathrm{~min}$. Finally, the total protein amount was quantified using Pierce ${ }^{\mathrm{TM}}$ BCA Protein Assay Kit (Life Technologies, Milan, Italy) following the manufacturer's instructions.

\subsubsection{Biological response}

Pre-osteoblastic murine cells MC3T3-E1 (ECACC, Salisbury, UK) were used to characterize the biological response in vitro. Cells were maintained in alpha MEM supplemented with 10\% FBS (Life Technologies, Milan, Italy), $100 \mathrm{U} / \mathrm{ml}$ penicillin, $100 \mathrm{mg} / \mathrm{ml}$ streptomycin, under a humidified atmosphere of $5 \% \mathrm{CO}_{2}$ in air, at $37^{\circ} \mathrm{C}$. To prevent contact inhibition, cells were always passaged at subconfluency. When required, to differentiate MC3T3 cells, the culture medium was supplemented with $10 \mathrm{mM}$ ß-glycerophosphate and $50 \mathrm{ug} / \mathrm{ml}$ ascorbic acid.

To examine cell morphology, MC3T3 cells were seeded at a concentration of 5000 cells/well in a 24-well plate. After 1 day, cells were fixed in 4\% paraphormaldheyde in PBS. RodaminePhalloidin and Dapi (Life Technologies, Milan, Italy) were, respectively, used to stain cytoskeleton and cell nuclei, thus evaluating cell adhesion and morphology. 
Alkaline phosphatase activity was quantified using the Alkaline Phosphatase Assay Kit (Abcam, Cambridge, UK). Following the manufacturer's instruction, the OD was measured at a wavelength of $405 \mathrm{~nm}$. The calcium deposed within the extracellular matrix was quantified colorimetrically through the Calcium Assay Kit (Cayman Chemical, Michigan, USA). Absorbance of the lysates was measured at $570 \mathrm{~nm}$.

Data were analyzed recurring to GraphPad Prism6 (GraphPad Software, Inc., La Jolla, CA, USA). Each experiment was repeated at least three times. Statistical analysis was performed using the Student t-test. A p value of $<0.05$ was considered significant.

\subsection{Results and discussion}

The success of dental implants is directly related to the bone implant interlock, which can be experimentally evaluated in animal living bone, by histomorphometry and/or biomechanical testing [50]. A moderately rough surface topography is known to positively affect the interfacial tissue reaction [86]. Surface modification of zirconia and its composites is, however, challenging. Among the roughening techniques used to attain proper bone-implant interfaces, it is convenient to remember the apposition of sintering particles, nano-technology, sandblasting and acid etching, and laser technology [50, 87-90]. In recent animal studies, in vivo evidence was found that alumina-toughened-zirconia is a suitable candidate for dental implantology [82], which was further supported by very recent clinical data at the University of Freiburg [84, 91]. Following Dohan Ehrenfest's classification [92], surface roughness was moderate ( $\mathrm{Sa}=1.51$ $\mu \mathrm{m})$ in case of Ziraldent implants or very high $(\mathrm{Sa}=5.4 \mu \mathrm{m})$ for our research group. Here, the microstructure of ATZ and ZTA was determined by SEM (Figure 3).

The materials show an almost defect-free surface, with a homogeneous distribution of both zirconia and alumina. Submicrometric grains are present in both composites, the darkest representing alumina phase. It is noteworthy that similar dimensions can be observed for alumina and zirconia grains only in ATZ material, whilst $\mathrm{ZrO}_{2}$ growth is inhibited by the predominant alumina content in ZTA composite.
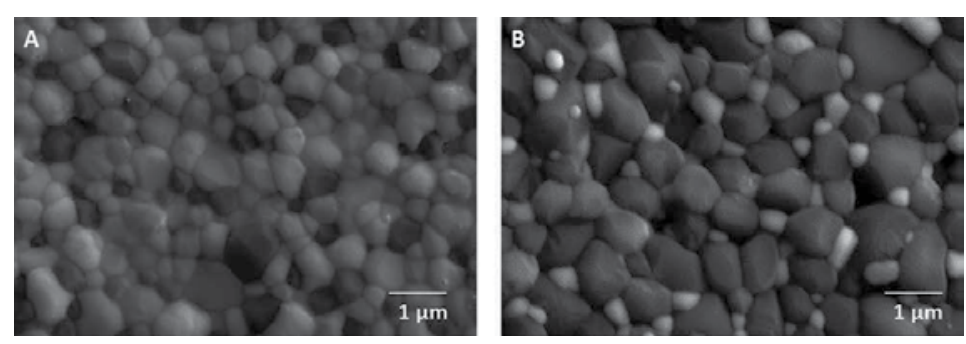

Figure 3. Scanning electron micrographs of ATZ (A) and ZTA (B).

Surface roughness was measured via profilometry (Table 4). As it can clearly be seen, polished and as-fired samples were, respectively, endowed with a very smooth and a highly rough surface, according to the expected values. 


\begin{tabular}{lllll}
\hline & ATZ & ZTA & \\
\cline { 2 - 5 } & Mirror polished & As fired & Mirror polished & As fired \\
\hline Sa $(\mu \mathrm{m})$ & 0.043990 & 0.376492 & 0.051174 & 0.485283 \\
SD & 0.003604 & 0.018970 & 0.005554 & 0.079454
\end{tabular}

Table 4. Surface roughness measured via profilometry.

Interestingly, from Figure 4, it can be inferred that the only condition capable to affect significantly the protein adsorption was surface roughness. No statistically significant difference was found among materials (ATZ vs. ZTA) or chemical treatment (hydrothermal cycle present + vs. absent -), although a trend in facilitating protein adsorption could be noted in roughened-treated surfaces.

\section{Protein Adsorption}

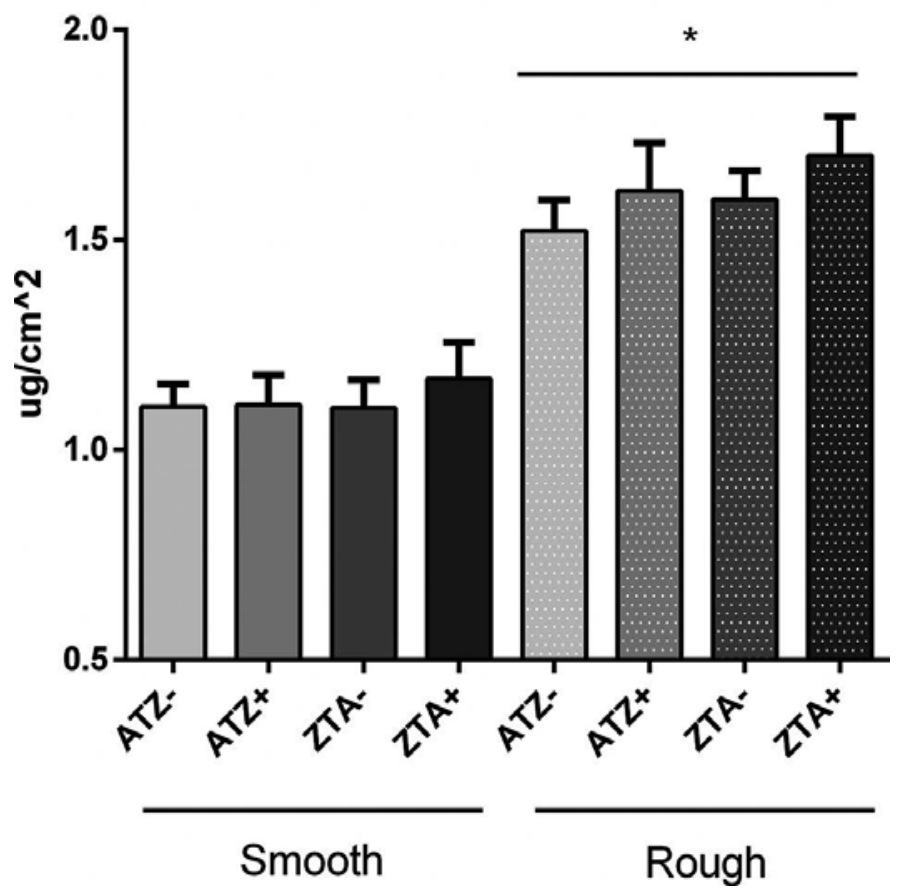

Figure 4. Quantification of adsorbed bovine serum albumin (BSA) by samples, as measured trough BCA assay (see Methods). The rough surfaces significantly increase the amount of adsorbed proteins.

The same trend described for protein adsorption was observed in the other cell-based assays whether they were focusing on the early cell response as in the focal adhesion density (Figure 5), or they were dealing with intermediate and late stages of osteogenic differentiation in vitro such as alkaline phosphatase activity (Figure 6A) and calcium deposition within the extracellular matrix (Figure 6B). 


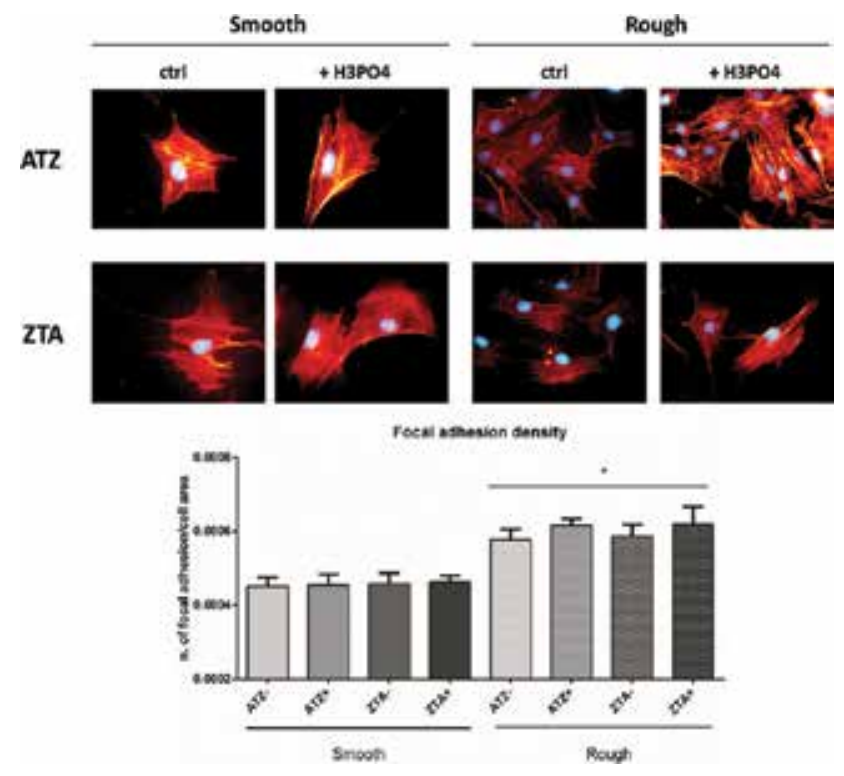

Figure 5. Morphology of MC3T3 cells seeded on different surfaces and stained with phalloidin-rhodamine and DAPI to visualize, respectively, the cytoskeleton and nucleus (see Methods). (A) Quantification of focal adhesion density measured by normalizing the number of focal adhesions on cell area (see Methods). (B) The rough surfaces significantly increase the density of focal adhesion.


Figure 6. Colorimetric quantification of ALP activity (A) and calcium deposition (B) (see Methods). The rough surfaces significantly increase the level of either ALP activity (A) and calcium deposition (B).

Although surface chemistry is known to play a role in cueing the biological systems [81], the present experimental data showed that roughened surfaces were more efficient in inducing an osteogenic response in vitro independently of the application of the chemical treatment. In other terms, roughness per se seemed to overpower the effect of the chemical treatment which was deemed bioactive on the ground of the Kokubo tests previously performed (i.e., the capacity to induce hydroxyapatite precipitation) [85]. Within the obvious limits of this 
experimental setting, our results support the importance of roughening modifications over the chemical treatment.

\section{Silicon nitride-titanium nitride}

\subsection{Background}

Silicon nitride $\left(\mathrm{Si}_{3} \mathrm{~N}_{4}\right)$ is a high-strength and tough ceramic used as a viable implant material [93-95]. Since the first clinical trial in 1986 [96], over two decades have passed before the introduction of $\mathrm{Si}_{3} \mathrm{~N}_{4}$ to the biomedical market of the US and EU. Since 2008, it has been used as a fusion cage for arthrodesis of the cervical and thoracolumbar spine [97], with few adverse reported events [98]. Silicon nitride has been shown to possess favorable cell interaction characteristics [94, 95, 99-104], along with bacteriostatic properties [105, 106]. Also, porous or unpolished $\mathrm{Si}_{3} \mathrm{~N}_{4}$ osseointegrates with adjacent bone [104, 105, 107-109].

Silicon nitride derives its strength and toughness through its microstructure, which is composed of asymmetric needle-like interlocking grains surrounded by a thin $(<2 \mathrm{~nm})$ refractory grain-boundary glass [110]. Unlike other ceramics, no phase transformation is involved. Thus, similar to alumina, $\mathrm{Si}_{3} \mathrm{~N}_{4}$ exists as an irreversibly stable phase at room temperature, but an advancing crack must navigate a high energy path through the ceramic, and bridging grains within the crack wake restrict its continued propagation [111-113].

Industrial standards have been adopted for $\mathrm{Si}_{3} \mathrm{~N}_{4}$ composition, processing, and properties $[114,115]$. However, sintered $\mathrm{Si}_{3} \mathrm{~N}_{4}$ is usually machined by hard grinding with diamond tools and the high hardness of $\mathrm{Si}_{3} \mathrm{~N}_{4}$ makes the production of complex shapes through conventional mechanical machining difficult and expensive. To address this issue, electrically conductive reinforcements, such as $\mathrm{TiN}, \mathrm{TiC}, \mathrm{TiB}_{2}, \mathrm{ZrB}_{2}$, were added to the $\mathrm{Si}_{3} \mathrm{~N}_{4}$ matrix, generating composites suitable to be wrought by electrical discharge machining (EDM) [116]. The EDM has been introduced with encouraging results, achieving complex shapes from dense electroconductive bulks with high densification [94]. Accurate semi-finished $\mathrm{Si}_{3} \mathrm{~N}_{4}-\mathrm{TiN}$ surfaces may be either used as they are, or further finished through diamond polishing [116]. Some preliminary data comparing in vitro the osteogenic behavior of two different surface modifications of a silicon nitride-titanium nitride $\left(\mathrm{Si}_{3} \mathrm{~N}_{4}-\mathrm{TiN}\right)$ composite are here presented. The two surfaces were, respectively, the very product of the EDM process (henceforth $\mathrm{Si}_{3} \mathrm{~N}_{4}-\mathrm{TiN} \_\mathrm{A}$ ) and the result of partial polishing with diamond suspensions (henceforth called $\mathrm{Si}_{3} \mathrm{~N}_{4}-\mathrm{TiN}_{-} \mathrm{B}$ ). For material and methods please refer to Sections 3.2.2 and 3.2.3.

\subsection{Results and discussion}

A detail of the two silicon nitride-titanium nitride surfaces is reported in Figure 7. 

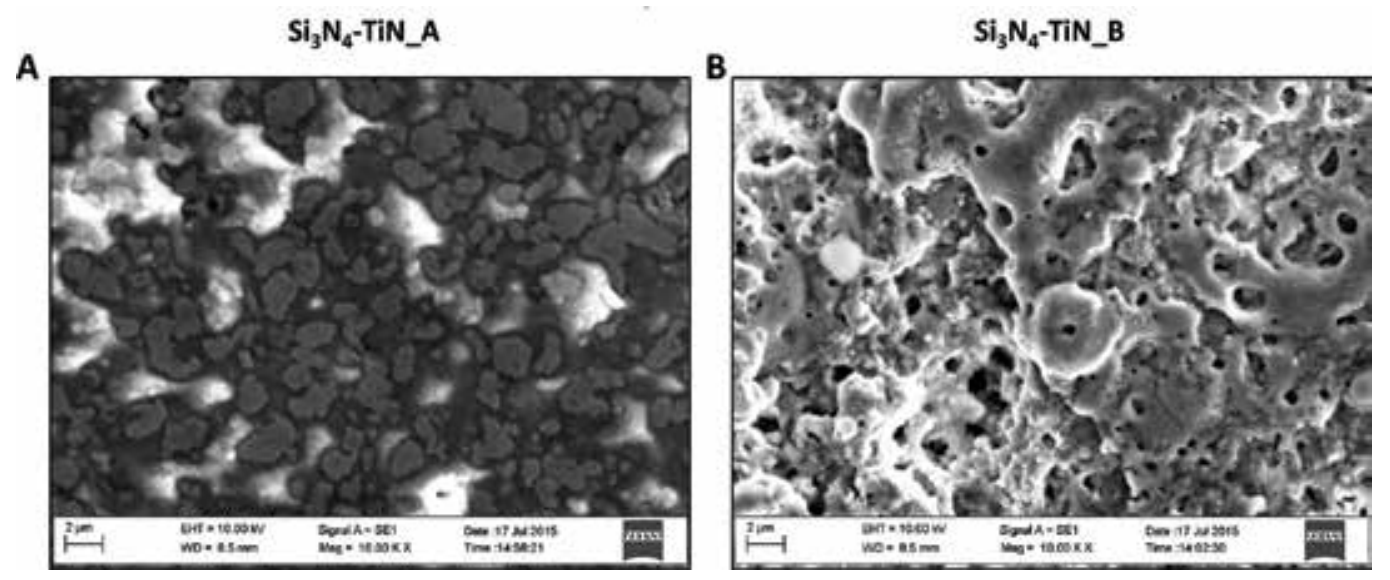

Figure 7. Surface electron micrographs of $\mathrm{Si}_{3} \mathrm{~N}_{4}-\mathrm{TiN} \_\mathrm{A}(\mathrm{A})$ and $\mathrm{Si}_{3} \mathrm{~N}_{4}-\mathrm{TiN} \_\mathrm{B}$ (B) at 10.000 magnifications.

$\mathrm{Si}_{3} \mathrm{~N}_{4}$-TiN_A showed an interesting coalesced structure derived from the melting generated during the manufacturing process, whilst, in $\mathrm{Si}_{3} \mathrm{~N}_{4}-\mathrm{TiN} \_\mathrm{B}$ the microstructure of silicon nitridetitanium nitride is clearly appreciable along with the remnants of the peaks after polishing. The tridimensional analysis of $\mathrm{Si}_{3} \mathrm{~N}_{4}-\mathrm{TiN} \_\mathrm{A}$ and $\mathrm{Si}_{3} \mathrm{~N}_{4}-\mathrm{TiN} \_\mathrm{B}$ is graphically depicted in Figure 8, whilst Sa values were, respectively, $2.92 \pm 0.07$ and $0.88 \pm 0.06 \mu \mathrm{m}$. Thus, $\mathrm{Si}_{3} \mathrm{~N}_{4}-\mathrm{TiN} \_\mathrm{A}$ resulted rougher than $\mathrm{Si}_{3} \mathrm{~N}_{4}-\mathrm{TiN} \_$B.

$\mathrm{Si}_{3} \mathrm{~N}_{4}-\mathrm{TiN} \_\mathrm{A}$

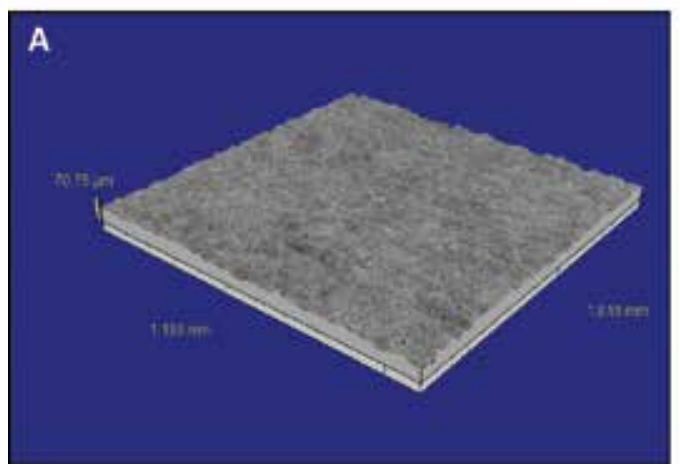

$\mathrm{Si}_{3} \mathrm{~N}_{4}-\mathrm{TiN}_{-} \mathrm{B}$

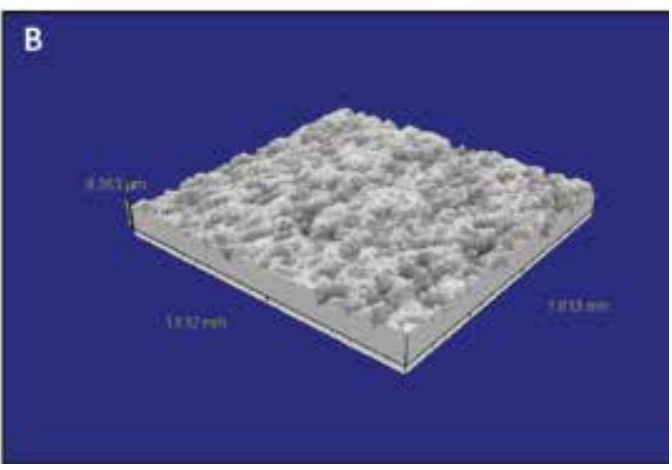

Figure 8. Tridimensional graphical representation of $\mathrm{Si}_{3} \mathrm{~N}_{4}-\mathrm{TiN}_{-} \mathrm{A}$ (A) and $\mathrm{Si}_{3} \mathrm{~N}_{4}-\mathrm{TiN}_{-} \mathrm{B}$ (B).

MC3T3 cells grew well on both samples. Notably, fluorescent images of adherent cells at $24 \mathrm{~h}$ (Figure 9A) clearly show that $\mathrm{Si}_{3} \mathrm{~N}_{4}-\mathrm{TiN} \_\mathrm{A}$ induced a more complex morphology with more tapered shape cells than $\mathrm{Si}_{3} \mathrm{~N}_{4}$-TiN S, as expected for rougher surfaces. Consistently, a higher density of focal adhesions was quantified on the $\mathrm{Si}_{3} \mathrm{~N}_{4}-\mathrm{TiN} \mathrm{R}$ surface [117] (Figure 9B). 
A

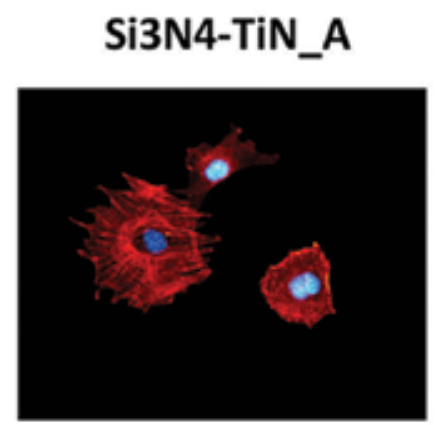

Si3N4-TiN_B

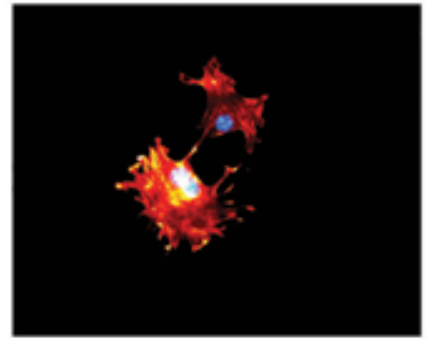

B

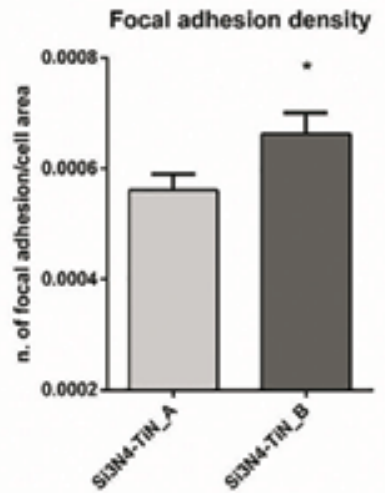

Figure 9. Morphology of MC3T3 cells seeded on $\mathrm{Si}_{3} \mathrm{~N}_{4}-\mathrm{TiN} \_\mathrm{A}$ and $\mathrm{Si}_{3} \mathrm{~N}_{4}-\mathrm{TiN} \_\mathrm{B}$ and stained with phalloidin-rhodamine and DAPI to visualize, respectively, the cytoskeleton and nucleus (see Methods). MC3T3 cells seeded on $\mathrm{Si}_{3} \mathrm{~N}_{4-}$ TiN_B display a more complex shape with a lower spreading level than $\mathrm{Si}_{3} \mathrm{~N}_{4}-\mathrm{TiN} \_\mathrm{A}$ (A). Quantification of focal adhesion density measured by normalizing the number of focal adhesions on cell area (see Methods) (B). $\mathrm{Si}_{3} \mathrm{~N}_{4}-\mathrm{TiN}_{-} \mathrm{B}$ significantly increase the density of focal adhesion.

The osteogenic differentiation was evaluated based on the alkaline phosphatase activity as well as the deposition of bone matrix on the specimens. A statistically significant difference between $\mathrm{Si}_{3} \mathrm{~N}_{4}-\mathrm{TiN} \_\mathrm{A}$ and $\mathrm{Si}_{3} \mathrm{~N}_{4}-\mathrm{TiN} \_\mathrm{B}$ was determined in favor the former, when ALP activity was determined (Figure 10A).

A

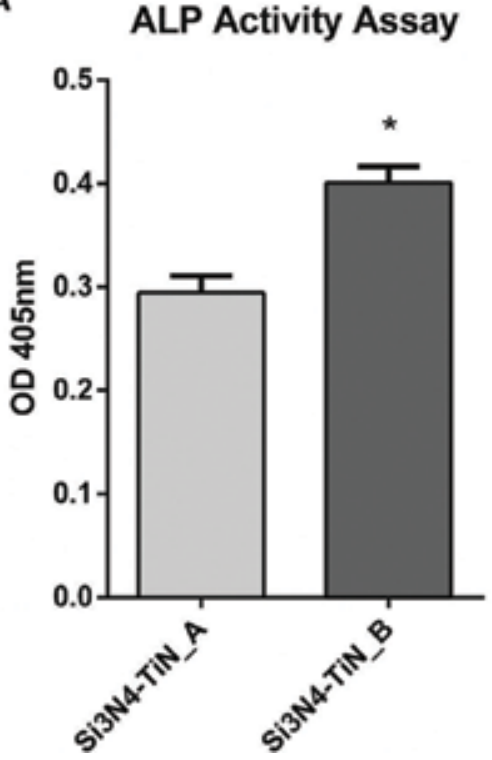

B

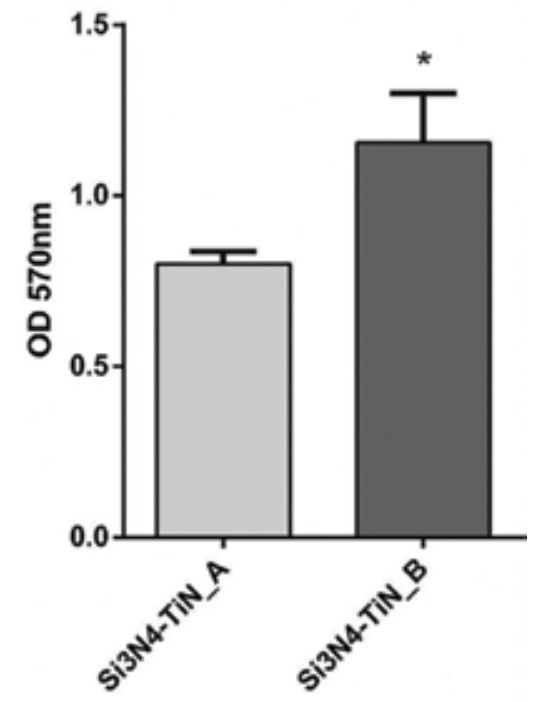

Figure 10. Colorimetric quantification of ALP activity (A) and calcium deposition (B) (see Methods). $\mathrm{Si}_{3} \mathrm{~N}_{4}-\mathrm{TiN}_{-} \mathrm{B}$ surface significantly increase the level of either ALP activity (A) and calcium deposition (B). 
The rougher surface promoted a greater osteogenic response than the smooth surface in terms of calcium deposition (Figure 10B).

The biological responses induced in MC3T3 cells, a widely diffused osteoblast model, were correlated with the surface roughness, even in this case. The effect of roughness on osteoblast adhesion has been mainly attributed to an increased surface-to-volume ratio that may provide more sites for cell attachment [118]. Consistently, the rougher surface tested $\left(\mathrm{Si}_{3} \mathrm{~N}_{4}-\mathrm{TiN} \_\mathrm{A}\right)$ could promote better cell viability, higher density of focal adhesions and more pronounced calcium deposition than the smoother one $\left(\mathrm{Si}_{3} \mathrm{~N}_{4}-\mathrm{TiN} \_\mathrm{B}\right)$. Taken together, these data confirmed the biocompatibility of silicon nitride-titanium nitride composites in accordance with the literature, which has indeed so far explored preferably the pristine $\mathrm{Si}_{3} \mathrm{~N}_{4}$ material $[93,94,99$, 119]. The possible application of surfaces directly obtained by EDM to $\mathrm{Si}_{3} \mathrm{~N}_{4}-\mathrm{TiN}$ is therefore noteworthy. Further research should be oriented at investigating the in vivo effects of such surface finishing, as well as the importance of the texture in the pattern recognition operated by cells.

\section{Concluding remarks}

As stated in previous sections, even though titanium and titanium alloys are the material of choice for dental implants, they are not without drawbacks. Among the possible issues, for instance, the hypersensitivity in allergic patients and some aesthetic concerns deserve attention. To address these problems, ceramics have been introduced to the market in the last decades. Y-TZP was first proposed owing to its biocompatibility, white root-like color and low plaque affinity. More recently, oxidic composites containing variable amounts of zirconium oxide such as zirconia-toughened alumina (ZTA) and especially alumina-toughened zirconia (AZT) were recently considered an improved alternative to Y-TZP. These implants seem very suitable to replace the anterior teeth to avoid the formation of dark shimmer in the presence of thin gingival biotype. However, one-piece ceramic implants may be more difficult to place than two-pieces titanium implants if angulated abutments are required.

Nevertheless, the demand of non-metallic materials endowed with high mechanical features is prompting research and industry to explore also ceramics such as silicon nitride. This non-oxidic material, whose use is almost completely limited to orthopedics in the biomedical field, possesses really promising quality even for dental application. The possibility to dope silicon nitride with titanium nitride, thus rendering it electroconductive, enables a range of manufacturing processes like the electro discharge machining. This opens compelling perspectives in the future as biomaterials are supposed to be increasingly customizable, maneuverable, and adaptable to the particular necessity of the single case, possibly entering the digital work-flow. 


\section{Author details}

Federico Mussano $^{1 *}$, Tullio Genova ${ }^{1,2}$, Luca Munaron ${ }^{1,2}$, Maria Giulia Faga ${ }^{3}$ and Stefano Carossa ${ }^{1}$

*Address all correspondence to: federico.mussano@unito.it

1 CIR Dental School, Department of Surgical Sciences, Turin, Italy

2 Department of Life Sciences and Systems Biology, Turin, Italy

3 IMAMOTER-National Council of Research, Turin, Italy

\section{References}

[1] Albrektsson T, Sennerby L. State of the art in oral implants. J Clin Periodontol [Internet]. 1991;18(6):474-81. Available from: http://www.ncbi.nlm.nih.gov/pubmed/1890231 [cited 2016 Jan 31].

[2] Lindquist LW, Carlsson GE, Jemt T. A prospective 15-year follow-up study of mandibular fixed prostheses supported by osseointegrated implants. Clinical results and marginal bone loss. Clin Oral Implants Res [Internet]. 1996;7(4):329-36. Available from: http://www.ncbi.nlm.nih.gov/pubmed/9151599 [cited 2016 Jan 31].

[3] English CE. Cylindrical implants. Parts I, II, III. California Dent Assoc J. 1988;16:17-38.

[4] Jokstad A. How many implant systems do we have and are they documented? In: Jokstad A, editor. Osseointegration and Dental Implants [Internet]. Wiley Blackwell; 2009. Available from: http://media.wiley.com/product_data/excerpt/ 17/08138134/0813813417-1.pdf

[5] Evrard L, Waroquier D, Parent D. Allergies to dental metals. Titanium: a new allergen. Rev Med Brux. 2010;31(1):44-9.

[6] Pigatto PDPD, Guzzi G, Brambilla L, Sforza C. Titanium allergy associated with dental implant failure. Clin Oral Implants Res [Internet]. 2009;20(8):857. Available from: http:// www.ncbi.nlm.nih.gov/pubmed/19604283 [cited 2016 Jan 31].

[7] Sicilia A, Cuesta S, Coma G, Arregui I, Guisasola C, Ruiz E, . Titanium allergy in dental implant patients: a clinical study on 1500 consecutive patients. Clin Oral Implants Res [Internet]. 2008;19(8):823-35. Available from: http://www.ncbi.nlm.nih.gov/pubmed/ 18705814 [cited 2016 Jan 31].

[8] Koutayas SO, Vagkopoulou T, Pelekanos S, Koidis P, Strub JR. Zirconia in dentistry: part 2. Evidence-based clinical breakthrough. Eur J Esthet Dent. 2009;4(4):348-80. 
[9] Onodera K, Ooya K, Kawamura H. Titanium lymph node pigmentation in the reconstruction plate system of a mandibular bone defect. Oral Surg Oral Med Oral Pathol. 1993;75(4):495-7.

[10] Jacobs JJ, Skipor AK, Patterson LM, Hallab NJ, Paprosky WG, Black J, . Metal release in patients who have had a primary total hip arthroplasty: a prospective, controlled, longitudinal study. J Bone Joint Surg Am. 1998;80(10):1447-58.

[11] Bågedahl-Strindlund $M$, Ilie M, Furhoff AK, Tomson $Y$, Larsson KS, SandborghEnglund G, . A multidisciplinary clinical study of patients suffering from illness associated with mercury release from dental restorations: psychiatric aspects. Acta Psychiatr Scand [Internet]. 1997;96(6):475-82. Available from: http:// www.ncbi.nlm.nih.gov/pubmed/9421345 [cited 2016 Jan 31].

[12] Duraccio D, Mussano F, Faga MG. Biomaterials for dental implants: current and future trends. J Mater Sci. 2015;50:4779-812.

[13] E. C. Subbarao, "Zirconia-an overview"; pp. 1-24 in "Science and Technology of Zirconia", Advances in Ceramics, Vol. 3. Edited by A. H. Heuer and L. W. Hobbs. The American Ceramic Society, Columbus, Ohio, 1981

[14] Heuer AH, Lange FF, Swain MV, Evans AG. Transformation toughening: an overview. J Am Ceram Soc [Internet]. 1986;69(3):i-iv. Available from: http://doi.wiley.com/ 10.1111/j.1151-2916.1986.tb07400.x [cited 2016 Feb 1].

[15] Nicholson G. Phase analysis in zirconia systems. J Am Ceram Soc [Internet]. 1972;55(6): 303-5. Available from: http://doi.wiley.com/10.1111/j.1151-2916.1972.tb11290.x [cited 2016 Feb 1].

[16] Piconi C, Maccauro G. Zirconia as a ceramic biomaterial. Biomaterials. 1999;20(1):1-25.

[17] Christel P, Meunier A, Heller M, Torre JP, Peille CN. Mechanical properties and shortterm in-vivo evaluation of yttrium-oxide-partially-stabilized zirconia. J Biomed Mater Res [Internet]. 1989;23(1):45-61. Available from: http://www.ncbi.nlm.nih.gov/ pubmed/2708404 [cited 2016 Jan 14].

[18] Morena R, Lockwood PE, Evans L, Fairhurst CW. Toughening of dental porcelain by tetragonal $\mathrm{ZrO}_{2}$ additions. J Am Ceram Soc [Internet]. 1986;69(4):C-75-C-77. Available from: http://doi.wiley.com/10.1111/j.1151-2916.1986.tb04756.x [cited 2016 Feb 1].

[19] Kelly JR, Denry I. Stabilized zirconia as a structural ceramic: an overview. Dent Mater [Internet]. 2008;24(3):289-98. Available from: http://www.sciencedirect.com/science/ article/pii/S0109564107001121 [cited 2015 Aug 25].

[20] Piconi C, Burger W, Richter HG, Cittadini A, Maccauro G, Covacci V, . Y-TZP ceramics for artificial joint replacements. Biomaterials [Internet]. 1998;19(16):1489-94. Available from: http://www.ncbi.nlm.nih.gov/pubmed/9794524 [cited 2016 Feb 1].

[21] Deville S, Chevalier J, Fantozzi G, Bartolomé JF, Requena J, Moya JS, . Low-temperature ageing of zirconia-toughened alumina ceramics and its implication in biomedical 
implants. J Eur Ceram Soc [Internet]. 2003;23(15):2975-82. Available from: http:// www.sciencedirect.com/science/article/pii/S0955221903003133 [cited 2016 Jan 31].

[22] Chevalier J, Gremillard L, Deville S. Low-temperature degradation of zirconia and implications for biomedical implants. Annu Rev Mater Res [Internet]. Annual Reviews; 2007;37(1):1-32. Available from: http://www.annualreviews.org/doi/abs/10.1146/ annurev.matsci.37.052506.084250 [cited 2016 Jan 31].

[23] Kosmac T, Oblak C, Jevnikar P, Funduk N, Marion L. The effect of surface grinding and sandblasting on flexural strength and reliability of Y-TZP zirconia ceramic. Dent Mater [Internet]. 1999;15(6):426-33. Available from: http://www.ncbi.nlm.nih.gov/ pubmed/10863444 [cited 2016 Jan 22].

[24] Denry I, Kelly JR. State of the art of zirconia for dental applications. Dent Mater. 2008;24(3):299-307.

[25] Clarke IC, Manaka M, Green DD, Williams P, Pezzotti G, Kim Y-H, . Current status of zirconia used in total hip implants. J Bone Joint Surg Am [Internet]. 2003;85-A Suppl: 73-84. Available from: http://www.ncbi.nlm.nih.gov/pubmed/14652396 [cited 2015Sep 17].

[26] Chevalier J, Gremillard L. Ceramics for medical applications: a picture for the next 20 years. J Eur Ceram Soc [Internet]. 2009;29(7):1245-55. Available from: http:// www.sciencedirect.com/science/article/pii/S0955221908004391 [cited 2015 Nov 13].

[27] Chevalier J. What future for zirconia as a biomaterial? Biomaterials [Internet]. 2006;27(4):535-43. Available from: http://www.sciencedirect.com/science/article/pii/ S0142961205007039 [cited 2016 Jan 7].

[28] Deville S, Guénin G, Chevalier J. Martensitic transformation in zirconia. Acta Mater [Internet]. 2004;52(19):5709-21. Available from: http://www.sciencedirect.com/science/ article/pii/S1359645404005269 [cited 2016 Feb 1].

[29] Deville S, Chevalier J. Martensitic relief observation by atomic force microscopy in yttria-stabilized zirconia. J Am Ceram Soc [Internet]. 2003;86(12):2225-7. Available from: http://doi.wiley.com/10.1111/j.1151-2916.2003.tb03639.x [cited 2016 Feb 1].

[30] Chevalier J, Cales B, Drouin JM. Low-temperature aging of Y-TZP ceramics. J Am Ceram Soc [Internet]. 2004;82(8):2150-4. Available from: http://doi.wiley.com/10.1111/ j.1151-2916.1999.tb02055.x [cited 2016 Feb 1].

[31] Lawson S. Environmental degradation of zirconia ceramics. J Eur Ceram Soc [Internet]. 1995;15(6):485-502. Available from: http://www.sciencedirect.com/science/article/pii/ 095522199500035S [cited 2015 Oct 19].

[32] Cattani-Lorente M, Scherrer SS, Ammann P, Jobin M, Wiskott HWA. Low temperature degradation of a Y-TZP dental ceramic. Acta Biomater [Internet]. 2011;7(2):858-65. Available from: http://www.ncbi.nlm.nih.gov/pubmed/20854937 [cited 2016 Feb 1]. 
[33] Lughi V, Sergo V. Low temperature degradation aging of zirconia: a critical review of the relevant aspects in dentistry. Dent Mater [Internet]. 2010;26(8):807-20. Available from: http://www.ncbi.nlm.nih.gov/pubmed/20537701 [cited 2016 Feb 1].

[34] Vagkopoulou T, Koutayas SO, Koidis P, Strub JR. Zirconia in dentistry: part 1. Discovering the nature of an upcoming bioceramic. Eur J Esthet Dent [Internet]. 2009;4(2):13051. Available from: http://www.ncbi.nlm.nih.gov/pubmed/19655651 [cited 2016 Feb 1].

[35] Deville S, Chevalier J, Gremillard L. Influence of surface finish and residual stresses on the ageing sensitivity of biomedical grade zirconia. Biomaterials [Internet]. 2006;27(10): 2186-92. Available from: http://www.sciencedirect.com/science/article/pii/ S0142961205010379 [cited 2016 Jan 31].

[36] Naito Y, Jimbo R, Bryington MS, Vandeweghe S, Chrcanovic BR, Tovar N, . The influence of 1 $\alpha .25$-dihydroxyvitamin $\mathrm{d} 3$ coating on implant osseointegration in the rabbit tibia. J Oral Maxillofac Res [Internet]. 2014;5(3):e3. Available from: http:// www.pubmedcentral.nih.gov/articlerender.fcgi?artid=4219862\&tool=pmcentrez\&rendertype $=$ abstract [cited 2016 Feb 1].

[37] Andreiotelli M, Wenz HJ, Kohal R-J. Are ceramic implants a viable alternative to titanium implants? A systematic literature review. Clin Oral Implants Res [Internet]. 2009;20 Suppl 4:32-47. Available from: http://www.ncbi.nlm.nih.gov/pubmed/ 19663947 [cited 2016 Jan 24].

[38] Covani U, Bortolaia C, Barone A, Sbordone L. Bucco-lingual crestal bone changes after immediate and delayed implant placement. J Periodontol [Internet]. 2004;75(12):160512. Available from: http://www.ncbi.nlm.nih.gov/pubmed/15732861 [cited 2016 Jan 7].

[39] Cosyn J, Hooghe N, De Bruyn H. A systematic review on the frequency of advanced recession following single immediate implant treatment. J Clin Periodontol [Internet]. 2012;39(6):582-9. Available from: http://www.ncbi.nlm.nih.gov/pubmed/22509794 [cited 2016 Feb 1].

[40] den Hartog L, Slater JJRH, Vissink A, Meijer HJA, Raghoebar GM. Treatment outcome of immediate, early and conventional single-tooth implants in the aesthetic zone: a systematic review to survival, bone level, soft-tissue, aesthetics and patient satisfaction. J Clin Periodontol [Internet]. 2008;35(12):1073-86. Available from: http:// www.ncbi.nlm.nih.gov/pubmed/19040585 [cited 2016 Feb 1].

[41] Hisbergues M, Vendeville S, Vendeville P. Zirconia: Established facts and perspectives for a biomaterial in dental implantology. Journal of Biomedical Materials Research Part B: Applied Biomaterials. 2009;88B:519-29

[42] Esposito M, Maghaireh H, Grusovin MG, Ziounas I, Worthington HV. Interventions for replacing missing teeth: management of soft tissues for dental implants. Cochrane Database Syst Rev [Internet]. 2012;2:CD006697. Available from: http:// www.ncbi.nlm.nih.gov/pubmed/22336822 [cited 2016 Jan 22]. 
[43] Cooper LF, Zhou Y, Takebe J, Guo J, Abron A, Holmén A, . Fluoride modification effects on osteoblast behavior and bone formation at $\mathrm{TiO}_{2}$ grit-blasted c.p. titanium endosseous implants. Biomaterials [Internet]. 2006;27(6):926-36. Available from: http:// www.ncbi.nlm.nih.gov/pubmed/16112191 [cited 2016 Feb 1].

[44] Kohal R-J, Klaus G, Strub JR. Zirconia-implant-supported all-ceramic crowns withstand long-term load: a pilot investigation. Clin Oral Implants Res [Internet]. 2006;17(5): 565-71. Available from: http://www.ncbi.nlm.nih.gov/pubmed/16958698 [cited 2016 Feb 1].

[45] Andreiotelli M, Kohal R-J. Fracture strength of zirconia implants after artificial aging. Clin Implant Dent Relat Res [Internet]. 2009;11(2):158-66. Available from: http:// www.ncbi.nlm.nih.gov/pubmed/18657150 [cited 2016 Feb 1].

[46] Kohal R-J, Finke HC, Klaus G. Stability of prototype two-piece zirconia and titanium implants after artificial aging: an in vitro pilot study. Clin Implant Dent Relat Res [Internet]. 2009;11(4):323-9. Available from: http://www.ncbi.nlm.nih.gov/pubmed/ 18783418 [cited 2016 Feb 1].

[47] Josset Y, Oum'Hamed Z, Zarrinpour A, Lorenzato M, Adnet JJ, Laurent-Maquin D. In vitro reactions of human osteoblasts in culture with zirconia and alumina ceramics. J Biomed Mater Res [Internet]. 1999;47(4):481-93. Available from: http:// www.ncbi.nlm.nih.gov/pubmed/10497283 [cited 2016 Feb 1].

[48] Bächle M, Butz F, Hübner U, Bakalinis E, Kohal RJ. Behavior of CAL72 osteoblast-like cells cultured on zirconia ceramics with different surface topographies. Clin Oral Implants Res [Internet]. 2007;18(1):53-9. Available from: http://www.ncbi.nlm.nih.gov/ pubmed/17224024 [cited 2016 Feb 1].

[49] Scarano A, Di Carlo F, Quaranta M, Piattelli A. Bone response to zirconia ceramic implants: an experimental study in rabbits. J Oral Implantol [Internet]. 2003;29(1):8-12. Available from: http://www.ncbi.nlm.nih.gov/pubmed/12614079 [cited 2016 Feb 1].

[50] Sennerby L, Dasmah A, Larsson B, Iverhed M. Bone tissue responses to surfacemodified zirconia implants: a histomorphometric and removal torque study in the rabbit. Clin Implant Dent Relat Res [Internet]. 2005;7(Suppl. 1):S13-20. Available from: http://www.ncbi.nlm.nih.gov/pubmed/16137083 [cited 2016 Feb 1].

[51] Kohal RJ, Weng D, Bächle M, Strub JR. Loaded custom-made zirconia and titanium implants show similar osseointegration: an animal experiment. J Periodontol [Internet]. 2004;75(9):1262-8. Available from: http://www.ncbi.nlm.nih.gov/pubmed/15515343 [cited 2016 Feb 1].

[52] Akagawa Y, Ichikawa Y, Nikai H, Tsuru H. Interface histology of unloaded and early loaded partially stabilized zirconia endosseous implant in initial bone healing. J Prosthet Dent [Internet]. 1993;69(6):599-604. Available from: http:// www.ncbi.nlm.nih.gov/pubmed/8320646 [cited 2016 Feb 1]. 
[53] Shimizu K, Oka M, Kumar P, Kotoura Y, Yamamuro T, Makinouchi K, . Time-dependent changes in the mechanical properties of zirconia ceramic. J Biomed Mater Res [Internet]. 1993:729-34. Available from: http://www.ncbi.nlm.nih.gov/pubmed/? term=Time-dependent+changes+in+the+mechanical+properties+of+zirconia+cerami [cited 2016 Feb 1].

[54] Mellinghoff J. Erste klinische Ergebnisse zu dentalen Schraubenimplantaten aus Zirkonoxid. Zeitschr'ift filir Zahnarztliche Implantologie. 2006; 22:288-93

[55] Gittens RA, Olivares-Navarrete R, Tannenbaum R, Boyan BD, Schwartz Z. Electrical implications of corrosion for osseointegration of titanium implants. J Dent Res [Internet]. 2011;90(12):1389-97. Available from: http://www.pubmedcentral.nih.gov/ articlerender.fcgi?artid=3215755\&tool=pmcentrez\&rendertype=abstract [cited 2015 Feb 12].

[56] Lambrich M, Iglhaut G. Vergleich der Überlebensrate von Zirkondioxid-und Titanimplantaten. Zeitschrift für Zahnärztliche Implantologie. 2008; 24:182-91

[57] Depprich R, Naujoks C, Ommerborn M, Schwarz F, Kübler NR, Handschel J. Current findings regarding zirconia implants. Clin Implant Dent Relat Res [Internet]. 2014;16(1): 124-37. Available from: http://doi.wiley.com/10.1111/j.1708-8208.2012.00454.x [cited 2016 Feb 1].

[58] Payer M, Arnetzl V, Kirmeier R, Koller M, Arnetzl G, Jakse N. Immediate provisional restoration of single-piece zirconia implants: a prospective case series - results after 24 months of clinical function. Clin Oral Implants Res [Internet]. 2013;24(5):569-75. Available from: http://www.ncbi.nlm.nih.gov/pubmed/22335358 [cited 2016 Feb 1].

[59] Oliva J, Oliva X, Oliva JD. Five-year success rate of 831 consecutively placed Zirconia dental implants in humans: a comparison of three different rough surfaces. Int J Oral Maxillofac Implants. 2010;25(2):336-44.

[60] Kohal R-J, Knauf M, Larsson B, Sahlin H, Butz F. One-piece zirconia oral implants: oneyear results from a prospective cohort study. 1. Single tooth replacement. J Clin Periodontol. 2012;39(6):590-7.

[61] Guazzato M, Albakry M, Quach L, Swain MV. Influence of surface and heat treatments on the flexural strength of a glass-infiltrated alumina/zirconia-reinforced dental ceramic. Dent Mater [Internet]. 2005;21(5):454-63. Available from: http:// www.ncbi.nlm.nih.gov/pubmed/15826702 [cited 2016 Feb 1].

[62] Fabbri P, Piconi C, Burresi E, Magnani G, Mazzanti F, Mingazzini C. Lifetime estimation of a zirconia-alumina composite for biomedical applications. Dent Mater [Internet]. 2014;30(2):138-42. Available from: http://www.ncbi.nlm.nih.gov/pubmed/24246473 [cited 2016 Feb 1].

[63] Hallmann L, Ulmer P, Reusser E, Louvel M, Hämmerle CHF. Effect of dopants and sintering temperature on microstructure and low temperature degradation of dental Y-TZP-zirconia. J Eur Ceram Soc [Internet]. 2012;32(16):4091-104. Available from: 
http://www.sciencedirect.com/science/article/pii/S0955221912004281 [cited 2016 Jan 11].

[64] De Aza AH, Chevalier J, Fantozzi G, Schehl M, Torrecillas R. Crack growth resistance of alumina, zirconia and zirconia toughened alumina ceramics for joint prostheses. Biomaterials. 2002;23(3):937-45.

[65] Shimada MTK. Thermal stability of Y2O3-partiallystabilized (Y-PSZ) and Y-PSZ/ Al2O3composites. J Mater Sci Lett. 1985;4:857-61.

[66] Tsubakino H, Nozato R, Hamamoto M. Effect of alumina addition on the tetragonalto-monoclinic phase transformation in zirconia-3 mol\% yttria. J Am Ceram Soc [Internet]. 1991;74(2):440-3. Available from: http://doi.wiley.com/10.1111/j. 1151-2916.1991.tb06905.x [cited 2016 Feb 1].

[67] Gutknecht D, Chevalier J, Garnier V, Fantozzi G. Key role of processing to avoid low temperature ageing in alumina zirconia composites for orthopaedic application. J Eur Ceram Soc [Internet]. 2007;27(2-3):1547-52. Available from: http://www.sciencedirect.com/science/article/pii/S0955221906001750 [cited 2015 Nov 25].

[68] Spies BC, Sauter C, Wolkewitz M, Kohal R-J. Alumina reinforced zirconia implants: effects of cyclic loading and abutment modification on fracture resistance. Dent Mater [Internet]. 2015;31(3):262-72. Available from: http://www.ncbi.nlm.nih.gov/pubmed/ 25582058 [cited 2016 Feb 1].

[69] Md Ani S, Muchtar A, Muhamad N, Ghani JA. Fabrication of zirconia-toughened alumina parts by powder injection molding process: optimized processing parameters. Ceram Int [Internet]. 2014;40(1):273-80. Available from: http://www.sciencedirect.com/ science/article/pii/S0272884213006500 [cited 2016 Jan 30].

[70] Kim DJ, Lee MH, Lee DY, Han JS. Mechanical properties, phase stability, and biocompatibility of $(\mathrm{Y}, \mathrm{Nb})-\mathrm{TZP} / \mathrm{Al} 2 \mathrm{O} 3$ composite abutments for dental implant. J Biomed Mater Res 2000; 53: 438-43.

[71] Maria Cecilia Corrêa de Sá e Benevides de MoraesI,; Carlos Nelson EliasI; Jamil Duailibi FilhoII; Leandra Guimarães de Oliveira Mechanical properties of alumina-zirconia composites for ceramic abutments. Mater Res [Internet]. Materials Research; 2004;7(4): 643-9. Available from: http://www.scielo.br/scielo.php?script=sci_arttext\&pid=S1516-14392004000400021\&lng=en\&nrm=iso\&tlng=en [cited 2016 Feb 1]

[72] Affatato S, Testoni M, Cacciari GL, Toni A. Mixed-oxides prosthetic ceramic ball heads. Part II: effect of the $\mathrm{ZrO}_{2}$ fraction on the wear of ceramic on ceramic joints. Biomaterials [Internet]. 1999;20(20):1925-9. Available from: http://www.sciencedirect.com/science/ article/pii/S0142961299000939 [cited 2016 Feb 1].

[73] Nevarez-Rascon A, Aguilar-Elguezabal A, Orrantia E, Bocanegra-Bernal MH. On the wide range of mechanical properties of ZTA and ATZ based dental ceramic composites 
by varying the $\mathrm{Al}_{2} \mathrm{O}_{3}$ and $\mathrm{ZrO}_{2}$ content. Int J Refract Metals Hard Mater. 2009;27(6):96270 .

[74] Nevarez-Rascon A, Aguilar-Elguezabal A, Orrantia E, Bocanegra-Bernal MH. $\mathrm{Al}(2) \mathrm{O}(3(\mathrm{w}))-\mathrm{Al}(2) \mathrm{O}(3(\mathrm{n}))-\mathrm{ZrO}(2)(\mathrm{TZ}-3 \mathrm{Y})(\mathrm{n})$ multi-scale nanocomposite: an alternative for different dental applications? Acta Biomater [Internet]. 2010;6(2):563-70. Available from: http://www.ncbi.nlm.nih.gov/pubmed/19560564 [cited 2016 Feb 1].

[75] Kurtz SM, Kocagöz S, Arnholt C, Huet R, Ueno M, Walter WL. Advances in zirconia toughened alumina biomaterials for total joint replacement. J Mech Behav Biomed Mater [Internet]. 2014;31:107-16. Available from: http://www.sciencedirect.com/ science/article/pii/S1751616113001112 [cited 2016 Feb 1].

[76] Magnani G, Brillante A. Effect of the composition and sintering process on mechanical properties and residual stresses in zirconia-alumina composites. J Eur Ceram Soc [Internet]. 2005;25(15):3383-92. Available from: http://www.sciencedirect.com/science/ article/pii/S0955221904004224 [cited 2016 Feb 1].

[77] Maccauro G, Bianchino G, Sangiorgi S, Magnani G, Marotta D, Manicone PF,. Development of a new zirconia-toughened alumina: promising mechanical properties and absence of in vitro carcinogenicity. Int J Immunopathol Pharmacol [Internet]. 2009;22(3):773-9. Available from: http://www.ncbi.nlm.nih.gov/pubmed/19822094 [cited 2016 Feb 1].

[78] Spinelli MS, Maccauro G, Graci C, Cittadini A, Magnani G, Sangiorgi S, . Zirconia toughened alumina (ZTA) powders: ultrastructural and histological analysis. Int J Immunopathol Pharmacol [Internet]. 2011;24(1 Suppl. 2):153-6. Available from: http:// www.ncbi.nlm.nih.gov/pubmed/21669156 [cited 2016 Feb 1].

[79] Kohal R-J, Wolkewitz M, Mueller C. Alumina-reinforced zirconia implants: survival rate and fracture strength in a masticatory simulation trial. Clin Oral Implants Res [Internet]. 2010;21(12):1345-52. Available from: http://www.ncbi.nlm.nih.gov/ pubmed/20626420 [cited 2016 Feb 1].

[80] Douillard T, Chevalier J, Descamps-Mandine A, Warner I, Galais Y, Whitaker P, . Comparative ageing behaviour of commercial, unworn and worn $3 \mathrm{Y}-\mathrm{TZP}$ and zirconiatoughened alumina hip joint heads. J Eur Ceram Soc [Internet]. 2012;32(8):1529-40. Available from: http://www.sciencedirect.com/science/article/pii/S0955221912000179 [cited 2016 Feb 1].

[81] Vallée A, Faga MG, Mussano F, Catalano F, Tolosano E, Carossa S, . Alumina-zirconia composites functionalized with laminin- 1 and laminin- 5 for dentistry: effect of protein adsorption on cellular response. Colloids Surf B Biointerfaces. 2014;114:284-93.

[82] Schierano G, Mussano F, Faga MG, Menicucci G, Manzella C, Sabione C, . An alumina toughened zirconia composite for dental implant application: in vivo animal results. Biomed Res Int. 2015;2015:157360. 
[83] Kohal RJ, Bächle M, Renz A, Butz F. Evaluation of alumina toughened zirconia implants with a sintered, moderately rough surface: An experiment in the rat. Dent Mater [Internet]. 2015;32(1):65-72. Available from: http://www.ncbi.nlm.nih.gov/pubmed/ 26621027 [cited 2015 Dec 15].

[84] Spies BC, Balmer M, Patzelt SBM, Vach K, Kohal RJ. Clinical and patient-reported outcomes of a zirconia oral implant: three-year results of a prospective cohort investigation. J Dent Res [Internet]. 2015;94(10):1385-91. Available from: http:// www.ncbi.nlm.nih.gov/pubmed/26232388 [cited 2016 Feb 1].

[85] Faga MG, Vallée A, Bellosi A, Mazzocchi M, Thinh NN, Martra G, . Chemical treatment on alumina-zirconia composites inducing apatite formation with maintained mechanical properties. J Eur Ceram Soc. 2012;32(10):2113-20.

[86] Albrektsson T, Wennerberg A. Oral implant surfaces: Part 1--review focusing on topographic and chemical properties of different surfaces and in vivo responses to them. Int J Prosthodont [Internet]. 2004;17(5):536-43. Available from: http:// www.ncbi.nlm.nih.gov/pubmed/15543910 [cited 2016 Feb 1].

[87] Hoffmann O, Angelov N, Zafiropoulos G-G, Andreana S. Osseointegration of zirconia implants with different surface characteristics: an evaluation in rabbits. Int J Oral Maxillofac Implants [Internet]. 2012;27(2):352-8. Available from: http:// www.ncbi.nlm.nih.gov/pubmed/22442775 [cited 2016 Feb 1].

[88] Lee J, Sieweke JHJH, Rodriguez NANA, Schüpbach P, Lindström H, Susin C, . Evaluation of nano-technology-modified zirconia oral implants: a study in rabbits. J Clin Periodontol [Internet]. 2009;36(7):610-7. Available from: http:// www.ncbi.nlm.nih.gov/pubmed/19538335 [cited 2016 Feb 1].

[89] Bacchelli B, Giavaresi G, Franchi M, Martini D, De Pasquale V, Trirè A, . Influence of a zirconia sandblasting treated surface on peri-implant bone healing: an experimental study in sheep. Acta Biomater [Internet]. 2009;5(6):2246-57. Available from: http:// www.ncbi.nlm.nih.gov/pubmed/19233751 [cited 2016 Feb 1].

[90] Ferguson SJ, Langhoff JD, Voelter K, von Rechenberg B, Scharnweber D, Bierbaum S, . Biomechanical comparison of different surface modifications for dental implants. Int J Oral Maxillofac Implants [Internet]. 2008;23(6):1037-46. Available from: http:// www.ncbi.nlm.nih.gov/pubmed/19216272 [cited 2016 Feb 1].

[91] Spies BC, Sperlich M, Fleiner J, Stampf S, Kohal RJ. Alumina reinforced zirconia implants: 1-year results from a prospective cohort investigation. Clin Oral Implants Res 2016 Apr;27(4):481-90. doi: 10.1111/clr.12560. Epub 2015 Feb 11

[92] Dohan Ehrenfest DM, Coelho PG, Kang B-S, Sul Y-T, Albrektsson T. Classification of osseointegrated implant surfaces: materials, chemistry and topography. Trends Biotechnol [Internet]. 2010;28(4):198-206. Available from: http:// www.ncbi.nlm.nih.gov/pubmed/20116873 [cited 2016 Feb 1]. 
[93] Bal BS, Rahaman MN. Orthopedic applications of silicon nitride ceramics. Acta Biomater [Internet]. 2012;8(8):2889-98. Available from: http://www.sciencedirect.com/ science/article/pii/S174270611200178X [cited 2015 May 12].

[94] Mazzocchi M, Bellosi A. On the possibility of silicon nitride as a ceramic for structural orthopaedic implants. Part I: processing, microstructure, mechanical properties, cytotoxicity. J Mater Sci Mater Med [Internet]. 2008;19(8):2881-7. Available from: http:// www.ncbi.nlm.nih.gov/pubmed/18347952 [cited 2015 Jul 31].

[95] Mazzocchi M, Gardini D, Traverso PL, Faga MG, Bellosi A. On the possibility of silicon nitride as a ceramic for structural orthopaedic implants. Part II: chemical stability and wear resistance in body environment. J Mater Sci Mater Med [Internet]. 2008;19(8): 2889-901. Available from: http://www.ncbi.nlm.nih.gov/pubmed/18415002 [cited 2016 Feb 1].

[96] Sorrell CC, Hardcastle PH, Druitt RK, Howlett CR, McCartney ER. Results of 15-Year Clinical Study of Reaction Bonded Silicon Nitride Intervertebral Spacers. 7th World Biomater Conf. 2004. p. 1872.

[97] Taylor RM, Bernero JP, Patel AA, Brodke DS, Khandkar AC. Silicon nitride: a new material for spinal implants. Orthop Proc [Internet]. Orthopaedic Proceedings; 2010;92B(SUPP I):133. Available from: http://www.bjjprocs.boneandjoint.org.uk/content/92-B/ SUPP_I/133.1.abstract [cited 2016 Feb 1].

[98] McEntire BJ, Bal BS, Rahaman MN, Chevalier J, Pezzotti G. Ceramics and ceramic coatings in orthopaedics. J Eur Ceram Soc [Internet]. 2015;35(16):4327-69. Available from: http://www.sciencedirect.com/science/article/pii/S0955221915300790 [cited 2015 Oct 20].

[99] Neumann A, Reske T, Held M, Jahnke K, Ragoss C, Maier HR. Comparative investigation of the biocompatibility of various silicon nitride ceramic qualities in vitro. J Mater Sci Mater Med [Internet]. 2004;15(10):1135-40. Available from: http:// www.ncbi.nlm.nih.gov/pubmed/15516875 [cited 2015 Jul 31].

[100] Howlett CR, McCartney E, Ching W. The effect of silicon nitride ceramic on rabbit skeletal cells and tissue. An in vitro and in vivo investigation. Clin Orthop Relat Res [Internet]. 1989;(244):293-304. Available from: http://www.ncbi.nlm.nih.gov/pubmed/ 2743672 [cited 2015 Sep 4].

[101] Santos C, Ribeiro S, Daguano JKMF, Rogero SO, Strecker K, Silva CRM. Development and cytotoxicity evaluation of SiAlONs ceramics. Mater Sci Eng C [Internet]. 2007;27(1): 148-53. Available from: http://www.sciencedirect.com/science/article/pii/ S0928493106000336 [cited 2016 Feb 1].

[102] Cappi B, Neuss S, Salber J, Telle R, Knüchel R, Fischer H. Cytocompatibility of high strength non-oxide ceramics. J Biomed Mater Res A [Internet]. 2010;93(1):67-76. Available from: http://www.ncbi.nlm.nih.gov/pubmed/19484770 [cited 2016 Feb 1]. 
[103] Neumann A, Kramps M, Ragoß C, Maier HR, Jahnke K. Histological and microradiographic appearances of Silicon Nitride and Aluminum Oxide in a rabbit femur implantation model. Materwiss Werksttech [Internet]. 2004;35(9):569-73. Available from: http://doi.wiley.com/10.1002/mawe.200400778 [cited 2016 Feb 1].

[104] Neumann A, Unkel C, Werry C, Herborn CU, Maier HR, Ragoss C,. Prototype of a silicon nitride ceramic-based miniplate osteofixation system for the midface. Otolaryngol Head Neck Surg [Internet]. 2006;134(6):923-30. Available from: http:// www.ncbi.nlm.nih.gov/pubmed/16730531 [cited 2016 Feb 1].

[105] Webster TJ, Patel AA, Rahaman MN, Sonny Bal B. Anti-infective and osteointegration properties of silicon nitride, poly(ether ether ketone), and titanium implants. Acta Biomater [Internet]. 2012;8(12):4447-54. Available from: http://www.sciencedirect.com/science/article/pii/S1742706112003571 [cited 2015 Sep 4].

[106] Gorth DJ, Puckett S, Ercan B, Webster TJ, Rahaman M, Bal BS. Decreased bacteria activity on $\mathrm{Si}_{3} \mathrm{~N}_{4}$ surfaces compared with PEEK or titanium. Int J Nanomed [Internet]. 2012;7:4829-40. Available from: http://www.pubmedcentral.nih.gov/articlerender.fcgi?artid=3439860\&tool=pmcentrez\&rendertype=abstract [cited 2015 Sep 4].

[107] Guedes e Silva CC, König B, Carbonari MJ, Yoshimoto M, Allegrini S, Bressiani JC. Tissue response around silicon nitride implants in rabbits. J Biomed Mater Res A [Internet]. 2008;84(2):337-43. Available from: http://www.ncbi.nlm.nih.gov/pubmed/ 17607762 [cited 2016 Feb 1].

[108] Guedes e Silva CC, König B, Carbonari MJ, Yoshimoto M, Allegrini S, Bressiani JC. Bone growth around silicon nitride implants - an evaluation by scanning electron microscopy. Mater Charact [Internet]. 2008;59(9):1339-41. Available from: http:// www.sciencedirect.com/science/article/pii/S1044580307003968 [cited 2016 Feb 1].

[109] Anderson MC, Olsen R. Bone ingrowth into porous silicon nitride. J Biomed Mater Res A [Internet]. 2010;92(4):1598-605. Available from: http://www.ncbi.nlm.nih.gov/ pubmed/19437439 [cited 2016 Feb 1].

[110] Roebben G, Sarbu C, Lube T, Van der Biest O. Quantitative determination of the volume fraction of intergranular amorphous phase in sintered silicon nitride. Mater Sci Eng A [Internet]. 2004;370(1-2):453-8. Available from: http://linkinghub.elsevier.com/ retrieve/pii/S0921509303009419 [cited 2016 Feb 1].

[111] Becher PF. Microstructural design of toughened ceramics. J Am Ceram Soc [Internet]. 1991;74(2):255-69. Available from: http://doi.wiley.com/10.1111/j. 1151-2916.1991.tb06872.x [cited 2016 Feb 1].

[112] Sun EY, Becher PF, Plucknett KP, Hsueh C-H, Alexander KB, Waters SB, . Microstructural design of silicon nitride with improved fracture toughness: II, effects of yttria and alumina additives. J Am Ceram Soc [Internet]. 2005;81(11):2831-40. Available from: http://doi.wiley.com/10.1111/j.1151-2916.1998.tb02703.x [cited 2016 Feb 1]. 
[113] Becher PF, Sun EY, Plucknett KP, Alexander KB, Hsueh C-H, Lin H-T,. Microstructural design of silicon nitride with improved fracture toughness: I, effects of grain shape and size. J Am Ceram Soc [Internet]. 2005;81(11):2821-30. Available from: http:// doi.wiley.com/10.1111/j.1151-2916.1998.tb02702.x [cited 2016 Feb 1].

[114] ISO 26602:2009 - Fine ceramics (advanced ceramics, advanced technical ceramics) -Silicon nitride materials for rolling bearing balls - 2009-02-01

[115] ASTM-F2094/F2094M-11 - Standard Specification for Silicon Nitride Bearing Balls May 1, 2011

[116] Bucciotti F, Mazzocchi M, Bellosi A. Perspectives of the $\mathrm{Si}_{3} \mathrm{~N}_{4}-\mathrm{TiN}$ ceramic composite as a biomaterial and manufacturing of complex-shaped implantable devices by electrical discharge machining (EDM). J Appl Biomater Biomech [Internet]. 2010;8(1): 28-32. Available from: http://www.ncbi.nlm.nih.gov/pubmed/20740419 [cited 2015Sep 5].

[117] Passeri G, Cacchioli A, Ravanetti F, Galli C, Elezi E, Macaluso GM. Adhesion pattern and growth of primary human osteoblastic cells on five commercially available titanium surfaces. Clin Oral Implants Res [Internet]. 2010;21(7):756-65. Available from: http://www.ncbi.nlm.nih.gov/pubmed/20636730 [cited 2015 Jul 22].

[118] Martin JY, Schwartz Z, Hummert TW, Schraub DM, Simpson J, Lankford J,. Effect of titanium surface roughness on proliferation, differentiation, and protein synthesis of human osteoblast-like cells (MG63). J Biomed Mater Res [Internet]. 1995;29(3):389-401. Available from: http://www.ncbi.nlm.nih.gov/pubmed/7542245 [cited 2015 Sep 5].

[119] Guedes e Silva CC, Higa OZ, Bressiani JC. Cytotoxic evaluation of silicon nitride-based ceramics. Mater Sci Eng C [Internet]. 2004;24(5):643-6. Available from: http:// www.sciencedirect.com/science/article/pii/S0928493104000736 [cited 2015 Sep 4]. 
Chapter 5

\title{
Ceramic Materials as an Alternative to Titanium for Dental Implant Fabrication
}

\author{
Mobilio Nicola, Mollica Francesco and \\ Catapano Santo \\ Additional information is available at the end of the chapter \\ http://dx.doi.org/10.5772/64066
}

\begin{abstract}
Titanium is the gold standard material to produce dental implants from more than 30 years, showing high success rate in different clinical scenarios. Zirconia implants were recently introduced to overwhelm some aesthetic and biological problems that can arise from titanium. Preclinical studies show that, from a mechanical point of view, zirconia may be a suitable substitute for titanium in implant fabrication. Three-dimensional finite element analysis (FEA) models found no difference between titanium and titaniumzirconium alloy implants, neither for early nor conventional functional loading. Nevertheless, zirconia presents the same osseoconductive properties of the titanium, even if the few clinical studies show survival and success rates slightly inferior for zirconia implants comparing to titanium ones, and long-term follow-ups are missing. For these reasons, the majority of authors agree to be cautious for proposing zirconia implants as widespread substitute of titanium implants.
\end{abstract}

Keywords: dental implants, one-piece implant, zirconia, zirconia implant

\section{Introduction}

Commercially pure (CP) titanium is the gold standard material used to produce dental implants over more than 30 years [1], showing a high success rate in different clinical scenarios [2-4].

Nevertheless, titanium implants may present some esthetic issues: the gray color of titanium implant may be visible in the presence of thin peri-implant tissue, leading to esthetic concern, especially in the anterior area [5]. This aspect can get dramatically worse In case of peri-implant 
mucosa recedes over time. The availability of a "white" implant may be crucial in those clinical cases in which esthetic result is mandatory.

Furthermore, titanium particles due to wear and corrosion products may be released in tissues close to implants, and they were found in regional lymph nodes [6]. In some cases, this may lead to host reaction or sensitization [7]. Some cases of allergic reaction to titanium are documented, even if rare $[8,9]$. So, using some nonmetallic material as an alternative to the titanium implant may be useful and, in some cases, critical. Last but not least, always more patients request completely metal-free prosthetic reconstructions.

Ceramic implants were introduced to overwhelm some esthetic and biological problems that can arise from titanium. The first ceramic dental implant was made from alumina (i.e., aluminum oxide, $\mathrm{Al}_{2} \mathrm{O}_{3}$ ) between 1960s and 1970s, and that was the only ceramic material used until recently. However, alumina presented some biomechanical problems (like low fracture toughness), and it was then completely abandoned and replaced with zirconia that is nowadays the only alternative ceramic material to titanium for dental implants (Figure 1) [5].

The aim of this chapter is to review the existing literature regarding zirconia dental implants, highlighting the strong points and stressing the so far unclear aspects.

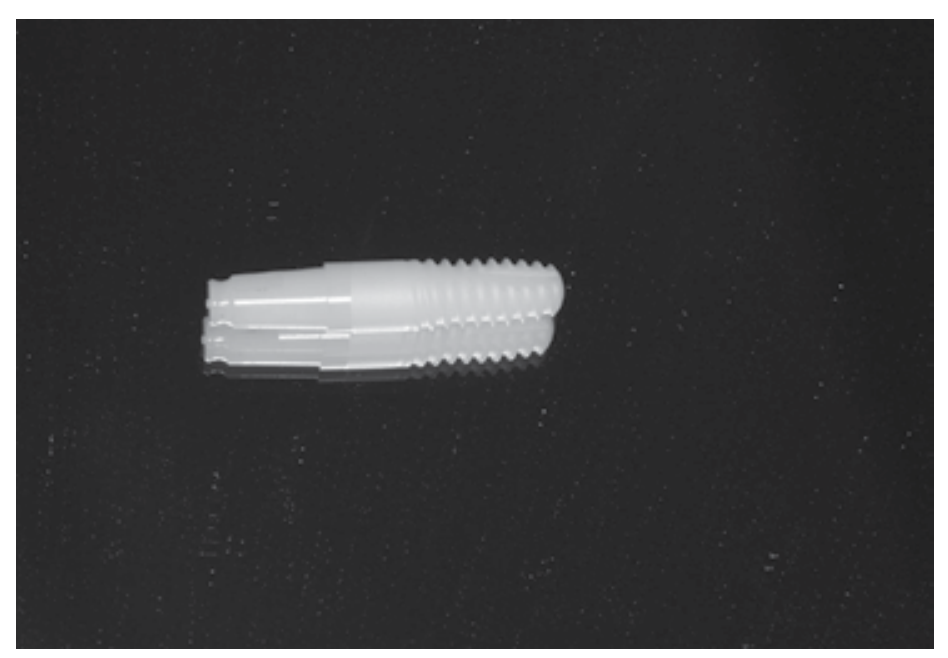

Figure 1. A one-piece zirconia implant (courtesy of Prof. Andrea Enrico Borgonovo, University of Milan).

\section{Zirconia}

\subsection{Mechanical aspects}

Zirconia (zirconium dioxide, $\mathrm{ZrO}_{2}$ ) is a white crystalline oxide of zirconium. It is polymorphic in nature, transforming its crystalline reticule from monoclinic (at room temperature) to 
tetragonal to cubic at increasing temperatures. By adding some oxides to zirconia, it is possible to stabilize the tetragonal and/or cubic phases. The so-called partially stabilized zirconia (PSZ) consists mainly of a cubic phase, with monoclinic and tetragonal zirconia as minor phases. By adding 2-3\% of yttria (yttrium oxide, $\mathrm{Y}_{2} \mathrm{O}_{3}$ ), it is possible to obtain a completely tetragonal zirconia, the so-called yttria-stabilized tetragonal zirconia polycrystal ( $Y-T Z P)$. The $Y-$ TZP is the most performing zirconia from a mechanical point of view and the most used in dentistry to produce implants, implant abutments and frameworks for crowns and bridges.

Its interesting and in some cases unique mechanical properties are the reasons why zirconia is often called "ceramic steel": a high corrosion and wear resistance, high Young's modulus (200 GPa), a very high flexural strength (up to $1200 \mathrm{MPa}$ ), a high fracture toughness and a polymorphic behavior [10]. The latter is probably the most interesting aspect: zirconia may adapt the three-dimensional disposition of the structure when some energy is provided, that is what happens in a crack initiation. In proximity of the crack, the energy changes the phase locally, turning the reticule from tetragonal to monoclinic. This phase transformation happens with an increase in volume (3-4\%): the expansion of the crystals opposes to crack propagation and prevents macroscopic failure, enhancing fracture toughness. This mechanism is known as transformation toughening [11,12].

Such a phenomenal mechanism of action against crack propagation has been questioned because of the so-called low-temperature degradation process, a sort of aging of zirconia. It seems that in the presence of water, the yttrium ions can be leached, and their stabilizing effect can be lost [13]. In that case, a spontaneous irreversible transformation from the metastable tetragonal phase to the stable monoclinic phase can occur on the surface of zirconia. Such a stabilized monoclinic phase does not have the capacity anymore to rearrange the crystalline reticule and so to oppose to an incoming fracture. However, the impact of this issue on the long-term clinical behavior of zirconia prosthetic components and implants is still unclear [5].

\subsection{Biological aspects}

The biocompatibility of zirconia is well established from both in vitro and in vivo studies [14]. In-vitro tests were conducted on various cellular lines, such as osteoblasts, fibroblasts, lymphocytes, monocytes, and macrophages, showing no cytotoxic effects. In vivo tests also showed no cytotoxicity in soft (connective) or hard (bone) tissues [12]. For this reason, its use as a biomedical implant (e.g., in orthopedic surgery) is widespread [15].

\section{Mechanical properties of zirconia implants from experimental and clinical data}

Considering the difficulty of analyzing the mechanical outcome of implants in clinical scenarios, preclinical studies are fundamental to accomplish this issue. Different in vitro studies evaluated the biomechanical behavior of zirconia implants with prosthetic reconstructions. The fracture strength of zirconia crowns on zirconia implants was compared to that of 
metal-ceramic crowns on titanium implants, in an upper central incisor model. No difference was found between implants, with and without cyclic loading before fracture test [16]. The same authors also showed that preparation of zirconia implants to receive prosthetic crown may negatively affect the fracture strength, even if it was still in an acceptable clinical range [17]. Another in vitro study evaluated the fracture strength of zirconia implants in comparison with that of titanium implants under a $130^{\circ}$ angled load, simulating that of an upper central incisor. Despite the high dispersion of fracture loads (typical of ceramic materials), the mean fracture strength ranged within the limits of clinical acceptance [18].

With caution, it is possible to affirm that from experimental preclinical studies, the biomechanical behavior of zirconia implants does not differ from that of titanium implants. So, no biomechanical contraindications are present for clinical use of zirconia implants [12].

The majority of clinical studies focused on achieving and maintaining osseointegration in time. In these studies, the main cause of failure is represented by marginal bone loss and/or the loss of osseointegration (see below). However, one clinical study considered just implant fracture as cause of failure: the survival rate was $92.5 \%$ after about 5 years, the loss of osseointegration has not been taken into account [19].

\section{Osseointegration}

The capacity to achieve osseointegration is the most investigated aspect regarding zirconia implants. To evaluate implant osseointegration, the following parameters are widely used:

- bone-to-implant contact (BIC) value;

- torque removal force;

- crestal bone loss (CBL).

The BIC value is usually studied using histomorphometry on histological sections. The torque removal force is considered a biomechanical measure of osseointegration: the greater the force is required to remove implants, the greater the strength of osseointegration. CBL is a clinical parameter related to the maintenance of osseointegration in time, and so it is related to survival and success rate of implant therapy (see Section 5).

One of the first animal studies investigating the osseointegration of zirconia implants was conducted in a rabbit model [20]. After 1 month from the insertion, the histological analysis showed newly formed bone close to the implant surface, affirming the osteoconductive property of zirconia. Titanium and zirconia implants were inserted in monkeys and after 3 months were functionally loaded for 5 months. The histological analysis performed later revealed no difference in osseointegration [21]. Titanium, machined zirconia, and surfacemodified zirconia implants were inserted into rabbit. No difference in the removal torque was found between titanium and surface-modified zirconia, but machined surface zirconia implants performed badly. Such results seem to suggest that a modification of the zirconia surface is recommended to increase the bone tissue response [22]. Titanium, machined 
zirconia, and sandblasted (rough) zirconia were inserted into the maxillae of miniature pigs, and then removed. The removal torque test revealed that rough zirconia implants can achieve a higher stability than machined implants [23]. A detailed analysis performed using scanning electron microscopy (SEM) [24] and histomorphometry [25] revealed no difference of osseointegration between titanium and zirconia implants inserted into minipigs. A study compared the osseointegration of zirconia and titanium implants in dogs, indicating no difference in BIC values between the two types of implants [26]. Another study performed a similar analysis in pigs. After 4 weeks from the insertion, no difference in terms of BIC was found between zirconia and titanium implants (Figure 2) [27]. Another histomorphometric study conducted on dogs found no difference in osseointegration and tissue response between titanium, and coated and noncoated zirconia implants [28]. Different implants (titanium and zirconia) used in pigs showed no significance difference in BIC values [29]. Calvo-Guirado et al. [30] found no difference in BIC values between zirconia and titanium implants in an animal model, and they concluded that both implant types produce good osseointegration.

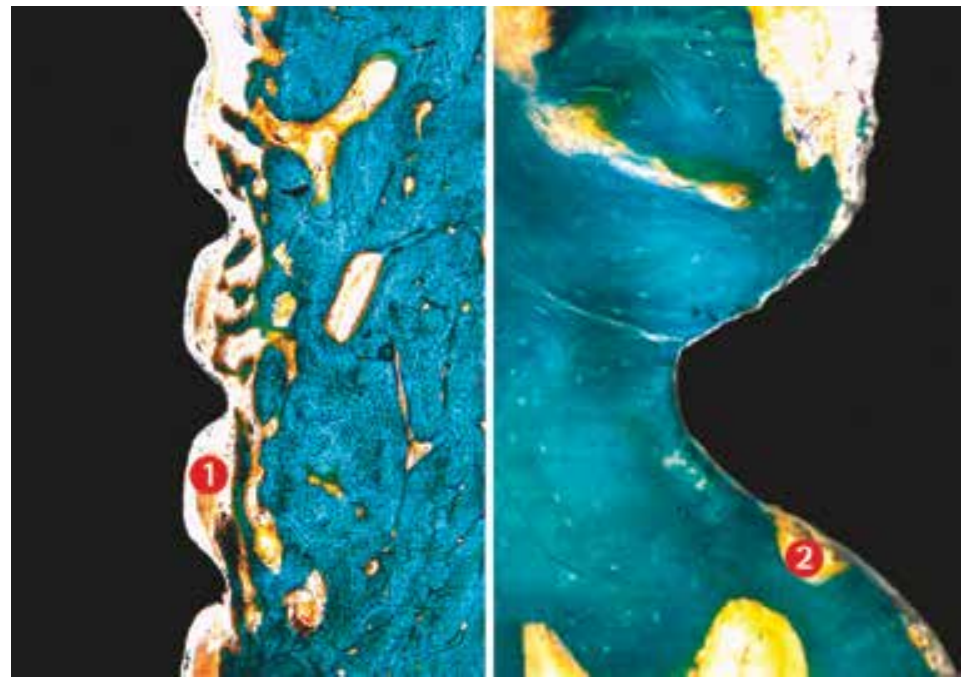

Figure 2. Histological section of zirconia implants inserted into a minipig. 1: neo-osteogenesis; 2: osteoblasts on the implant surface (courtesy of Dr. Mai, University of Dresden).

From the totality of animal studies, it is possible to conclude that zirconia is an osseoconductive material [14], and therefore it can be utilized as a material for dental implants [31].

\section{Crestal bone loss around zirconia implants and survival and success rate}

As zirconia implants have been used over relatively few years, a few clinical studies with limited follow-up are available. Furthermore, the results are not easy to compare. It is important to keep this statement in mind analyzing the following studies and the consistent 
conclusions. The largest prospective clinical study (831 implants in 378 patients) reported a success rate of $95 \%$ after 5 years [32]. The success rate of the acid-etched implants was slightly higher than that of coated and noncoated implants. A 1-year follow-up case series analyzed 56 implants (12 in upper jaws and 44 in mandibles) inserted into 28 patients. A survival rate of $98.2 \%$ was found, with an average marginal bone loss of almost $2 \mathrm{~mm}$, which appears quite high, lowering the success rate to $60 \%$ [33]. A prospective study with a very small number of cases found a success rate of $100 \%$, with a minimal bone loss after 4 years $(0.6 \mathrm{~mm})$ [34]. An in vivo study found a greater bone loss around zirconia implants in respect to titanium implants after 12 months of function. However, no difference in the survival rate was recorded [35]. A recent systematic review of 13 studies (maximum follow-up of 4 years) concluded that the survival rate of zirconia implants ranges from 67.6 to $100 \%$ [36].

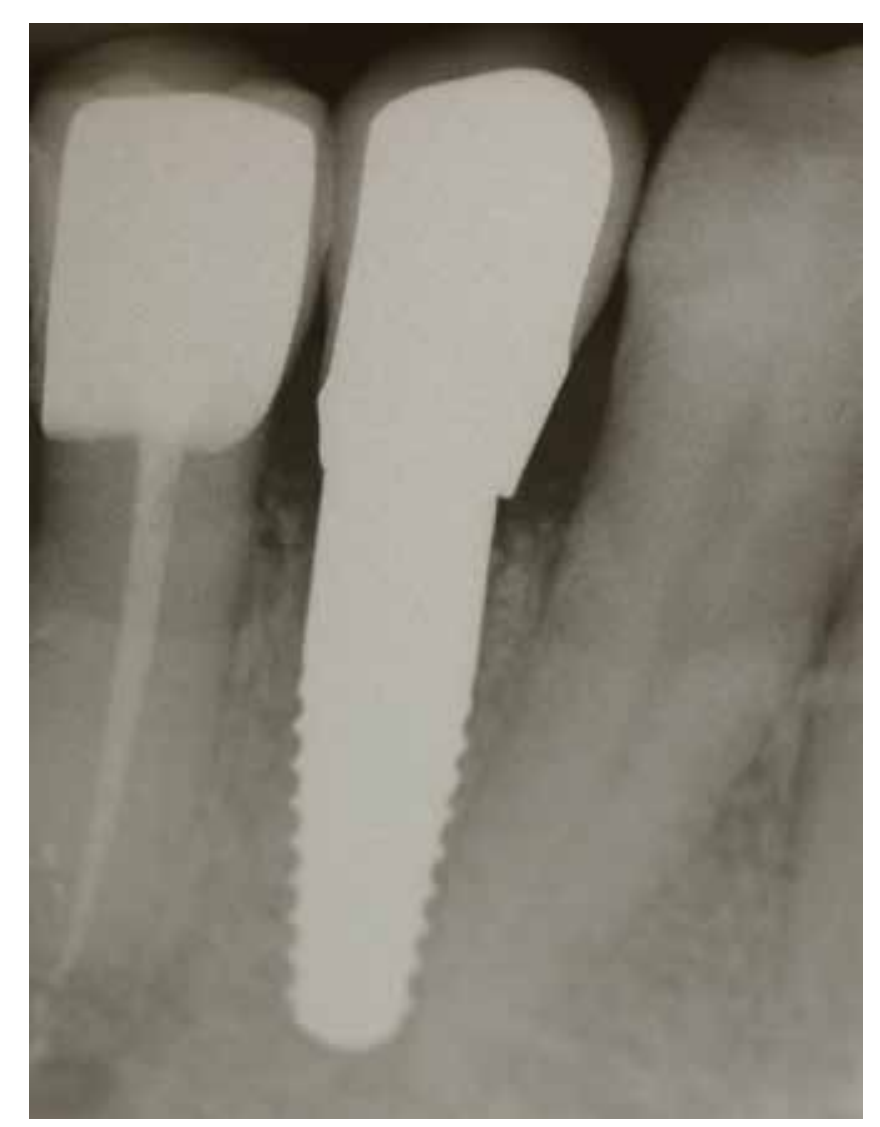

Figure 3. The radiographic control of prosthetic crown cemented on a zirconia implant (courtesy of Prof. Andrea Enrico Borgonovo, University of Milan).

In conclusion, from the available data the osseointegration of zirconia implants seems not to be a problem (Figure 3) [37]. Nevertheless, survival and success rates of zirconia implants are inferior to those of titanium ones [13]. For this reason, the majority of authors [12] remain 
cautious and agree that further follow-ups are needed to evaluate the long-term success rates, before a routine use of zirconia implants can be recommend widely.

\section{Zirconia and surrounding bone}

As the stiffness of zirconia is twice that of titanium, an excessive stress on the trabecular bone around the implant may be expected. Various mathematical studies were performed to analyze the biomechanical behavior of the surrounding bone. One of the first studies in this field compared the response of surrounding bone around titanium and zirconia root-shape implants. No difference emerged from finite element analysis (FEA) [38]. A three-dimensional FEA found no difference in the stress distribution of bone between two versions of the same implant: one made of titanium and the other one made of zirconia [39]. A numeric stress analysis was performed to reproduce the mechanical behavior of the bone around zirconia and titanium implants [40]. The numeric model was also validated from the experimental point

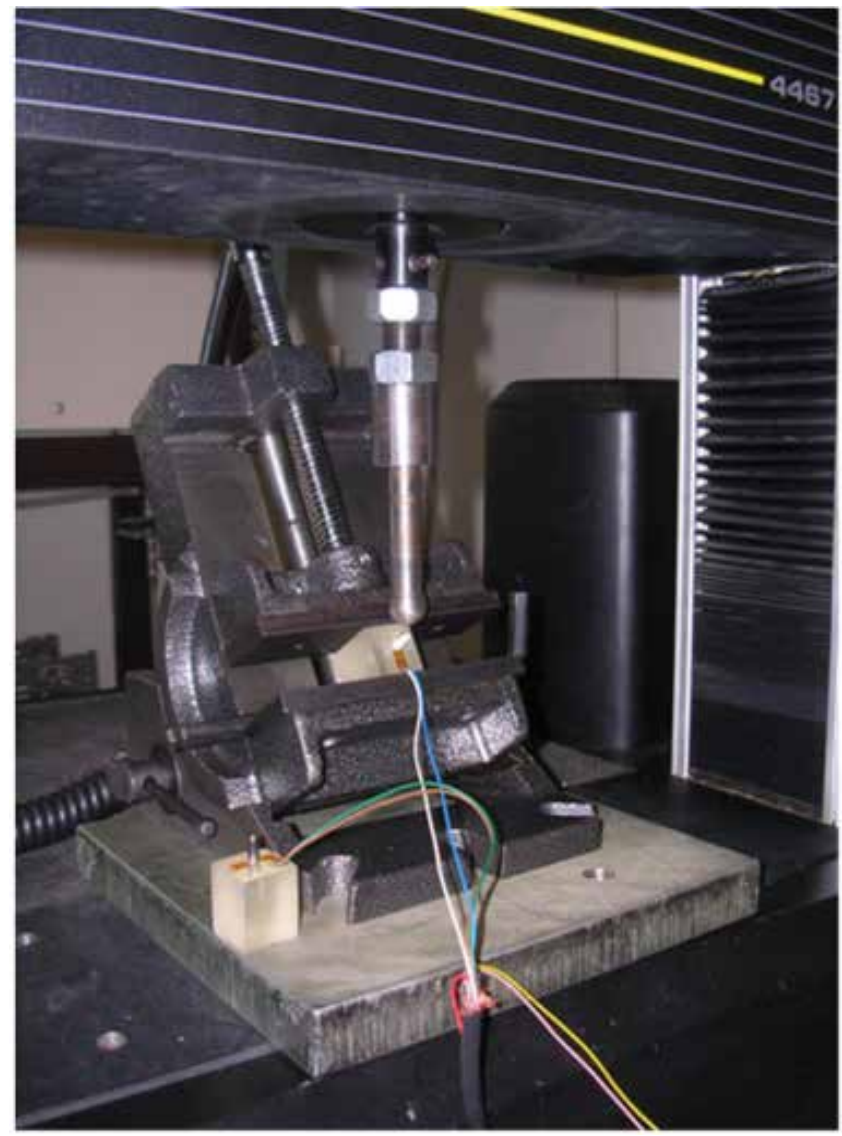

Figure 4. The experimental validation of numeric model of a zirconia implant (from Mobilio 2013). 


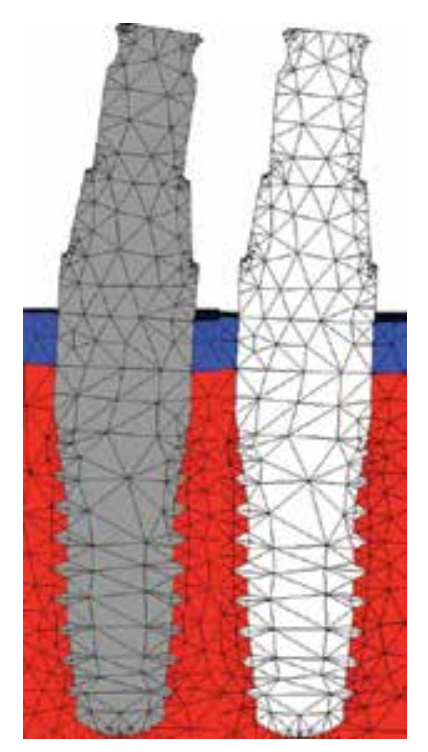

Figure 5. Deformed shape of the titanium (on right) and zirconia implants (30× magnification): the titanium implant shows a higher head displacement in the $x$-direction (from Mobilio 2013).

of view (Figure 4). The results showed that stress states generated in the bone by the two implant types were very similar; therefore, from a mechanical point of view, zirconia is found to be a feasible substitute for titanium. But more interestingly, results showed that the two implants moved differently: titanium implants generate higher stress on the cortical bone, whereas zirconia implants produce stress mainly in the trabecular bone. This different behavior is directly related to different Young's modulus values of the two materials: while titanium leans against the cortical bone and its exterior part is more prone to bending under load, zirconia is too stiff to bend and transmits stresses along its axis down to the trabecular bone, thus moving more as a rigid body (Figure 5). This difference in motion between the two implants is important considering crestal bone loss. Bone resorption around implants is a common phenomenon that begins at the cervical level and can progress in the apical direction. No conclusive data are available on contributing factors involved in such a bone loss, but concentration of stresses around the neck of the implant due to functional and nonfunctional loads may be one such factor. In this view, it can be speculated that decreasing the stress concentration at the cervical level may reduce the effect of mechanical factors on crestal bone loss.

Other FEA studies found similar results. The model of a maxillary overdenture on four implants with ball attachments revealed no difference in the stress and strain values in periimplant bone, using titanium or zirconia [41]. A three-dimensional FEA model found no difference between titanium and titanium-zirconium alloy implants, neither for early nor conventional functional loading [42]. A study found difference in bone behavior depending on the macrogeometry of the zirconia fixture [43]. 


\section{Peri-implant soft tissue response}

Zirconia is advocated to have high biocompatibility and to have no adverse effect on the surrounding tissues (Figures 6 and 7) [44]. Many studies evaluated tissue response to zirconia, concluding that zirconia has the ability to interact with peri-implant soft tissues (Figure 8) [14]. The low bacterial colonization typical of the zirconia surface maybe plays a role in this high biocompatibility [12]. In a randomized-controlled trial (RCT), both titanium and zirconia onepiece implants supporting overdentures were evaluated [35]. Even if the crestal bone level changed greatly, no difference in clinical parameters (probing depth, bleeding index, plaque index, etc.) was found around the two types of implants after 12 months of function.

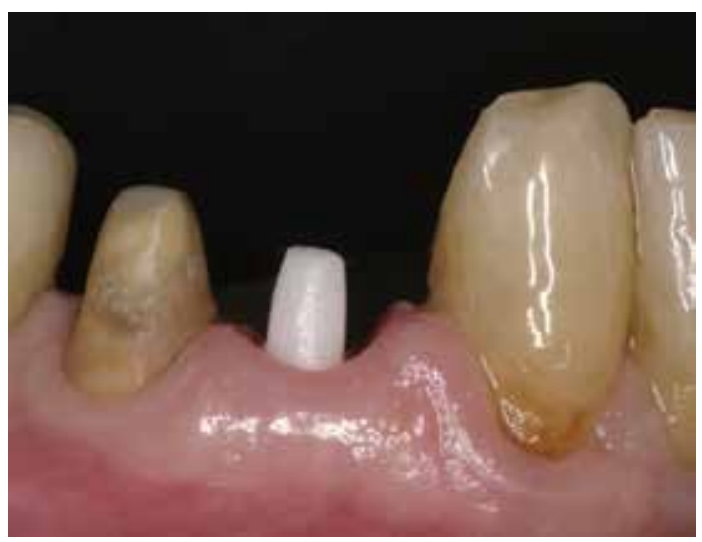

Figure 6. Clinical aspect of the abutment part of zirconia implant before cementation of crown (courtesy of Prof. Andrea Enrico Borgonovo, University of Milan).

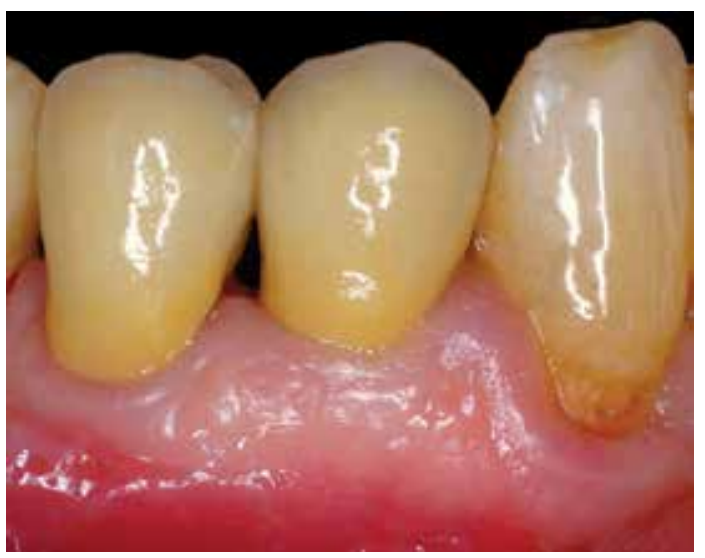

Figure 7. Clinical aspect after finalization (courtesy of Prof. Andrea Enrico Borgonovo, University of Milan). 


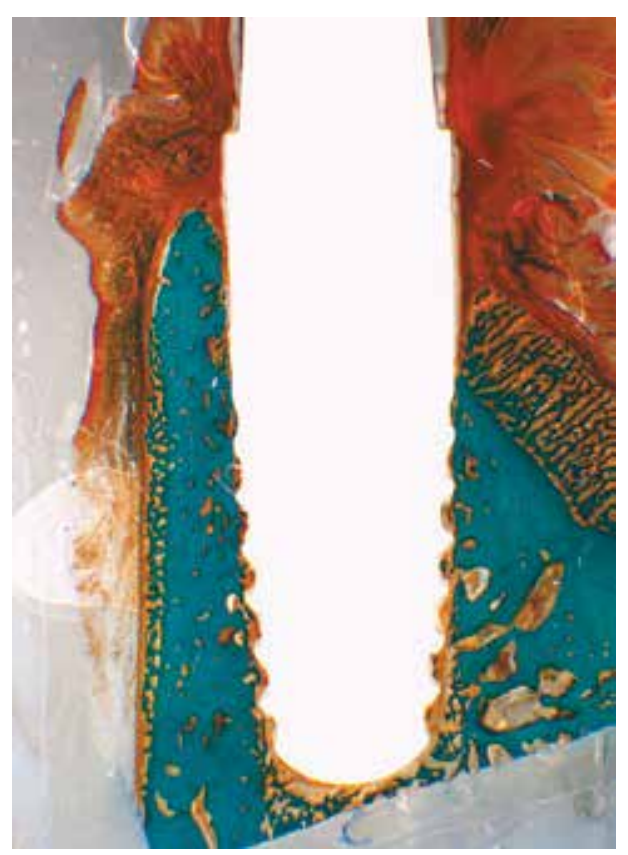

Figure 8. Histological section of zirconia implant inserted into a minipig. The tight connection of the soft tissue to the implant surface is shown (courtesy of Dr. Mai, University of Dresden).

\section{Available products}

\begin{tabular}{lll}
\hline Product & Manufactory & Web site \\
\hline WhiteSky & Bredent Medical \& Co & $\begin{array}{l}\text { http://www.bredent-medical.com/en/medical/product-informations/ } \\
2002 / 14 /\end{array}$ \\
& & $\begin{array}{l}\text { http://www.ceraroot.com/professionals/products/implants } \\
\text { Ceraroot }\end{array}$ \\
Axis & Axis Biodental & $\begin{array}{l}\text { http://www.axis-biodental.ch/biodentalnew.php? } \\
\text { id_structure=7\&portail=2\&langue=en }\end{array}$ \\
Y-TZP BIO-HIP & Incermed & http://www.incermed.ch \\
Sigma ${ }^{\circledR}$ & & \\
Z-Look3 & Zirkolith & http://zsystems.com/en/doctors/products-z5-zirkolithr-ceramic- \\
& & implants/z5m-lblc-zirkolithr-implant.html \\
Zit-Z & Ziterion & http://www.ziterion.com \\
\hline
\end{tabular}

Many zirconia implants are commercially available. The most famous products are listed in Table 1. Even if all available implants are constituted by Y-TZP, the surface characterization (regarding in particular some parameters such as carbon contamination and phase transfor- 
mation) is far to be the same for all products [45], and few independent data are available on this issue. Contrary to $\mathrm{CP}$ titanium, the name "Y-TZP" is often insufficient to characterize the material, and the clinician must pay attention to the details of the selected product.

\section{Conclusions}

Ceramic implants were introduced to solve some esthetic and biologic problems related to traditional titanium implants. Y-TZP has the biomechanical properties suitable to produce dental implants. To date, in vitro and in vivo studies have shown good results from a mechanical point of view. Furthermore, zirconia is an osteoconductive material, so achieving osseointegration is not a problem, and the simulation of stress distribution into the bone did not find essential difference from titanium. Unfortunately, long-term follow-ups are missing, so no solid clinical evidence is currently available to recommend routine use of zirconia implants or to replace titanium implants, which is still found to be the gold standard for dental implantology. So, even if zirconia implants are a good option from theoretical and experimental point of view, the clinical long-term response is not yet available. Almost all the authors agree to be cautious for proposing zirconia implants as substitutes of titanium implants for replacing teeth. Long-term, well-designed perspective clinical studies are needed to address the missing aspects of this undoubtful promising alternative.

\section{Acknowledgements}

The authors thank Prof. Andrea Enrico Borgonovo, University of Milan, for the clinical and radiographic documentation of zirconia implants, and Dr. Mai, University of Dresden for the histological documentation

\section{Author details}

Mobilio Nicola ${ }^{1 *}$, Mollica Francesco ${ }^{2}$ and Catapano Santo ${ }^{1}$

*Address all correspondence to: nicola.mobilio@unife.it

1 Department of Prosthodontics, Dental School, Dental Clinic, University of Ferrara, Ferrara, Italy

2 Department of Engineering, University of Ferrara, Ferrara, Italy 


\section{References}

[1] Brånemark P-I, Breine U, Adell R, Hansson BO, Lindström J, Ohlsson. Intra-osseous anchorage of dental prostheses: I. Experimental studies. Scand J Plast Reconstr Surg. 1969;3:81-100.

[2] Adell R, Eriksson B, Lekholm U, Brånemark P-I, Jemt T. Long-term follow-up study of osseointegrated implants in the treatment of totally edentulous jaws. Int J Oral Maxillofac Implants. 1990;5:347-59.

[3] Jung RE, Zembic A, Pjetursson BE, Zwahlen M, Thoma DS. Systematic review of the survival rate and the incidence of biological, technical, and aesthetic complications of single crowns on implants reported in longitudinal studies with a mean follow-up of 5 years. Clin Oral Implants Res. 2012;23 Suppl 6:2-21. DOI: 10.1111/j. 1600-0501.2012.02547.x

[4] Pjetursson BE, Thoma D, Jung R, Zwahlen M, Zembic A. A systematic review of the survival and complication rates of implant-supported fixed dental prostheses (fdps) after a mean observation period of at least 5 years. Clin Oral Implants Res. 2012;23 Suppl 6:22-38. DOI: 10.1111/j.1600-0501.2012.02546.x

[5] Wenz HJ, Bartsch J, Wolfart S, Kern M. Osseointegration and clinical success of zirconia dental implants: A systematic review. Int J Prosthodont. 2008;21:27-36.

[6] Weingart D, Steinemann S, Schilli W, Strub JR, Hellerich U, Assenmacher J, et al. Titanium deposition in regional lymph nodes after insertion of titanium screw implants in maxillofacial region. Int J Oral Maxillofac Surg. 1994;23:450-2.

[7] Lalor PA, Revell PA, Gray AB, Wright S, Railton GT, Freeman MA. Sensitivity to titanium. A cause of implant failure? J Bone \& Joint Surg, Br. 1991;73:25-8.

[8] Siddiqi A, Payne AG, De Silva RK, Duncan WJ. Titanium allergy: Could it affect dental implant integration? Clin Oral Implants Res. 2011;22:673-80. DOI: 10.1111/j. 1600-0501.2010.02081.x

[9] Javed F, Al-Hezaimi K, Almas K, Romanos GE. Is titanium sensitivity associated with allergic reactions in patients with dental implants? A systematic review. Clin Implant Dent Relat Res. 2013;15:47-52. DOI: 10.1111/j.1708-8208.2010.00330.x

[10] Kelly JR, Denry I. Stabilized zirconia as a structural ceramic: An overview. Dent Mater. 2008;24:289-98. DOI: 10.1016/j.dental.2007.05.005

[11] Cavalcanti AN, Foxton RM, Watson TF, Oliveira MT, Giannini M, Marchi GM. Y-TZP ceramics: Key concepts for clinical application. Oper Dent. 2009;34:344-51.

[12] Apratim A, Eachempati P, Krishnappa Salian KK, Singh V, Chhabra S, Shah S. Zirconia in dental implantology: A review. J Int Soc Prev Community Dent. 2015;5:147-56. DOI: 10.4103/2231-0762.158014 
[13] Depprich R, Naujoks C, Ommerborn M, Schwarz F, Kübler NR, Handschel J. Current findings regarding zirconia implants. Clin Implant Dent Relat Res. 2014;16:124-37. DOI: $10.1111 / j .1708-8208.2012 .00454 . x$

[14] Hisbergues M, Vendeville S, Vendeville P. Zirconia: Established facts and perspectives for a biomaterial in dental implantology. J Biomed Mater Res B Appl Biomater. 2009;88:519-29. DOI: 10.1002/jbm.b.31147

[15] Manicone PF, Rossi Iommetti P, Raffaelli L, Paolantonio M, Rossi G, Berardi D, et al. Biological considerations on the use of zirconia for dental devices. Int J Immunopathol Pharmacol. 2007;20:9-12.

[16] Kohal RJ, Klaus G, Strub JR. Zirconia-implant-supported all-ceramic crowns withstand long-term load: A pilot investigation. Clin Oral Implants Res. 2006;17:565-71. DOI: 10.1111/j.1600-0501.2006.01252.x

[17] Kohal RJ, Wolkewitz M, Tsakona A. The effects of cyclic loading and preparation on the fracture strength of zirconium-dioxide implants: An in vitro investigation. Clin Oral Implants Res. 2011;22:808-14. DOI: 10.1111/j.1600-0501.2010.02067.x

[18] Andreiotelli M, Kohal RJ. Fracture strength of zirconia implants after artificial aging. Clin Implant Dent Relat Res. 2009;11:158-66. DOI: 10.1111/j.1708-8208.2008.00105.x

[19] Gahlert M, Burtscher D, Grunert I, Kniha H, Steinhauser E. Failure analysis of fractured dental zirconia implants. Clin Oral Implants Res. 2012;23:287-93. DOI: 10.1111/j. 1600-0501.2011.02206.x

[20] Scarano A, Di Carlo F, Quaranta M, Piattelli A. Bone response to zirconia ceramic implants: An experimental study in rabbits. J Oral Implantol. 2003;29:8-12. DOI: 10.1563/1548-1336(2003)029<0008:BRTZCI>2.3.CO;2

[21] Kohal RJ, Weng D, Bächle M, Strub JR. Loaded custom-made zirconia and titanium implants show similar osseointegration: An animal experiment. J Periodontol. 2004;75:1262-8. DOI: 10.1902/jop.2004.75.9.1262

[22] Sennerby L, Dasmah A, Larsson B, Iverhed M. Bone tissue responses to surfacemodified zirconia implants: A histomorphometric and removal torque study in the rabbit. Clin Implant Dent Relat Res. 2005;7 Suppl 1:S13-20.

[23] Gahlert M, Gudehus T, Eichhorn S, Steinhauser E, Kniha H, Erhardt W. Biomechanical and histomorphometric comparison between zirconia implants with varying surface textures and a titanium implant in the maxilla of miniature pigs. Clin Oral Implants Res. 2007;18:662-8.

[24] Depprich R, Zipprich H, Ommerborn M, Mahn E, Lammers L, Handschel J, et al. Osseointegration of zirconia implants: An SEM observation of the bone-implant interface. Head Face Med. 2008;4:25. DOI: 10.1186/1746-160X-4-25 
[25] Depprich R, Zipprich H, Ommerborn M, Naujoks C, Wiesmann HP, Kiattavorncharoen $S$, et al. Osseointegration of zirconia implants compared with titanium: An in vivo study. Head Face Med. 2008;4:30. DOI: 10.1186/1746-160X-4-30

[26] Koch FP, Weng D, Krämer S, Biesterfeld S, Jahn-Eimermacher A, Wagner W. Osseointegration of one-piece zirconia implants compared with a titanium implant of identical design: A histomorphometric study in the dog. Clin Oral Implants Res. 2010;21:350-6. DOI: $10.1111 / j .1600-0501.2009 .01832 . x$

[27] Stadlinger B, Hennig M, Eckelt U, Kuhlisch E, Mai R. Comparison of zirconia and titanium implants after a short healing period. A pilot study in minipigs. Int J Oral Maxillofac Surg. 2010;39:585-92. DOI: 10.1016/j.ijom.2010.01.015

[28] Koch FP, Weng D, Kramer S, Wagner W. Soft tissue healing at one-piece zirconia implants compared to titanium and PEEK implants of identical design: A histomorphometric study in the dog. Int J Periodontics Restor Dent. 2013;33:669-77.

[29] Gredes T, Kubasiewicz-Ross P, Gedrange T, Dominiak M, Kunert-Keil C. Comparison of surface modified zirconia implants with commercially available zirconium and titanium implants: A histological study in pigs. Implant Dent. 2014;23:502-7. DOI: 10.1097/ID.0000000000000110

[30] Calvo-Guirado JL, Aguilar-Salvatierra A, Delgado-Ruiz RA, Negri B, Fernández MP, Maté Sánchez de Val JE, et al. Histological and histomorphometric evaluation of zirconia dental implants modified by femtosecond laser versus titanium implants: An experimental study in fox hound dogs. Clin Implant Dent Relat Res. 2015;17:525-32. DOI: $10.1111 /$ cid.12162

[31] Van Dooren E, Calamita M, Calgaro M, Coachman C, Ferencz JL, Pinho C, et al. Mechanical, biological and clinical aspects of zirconia implants. Eur J Esthet Dent. 2012;7:396-417.

[32] Oliva J, Oliva X, Oliva JD. Five-year success rate of 831 consecutively placed zirconia dental implants in humans: A comparison of three different rough surfaces. Int J Oral Maxillofac Implants. 2010;25:336-44.

[33] Kohal RJ, Patzelt SB, Butz F, Sahlin H. One-piece zirconia oral implants: One-year results from a prospective case series. 2. Three-unit fixed dental prosthesis (FDP) reconstruction. J Clin Periodontol. 2013;40:553-62. DOI: 10.1111/jcpe.12093

[34] Borgonovo AE, Vavassori V, Censi R, Calvo JL, Re D. Behavior of endosseous one-piece yttrium stabilized zirconia dental implants placed in posterior areas. Minerva Stomatol. 2013;62:247-57.

[35] Siddiqi A, Kieser JA, De Silva RK, Thomson WM, Duncan WJ. Soft and hard tissue response to zirconia versus titanium one-piece implants placed in alveolar and palatal sites: A randomized control trial. Clin Implant Dent Relat Res. 2015;17:483-96. DOI: 10.1111/cid.12159 
[36] Vohra F, Al-Kheraif AA, Ab Ghani SM, Abu Hassan MI, Alnassar T, Javed F. Crestal bone loss and periimplant inflammatory parameters around zirconia implants: A systematic review. J Prosthet Dent. 2015;114:351-7. DOI: 10.1016/j.prosdent.2015.03.016

[37] Andreiotelli M, Wenz HJ, Kohal RJ. Are ceramic implants a viable alternative to titanium implants? A systematic literature review. Clin Oral Implants Res. 2009;20 Suppl 4:32-47. DOI: 10.1111/j.1600-0501.2009.01785.x

[38] Kohal RJ, Papavasiliou G, Kamposiora P, Tripodakis A, Strub JR. Three-dimensional computerized stress analysis of commercially pure titanium and yttrium-partially stabilized zirconia implants. Int J Prosthodont. 2002;15:189-94.

[39] Chang CL, Chen CS, Yeung TC, Hsu ML. Biomechanical effect of a zirconia dental implant-crown system: A three-dimensional finite element analysis. Int J Oral Maxillofac Implants. 2012;27:e49-57.

[40] Mobilio N, Stefanoni F, Contiero P, Mollica F, Catapano S. Experimental and numeric stress analysis of titanium and zirconia one-piece dental implants. Int J Oral Maxillofac Implants. 2013;28:e135-42.

[41] Osman RB, Elkhadem AH, Ma S, Swain MV. Titanium versus zirconia implants supporting maxillary overdentures: Three-dimensional finite element analysis. Int J Oral Maxillofac Implants. 2013;28:e198-208. DOI: 10.11607/jomi.3019

[42] Akça K, Eser A, Çavuşoğlu Y, Sağırkaya E, Çehreli MC. Numerical assessment of bone remodeling around conventionally and early loaded titanium and titanium-zirconium alloy dental implants. Med Biol Eng Comput. 2015;53:453-62. DOI: 10.1007/ s11517-015-1256-0

[43] Caglar A, Bal BT, Aydin C, Yilmaz H, Ozkan S. Evaluation of stresses occurring on three different zirconia dental implants: Three-dimensional finite element analysis. Int J Oral Maxillofac Implants. 2010;25:95-103.

[44] Assal PA. The osseointegration of zirconia dental implants. Schweiz Monatsschr Zahnmed. 2013;123:644-54.

[45] Zinelis S, Thomas A, Syres K, Silikas N, Eliades G. Surface characterization of zirconia dental implants. Dent Mater. 2010;26:295-305. DOI: 10.1016/j.dental.2009.11.079 

Section 3

Implant Surface Treatment 

Chapter 6

\title{
Treatments to Optimize Dental Implant Surface Topography and Enhance Cell Bioactivity
}

\author{
Jaume Miranda-Rius, Eduard Lahor-Soler, \\ Lluís Brunet-Llobet, David de Dios and \\ Francesc Xavier Gil
}

Additional information is available at the end of the chapter

http://dx.doi.org/10.5772/62682

\begin{abstract}
Osseointegration is a biological process in which histological, surgical, infectious factors, biomechanical load, and the choice of biomaterials all play important roles. In the case of dental implants, the success of this process is also influenced by the design, composition, and properties of the implant surface, which may stimulate cell bioactivity and promote osteoblast adhesion. Currently, the raw materials most frequently used in the manufacture of dental implants are titanium, its alloys, and certain ceramic materials such as zirconia. Multiple macroscopic designs incorporating various diameters, lengths, shapes, and types of screw offer different options for specific clinical situations. The characteristics of implant surfaces have aroused great interest, due to their importance in osseointegration. The different methods used to modify surface properties are classified as additive (i.e., impregnation and coating) or subtractive (i.e., physical, mechanical and chemical methods). The surface characteristics of dental implants also have a significant influence on peri-implant microbiota.
\end{abstract}

Keywords: Dental implant, Titanium, Osseointegration, Surface roughness, Coating, Peri-implantitis

\section{Introduction}

Over many years, dental implants have been developed and modified in order to achieve an optimal interaction between the body and the implanted material and thus to improve osseointegration and reduce the complications due to colonization of bacterial plaque [1]. 
Proper integration of the surface of a dental implant with the surrounding bone is essential to ensure the longevity and function of the prosthesis supported by the implant [2]. The cell adhesion between the bone interface and the implant surface is considered the most biologically important stage in the process. This structural and functional integration is influenced by the activity of adjacent cells and by the properties of the implant surface itself.

Some implant surfaces may influence the differentiation and proliferation of osteoblasts and may affect the regulation of the transcription factors responsible for the expression of the genes associated with the formation of the bone matrix. Their use may even shorten the implant integration period [3].

The treatment of a surface can be classified according to mechanical, chemical, and physical processes. In dental implants, the modifications of the outer surface are designed to modify the topography and surface energy. This improves wettability and increases cell growth and proliferation, which eventually accelerates the process of osseointegration [4-7].

The biocompatibility and roughness of the materials are the key features in the interaction between the tissue and osseointegration [8]. In addition, the surface of dental implants can be significantly increased using suitable modification procedures such as additive or subtractive techniques $[9,10]$.

\section{Biomaterials for dental implants}

Currently, the main materials used in the composition of dental implants are commercially pure titanium (cp Ti), Ti alloys, and ceramic compounds.

\subsection{Alloys}

Titanium (Ti) is a silver-gray, biologically inert transition metal with a high corrosion resistance due to the spontaneous formation of a surface oxide film (3-10 nm thick) which insulates it from the environment [11, 12]. Thanks to its composition and thickness, this oxide layer makes Ti biocompatible. Ti has four grades of purity which are related to the corrosion resistance, ductility, and strength. Grade $1 \mathrm{Ti}$ is the purest and most ductile and has the highest corrosion resistance, but it is also the weakest. Grade $4 \mathrm{Ti}$ is the strongest and has moderate plasticity and is therefore the grade most frequently used in dental implants [13].

Titanium alloys. Manufacturers of dental implants use a specifically designed alloy which has the following composition: $6 \%$ aluminum, $4 \%$ vanadium, up to $0.25 \%$ iron, up to $0.2 \%$ oxygen, and $90 \% \mathrm{Ti}[14]$. This alloy has a greater corrosion resistance, high resistance to fatigue, and low elastic modulus [11]. Due to the strict mechanical demands on dental implants during chewing, especially in the posterior areas, $\mathrm{Ti}$ alloys are preferred to $\mathrm{cp}$ Ti [2]. 


\subsection{Ceramic compounds}

Zirconia is a highly biocompatible ceramic compound with osseointegration capacity $[15,16]$. It possesses ideal physical properties as a biomaterial, with good values of resistance to flexion, hardness, and corrosion resistance. Some authors have reported that zirconia has similar biocompatibility and osseointegration values to $\mathrm{Ti}$ [17]. However, other comparisons of the two biomaterials have reported lower osseointegration values for zirconia implants and have attributed these differences to the treatment of the surfaces rather than to the material itself [18].

Zirconia implants, as a substitute for metals, are indicated in the restoration of anterior teeth with aesthetic aims. However, more prospective studies of their survival and long-term stability are required; indeed, some authors still recommend caution with regard to considering zirconia implants [19].

Hydroxyapatite (HA) is a bioceramic used as a surface coating on Ti implants, incorporating calcium phosphates to facilitate prompt osseointegration. HA has excellent biocompatibility, osseoconductive capacity, and satisfactory mechanical properties which make it a good surface biomaterial [20].

Implants with HA coating have demonstrated a faster reduction in early mobility and other potential advantages such as its short-term osseoconductive capacity. However, the rate of long-term survival of these implants is still controversial [21-25].

\section{Macro-design of dental implants}

The macro-design of dental implants determines their stability and their capacity to withstand the functional loads. The length, diameter, shape, and design of the screw are influential factors in the bone-implant interface. In the long term, these features may even determine the implant's survival.

\subsection{Implant length}

Implant length is the distance from the prosthetic platform to the apex of the implant. Some authors have reported a lower survival rate for short implants, especially those $<7 \mathrm{~mm}$ long $[26,27]$. Eckert et al. [28], however, noted that the relation between implant length and survival was limited and was only noticeable when implants were $<13 \mathrm{~mm}$ in length.

The type of bone and the cortical bone anchoring are probably more important factors than the implant length. Nonetheless, the indications of implants with extra short lengths $(5-6 \mathrm{~mm})$ should be carefully studied and considered, especially in areas with poor bone quality. Manufacturers are making great efforts to improve these implant surfaces so as to increase the area in contact with the bone and thus improve their prognosis [29, 30]. 


\subsection{Implant diameter}

The implant diameter is the distance from the outermost point of the screw to the opposite side. It measures the external dimension of the implant screw and should not be confused with the size of the implant platform.

Implant diameters usually range from 3 to $7 \mathrm{~mm}$ to make them compatible with the most sizes of alveolar processes. The choice of diameter depends on both surgical and prosthetic factors. In order to achieve maximum primary stability, the implant should be lodged between the vestibular-lingual/palatal cortical bones. From a biomechanical point of view, wider implants are able to join a larger amount of bone to the implant surface and obtain a higher bicortical anchorage, thus achieving a better distribution of stress in the surrounding bone. Another advantage of large diameter implants is that they can be inserted immediately in failure sites [31-33]. Some authors have found that increasing implant diameter by $1 \mathrm{~mm}$ increases the surface of bone-implant contact by 35\% [34]. However, another parameter to consider is the crestal bone around the implant. According to Misch [35], this bone has a strong influence on the occlusal load; this author hypothesizes that it may be even more important than the length and diameter of the implant itself.

The primary stability of dental implants at the time of surgery has been considered an important factor for integration [36]. Langer et al. recommended large diameter implants to improve primary stability in low-density bones. The authors argue that increasing the diameter increases the bone-implant contact, thereby reducing initial implant mobility [37].

Small diameter implants have been introduced for narrow residual alveolar ridges and for edentulous spaces with small interdental distances. These implants do not include miniimplants, which are used to hold temporary dentures and have diameters $<2.7 \mathrm{~mm}$ [38]. The main indications for narrow implants are the lower incisors, upper lateral incisors, and the restoration of teeth with residual spaces smaller than $5 \mathrm{~mm}$ without any possibility of space recovery or bone regeneration [39]. The main limitation of these implants is their reduced resistance to occlusal loads [40].

\subsection{Implant shape}

Shape has been one of the most thoroughly studied aspects of implant design. The most current implant systems are solid cylinders with thread; hollow implants are rare today. As for the design of the thread, attempts have been made to increase their self-threading capacity and to reduce heat generation during implantation. These design variations are most often applied in the crestal and apical areas. Some designs have attempted to imitate the natural root with a stepped cylindrical shape in the apical and crestal third of the implant. Some authors note that stepped cylindrical implants achieve better stress distribution and crestal bone load than conical and cylindrical implants [41].

Kan et al. [42] reported that threaded implants provide the best immediate retention. Other studies show that the use of a serrated thread can increase primary stability and that thread geometry plays an important role in the biomechanical properties of the implants [43,44]. 


\section{Dental implant surface treatments}

Currently, the most manufacturers of dental implants are introducing changes in implant surfaces in order to improve the success and quality of osseointegration.

Some studies have noted that with greater surface roughness, the rate of osseointegration, and the biomechanical fixation of Ti implants both increase $[45,46]$. The methods used to modify the surface properties can be divided into additive and subtractive. Before certain surface treatments, pretreatment such as grit blasting or polishing may sometimes be indicated to guarantee the absence of contaminations, scratches, and irregularities [47, 48].

\subsection{Additive methods}

Additive methods supply extra materials to the implant surface, either via coating or via impregnation. Coating involves the addition of a material of variable thickness to the surface of the core material. The techniques used are Ti plasma spraying (TPS), plasma-sprayed HA coating, alumina coating, and biomimetic calcium phosphate $(\mathrm{CaP})$. For its part, impregnation requires the full integration of the chemical material or agent into the Ti core. This is the case of $\mathrm{CaP}$ crystals within the $\mathrm{TiO}_{2}$ oxide layer or the incorporation of fluoride ions to the surface [8].

Plasma Spray Coating: The coating process includes the spraying of thermally melted materials on the implant substrates [8]. This technique usually involves a fine layer of deposits such as $\mathrm{HA}$ and Ti. The combination of HA coating on Ti alloy substrates offers attractive mechanical properties and good biocompatibility [49]. Plasma spray significantly increases the surface area of the implant by increasing its roughness [50]. Thus, many studies have shown that plasma spray is a good additive method for improving the biomechanical behavior [47, 5155]. Some studies have even described a possible optimization of scar formation and cell proliferation thanks to HA coating $[56,57]$.

\subsection{Subtractive methods}

Subtractive techniques are procedures that remove a layer of core material or deform the surface in order to increase its roughness [58]. These methods can be divided into mechanical, chemical, and physical. Removal of surface material using mechanical methods includes shaping/ removing, grinding, machining, or grit blasting using physical force. Chemical treatment of Ti alloys using either alkaline or acid solutions is carried out not only to increase the roughness but also to modify the composition and improve the wettability and surface energy [59]. Complementary physical treatment of the coating surface, such as thermal spray and plasma spray, improves the aesthetic appearance of the materials and their performance [8].

Grit blasting is a mechanical subtractive procedure which increases surface roughness by the pressurized projection of particles onto the surface of the implant. The main materials used are sand, $\mathrm{HA}$, alumina, or $\mathrm{TiO}_{2}$ particles. After grit blasting, acid etching is applied to remove the residual particles. Grit blasting is one of the most commonly used surface treatments for 
increasing the surface roughness of dental implants. However, in itself, it does not accelerate the osseointegration capacity [8, 60] (Figure 1A).
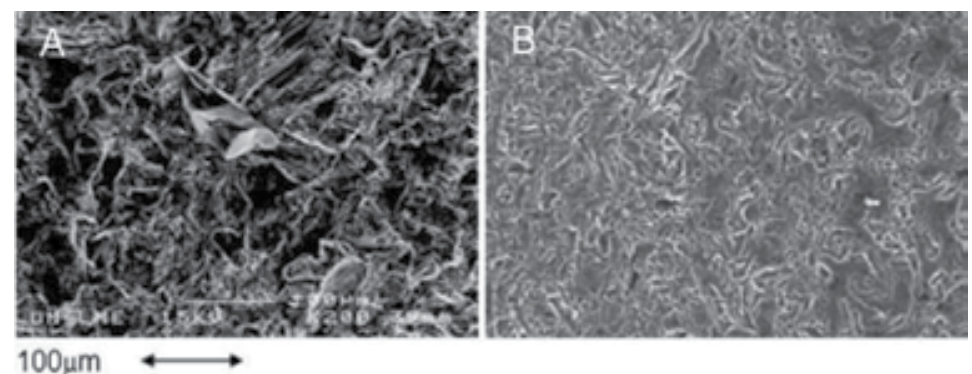

Figure 1. Environmental scanning electron microscope micrograph (ESEM) of the surface of dental implants: (A) shotblasted; (B) acid etched [66].

Aparicio et al. [61] observed that the increase in the surface roughness of the material induced by blasting in cp Ti was not the only cause of the differences in the electrochemical behavior and corrosion resistance; they also mentioned the compressive residual surface stresses induced by shotblasting.

Commercially, pure Ti is a bioinert material which lacks the ability to establish chemical bonds with surrounding bone. Kokubo et al. [62] demonstrated that the treatment of this Ti with heat and alkali procedures rendered it bioactive. Aparicio et al. [63] observed that the surface of the implant achieved by grit blasting and thermo-chemical treatment improved adhesion and differentiation of human osteoblasts. Gil et al. [64] also observed positive results for this bioactive $\mathrm{Ti}$, although improvements are necessary in order to prevent bacterial colonization. It is important to bear in mind that bacteria have a greater capacity to colonize rough surfaces [8] (Figure 2).

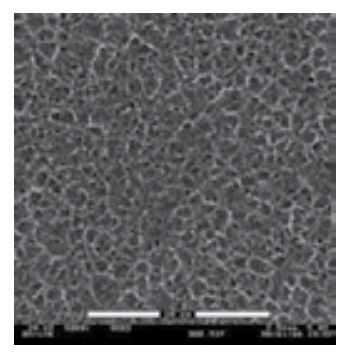

Figure 2. ESEM micrograph of the sodium titanate surface of the implants treated by shotblasting and thermochemical treatment (two-step treatment) [66].

Some researchers have found that the apatite layers formed on grit-blasted surfaces have a higher adhesion strength to the substrate than plasma-sprayed apatite coatings. They note the potential clinical application of this type of surface treatment in dental implants [65]. 
The evolution of bioactive surfaces into osseoconductive biomimetic surfaces (Contact Ti) was described by Gil et al. In this process, a CaP layer is obtained on the implant surface by thermochemical treatments. This achieves a structure equal to the $\mathrm{CaP}$ formed by the mineral content of the bone (HA). This apatite should not be confused with an additive coating; in this case, there is an extremely strong chemical bond and so it is not dislodged by mechanical action. These bioactive implant surfaces significantly reduce the time of osseointegration. The most important mechanisms involved are the protein adsorption capacity, wettability, and an optimized zeta potential which reduces the electrostatic dispersion between particles. Finally, this procedure also aims to increase the kinetics of adhesion, proliferation, and differentiation of osteoblast cells compared to other current surface treatments in order to facilitate bone formation around the implants [66-68] (Figure 3).

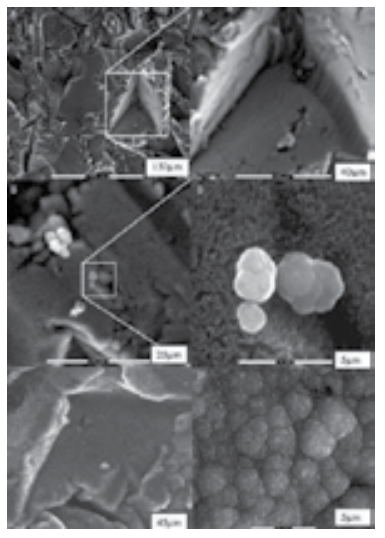

Figure 3. ESEM images showing: (A) $2 S$ bioactive surface; (B) in vitro nucleation of apatite on $2 \mathrm{~S}$ bioactive surface; (C) in vitro formed apatite layer on $2 \mathrm{~S}$ bioactive surface; (D) $2 \mathrm{~S}$ bioactive surface at higher magnification [67].

Anodic oxidation is an electrolytic process used to strengthen and increase the thickness of the natural oxide layer. This passivation technique manages to turn a smooth Ti surface into a tubular nanostructure with diameters below $100 \mathrm{~nm}$ [69]. Some authors suggest that by modifying the parameters of voltage, current density, and chemistry of electrolytes, it is possible to control the physical and chemical properties of the implant surfaces, the spacing, and the diameter of nanotubes [70]. Anodization forms pillar-like nanostructures with tunable size on the surface of $\mathrm{Ti}$ and deposits long nanotube arrays (10 microns), thus improving the cell bioactivity [71].

Acid treatment is a chemical subtractive method that cleans the surface of the metal and modifies its roughness. Hydrofluoric acid $(\mathrm{HF})$, nitric acid $\left(\mathrm{HNO}_{3}\right)$, and sulfuric acid $\left(\mathrm{H}_{2} \mathrm{SO}_{4}\right)$ are commonly used, either alone or in combination [8]. This technique obtains a homogeneous surface roughness for different sizes and shapes. The acid-etched surfaces facilitate the process of osseointegration by increasing the capacity of cell adhesion and bone formation [72-74]. Furthermore, the surface roughness of Ti also determines the stability of the bone formation and resorption at the interface with the implant [75]. The dual acid etching treats the surface 
by chemical means or by acids applied sequentially or in combination [76, 77]. This technique achieves a surface with micro-roughness, which some authors associate with higher values of reverse removal torque than machined surface implants [78] (Figure 1B).

Alkali treatment is a procedure in which the Ti implant is immersed in either potassium or sodium hydroxide followed by heat treatment $\left(800^{\circ} \mathrm{C}\right.$ for $\left.20 \mathrm{~min}\right)$ and subsequent rinsing with distilled water. This technique achieves a nanostructured and bioactive sodium titanate layer on the surface of the dental implant, which provides favorable conditions for bone marrow cell differentiation [69]. The thermal oxidation works by changing the crystal structure of the nanometric oxide layer and thus increases the bioactivity of a biocompatible metal [79].

Sandblast, large grit, and acid etching (SLA) applies a strong acid on the blasted surface for the purposes of abrasion. The procedure starts with large particle blasting, which obtains a rough, irregular surface. Then, the acid etching produces surface uniformity and obtains a macroroughness and micro-pits which are able to improve osseointegration. Kim et al. [80] observed that human osteoblasts grow well on the SLA surface which provides space for cell adhesion and proliferation.

\subsection{Other techniques}

Other procedures such as ion implantation, laser treatment, sputtering, and the combination of some of the techniques already mentioned have also been studied in order to improve the surface properties of dental implants [81-84].

Ion implantation causes atomic rearrangement. It permits the injection of any element on a nearby surface with a beam of high-energy ions $(10 \mathrm{KeV})$ which impacts on the surface of the metal in a vacuum chamber. On colliding with the ions of the substrate material, the incident ions lose energy and settle on the surface of the nearby metal. This technique is considered an ultra clean process because the concentration and depth of the impurities are easy to control, allowing the creation of a layer of high purity. Furthermore, the adhesion between the implanted surface and the substrate is excellent; the process does not alter the properties of the core and is highly reproducible and controllable [85]. However, some authors warn that the possible modification of the nanoscale features and the creation of stress on the Ti surface should be taken into consideration $[86,87]$.

Ultraviolet (UV) photo-functionalization is one of the recent advances in the chemical modification of implant surfaces which does not alter the bioactive properties.

Laser technology is an extremely clean, fast, and accurate method which allows nanostructural micromachining at the implant surface [88]. Laser peening involves striking the metal with high-intensity pulses of a laser light beam which produces a deep, regular honeycomb pattern with small pores [2].

The slow rate sputter deposition method achieves a thin layer of Ti oxide ( $300 \mathrm{pm}-6.3 \mathrm{~nm})$. This technique increases the oxygen components without altering the surface topography. These biological activities are correlated with the thickness of the $\mathrm{TiO}_{2}$ coating and the oxygen 
saturation of the surface. This means that the biological response of Ti can be improved even with picometer super thin coatings [69].

\section{Peri-implantitis related to dental implant surfaces}

Peri-implantitis is an infectious disease of an already integrated dental implant that causes inflammation of the surrounding hard and soft tissue, leading to the loss of supporting bone (Figure 4 and 5). The sequence of microbial colonization on dental implants and biofilm formation is similar to that of teeth. The bacteria that colonize dental implants include the same species as those present in healthy gums and in locations with gingivitis [89-91]. Several in vivo studies show that streptococci and Actinomyces species predominate in the initial colonization; their presence prepares the environment for colonization by other species such as Porphyromonas, Prevotella, Capnocytophaga, and Fusobacterium which cause the peri-implantitis [91] (Table 1).

Figure 4. Intraoral radiograph taken 8 years after implant placement-sandblasted, large-grit and acid etched (SLA) surface treatment type. Note the bone crater-like defect around the implant revealing a severe peri-implantitis (Clinical records, Dr. Jaume Miranda-Rius).

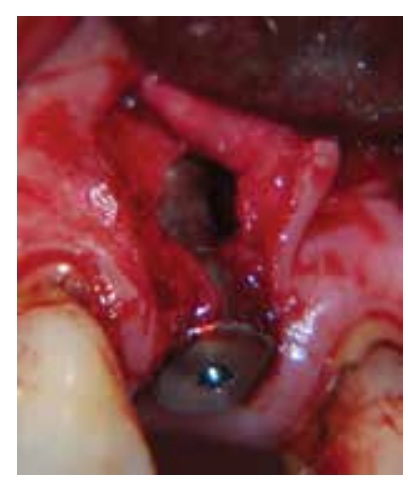

Figure 5. Peri-implantitis clinical image. Surgical debridement of the granulation tissue around the implant (Clinical records, Dr. Jaume Miranda-Rius). 
Streptococcus sanguis

Streptococcus mitis

Aggregatibacter actonimycemetcomitans

Porphyromonas gingivalis

Prevotella intermedia

Tannerella forsythia

Treponema denticola
Capnocytophaga spp.

Campylobacter rectus

Spirochetes

Veillonella parvula

Staphylococcus aureus

Fusobacterium spp.

Peptostreptococcus prevoti

Table 1. List of bacterial species associated to dental implant biofilm.

The surface characteristics of dental implants - roughness, wettability, surface free energy, and composition - play a crucial role in bacterial adhesion and colonization. The highest adhesion capacity is observed on rough Ti surfaces. Some authors have observed that mean roughness values below 0.088 microns significantly inhibit plaque adhesion and maturation [92]. Furthermore, decreasing the wettability of dental implants favors bacterial colonization. Some authors suggest that autoclave-sterilized Ti presents a higher rate of bacterial colonization, given the loss of surface wettability (Figure 5).

Surface free energy is the sum of the forces of cohesion and adhesion that determine whether or not there is impregnation (the dispersion of the liquid over a surface). Decreasing surface free energy inhibits bacterial adhesion and biofilm formation on the surface of dental implants and abutments [93]. Thus, bacterial adherence is correlated with the presence of surface components with nonpolar or hydrophobic characteristics [93-95]. Finally, the type of metal and its composition also has an effect on bacterial adhesion and biofilm formation on its surface. Pure metals, especially Ti, nickel, iron, and vanadium, have some bacteriostatic capacity [96].

Some authors have concluded that $\mathrm{ZnO}$ and $\mathrm{TiO}_{2}$ reduce the adhesion of staphylococcal bacteria and increase the adhesion of osteoblasts [97]. The addition of silver compounds to increase antimicrobial action has also been studied [98]. Other authors have analyzed the behavior of Ti surfaces modified with vancomycin attached via covalent bonds and have reported a stable surface with a greater inhibition of bacterial adhesion than with Ti alone [99].

\section{Conclusion}

In this chapter, we have highlighted the important role of the macro- and micro-design of implants and their composition in the process of osseointegration. We have also stressed the significant influence of the surface characteristics of implants on the peri-implant microbiota. All in all, peri-implantitis is an important area for future research. It is extremely difficult to control the progress of an infection once it is established around an implant. The rough surfaces facilitate osseointegration, but also favor the adhesion of oral biofilm. Because of the multifactorial nature of infectious peri-implant complications, studies should also take into account 
the influence of the permucosal seal. This biological seal aims to integration the neck of the implant or the abutment with the gingival tissue and thus prevent peri-implant infections. Currently, the challenge in the treatment of implant surfaces is to demonstrate the potential of certain coatings for releasing local antimicrobial agents. Given the clear increase in inflammatory peri-implant diseases, we believe that future research should aim to devise new strategies for obtaining antibacterial biomaterials that can help in the prevention or treatment of peri-implantitis.

\section{Author details}

Jaume Miranda-Rius ${ }^{1 *}$, Eduard Lahor-Soler ${ }^{1}$, Lluís Brunet-Llobet ${ }^{2}$, David de Dios ${ }^{3}$ and Francesc Xavier Gil ${ }^{4}$

*Address all correspondence to: jmiranda-rius@ub.edu

1 Dental and Oral Department, Faculty of Medicine and Health Sciences, University of Barcelona, Barcelona, Spain

2 Division of Orthodontics and Paediatric Dentistry, Hospital Sant Joan de Déu, University of Barcelona, Barcelona, Spain

3 Health Sciences Program, Autonomous University of Barcelona, Barcelona, Spain

4 Material Sciences Department, Bioengineering Research Center, Polytechnic University of Catalonia, Barcelona, Spain

\section{References}

[1] Ananth H, Kundapur V, Mohammed HS, Anand M, Amarnath GS, Mankar S. A review on biomaterials in dental implantology. Int J Biomed Sci. 2015; 11(3): 113-120.

[2] Ogle OE. Implant surface material, design, and osseointegration. Dent Clin N Am. 2015; 59(2): 505-20. doi:10.1016/j.cden.2014.12.003

[3] Cochran DL, Buser D, ten Bruggenkate CM, et al. The use of reduced healing times on ITI implants with a sandblasted and acid-etched (SLA) surface: early results from clinical trials on ITI SLA implants. Clin Oral Implants Res. 2002; 13(2): 144-153. doi: 10.1034/j.1600-0501.2002.130204.x

[4] Rosales-Leal JI, Rodríguez-Valverde MA, Mazzaglia G, et al. Effect of roughness, wettability and morphology of engineered titanium surfaces on osteoblast-like cell adhesion. Colloids Surf A Physicochem Eng Asp. 2010; 365(1-3): 222-229. doi:10.1016/ j.colsurfa.2009.12.017 
[5] Nakae H, Yoshida M, Yokota M. Effects of roughness pitch of surfaces on their wettability. J Mater Sci. 2005; 40(9-10): 2287-2293.

[6] Ponsonnet L, Reybier K, Jaffrezic N, et al. Relationship between surface properties (roughness, wettability) of titanium and titanium alloys and cell behaviour. Mater Sci Eng C. 2003; 23(4): 551-560. doi:10.1016/S0928-4931(03)00033-X

[7] Sollazo V, Pezzetti F, Scarano A, et al. Zirconium oxide coating improves implant osseointegration in vivo. Dent Mater. 2008; 24(3): 357-361. doi:10.1016/j.dental. 2007.06.003

[8] Jemat A, Ghizali MJ, Razali M, Otsuka Y. Surface modifications and their effects on titanium dental implants. Biomed Res Int. 2015; 2015: 791725. doi:10.1155/2015/791725

[9] Lacefield WR. Materials characteristics of uncoated/ceramic coated implant materials. Adv Dent Res. 1999; 13: 21-26. doi:10.1177/08959374990130011001

[10] Ozcan M, Hammerle C. Titanium as a reconstruction and implant material in dentistry: advantages and pitfalls. Materials. 2012; 5(9): 1528-1545. doi:10.3390/ma5091528

[11] Jacobs JJ, Gilbert JL, Urban RM. Current concepts review: corrosion of metal orthopaedic implants. J Bone Jt Surg Am. 1998; 80A: 268-282.

[12] Neoh KG, Hu X, Zheng D, et al. Balancing osteoblast functions and bacterial adhesion on functionalized titanium surfaces. Biomaterials. 2012; 33: 2813-2822. doi:10.1016/ j.biomaterials.2012.01.018

[13] Steinemann S. Titanium - the material of choice? Periodontology. 2000, 1998; 17(1): 721. doi:10.1111/j.1600-0757.1998.tb00119.x

[14] ASM Material Data Sheet. Available at: http://asm.matweb.com/search/SpecificMaterial.asp?bassnum5MTP642. Accessed December 2015.

[15] Delgado-Ruiz RA, Calvo-Guirado JL, Abboud M, et al. Histologic and histomorphometric behavior of microgrooved zirconia dental implants with immediate loading. Clin Implant Dent Relat Res. 2013; 16(6): 856-872. doi:10.1111/cid.12069

[16] Koch FP, Weng D, Krämer S, et al. Osseointegration of one-piece zirconia implants compared with a titanium implant of identical design: a histomorphometric study in the dog. Clin Oral Implants Res. 2010; 21(3): 350-356. doi:10.1111/j. 1600-0501.2009.01832.x

[17] Moller B, Terheyden H, Acil Y, et al. A comparison of biocompatibility and osseointegration of ceramic and titanium implants: an in vivo and in vitro study. Int J Oral Maxillofac Surg. 2012; 41(5): 638-645. doi:10.1016/j.ijom.2012.02.004

[18] Assal PA. The osseointegration of zirconia dental implants. Schweiz Monatsschr. Zahnmed. 2013; 123(7-8): 644-654. 
[19] Wennerberg A, Albrektsson T. On implant surfaces: a review of the current knowledge and opinions. Int J Oral Maxillofac Implants. 2010; 25(1): 63-74.

[20] Strnad Z, Strnad J, Povysil C, et al. Effect of plasma-sprayed hydroxyapatite coating on the osteoconductivity of commercially pure titanium implants. Int J Oral Maxillofac Implants. 2000; 15(4): 483-490.

[21] Geurs NC, Jeffcoat RL, McGlumphy EA, Reddy MS, Jeffcoat MK. Influence of implant geometry and surface characteristics on progressive osseointegration. Int J Oral Maxillofac Implants. 2002; 17(6): 811-815.

[22] Faeda RS, Tavares HS, Sartori R, Guastaldi AC, Marcantonio EJR. Biological performance of chemical hydroxyapatite coating associated with implant surface modification by laser beam: biomechanical study in rabbit tibias. J Oral Maxillofac Surg. 2009; 67: 1706-1715. doi:10.1016/j.joms.2009.03.046

[23] Gottlander M, Johansson CB, Albrektsson T. Short and long-term animal studies with a plasma-sprayed calcium phosphate-coated implant. Clin Oral Implants Res. 1997; 8(5): 345-351.

[24] Jones JD, Saigusa M, Van Sickels JE, Tiner BD, Gardner WA. Clinical evaluation of hydroxyapatite-coated titanium plasma-sprayed and titanium plasma-sprayed cylinder dental implants: a preliminary report. Oral Surg Oral Med Oral Pathol Oral Radiol Endodontol. 1997; 84(2): 137-141. doi:10.1016/S1079-2104(97)90058-5

[25] Zhou W, Liu Z, Xu S, Hao P, Xu F, Sun A. Long-term survivability of hydroxyapatitecoated implants: a meta-analysis. Oral Surg. 2011; 4(1): 2-7. doi:10.1111/j.1752-248X. 2010.01112.x

[26] Winkler S, Morris HF, Ochi S. Implant survival to 36 months as related to length and diameter. Ann Periodontol. 2000; 5(1): 22-31.

[27] Wyatt CC, Zarb GA. Treatment outcomes of patients with implant supported fixed partial prostheses. Int J Oral Maxillofac Implants. 1998; 13(2): 204-211.

[28] Eckert SE, Koka S, Wolfinger G, Choi YG. Survey of implant experience by prosthodontists in the United States. J Prosthodont. 2002; 11(3): 194-201. doi:10.1053/jopr. 2002.127768

[29] Geng JP, Tan KB, Liu GR. Application of finite element analysis in implant dentistry: a review of the literature. J Prosthet Dent. 2001; 85(6): 585-598. doi:10.1067/mpr. 2001.115251

[30] Nedir R, Bischof M, Briaux JM, Beyer S, Szmukler-Moncler S, Bernard JP. A 7-year life table analysis from a prospective study on ITI implants with special emphasis on the use of short implants. Results from a private practice. Clin Oral Implants Res. 2004; 15(2): 150-157. doi:10.1111/j.1600-0501.2004.00978.x 
[31] Ivanoff CJ, Sennerby L, Johansson C, Rangert B, Lekholm U. Influence of implant diameters on the integration of screw implants. An experimental study in rabbits. Int J Oral Maxillofac Surg. 1997; 26(2): 141-148. doi:10.1016/S0901-5027(05)80837-9

[32] Mahon JM, Norling BK, Phoenix RD. Effect of varying fixture width on stress and strain distribution associated with an implant stack system. Implant Dent. 2000; 9(4):310-320.

[33] Ettinger RL, Spivey JD, Han DH, Koorbusch GF. Measurement of the interface between bone and immediate endosseous implants: a pilot study in dogs. Int J Oral Maxillofac Implants. 1993; 8(4): 420-427.

[34] Misch CE. Contemporary implant dentistry. St. Louis: Elsevier. 3rd ed. 1999. ISBN: 978-0-323-04373-1.

[35] Misch CE. Implant design considerations for the posterior regions of the mouth. Implant Dent. 1999; 8(4): 376-386.

[36] Kohn DH. Overview of factors important in implant design. J Oral Implantol. 1992; 18(3): 204-219.

[37] Langer B, Langer L, Herrmann I, Jorneus L. The wide fixture: a solution for special bone situations and a rescue for the compromised implant. Part 1. Int J Oral Maxillofac Implants. 1993; 8(4): 400-408.

[38] Kanie T, Nagata M, Ban S. Comparison of the mechanical properties of 2 prosthetic mini-implants. Implant Dent. 2004; 13(3): 251-256.

[39] Vigolo P, Givani A. Clinical evaluation of single-tooth mini-implant restoration: a fiveyear retrospective study. J Prosthet Dent. 2000; 84: 50-54. doi:10.1067/mpr.2000.107674

[40] Himmlova L, Dostalova T, Kacovsky A, Konvickova S. Influence of implant length and diameter on stress distribution: a finite element analysis. J Prosthet Dent. 2004; 91(1): 20-25. doi:10.1016/j.prosdent.2003.08.008

[41] Holmgren EP, Seckinger RJ, Kilgren LM, Mante F. Evaluating parameters of osseointegrated dental implants using finite element analysis - a two dimensional comparative study examining the effects of implant diameter, implant shape, and load direction. J Oral Implantol. 1998; 24(2): 80-88.

[42] Kan JY, Rungcharassaeng K, Kim J, Lozada JL, Goodacre CJ. Factors affecting the survival of implants placed in grafted maxillary sinuses: a clinical report. J Prosthet Dent. 2002; 87(5): 485-489. doi:10.1067/mpr.2002.124202

[43] Hansson S, Werke M. The implant thread as a retention element in cortical bone: the effect of thread size and thread profile: a finite element study. J Biomech. 2003; 36(2): 1247-1258. doi:10.1016/S0021-9290(03)00164-7

[44] Lin S, Shi S, LeGeros RZ, LeGeros JP. Three-dimensional finite element analyses of four designs of a high-strength silicon nitride implant. Implant Dent. 2000; 9(1): 53-60. 
[45] Cochran DL, Schenk RK, Lussi A, Higginbottom FL, Buser D. Bone response to unloaded and loaded titanium implants with a sandblasted and acid-etched surface: a histometric study in the canine mandible. J Biomed Mater Res. 1998; 40(1): 1-11.

[46] Wennerberg A, Hallgren C, Johansson C, Danelli S. A histomorphometric evaluation of screw-shaped implants each prepared with two surface roughnesses. Clin Oral Implants Res. 1998; 9(1): 11-19. doi:10.1034/j.1600-0501.1998.090102.x

[47] Gu YW, Khor KA, Pan D, Cheang P. Activity of plasma sprayed yttria stabilized zirconia reinforced hydroxyapatite/Ti6-Al-4V composite coatings in simulated body fluid. Biomaterials. 2004; 25(16): 3177-3185. doi:10.1016/j.biomaterials.2003.09.101

[48] Ferraris S, Spriano S, Pan G, et al. Surface modification of Ti-6Al-4V alloy for biomineralization and specific biological response: part I, inorganic modification. J Mater Sci Mater Med. 2001; 22(3): 533-545. doi:10.1007/s10856-011-4246-2

[49] Simmons CA, Valiquette N, Pilliar RM. Osseointegration of sintered porous-surfaced and plasma spray-coated implants: an animalmodel study of early postimplantation healing response and mechanical stability. J Biomed Mater Res. 1999; 47(2): 127-138.

[50] Ong JL, Chan DCN. Hydroxyapatite and their use as coatings in dental implants: a review. Crit Rev Biomed Eng. 2000; 28(5-6): 667-707. doi:10.1615/CritRevBiomedEng.v28.i56.10

[51] Knabe C, Klar F, Fitzner R, Radlanski RJ, Gross U. In vitro investigation of titanium and hydroxyapatite dental implant surfaces using a rat bone marrow stromal cell culture system. Biomaterials. 2002; 23(15): 3235-3245. doi:10.1016/ S0142-9612(02)00078-9

[52] Hung KY, Lo SC, Shih CS, Yang YC, Feng HP, Lin YC. Titanium surface modified by hydroxyapatite coating for dental implants. Surf Coat Technol. 2013; 231: 337-345. doi: 10.1016/j.surfcoat.2012.03.037

[53] Eom TG, Jeon GR, Jeongetal CM. Experimental study of bone response to hydroxyapatite coating implants: bone implant contact and removal torque test. Oral Surg Oral Med Oral Pathol Oral Radiol. 2012; 114(4): 411-418. doi:10.1016/j.oooo.2011.10.036

[54] Ochsenbein A, Chai F, Winter S, Traisnel M, Breme M, Hildebrand HF. Osteoblast responses to different oxide coatings produced by the sol-gel process on titanium substrates. Acta Biomater. 2008; 4(5): 1506-1517. doi:10.1016/j.actbio.2008.03.012

[55] Braceras I, Alava JI, Oñate JI, et al. Improved osseointegration in ion implantationtreated dental implants. Surf Coat Technol. 2002; 158-159: 28-32. doi:10.1016/ S0257-8972(02)00203-7

[56] Fouda MFA, Nemat A, Gawish A, Baiuomy AR. Does the coating of titanium implants by hydroxyapatite affect the elaboration of free radicals. An experimental study. Aust J Basic Appl Sci. 2009; 3: 1122-1129. 
[57] Xie Y, Liu X, Zheng X, Ding C, Chu PK. Improved stability of plasma-sprayed dicalcium silicate/zirconia composite coating. Thin Solid Films. 2006; 515(3): 1214-1218. doi: 10.1016/j.tsf.2006.07.124

[58] Le Guéhennec L, Soueidan A, Layrolle P, Amouriq Y. Surface treatments of titanium dental implants for rapid osseointegration. Dent Mater. 2007; 23(7): 844-854. doi: 10.1016/j.dental.2006.06.025

[59] Liu X, Chu PK, Ding C. Surface modification of titanium, titanium alloys, and related materials for biomedical applications. Mater Sci Eng R Rep. 2004; 47(3-4): 49-121. doi: 10.1016/j.mser.2004.11.001

[60] Jones FH. Teeth and bones: applications of surface science to dental materials and related biomaterials. Surf Sci Rep. 2001; 42(3-5): 75-205. doi:10.1016/ S0167-5729(00)00011-X

[61] Aparicio C, Gil FJ, Fonseca C, Barbosa M, Planell JA. Corrosion behaviour of commercially pure titanium shot blasted with different materials and sizes of shot particles for dental implant applications. Biomaterials. 2003; 24(2): 263-273. doi:10.1016/ S0142-9612(02)00314-9

[62] Kokubo T, Miyaji F, Kim HM, Nakamura T. Spontaneous formation of bonelike apatite layer on chemically treated titanium metals. J Am Ceram Soc. 1996; 79(4): 1127-1129. doi:10.1111/j.1151-2916.1996.tb08561.x

[63] Aparicio C, Gil FJ, Planell JA. Human-osteoblast proliferation and differentiation on grit-blasted and bioactive titanium for dental applications. J Mater Sci Mater Med. 2002; 13(12): 1105-1111.

[64] Gil FJ, Padrós A, Manero JM, Aparicio C, Nilsson M, Planell JA. Growth of bioactive surfaces on titanium and its alloys for orthopaedic and dental implants. Mater Sci Eng C. 2002; 22(1): 53-60. doi:10.1016/S0928-4931(01)00389-7

[65] Aparicio C, Rodriguez D, Gil FJ. Variation of roughness and adhesion strength of deposited apatite layers on titanium dental implants. Mater Sci Eng C. 2011;31(2): 320324. doi:10.1016/j.msec.2010.09.018

[66] Gil FJ, Manzanares N, Badet A, Aparicio C. Biomimetic treatment on dental implants for short-term bone regeneration. Clin Oral Investig. 2014; 18(1): 59-66. doi:10.1007/ s00784-013-0953-z

[67] Gil FJ, Espinar E, Llamas JM, Sevilla P. Fatigue live of bioactive titanium dental implants treated by means of grit-blasting and thermo-chemical treatment. Clin Implant Dent Res. 2014; 16(2): 273-281. doi:10.1111/j.1708-8208.2012.00468.x

[68] Albertini M, Fernández-Yague M, Lázaro P, Herrero-Climent, et al. Advances in surfaces and osseointegration in implantology. Biomimetic surfaces. Med Oral Patol Oral Cir Bucal. 2015; 20(3): 316-325. 
[69] Pachauri P, Bathala LR, Sangur R. Techniques for dental implant nanosurface modifications. J Adv Prosthodont. 2014; 6(6): 498-504. doi:10.4317/medoral.20353

[70] Park J, Bauer S, Schlegel KA, Neukam FW, von der Mark K, Schmuki P. TiO ${ }_{2}$ nanotube surfaces: $15 \mathrm{~nm}$-an optimal length scale of surface topography for cell adhesion and differentiation. Small. 2009; 5: 666-671. doi:10.1002/smll.200801476

[71] Sjöström T, Dalby MJ, Hart A, Tare R, Oreffo RO, Su B. Fabrication of pillar-like titania nanostructures on titanium and their interactions with human skeletal stem cells. Acta Biomater. 2009; 5(5): 1433-1441. doi:10.1016/j.actbio.2009.01.007

[72] Cho SA, Park KT. The removal torque of titanium screw inserted in rabbit tibia treated by dual acid etching. Biomaterials. 2003; 24(20): 3611-3617. doi:10.1016/ S0142-9612(03)00218-7

[73] Al-Radha ASD, Dymock D, Younes C, O'Sullivan D. Surface properties of titanium and zirconia dental implant materials and their effect on bacterial adhesion. J Dent. 2012; 40(2): 146-153. doi:10.1016/j.jdent.2011.12.006

[74] Novaes ABJr, Papalexiou V, Grisi MFM, Souza SSLS, Taba MJr, Kajiwara JK. Influence of implant microstructure on the osseointegration of immediate implants placed in periodontally infected sites. Clin Oral Implants Res. 2004; 15(1): 34-43. doi:10.1046/j. 1600-0501.2003.00968.x

[75] Suzuki K, Aoki K, Ohya K. Effects of surface roughness of titanium implants on bone remodeling activity of femur in rabbits. Bone. 1997; 21(6): 507-514. doi:10.1016/ S8756-3282(97)00204-4

[76] Vanzillotta P, Soares GA, Bastos IN, Simao RA, Kuromoto NK. Potentialities of some surface characterization techniques for the development of titanium biomedical alloys. Mater Res. 2004; 7(3): 437-444. doi:10.1590/S1516-14392004000300011

[77] Takeuchi M, Abe Y, Yoshida Y, Nakayama Y, Okazaki M, Akagawa Y. Acid pretreatment of titanium implants. Biomaterials. 2003; 24(10): 1821-1827. doi:10.1016/ S0142-9612(02)00576-8

[78] Ban S, Iwaya Y, Kono H, Sato H. Surface modification of titanium by etching in concentrated sulfuric acid. Dent Mater. 2006; 22(12): 1115-1120. doi:10.1016/j.dental. 2005.09.007

[79] Vandrovcova M, Jirka I, Novotna K, Lisa V, Frank O, Kolska Z, Stary V, Bacakova L. Interaction of human osteoblast-like Saos-2 and MG-63 cells with thermally oxidized surfaces of a titanium-niobium alloy. Plos One 2014; 9: e100475. doi:10.1371/journal.pone. 0100475

[80] Kim H, Choi SH, Ryu JJ, Koh SY, Park JH, Lee IS. The biocompatibility of SLA-treated titanium implants. Biomed Mater. 2008; 3(2): 025011. doi:10.1088/1748-6041/3/2/025011 
[81] Aparicio C, Padrós A, Gil FJ. In vivo evaluation of micro-rough and bioactive titanium dental implants using histometry and pull-out tests. J Mech Behav Biomed Mater. 2011; 4(8): 1672-1682. doi:10.1016/j.jmbbm.2011.05.005

[82] Ban S, Iwaya Y, Kono H, Sato H. Surface modification of titanium by etching in concentrated sulfuric acid. Dent Mater. 2006; 22(12): 1115-1120. doi:10.1016/j.dental. 2005.09.007

[83] Velasco-Ortega E, Jos A, Cameán AM, Pato-Mourelo J, Segura-Egea JJ. In vitro evaluation of cytotoxicity and genotoxicity of a commercial titanium alloy for dental implantology. Mutat Res Genet Toxicol Environ Mutagen. 2010; 702(1): 17-23. doi: 10.1016/j.mrgentox.2010.06.013

[84] Braceras I, Alava JI, Oñateetal JI. Improved osseointegration in ion implantationtreated dental implants. Surf Coat Technol. 2002; 158-159: 28-32. doi:10.1016/ S0257-8972(02)00203-7

[85] Rautray TR, Narayanan R, Kim KH. Ion implantation of titanium based biomaterials. Prog Mater Sci. 2011; 56(8): 1137-77. doi:10.1016/j.pmatsci.2011.03.002

[86] Hanawa T, Kamiura Y, Yamamoto S, Kohgo T, Amemiya A, Ukai H, Murakami K, Asaoka K. Early bone formation around calcium-ion-implanted titanium inserted into rat tibia. J Biomed Mater Res. 1997; 36(1): 131-136. doi:10.1002/(SICI)1097-4636(199707)36:1<131::AID-JBM16>3.0.CO;2-L

[87] Rautray TR, Narayanan R, Kwon TY, Kim KH. Surface modification of titanium and titanium alloys by ion implantation. J Biomed Mater Res B Appl Biomater. 2010; 93B(2): 581-591. doi:10.1002/jbm.b.31596

[88] Fasasia AY, Mwenifumbob S, Rahbarb N, Chenb J, Lid M, Beyeb AC, Arnoldb CB, Soboyejob WO. Nano-second UV laser processed micro-grooves on Ti6Al4V for biomedical applications. Mater Sci Eng C. 2009; 29(1): 5-13. doi:10.1016/j.msec. 2008.05.002

[89] Tanner A, Maiden MF, Lee K, Shulman LB, Weber HB. Dental implant infections. Clin Infect Dis. 1997; 25(Suppl. 2): S213-S217.

[90] Mombelli A, Van Oosten MA, Schurch EJr, Lang NP. The microbiota associated with successful or failing osseointegrated titanium implants. Oral Microbiol Immunol. 1987; 2(4): 145-151. doi:10.1111/j.1399-302X.1987.tb00298.x

[91] Rams TE, Roberts TW, Feik D, Molzan AK, Slots J. Clinical and microbiological findings on newly inserted hydroxyapatite-coated and pure titanium human dental implants. Clin Oral Implant Res. 1991; 2: 121-127. doi:10.1034/j.1600-0501.1991.020304.x

[92] Wu-Yuan CD, Eganhouse KJ, Keller JC, Walters KS. Oral bacterial attachment to titanium surfaces: a scanning electron microscopy study. J Oral Implantol. 1995; 21(3): 207-213. 
[93] Subramani K, Jung RE, Molenberg A. Hammerle CHF. Int J Oral Maxillofac Implants. 2009; 24: 616.

[94] Mabboux F, Ponsonnet L, Morrier JJ, Jaffrezic N, Barsotti O. Surface free energy and bacterial retention to saliva-coated dental implant materials - an in vitro study. Colloid Surf B Biointerfaces. 2004; 39(4): 199-205. doi:10.1016/j.colsurfb.2004.08.002

[95] Sardin S, Morrier JJ, Benay G, Barsotti O. In vitro streptococcal adherence a prosthetic and implant materials. Interactions with physicochemical surface properties. J Oral Rehabil. 2004; 31(2): 140-148. doi:10.1046/j.0305-182X.2003.01136.x

[96] Bundy KJ, Butler MF, Hochman RF. An investigation of the bacteriostatic properties of pure metals. J Biomed Mater Res. 1980; 14(5): 653-663. doi:10.1002/jbm.820140511

[97] Colon G, Ward BC, Webster TJ. Increased osteoblast and decreased Staphylococcus epidermidis functions on nanophase $\mathrm{ZnO}$ and $\mathrm{TiO}_{2}$. J Biomed Mater Res A. 2006; 78A(3): 595-604. doi:10.1002/jbm.a.30789

[98] Ewald A, Glückermann SK, Thull R, Gbureck U. Antimicrobial titanium/silver PVD coatings on titanium. Biomed Eng Online. 2006; 5: 22. doi:10.1186/1475-925X-5-22

[99] Lauson MC, Bowman CN, Anseth KS. Vancomycin derivative photopolymerized to titanium kills S. epidermidis. Clin Orthop Relat Res. 2007; 461: 96-105. doi:10.1097/BLO. 0b013e3180986706 

Chapter 7

\title{
The Role of Hydrophilic Sandblasted Titanium and Laser Microgrooved Zirconia Surfaces in Dental Implant Treatment
}

\author{
Aleksa Markovic \\ Additional information is available at the end of the chapter
}

http://dx.doi.org/10.5772/62702

\begin{abstract}
Dental implant surface modifications affect surface roughness, chemistry, topography, and consequently influence biological bone response. Current surface treatments are directed toward increased hydrophilicity and wettability of dental surfaces that allow earlier implant loading due to accelerated osseointegration. This is clinically reflected in increased implant stability and mainteined crestal bone level. Further modification includes microgrooving of zirconia implants by femtosecond laser ablation. Favorable initial results encourage further clinical assessment of this microgrooved zirconia implants.
\end{abstract}

Keywords: Dental implant surface, Femtosecond laser, Hydrophilicity, Titanium, Zirconia

\section{Introduction}

Dental implant surfaces can be modified using several additive and subtractive techniques. Additive techniques involve impregnation and coating. In contrast to impregnation, when chemical agent is integrated into the core material (e.g., fluoride ions incorporated to titanium surface or calcium phosphate crystals within $\mathrm{TiO}_{2}$ layer), the coating is addition of an agent of various thicknesses superficially on the surface of core material [1].

The subtractive techniques imply removal of the layer of core material or plastic deformation of the superficial surface. This is achieved through mechanical or chemical treatments. Mechanical methods used for surface alteration are grinding, blasting, and machining. Sand, 
hydroxyapatite, $\mathrm{TiO}_{2}$, and $\mathrm{Al}_{2} \mathrm{O}_{3}$ particles are usually used for grit blasting. Grit blasting is always followed by an acid etching to remove the residual blasting particles as well as to smooth out sharp peaks and to provide roughness that would promote protein adhesion during early healing [1, 2]. Acid etching is a chemical method of surface modification that usually implies hydrofluoric, nitric, or sulfuric acid or their combinations [3].

Current modification of dental implant surfaces is based on the use of lasers. Their main applications are laser-assisted coatings and laser texturing. Laser pulses are used to evaporate the target materials which later condense on the substrate forming a thin coating. Their further role is in dental implant surface texturing in order to form three-dimensional structures on micrometer or submicrometer scales. Several laser sources such as Nd:YAG, $\mathrm{CO}_{2}$, Excimer, and diode lasers have been examinated for surface modifications [4].

Lasers are particularly useful for dental implants with complex surface geometry or for those made of material difficult to be removed. Dental implant surface modification by laser is a noncontact, clean and fast process with high precision [4]. Lasers overcome drawbacks of conventional mechanical and chemical surface modification techniques such as unreliable control of achieved roughness or inability of surface texturing. However, laser processing might be associated with microcracks and heat-affected zones [4, 5].

\subsection{Surface topography}

Scientific evidence from in vitro studies indicates that micro-topography of dental implant surfaces affects cellular behavior, mainly, proliferation, cell differentiation, and cell adhesion as well as the production of growth factors [6]. Microgrooves at implant surfaces direct cell spreading and cell alignment and define the orientation of ECM proteins. This directional movement of bone cells known as "contact guidance" contributes to bone-implant interlocking and thus provides favorable conditions for further healing events [7]. Microtextured surfaces suppress fibroblast spreading and growth preventing fibrous encapsulation of dental implants. Important parameters of surface roughness are average height deviation (Sa) and developed surface area ratio (Sdr) that indicates surface enlargement if a surface is flattened out. According to Sa values determined by optical interferometry, implant surfaces are considered as smooth with an Sa value of $0.5 \mu \mathrm{m}$; minimally rough surfaces with an Sa of 0.5-1 $\mu \mathrm{m}$, moderately rough surfaces with Sa 1-2 $\mu \mathrm{m}$, and rough surfaces with an Sa of $42 \mu \mathrm{m}$. Moderately rough surfaces with Sa $1.5 \mu \mathrm{m}$ and Sdr of $50 \%$ promote the strongest bone response [2]. To mimick the architecture of natural bone that consists of nanosized hydroxiapatit and organic protein collagen, dental implant surfaces with nano-features have been introduced. Although initial data are promising, the effect of surface nanoroughness on biological response is still uncertain [3].

Surface topography is usually examined by scanning electron microscopy (SEM), light interferometry (LIF), and atomic force microscopy (AFM), whereas X-ray photoelectron spectroscopy (XPS), Auger electron spectroscopy (AES) and energy dispersive X-ray spectroscopy (EDX) provide information related to surface chemical composition [3, 8]. 
SEM is the gold standard for characterization of dental implant topography at the micrometer level. For the characterization of nanotopography of dental implant surfaces, field emissionSEM with higher resolution is required [3].

LIF is an efficient optical tool for quantitative analysis of implant surfaces. This technique uses reflecting light as an optical stylus allowing easy access to even unapproachable parts of the implant flunks. Despite its high resolution in height direction, LIF is suitable for characterization of dental implant surfaces at a micrometer scale, because of limited spatial resolution [8].

AFM can be used to assess dental implant surface topography at nano-level. An atomic force microscope consists of a tip mounted on a cantilever. When tip scans a dental surface, interatomic forces between the tip and the sample surface displace the tip which results in the cantilever bending. Consequently, specialized software produces topographical image of the surface with atomic resolution based on data from detector regarding the laser beam reflected from the cantiliver. This tool has resolution at molecular level, but its usage is unreliable for certain level of surface roughness because their microtopography significantly interferes with the vertical piezoelectric AFM scanning probe $[3,8]$.

XPS also known as electron spectroscopy for chemical analysis (ESCA) determines what elements (except hydrogen and helium) and in which chemical state and quantity are present within the top 1-12 nm of the implant surface. This tool also provides information related to possible contamination on the surface or in the bulk of the sample as well as those related to the presence and thickness of layers of different materials within the top $12 \mathrm{~nm}$ of the implant surface. XPS spectra are obtained by irradiating a dental implant surface with a beam of Xrays and measuring the kinetic energy and number of electrons emitted from the top of the surface $[3,8]$.

AES provides quantitative elemental and chemical state analysis of dental implant surfaces with lateral spatial resolution of only $8 \mathrm{~nm}$. Approximate depth resolution of AES is $5 \mathrm{~nm}$. However, ion-sputtering used with Auger spectroscopy allows depth chemical profiling up to $100 \mathrm{~nm}$, which is suitable for the characterization of coatings on implant surfaces or impregnation within a $\mathrm{TiO}_{2}$ layer [3]. For the AES analysis, implant surface is excited with a finely focused electron beam while an electron energy analyzer measures the energy of Auger electrons emitted from the surface. Based on the kinetic energy and intensity of an Auger peak, elements from the implant surfaces are identified.

EDX is used for the elemental analysis or chemical characterization of a dental implant surface. It is based on the unique set of peaks on X-ray emission spectrum of each element. Coupled to SEM, EDX determine the elemental composition of structures observed with SEM down to the nanoscale [3].

\subsection{Surface wettability}

Important characteristic of dental implant surfaces is surface energy that dertermines wettability of surfaces. It is measured by liquid-solid contact angle (CA) which is an angle between the tangent line to a liquid drop's surface at the three-phase boundary, and the horizontal solid's surface [9]. There are two methods commonly used to assess CA of dental implant 
surfaces: the sessile drop technique where CA of the droplet deposited by a syringe onto the sample surface is measured directly by goniometer or image analysis software and the second, tensiometry (Wilhelmy method) that indirectly measure CA according to the force exerted on the sample surface by the liquid, while sample surface attached to a force meter is vertically dipped into a pool of the probe liquid [10].

The CA ranges from $0^{\circ}$ to $180^{\circ}$ where CA lower than $90^{\circ}$ designate surfaces as hydrophilic and CA very close to $0^{\circ}$ as superhydrophilic. Dental implant surfaces with CA above $90^{\circ}$ are considered hydrophobic, and those with CA above $150^{\circ}$ are superhydrophobic [9]. Currently available dental implants are mainly hydrophobic [11]. Although optimal degree of wettability is not known, there is abundant scientific evidence that hydrophilic surfaces enhances early stages of osseointegration compared to hydrophobic ones [12-14].

Hydrophilicity of dental implant surfaces determines adhesion of proteins on the surface of placed implant, interaction of hard and soft tissue cells with implant surface, and consequently the rate of osseointegration [9]. Hydrophilic surfaces promotes superior adsorption and functional orientation of proteins from blood and interstitial fluids. Composition of the proteins adhered to the implant surface affects cell adhesion, morphology, and migration [15]. Hydrophilic dental implants favor osteoblastic differentiation of mesenchymal stem cells [16], enhance osteoblast maturation [17], produce an anti-inflammatory microenvironment [18], and increase the quantity and quality of mineralization [19]. These molecular and cellular events provide accelerated osseointegration of hydrophilic dental implants in contrast to hydrophobic which has been verified histomorphometricaly as increased bone-to-implantcontact (BIC) at very early point in healing [12-14].

Advantages of hydrophilic surfaces recognized in in vitro and in vivo studies on dental osseointegration have directed contemporary modifications of dental implant surfaces toward to greater hydrophilicity. Today, several methods of hydrophilizing dental implant surfaces are available including radio frequency glow discharge treatment, atmospheric pressure plasma, surface coating with crystalline $\mathrm{TiO}_{2}$, and irradiation by UV-A as well as Ti surface with native oxide hydrophilized using higher energy UV-C rays [9]. Also, changes in dental implant surface roughness and chemistry affect hydrophilicity, which complicates the analysis of the independent effect of each of these surface characteristics on clinical behavior of available dental implants.

\subsection{Clinical outcome of dental implant surfaces}

Osseointegration of dental implants is clinically reflected in implant stability. Primary implant stability is a mechanical issue determined by bone quantity and quality, surgical technique, and implant macro-design, whereas secondary implant stability as a biological phenomenon indicates bone apposition and remodeling processes and it is influenced by conditions of implant surface $[20,21]$. Contemporary implant surfaces accelerate osseointegration and provide conditions for early or even immediate implant loading if sufficient implant stability is achieved. Therefore, non-invasive, objective and quantitative tool for the assessment and monitoring of implant stability in clinical conditions is of great importance. 
Resonance frequency analysis (RFA) is a wireless system for the measurement of implant stability that includes a metal rod (a peg) screwed into the implant body and stimulated by magnetic pulses from a handheld computer. The result of a measurement is expressed as the implant stability quotient (ISQ) ranging from 1 (lowest stability) to 100 (highest stability) (Figure 1). ISQ values higher than 47 indicate stable implant [22]. The recommendations for immediate and early loading of single-implant crowns are ISQ 60-65 [23]. Implants with high ISQ values during the follow-up are successfully osseointegrated, whilst low and decreasing ISQ values may be a warning sign of ongoing implant failure [20, 21].

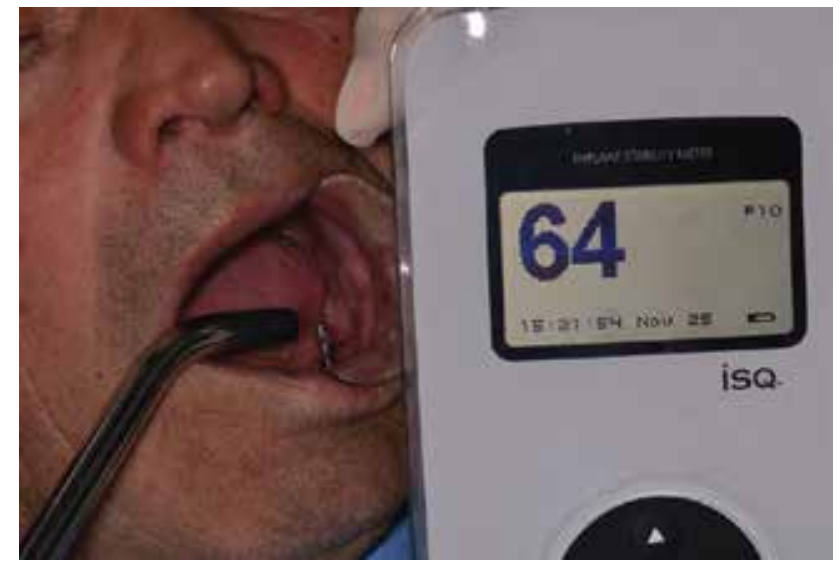

Figure 1. Resonance frequency analysis measurement using Ostell Mentor ${ }^{\circledR}$ device.

RFA is not suitable for the measurement of stability of one-piece dental implants and in such indication the use of the Periotest is recommended. The Periotest produces percussion of the implant and provides a stability number ranging from -8 to +50 , with the lower the Periotest value (PTV), the higher the stability (Figure 2) [24]. In the literature, different ranges of PTVs

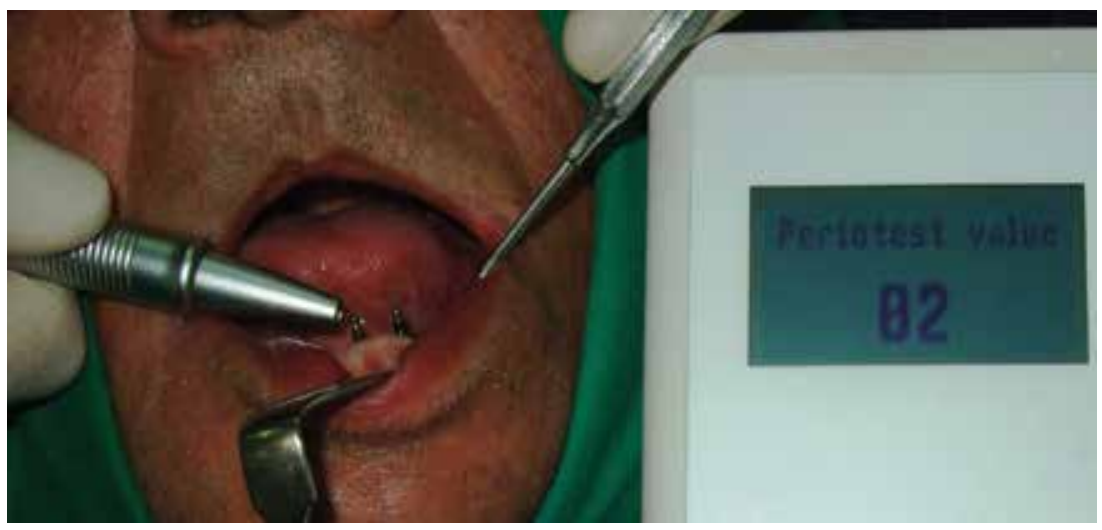

Figure 2. Measurement of implant stability of one-piece dental implants using Periotest. 
for successfully osseointegrated dental implants have been reported ( -9 to $+9 ;-5$ to $+5 ;-7$ to $0 ;-4$ to $-2 ;-4$ to +2$)$ [24-27].

Another important clinical parameter that reflects condition at implant-bone interface is change in crestal bone level. It is recommended to follow this parameter on retroalveolar radiographs obtained via long cone technique. This technique uses film holder that allows repeatability of tube orientation (Figure 3). Image analysis software is used for precise measurement of digitized radiographs following their calibration (Figure 4). Implant is considered successful with an crestal bone loss of $1.5 \mathrm{~mm}$ following 1 year of loading and subsequent loss of 0.2 per year [28].

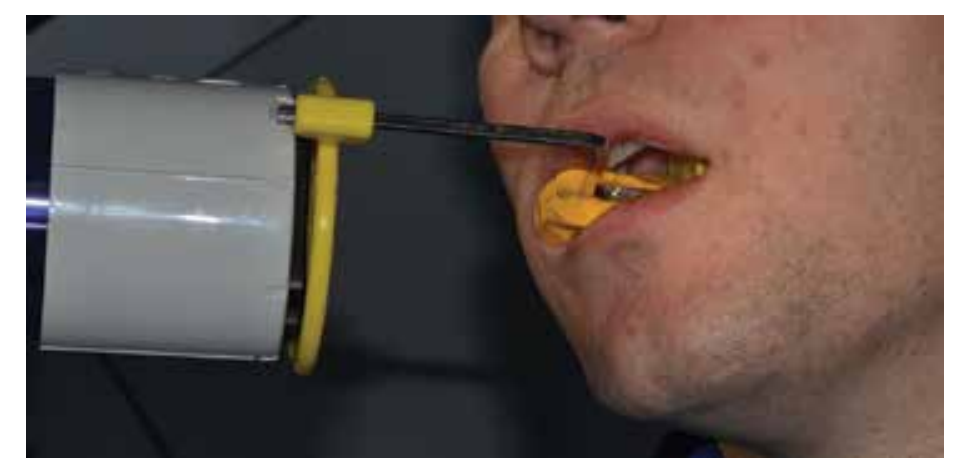

Figure 3. Obtaining radiographs using long cone technique. A plastic ring, connected to the film holder provided control of tube orientation.

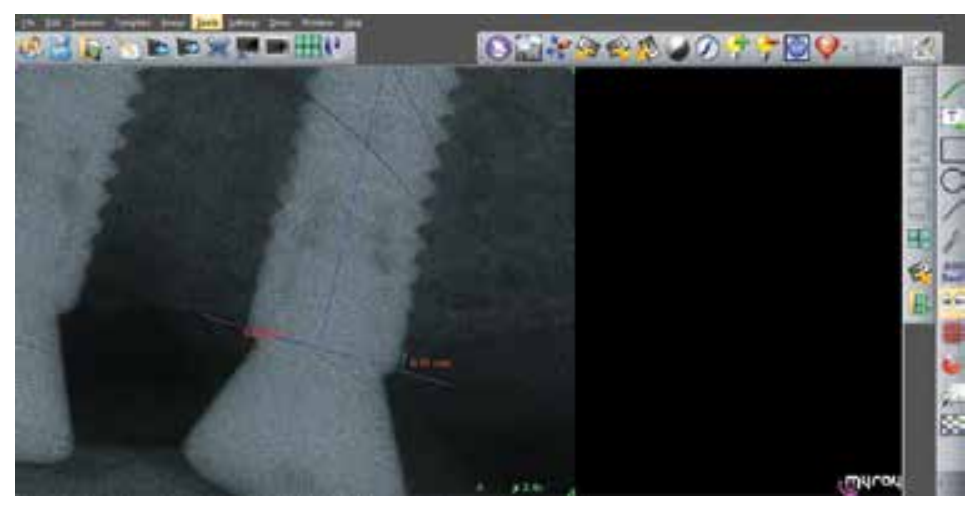

Figure 4. Image analysis software for crestal bone loss measurement.

\section{Role of SLActive surface in dental implant treatment}

SLActive dental implant surface (Institute Sraumann ${ }^{\circledR}$ AG, Basel, CH) is a hydrophilic with a sandblasted and acid-etched topography and was created as an aspiration to combine the 
advantages of surface roughness and hydrophilicity on implant osseointegration [14, 29]. This new surface is produced from the same cpTi alloy and subjected to the same roughening treatment with large grit size $(250-500 \mu \mathrm{m})$ corundum sandblasting plus acid etching $\left(\mathrm{H}_{2} \mathrm{SO}_{4} /\right.$ $\mathrm{HCl}$ ) as its predecessor SLA surface [30]. The only difference from its unmodified counterpart is that following acid-etching hydrophilic SLActive implant is rinsed under nitrogen protection and then stored in a sealed glass tube containing isotonic $\mathrm{NaCl}$ solution [29]. Such chemical modification provides hydrophilization of surface that is initially hydrophobic due to the microroughness, causing the air to be entrapped in the micropores, thus aggravating surface wetting [29]. Storage in $\mathrm{NaCl}$ solution allows prewetting of micropores and consequently faster wetting of implant surface [30]. CA of $0^{\circ}$ designates SLActive dental implant surface as superhydrophilic in contrast to hydrophobic SLA surface with CA of $139.9^{\circ}[9,29,30]$. Another reason for reduced hydrophilicity of Ti implants is contamination due to air exposure [29]. However, cleaning under nitrogen protection and storage in $\mathrm{NaCl}$ solution prevents the adsorption of potential contaminants from the atmosphere onto the SLActive surface which is proven by the decreased carbon concentration [29, 30]. SLActive surface keeps hydrophilicity even after any drying which is important from a clinical point [29].

Another possible reason for improved biological response to SLActive surface compared with its unmodified counterpart SLA is the difference in microtopography and nanoroughness [31]. Although both surfaces have similar Sa value (1.78 and $1.75 \mu \mathrm{m}$ for the SLA and SLActive, respectively), the SLActive surface has Sdr of $143 \%$ that is greater than Sdr of $97 \%$ for SLA. This difference indicates that SLActive has a much greater number of peaks/valleys across the surface compared with SLA [31,32]. SLActive surface also exhibits nano-features with Sa value of $97 \mathrm{~nm}$ at the nanometer resolution level [31].

Biological effect of aforementioned improvements of SLActive implant surface comprises of enhanced osteoblastic differentiation [33, 34], improved angiogenesis [35] and reduced local inflammation and its associated osteoclastogenesis [36]. These cellular events provides stronger bone formation around SLActive implants compared with SLA during the early healing phase, particularly between the second and fourth weeks, while the difference disappears after the first 6 weeks [37]. Such features of SLActive implant surface indicate its possible clinical relevance in cases when faster implant loading is needed or when enhanced bone formation is desirable as in osteoporotic or irradiated bone and in diabetic patients.

Contemporary improvement of dental implant surfaces has allowed shift from a conventional loading protocol providing 3-6 months of undisturbed healing toward immediate (within 1 week) or early loading (between 1 week and 2 months) in selected patients when sufficient primary implant stability could be achieved [38, 39]. Clinical and radiographic outcomes of SLA and SLActive dental implants submitted to immediate or early occlusal loading is comparable to those of implants submitted to conventional loading protocols (3-6 months) [40]. SLActive implants loaded at 3 weeks after placement have survival rate of $95-98 \%$ following 1-3 years after placement [41, 42]. Hydrophilic and nanostructured SLActive implants are safe and predictable for immediate and early loading even in poor-quality bone $[43,44]$. Early loaded SLA and SLActive implants achieves similar short- and long-term 
survival rates, although SLActive implants have better stability and a reduced marginal bone loss at the loading stage $[40,45]$.

As much as $97.3 \%$ of SLActive implants placed in low-density bone achieves implant stability of at least 60-65 ISQ required for immediate or early implant loading (Figure 5) [23, 46]. The stability dip in the second postoperative week indicates that afterward, formative processes predominated over the resorptive one within bone remodeling. This result suggests that nanostructured and hydrophilic SLActive implant surface promotes enhanced bone formation during the early stage of osseointegration. It is important that even in this critical time point stability values did not fall below the threshold for early loading. Afterward, implant stability steadily increases over time.

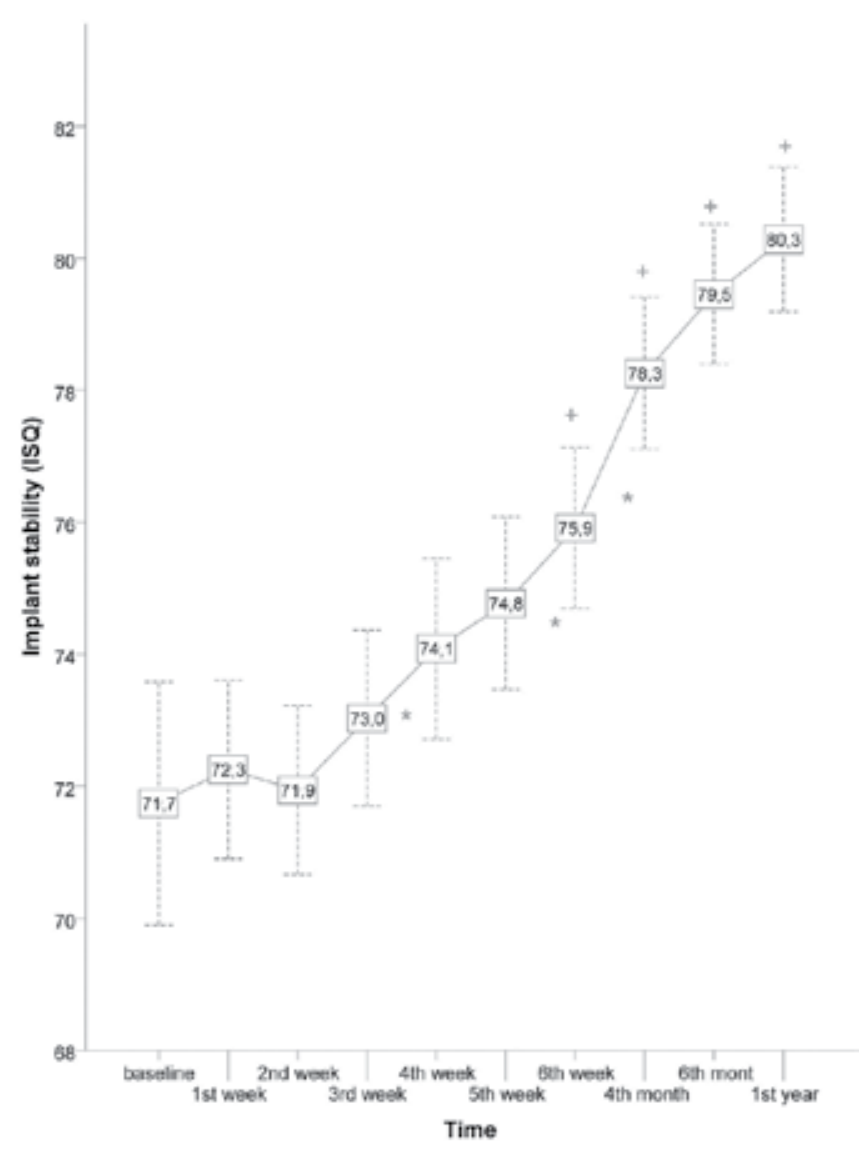

Figure 5. Stability of SLActive dental implants placed into low-density bone. Line represents mean, error bars represent $95 \%$ CI of mean. Asterisks indicate a statistically significant difference between two-consecutive weeks, whereas crosses indicate a statistically significant difference to baseline (implant placement) [46].

SLActive dental implants placed in low-density bone and early loaded (at week 6) are associated with mean bone loss of $-0.41 \pm 0.1 \mathrm{~mm}$ after 1 year that is in accordance with the 
acceptable $1 \mathrm{~mm}$ bone loss during the first year (Figure 6) [46]. These data suggest that SLActive dental implants predictably achieve and maintain successful tissue integration in low-density bone after undergoing an early loading protocol.

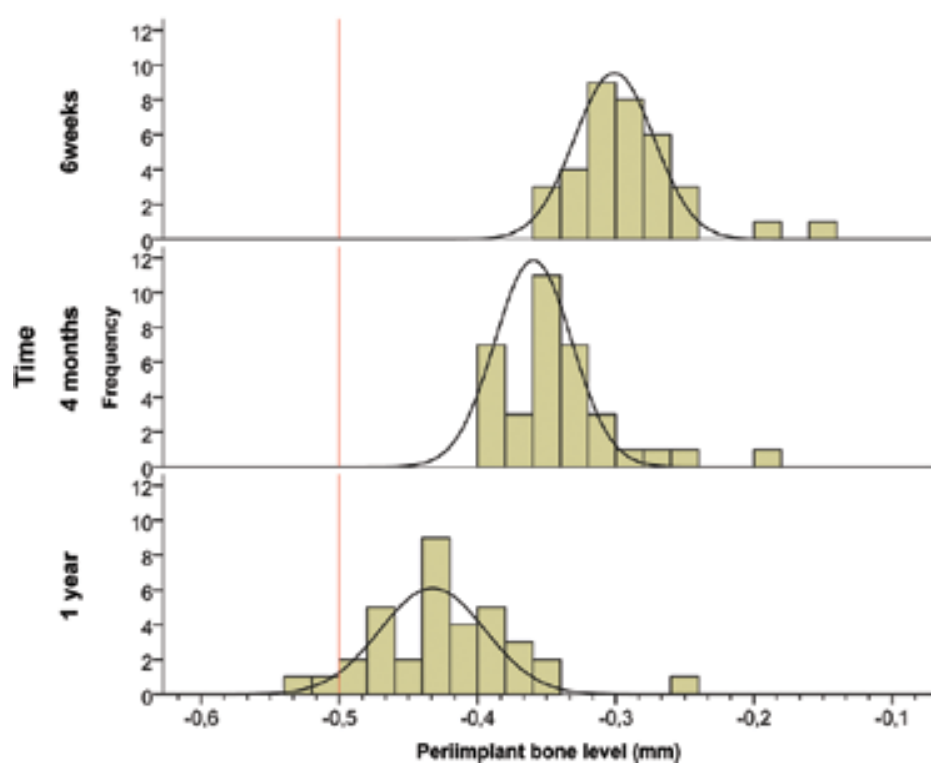

Figure 6. Frequency analysis of peri-implant bone level around early loaded SLActive dental implants in low-density bone.

Placement of implants into posterior maxillary region is often compromised by the bone resorption pattern, and pneumatization of the maxillary sinus beside the low-density bone present at this jaw region. Therefore, in such cases, sinus elevation is necessary to accommodate implants of sufficient length. Residual bone height determines surgical technique for sinus lift as well as whether implants can be placed simultaneously with sinus lift procedure or in the second stage [47]. When limited elevation of the sinus mucosa is required, this can be achieved through an implant bed using osteotomes, a technique known as osteotome sinus floor elevation and implant can be placed simultaneously [48]. The healing time prior to loading of implants inserted following sinus floor elevation is usually longer than the loading time required for implants inserted in bone of sufficient quantity [49]. Reduction of the healing time in atrophic posterior maxilla with low-density bone is particularly challenging due to reduced bone to implant contact and doubtful implant stability.

Around $95 \%$ of SLActive implants placed in the posterior maxilla via the osteotome sinus floor elevation technique without grafting achieves stability sufficient for early loading, in the sixth week of healing (Table 1). Favorable mid-term success rate indicates that implants with a sandblasted large-grit acid-etched active surface, when placed with the osteotome sinus floor elevation technique, can be subjected to an early loading protocol, providing their stability is confirmed by RFA [50]. 


\begin{tabular}{llllllll}
\hline ISQ & \multicolumn{7}{c}{ Time } \\
\cline { 2 - 7 } & Placement & 1 week & 2 weeks & 3 weeks & 4 weeks & 5 weeks & 6 weeks \\
\hline Minimum & 47 & 48 & 52 & 57 & 60 & 63 & 64 \\
Maximum & 75 & 74 & 75 & 75 & 77 & 77 & 78 \\
Mean \pm SD & $59.55 \pm 7.06$ & $61.12 \pm 6.34$ & $62.23 \pm 5.53$ & $63.75 \pm 4.56$ & $65.88 \pm 3.64$ & $66.80 \pm 3.03$ & $67.75 \pm 3.06$ \\
\hline
\end{tabular}

Table 1. Stability of SLActive implants placed via OSFE.

Density of bone at implant site affects implant stability. SLActive implants placed in the region of the second and the first premolar have comparable stability but their stability is significantly higher than implants inserted in the region of the first molar (Figure 7). Implant stability positively correlates with residual bone height (Figure 8) [50].

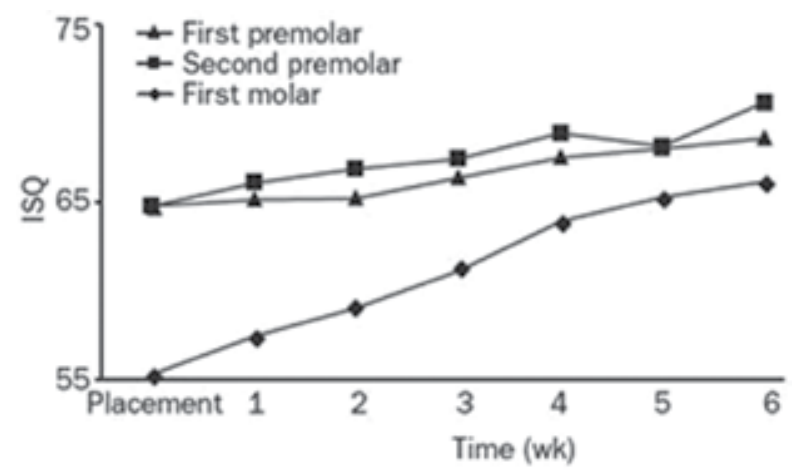

Figure 7. Stability of SLActive implants placed via OSFE regarding the jaw region.



Figure 8. Comparison of implant stability with initial residual bone height. 
Grafting material is not a prerequisite for the osseointegration of dental implants with hydrophilic and nanostructured SLActive surface placed via OSFE procedure. The usage of grafting material offers no significant advantage to stability or clinical success of dental implants placed simultaneously with OSFE (Figure 9) [51].

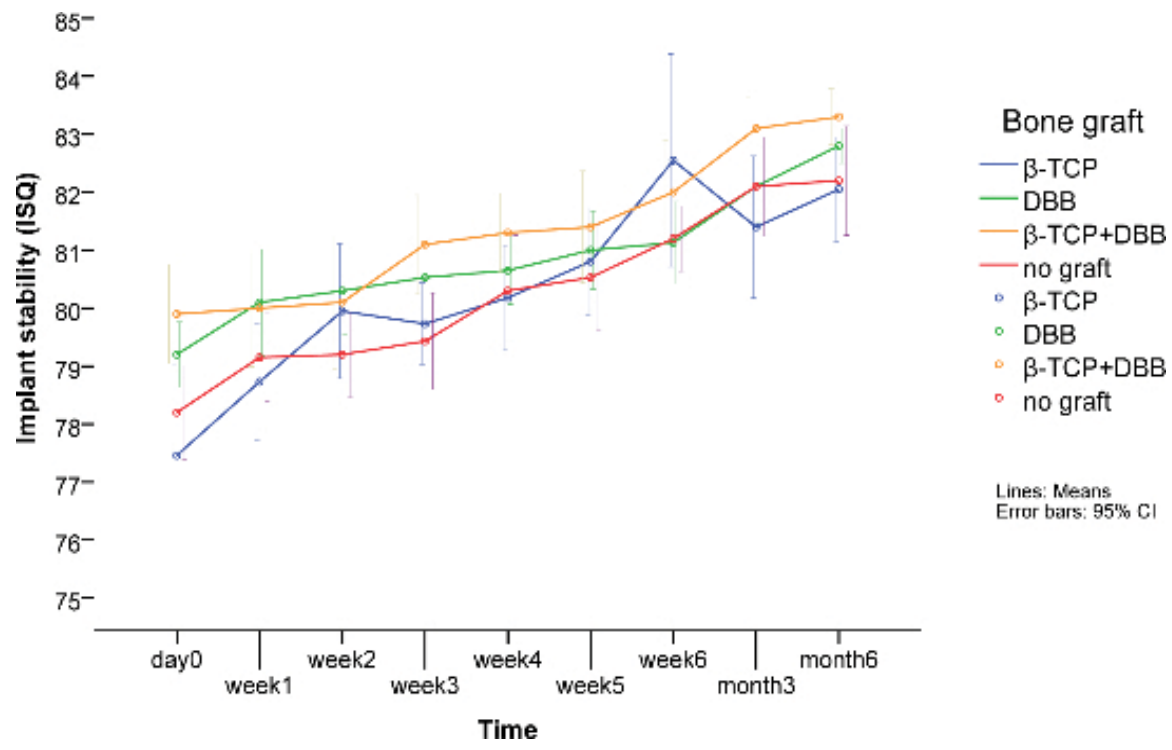

Figure 9. Stability of SLActive implants placed via OSFE regarding the usage of grafting material.

In atrophic maxillary ridges which require substantial raise of the sinus membrane implant placement using lateral sinus lift is mandatory. Eighty-three percent of SLActive implants placed simultaneously with lateral sinus lift and a mixture of autogenous bone chips and deproteinized bovine bone mineral reach the threshold stability after 8 weeks of healing, allowing an early loading protocol. This treatment protocol is associated with low early failure rate of $0.9 \%$ [52].

Another challenging indication that requires stronger bone response is implant placement into irradiated jaw. Radiation therapy causes endarteritis leading to hypoxia, hypovascularity, and hypocellularity that might jeopardize dental implant osseointegration [53]. Long-term survival rate of implants placed in irradiated jaws is $69-78 \%$, and it is influenced by the jaw region, irradited dose, and surface roughness [54-56]. Roughened dental implants have 2.9 times reduced risk for failure in irradiated jaws compared with turned implants [54]. Sandblasted acid-etched implants with or without a chemically modified surface can be used in irradiated patients with a high predictability of success. The overall cumulative 5-year survival rates of SLA and SLActive implants in irradiated jaws are similar and the crestal bone level around both implant surfaces remains stable at least 5 years after placement. Hydrophilic surface might affect only early survival of dental implant placed in irradiated bone [57]. 
Microangiopathies and hyperglycemia associated with diabetes mellitus impaires bone regeneration and might affect early implant failure rates in such patients. Diabetic patients with glycated hemoglobin above $8.0 \%$ have delayed implant osseointegration and require a longer healing time $[58,59]$. Despite the promising result of animal research that SLActive surface provides accelerated osseointegration of dental implants and better prognosis for implant treatment in diabetic patients, clinical assessment revealed similar outcomes for SLActive and SLA surfaces $[60,61]$.

\section{Role of laser microgrooved zirconia surface in dental implant treatment}

Although titanium can still be considered the reference standard material for dental implants with a few limitations such as rare allergy to metals or gingival retraction or translucidity in thin gingival biotypes and subsequent unsatisfactory esthetic [62,63]. The development of high mechanical strength ceramics has made them a viable alternative [64]. Yttrium-partially stabilized tetragonal zirconia (Y-TZP) offers several advantages due to its flexural strength and high resistance to fracture, favorable esthetics as well as excellent osseointegration observed in animal studies $[65,66]$.

However, roughening the surface of the zirconia implant is a challenge mainly due to its resistance to chemical or physical modifications. Several approaches have been proposed as follows: chemical and pharmacological surface modification, sand-blasting and acid etching, the use of nanotechnology, or biomimetic coatings, and addition of micro-and macro-retentions [67-69]. These modifications result in various degrees of surface roughness and content of contaminants.

The zirconia dental implants available on the market are sandblasted. Recently, technique for microstructuring cylindrical zirconia implants by femtosecond laser ablation has been introduced. In addition to sandblasting, surface is modified using femtosecond laser ablation, which creates an isotropic pattern of microgrooves on the implant surface [5]. This technique is fast, provides precise control of texture allowing production of textures with complex shape, and as a non-contact procedure, it does not cause contamination [5].

Cells modify their morphology, adhesion, and cytoskeletal organization according to the substrate topography [70]. On flat zirconia dental implant surface, osteoblasts are disorganized and loosely attached with few lamellipodia mainly directed toward the cracks or other topographical accidents (Figure 10a-c). Creation of microgrooves of $30 \mu \mathrm{m}$ width and $70 \mu \mathrm{m}$ separation on zirconia dental implant surface induces favorable cell morphology, increases cell density, and enhances cell activity [71]. Osteoblasts align along the axis of microgrooves with lamellipodia directed toward the inner surface and connected to the base and walls of the microgrooves (Figure 10d-f). Filopodia extensions retained in the nanometric structures of the microgroove walls cell further improve adhesion of osteoblasts to modified zirconia surface and increase cell density (Figure 11a-d). Osteoblasts adhesion occurs first in microgrooves and later on the flat area of zirconia surface (Figure 12a-f). Further, activity of the osteoblasts is tripled by adding the microgrooves to zirconia surface [71]. Microgrooves on 
zirconia implants host bioactive molecules and enhance the initial stages of bone formation [72].

Favorable cellular events directed by microgrooved zirconia implant surface are provided by increased roughness and enhanced chemical composition of the sandblasted zirconia surface following its laser modification. This surface treatment increases proportions of zirconium and oxygen, whereas decreases content of carbon and aluminum allowing high osteoblastic activity on sandblasted, laser micro-grooved zirconia [71]. This modified zirconia surface exhibit higher values of roughness parameters and reduced the presence of contaminants not only in comparison with its predecessor, nongrooved sandblasted zirconia, but also to sandblasted, hightemperature-etched titanium implants (Tables 2 and 3) [73].

\begin{tabular}{lllll}
\hline Roughness parameters & Surface & & \\
\cline { 2 - 5 } & $\begin{array}{l}\text { Sandblasted } \\
\text { zirconia }\end{array}$ & $\begin{array}{l}\text { Sandblasted } \\
\text { zirconia with } \\
\text { microgrooved } \\
\text { neck }\end{array}$ & $\begin{array}{l}\text { Sandblasted } \\
\text { zirconia all } \\
\text { microgrooved }\end{array}$ & $\begin{array}{l}\text { Sandblasted, } \\
\text { high temperature } \\
\text { etched titanium }\end{array}$ \\
\hline $\mathbf{R}_{\mathrm{a}}(\mu \mathrm{m})$ & $1.28 \pm 0.2$ & $2.43 \pm 0.6^{*}$ & $9.50 \pm 0.25^{*}$ & $1.78 \pm 0.6$ \\
$\mathbf{R}_{\mathrm{q}}(\mu \mathrm{m})$ & $1.82 \pm 0.51$ & $3.48 \pm 0.30^{*}$ & $11.51 \pm 0.31^{*}$ & $2.02 \pm 0.43$ \\
$\mathbf{R}_{\mathrm{z}}(\mu \mathrm{m})$ & $11.4 \pm 0.6$ & $40.42 \pm 0.25^{*}$ & $40.74 \pm 0.28^{*}$ & $15.8 \pm 0.5$ \\
$\mathbf{R}_{\mathrm{t}}(\mu \mathrm{m})$ & $18.46 \pm 0.82$ & $52.68 \pm 0.9^{*}$ & $60.36 \pm 0.22^{*}$ & $23.63 \pm 0.32$ \\
\hline
\end{tabular}

Surface roughness parameters $\left(\mathrm{R}_{\mathrm{a}}, \mathrm{R}_{\mathrm{q}}, \mathrm{R}_{\mathrm{z}}, \mathrm{R}_{\mathrm{t}}\right)$ expressed as $(\bar{x} \pm \mathrm{SD})\left({ }^{*} \mathrm{p}<0.05\right)$.

Table 2. Topographic characteristics of implant surfaces.

\begin{tabular}{|c|c|c|c|c|}
\hline \multirow[t]{2}{*}{ EDX surface analysis } & \multicolumn{4}{|l|}{ Surfaces } \\
\hline & $\begin{array}{l}\text { Sandblasted } \\
\text { zirconia }\end{array}$ & $\begin{array}{l}\text { Sandblasted } \\
\text { zirconia with } \\
\text { microgrooved } \\
\text { neck }\end{array}$ & $\begin{array}{l}\text { Sandblasted } \\
\text { zirconia all } \\
\text { microgrooved }\end{array}$ & $\begin{array}{l}\text { Sandblasted, } \\
\text { high temperature } \\
\text { etched titanium }\end{array}$ \\
\hline $\mathrm{C} \%$ & $19.7 \pm 0.8 \%$ & $1.6 \pm 0.35 \% *$ & $0.3 \pm 0.12 \% *$ & $2.3 \pm 1.7 \%$ \\
\hline $\mathrm{Al} \%$ & $4.3 \pm 0.9 \%$ & $1.16 \pm 0.2 \% *$ & $0.18 \pm 0.1 \% *$ & $1.7 \pm 0.3 \%$ \\
\hline $\mathrm{O} \%$ & $12.6 \pm 0.5 \%$ & $22.7 \pm 0.2 \% *$ & $23.1 \pm 0.12 \% *$ & $15 \pm 0.6 \%$ \\
\hline $\mathrm{Zr} \%$ & $60.2 \pm 0.7 \%$ & $73.7 \% \pm 0.15 \% *$ & $76.3 \pm 0.2 \% *$ & $0 \%$ \\
\hline $\mathrm{Ti} \%$ & $0 \%$ & $0 \%$ & $0 \%$ & $81 \pm 1.3 \%$ \\
\hline
\end{tabular}

Expressed in percentages as $\bar{x} \pm \mathrm{SD}\left({ }^{*} \mathrm{p}<0.05\right)$.

Table 3. Elements present in surface chemical composition. 
The addition of microgrooves in the 2-mm wide neck area of the implant increases surface roughness by 6.5 times and almost 12 times in the zirconia implants processed over the entire intraosseous surface. Microgrooves provide more retentive areas and greater bone-toimplant contact resulting in higher stability of this implants proven by the increase in insertion and removal torque and decrease of PTV values (Tables 4-6) [73].

\begin{tabular}{lllll}
\hline Surface & & \multicolumn{3}{c}{ IT(Ncm) } \\
\cline { 2 - 6 } & $\bar{x}$ & SD & SE & Median \\
\hline Sandblasted, high temperature etched titanium & 57.10 & 1.80 & 0.51 & 55.76 \\
Sandblasted zirconia & 46.08 & 0.70 & 0.20 & 44.87 \\
Sandblasted zirconia with microgrooved neck & 53.20 & 1.30 & 0.37 & 50.98 \\
Sandblasted zirconia all microgrooved & 69.60 & 1.20 & 0.34 & 67.82 \\
\hline
\end{tabular}

Table 4. Insertion Torque values (IT) recorded at implant placement.

\begin{tabular}{llll}
\hline Surface & RT (Ncm) & & \\
\cline { 2 - 4 } & Month 1 & Month 2 & Month 3 \\
\hline Sandblasted zirconia & $64.08 \pm 0.42(64.07)$ & $78.24 \pm 0.35(78.38)$ & $199.19 \pm 0.99(199.47)$ \\
Sandblasted zirconia with microgrooved neck & $69.19 \pm 0.37(69.17)$ & $88.82 \pm 0.41(88.86)$ & $215.13 \pm 0.99(215.06)$ \\
Sandblasted zirconia all microgrooved & $84.95 \pm 0.25(85.03)$ & $126.96 \pm 0.81(126.65)$ & $240.15 \pm 1.04(239.90)$ \\
Sandblasted, high temperature etched titanium & $71.25 \pm 0.43(71.28)$ & $99.85 \pm 0.44(99.98)$ & $226.98 \pm 1.06(226.72)$ \\
\hline
\end{tabular}

Table 5. Removal torque test (RT) performed at three evaluation time points.

\begin{tabular}{llll}
\hline Surface & PTV & & \\
\cline { 2 - 4 } & Month 1 & Month 2 & Month 3 \\
\hline Sandblasted zirconia & $-1.52 \pm 0.01(-1.52)$ & $-2.17 \pm 0.01(-2.17)$ & $-2.41 \pm 0.02(-2.41)$ \\
Sandblasted zirconia with microgrooved neck & $-1.85 \pm 0.02(-1.85)$ & $-2.42 \pm 0.01(-2.42)$ & $-3.11 \pm 0.01(-3.11)$ \\
Sandblasted zirconia all microgrooved & $-2.49 \pm 0.02(-2.5)$ & $-4.16 \pm 0.01(-4.16)$ & $-5.69 \pm 0.03(-5.7)$ \\
Sandblasted, high temperature etched titanium & $2.11 \pm 0.35(-2.00)$ & $-2.70 \pm 0.01(-2.70)$ & $-3.59 \pm 0.05(-3.60)$ \\
\hline
\end{tabular}

Values expressed as $\pm \mathrm{SD}$ (median).

Table 6. Changes in Periotests values (PTV) over time.

Microgrooved implants reduces crestal bone level in comparison with microthreaded titanium implants and particularly with rough neck implants without microthreading (sandblasted zirconia) (Table 7). Although microthreads at implant neck transform the shear force between the implants and crestal bone into the compressive force to which bone is the most 
resistant allowing preservation of bone tissue, the addition of microgrooves that interlock the adjacent bone seems to be more efficient $[73,74]$.

\begin{tabular}{llll}
\hline Surface & \multicolumn{3}{c}{ RCBL (mm) } \\
\cline { 2 - 4 } & Month 1 & Month 2 & Month 3 \\
\hline Sandblasted zirconia & $0.27 \pm 0.03(0.26)$ & $0.32 \pm 0.01(0.32)$ & $0.56 \pm 0.01(0.56)$ \\
Sandblasted zirconia with microgrooved neck & $025 \pm 0.03(0.23)$ & $0.22 \pm 0.02(0.23)$ & $0.36 \pm 0.01(0.36)$ \\
Sandblasted zirconia all microgrooved & $0.24 \pm 0.02(0.22)$ & $0.24 \pm 0.01(0.24)$ & $0.26 \pm 0.01(0.26)$ \\
Sandblasted, high temperature etched titanium & $0.27 \pm 0.04(0.28)$ & $0.30 \pm 0.02(0.30)$ & $0.36 \pm 0.01(0.36)$ \\
\hline
\end{tabular}

Values expressed as $\pm \mathrm{SD}$ (median).

Table 7. Radiographic crestal bone loss (RCBL).

The addition of microgrooves to the entire intraosseous surface of zirconia dental implants enhances primary and secondary implant stability, which promotes bone tissue ingrowth and preserves crestal bone levels [73]. Data from animal models indicate that zirconia femtosecond laser all-treated surface achieves good osseointegration and could be predictable treatment option in the implantological daily practice [75]. Histological, radiological, and histomorpho-
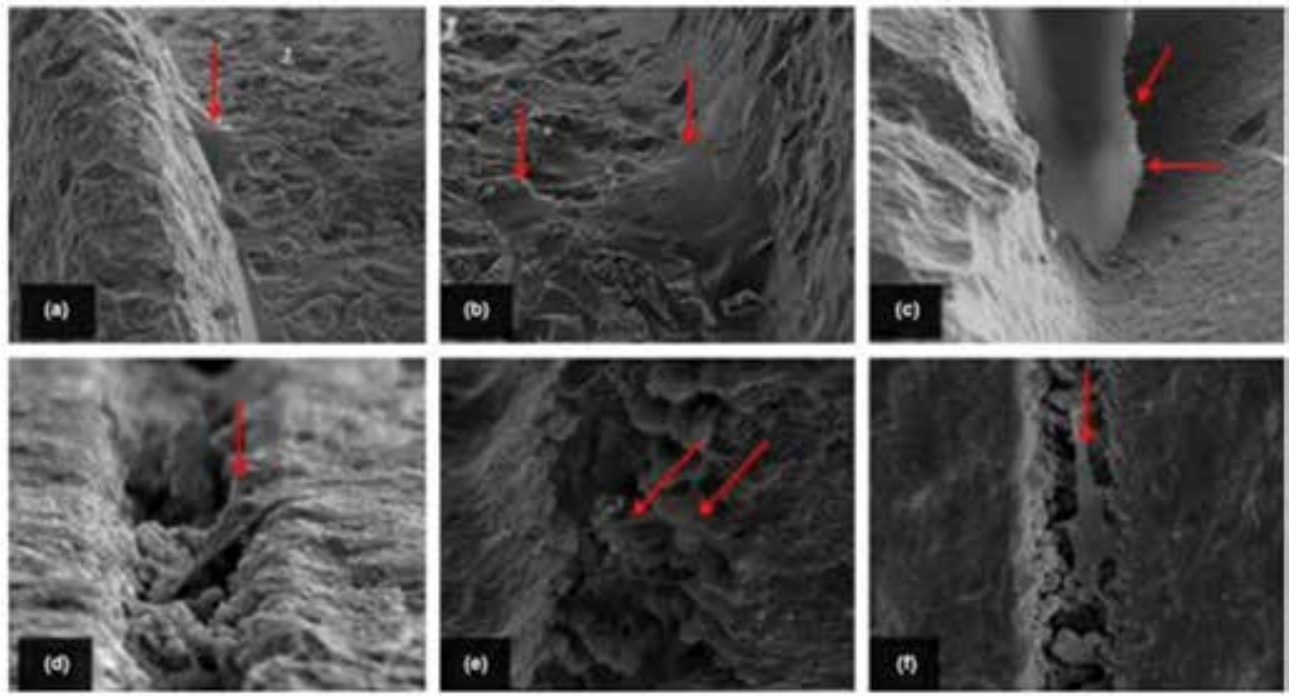

Figure 10. SEM evaluation of cell morphology on sandblasted (a-c) and sandblasted, laser micro grooved zirconia (d-F) at 7 days. (a) a cell in the base of an implant thread; (b) close-up view of a couple of cell bodies close to the base of the thread; (c) a cell body with very short cell lamellipodia located in a crack surface (shown at high magnification); (d) cell at the border of a microgroove; (e) lamellipodia extend inside microgrooves, bridging microgroove borders; (f) cell body aligned in the direction of the microgroove. 
metric evaluation of zirconia implants treated with femtosecond laser revealed that they can be successfully subjected to immediate loading protocol [72].
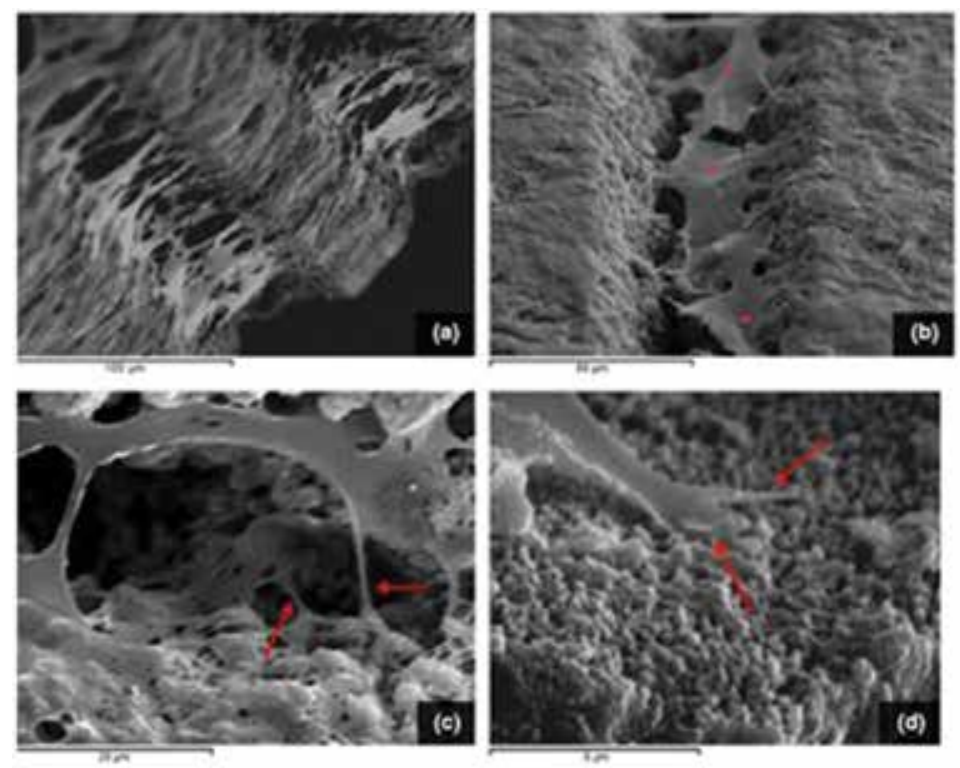

Figure 11. Cells on sandblasted, microgrooved zirconia surface at 7 days (high magnification). (a) lateral view of multiple cells firmly adhered to the inner surface of the microgrooves; (b) cell body alignment at the base of the microgrooves; (c) lamellipodia network at walls and base of the microgrooves; (d) inner wall of a microgroove showing filopodia connected to the nanorough texture of the microgroove walls.
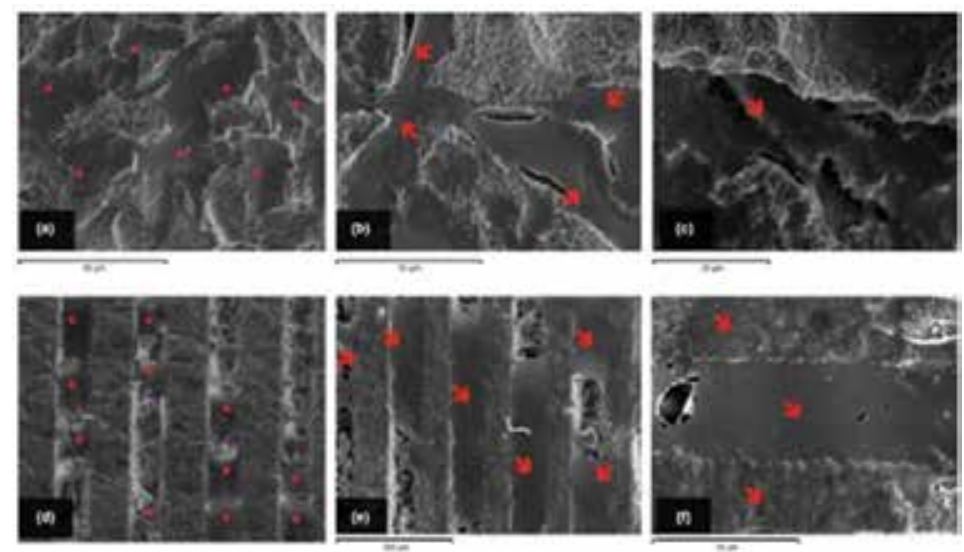

Figure 12. SEM evaluation of cell morphology on sandblasted $(a-c)$ and sandblasted, laser micro grooved zirconia $(d-f)$ at 15 days. The cells established intercellular contacts and formed layers; contact between the cell and the surface occur mainly in topographic accidents (high magnification) (a-c). Cells fill the microgroove completely; cells also form in the pitch areas $(\mathrm{d}-\mathrm{f})$. 


\title{
4. Conclusion and implications for future research
}

Surface modifications are of great clinical importance, regardless of the core implant material, titanium, or zirconium. Hidrophilic and nanostructured SLActive surface accelerates osseointegration and provides conditions for early or immediate loading. This surface ensures predictable implant outcome even in low-density bone due to enhanced biological response. Initial in vitro and in vivo animal studies indicate improved osteoblastic activity, enhanced osseointegration and stabile crestal bone level around microogroved zirconia implants treated with femtosecond laser. This recent findings make them a potential treatment option for everyday implantology. However, future research should examine clinical effects of laser microogroved zirconia implants in randomized clinical trials using sufficient sample size and proven methodology.

\section{Author details}

\author{
Aleksa Markovic \\ Address all correspondence to: maleksa64@gmail.com \\ Faculty of Dental Medicine, Belgrade, Serbia
}

\section{References}

[1] Jemat A, Ghazali MJ, Razali M, Otsuka Y. Surface modifications and their effects on titanium dental implants. BioMed Research International. 2015:(6)1-11.

[2] Wennerberg A, Albrektsson T. Effects of titanium surface topography on bone integration: a systematic review. Clinical Oral Implants Research. 2009;20(Suppl. 4):17284. doi:10.1111/j.1600-0501.2009.01775.x

[3] Dohan Ehrenfest DM, Coelho PG, Kang BS, Sul YT, Albrektsson T. Classification of osseointegrated implant surfaces: materials, chemistry and topography. Trends in Biotechnology. 2010;28(4):198-206. doi:10.1016/j.tibtech.2009.12.003

[4] Kurella A, Dahotre NB. Review paper: surface modification for bioimplants: the role of laser surface engineering. Journal of Biomaterials Applications. 2005;20(1):5-50. doi: $10.1177 / 0885328205052974$

[5] Delgado-Ruiz RA, Calvo-Guirado JL, Moreno P, Guardia J, Gomez-Moreno G, MateSanchez JE, et al. Femtosecond laser microstructuring of zirconia dental implants. Journal of Biomedical Materials Research Part B, Applied Biomaterials. 2011;96(1):91100. doi:10.1002/jbm.b.31743 
[6] Ismail FS, Rohanizadeh R, Atwa S, Mason RS, Ruys AJ, Martin PJ, et al. The influence of surface chemistry and topography on the contact guidance of MG63 osteoblast cells. Journal of Materials Science Materials in Medicine. 2007;18(5):705-14. doi:10.1007/ s10856-006-0012-2

[7] Walboomers $\mathrm{XF}$, Jansen JA. Cell and tissue behavior on micro-grooved surfaces. Odontology. 2001;89(1):2-11. doi:10.1007/s10266-001-8178-z

[8] Wennerberg A, Albrektsson T, Jimbo R, editors. Implant Surfaces and Their Biological and Clinical Impact. Berlin, Heidelberg: Springer-Verlag; 2015, Vol. XII, 182 p.

[9] Gittens RA, Scheideler L, Rupp F, Hyzy SL, Geis-Gerstorfer J, Schwartz Z, et al. A review on the wettability of dental implant surfaces II: biological and clinical aspects. Acta Biomaterialia. 2014;10(7):2907-18. doi:10.1016/j.actbio.2014.03.032

[10] Rupp F, Gittens RA, Scheideler L, Marmur A, Boyan BD, Schwartz Z, et al. A review on the wettability of dental implant surfaces I: theoretical and experimental aspects. Acta Biomaterialia. 2014;10(7):2894-906. doi:10.1016/j.actbio.2014.02.040

[11] Rupp F, Scheideler L, Eichler M, Geis-Gerstorfer J. Wetting behavior of dental implants. The International Journal of Oral \& Maxillofacial Implants. 2011;26(6):1256-66.

[12] Vasak C, Busenlechner D, Schwarze UY, Leitner HF, Munoz Guzon F, Hefti T, et al. Early bone apposition to hydrophilic and hydrophobic titanium implant surfaces: a histologic and histomorphometric study in minipigs. Clinical Oral Implants Research. 2014;25(12):1378-85. doi:10.1111/clr.12277

[13] Lee HJ, Yang IH, Kim SK, Yeo IS, Kwon TK. In vivo comparison between the effects of chemically modified hydrophilic and anodically oxidized titanium surfaces on initial bone healing. Journal of Periodontal \& Implant Science. 2015;45(3):94-100. doi:10.5051/ jpis.2015.45.3.94

[14] Sartoretto SC, Alves AT, Resende RF, Calasans-Maia J, Granjeiro JM, Calasans-Maia MD. Early osseointegration driven by the surface chemistry and wettability of dental implants. Journal of Applied Oral Science: Revista FOB. 2015;23(3):279-87. doi: 10.1590/1678-775720140483

[15] Wilson CJ, Clegg RE, Leavesley DI, Pearcy MJ. Mediation of biomaterial-cell interactions by adsorbed proteins: a review. Tissue Engineering. 2005;11(1-2):1-18. doi: 10.1089/ten.2005.11.1

[16] Olivares-Navarrete R, Hyzy SL, Hutton DL, Erdman CP, Wieland M, Boyan BD, et al. Direct and indirect effects of microstructured titanium substrates on the induction of mesenchymal stem cell differentiation towards the osteoblast lineage. Biomaterials. 2010;31(10):2728-35. doi:10.1016/j.biomaterials.2009.12.029

[17] Zhao G, Schwartz Z, Wieland M, Rupp F, Geis-Gerstorfer J, Cochran DL, et al. High surface energy enhances cell response to titanium substrate microstructure. Journal of Biomedical Materials Research Part A. 2005;74(1):49-58. doi:10.1002/jbm.a.30320 
[18] Hotchkiss KM, Reddy GB, Hyzy SL, Schwartz Z, Boyan BD, Olivares-Navarrete R. Titanium surface characteristics, including topography and wettability, alter macrophage activation. Acta Biomaterialia. 2016;31:425-34. doi:10.1016/j.actbio.2015.12.003

[19] Lim JY, Shaughnessy MC, Zhou Z, Noh H, Vogler EA, Donahue HJ. Surface energy effects on osteoblast spatial growth and mineralization. Biomaterials. 2008;29(12):177684. doi:10.1016/j.biomaterials.2007.12.026

[20] Sennerby L, Meredith N. Implant stability measurements using resonance frequency analysis: biological and biomechanical aspects and clinical implications. Periodontology 2000. 2008;47:51-66. doi:10.1111/j.1600-0757.2008.00267.x

[21] Meredith N. Assessment of implant stability as a prognostic determinant. The International Journal of Prosthodontics. 1998;11(5):491-501.

[22] Nedir R, Bischof M, Szmukler-Moncler S, Bernard JP, Samson J. Predicting osseointegration by means of implant primary stability. Clinical Oral Implants Research. 2004;15(5):520-8. doi:10.1111/j.1600-0501.2004.01059.x

[23] Gallucci GO, Benic GI, Eckert SE, Papaspyridakos P, Schimmel M, Schrott A, et al. Consensus statements and clinical recommendations for implant loading protocols. The International Journal of Oral \& Maxillofacial Implants. 2014;29(Suppl.):287-90. doi: 10.11607/jomi.2013.g4

[24] Olive J, Aparicio C. Periotest method as a measure of osseointegrated oral implant stability. The International Journal of Oral \& Maxillofacial Implants. 1990;5(4):390-400.

[25] Aparicio C. The use of the Periotest value as the initial success criteria of an implant: 8-year report. The International Journal of Periodontics \& Restorative Dentistry. 1997;17(2):150-61.

[26] Eitner S, Schlegel A, Emeka N, Holst S, Will J, Hamel J. Comparing bar and doublecrown attachments in implant-retained prosthetic reconstruction: a follow-up investigation. Clinical Oral Implants Research. 2008;19(5):530-7. doi:10.1111/j. 1600-0501.2007.01500.x

[27] Morris HE, Ochi S, Crum P, Orenstein I, Plezia R. Bone density: its influence on implant stability after uncovering. The Journal of Oral Implantology. 2003;29(6):263-9. doi: 10.1563/1548-1336(2003)029<0263:BDIIOI>2.3.CO;2

[28] Buser D, Mericske-Stern R, Bernard JP, Behneke A, Behneke N, Hirt HP, et al. Longterm evaluation of non-submerged ITI implants. Part 1: 8-year life table analysis of a prospective multi-center study with 2359 implants. Clinical Oral Implants Research. 1997;8(3):161-72.

[29] Rupp F, Scheideler L, Olshanska N, de Wild M, Wieland M, Geis-Gerstorfer J. Enhancing surface free energy and hydrophilicity through chemical modification of microstructured titanium implant surfaces. Journal of Biomedical Materials Research Part A. 2006;76(2):323-34. doi:10.1002/jbm.a.30518 
[30] Zinelis S, Silikas N, Thomas A, Syres K, Eliades G. Surface characterization of SLActive dental implants. The European Journal of Esthetic Dentistry. 2012;7(1):72-92.

[31] Wennerberg A, Albrektsson T. On implant surfaces: a review of current knowledge and opinions. The International Journal of Oral \& Maxillofacial Implants. 2010;25(1):63-74.

[32] Wennerberg A, Galli S, Albrektsson T. Current knowledge about the hydrophilic and nanostructured SLActive surface. Clinical, Cosmetic and Investigational Dentistry. 2011;3:59-67. doi:10.2147/CCIDEN.S15949

[33] Gu YX, Du J, Si MS, Mo JJ, Qiao SC, Lai HC. The roles of PI3K/Akt signaling pathway in regulating MC3T3-E1 preosteoblast proliferation and differentiation on SLA and SLActive titanium surfaces. Journal of Biomedical Materials Research Part A. 2013;101(3):748-54. doi:10.1002/jbm.a.34377

[34] Mamalis AA, Silvestros SS. Analysis of osteoblastic gene expression in the early human mesenchymal cell response to a chemically modified implant surface: an in vitro study. Clinical Oral Implants Research. 2011;22(5):530-7. doi:10.1111/j.1600-0501.2010.02049.x

[35] Raines AL, Olivares-Navarrete R, Wieland M, Cochran DL, Schwartz Z, Boyan BD. Regulation of angiogenesis during osseointegration by titanium surface microstructure and energy. Biomaterials. 2010;31(18):4909-17. doi:10.1016/j.biomaterials.2010.02.071

[36] Kou PM, Schwartz Z, Boyan BD, Babensee JE. Dendritic cell responses to surface properties of clinical titanium surfaces. Acta Biomaterialia. 2011;7(3):1354-63. doi: 10.1016/j.actbio.2010.10.020

[37] Lang NP, Salvi GE, Huynh-Ba G, Ivanovski S, Donos N, Bosshardt DD. Early osseointegration to hydrophilic and hydrophobic implant surfaces in humans. Clinical Oral Implants Research. 2011;22(4):349-56. doi:10.1111/j.1600-0501.2011.02172.x

[38] Branemark PI, Hansson BO, Adell R, Breine U, Lindstrom J, Hallen O, et al. Osseointegrated implants in the treatment of the edentulous jaw. Experience from a 10-year period. Scandinavian Journal of Plastic and Reconstructive Surgery Supplementum. 1977;16:1-132.

[39] Esposito M, Grusovin MG, Willings M, Coulthard P, Worthington HV. The effectiveness of immediate, early, and conventional loading of dental implants: a Cochrane systematic review of randomized controlled clinical trials. The International Journal of Oral \& Maxillofacial Implants. 2007;22(6):893-904.

[40] Chambrone L, Shibli JA, Mercurio CE, Cardoso B, Preshaw PM. Efficacy of standard (SLA) and modified sandblasted and acid-etched (SLActive) dental implants in promoting immediate and/or early occlusal loading protocols: a systematic review of prospective studies. Clinical Oral Implants Research. 2015;26(4):359-70. doi:10.1111/clr. 12347

[41] Bornstein MM, Schmid B, Belser UC, Lussi A, Buser D. Early loading of non-submerged titanium implants with a sandblasted and acid-etched surface. 5-year results of a 
prospective study in partially edentulous patients. Clinical Oral Implants Research. 2005;16(6):631-8. doi:10.1111/j.1600-0501.2005.01209.x

[42] Morton D, Bornstein MM, Wittneben JG, Martin WC, Ruskin JD, Hart CN, et al. Early loading after 21 days of healing of nonsubmerged titanium implants with a chemically modified sandblasted and acid-etched surface: two-year results of a prospective twocenter study. Clinical Implant Dentistry and Related Research. 2010;12(1):9-17. doi: 10.1111/j.1708-8208.2009.00204.x

[43] Ganeles J, Zollner A, Jackowski J, ten Bruggenkate C, Beagle J, Guerra F. Immediate and early loading of Straumann implants with a chemically modified surface (SLActive) in the posterior mandible and maxilla: 1-year results from a prospective multicenter study. Clinical Oral Implants Research. 2008;19(11):1119-28. doi:10.1111/j. 1600-0501.2008.01626.x

[44] Nicolau P, Korostoff J, Ganeles J, Jackowski J, Krafft T, Neves M, et al. Immediate and early loading of chemically modified implants in posterior jaws: 3-year results from a prospective randomized multicenter study. Clinical Implant Dentistry and Related Research. 2013;15(4):600-12. doi:10.1111/j.1708-8208.2011.00418.x

[45] Karabuda ZC, Abdel-Haq J, Arisan V. Stability, marginal bone loss and survival of standard and modified sand-blasted, acid-etched implants in bilateral edentulous spaces: a prospective 15-month evaluation. Clinical Oral Implants Research. 2011;22(8): 840-9. doi:10.1111/j.1600-0501.2010.02065.x

[46] Markovic A, Colic S, Scepanovic M, Misic T, Ethinic A, Bhusal DS. A 1-Year prospective clinical and radiographic study of early-loaded bone level implants in the posterior maxilla. Clinical Implant Dentistry and Related Research. 2015;17(5):1004-13. doi: $10.1111 /$ cid.12201

[47] Jensen OT, editor. The Sinus Bone Graft. Carol Stream, IL, USA: Quintessence Publishing; 1999, pp. 49-68.

[48] Summers RB. A new concept in maxillary implant surgery: the osteotome technique. Compendium. 1994;15(2):152, 4-6, 8 passim; quiz 62.

[49] Jensen OT, Shulman LB, Block MS, Iacono VJ. Report of the sinus consensus conference of 1996. The International Journal of Oral \& Maxillofacial Implants. 1998;13(Suppl.):1145.

[50] Markovic A, Colic S, Drazic R, Gacic B, Todorovic A, Stajcic Z. Resonance frequency analysis as a reliable criterion for early loading of sandblasted/acid-etched active surface implants placed by the osteotome sinus floor elevation technique. The International Journal of Oral \& Maxillofacial Implants. 2011;26(4):718-24.

[51] Markovic A, Misic T, Calvo-Guirado JL, Delgado-Ruiz RA, Janjic B, Abboud M. Twocenter prospective, randomized, clinical, and radiographic study comparing osteotome 
sinus floor elevation with or without bone graft and simultaneous implant placement. Clinical Implant Dentistry and Related Research. 2015. doi:10.1111/cid.12373

[52] Kuchler U, Chappuis V, Bornstein MM, Siewczyk M, Gruber R, Maestre L, et al. Development of Implant Stability Quotient values of implants placed with simultaneous sinus floor elevation - results of a prospective study with 109 implants. Clinical Oral Implants Research. 2016. doi:10.1111/clr.12768

[53] Ihde S, Kopp S, Gundlach K, Konstantinovic VS. Effects of radiation therapy on craniofacial and dental implants: a review of the literature. Oral Surgery, Oral Medicine, Oral Pathology, Oral Radiology, and Endodontics. 2009;107(1):56-65. doi:10.1016/ j.tripleo.2008.06.014

[54] Buddula A, Assad DA, Salinas TJ, Garces YI, Volz JE, Weaver AL. Survival of turned and roughened dental implants in irradiated head and neck cancer patients: a retrospective analysis. The Journal of Prosthetic Dentistry. 2011;106(5):290-6. doi:10.1016/ S0022-3913(11)60133-9

[55] Visch LL, van Waas MA, Schmitz PI, Levendag PC. A clinical evaluation of implants in irradiated oral cancer patients. Journal of Dental Research. 2002;81(12):856-9.

[56] Nelson K, Heberer S, Glatzer C. Survival analysis and clinical evaluation of implantretained prostheses in oral cancer resection patients over a mean follow-up period of 10 years. The Journal of Prosthetic Dentistry. 2007;98(5):405-10. doi:10.1016/ S0022-3913(07)60125-5

[57] Nack C, Raguse JD, Stricker A, Nelson K, Nahles S. Rehabilitation of irradiated patients with chemically modified and conventional SLA implants: five-year follow-up. Journal of Oral Rehabilitation. 2015;42(1):57-64. doi:10.1111/joor.12231

[58] Oates TW, Dowell S, Robinson M, McMahan CA. Glycemic control and implant stabilization in type 2 diabetes mellitus. Journal of Dental Research. 2009;88(4):367-71. doi:10.1177/0022034509334203

[59] Oates TW Jr., Galloway P, Alexander P, Vargas Green A, Huynh-Ba G, Feine J, et al. The effects of elevated hemoglobin $\mathrm{A}(1 \mathrm{c})$ in patients with type 2 diabetes mellitus on dental implants: survival and stability at one year. Journal of the American Dental Association. 2014;145(12):1218-26. doi:10.14219/jada.2014.93

[60] Schlegel KA, Prechtl C, Most T, Seidl C, Lutz R, von Wilmowsky C. Osseointegration of SLActive implants in diabetic pigs. Clinical Oral Implants Research. 2013;24(2):12834. doi:10.1111/j.1600-0501.2011.02380.x

[61] Khandelwal N, Oates TW, Vargas A, Alexander PP, Schoolfield JD, AlexMcMahan C. Conventional SLA and chemically modified SLA implants in patients with poorly controlled type 2 diabetes mellitus-a randomized controlled trial. Clinical Oral Implants Research. 2013;24(1):13-9. doi:10.1111/j.1600-0501.2011.02369.x

[62] Javed F, Al-Hezaimi K, Almas K, Romanos GE. Is titanium sensitivity associated with allergic reactions in patients with dental implants? A systematic review. Clinical 
Implant Dentistry and Related Research. 2013;15(1):47-52. doi:10.1111/j. 1708-8208.2010.00330.x

[63] Kan JY, Rungcharassaeng K, Lozada JL, Zimmerman G. Facial gingival tissue stability following immediate placement and provisionalization of maxillary anterior single implants: a 2- to 8-year follow-up. The International Journal of Oral \& Maxillofacial Implants. 2011;26(1):179-87.

[64] Andreiotelli M, Wenz HJ, Kohal RJ. Are ceramic implants a viable alternative to titanium implants? A systematic literature review. Clinical Oral Implants Research. 2009;20(Suppl. 4):32-47. doi:10.1111/j.1600-0501.2009.01785.x

[65] Scarano A, Di Carlo F, Quaranta M, Piattelli A. Bone response to zirconia ceramic implants: an experimental study in rabbits. The Journal of Oral Implantology. 2003;29(1):8-12. doi:10.1563/1548-1336(2003)029<0008:BRTZCI>2.3.CO;2

[66] Kohal RJ, Wolkewitz M, Hinze M, Han JS, Bachle M, Butz F. Biomechanical and histological behavior of zirconia implants: an experiment in the rat. Clinical Oral Implants Research. 2009;20(4):333-9. doi:10.1111/j.1600-0501.2008.01656.x

[67] Langhoff JD, Voelter K, Scharnweber D, Schnabelrauch M, Schlottig F, Hefti T, et al. Comparison of chemically and pharmaceutically modified titanium and zirconia implant surfaces in dentistry: a study in sheep. International Journal of Oral and Maxillofacial Surgery. 2008;37(12):1125-32. doi:10.1016/j.ijom.2008.09.008

[68] Lee J, Sieweke JH, Rodriguez NA, Schupbach P, Lindstrom H, Susin C, et al. Evaluation of nano-technology-modified zirconia oral implants: a study in rabbits. Journal of Clinical Periodontology. 2009;36(7):610-7. doi:10.1111/j.1600-051X.2009.01423.x

[69] Ferguson SJ, Langhoff JD, Voelter K, von Rechenberg B, Scharnweber D, Bierbaum S, et al. Biomechanical comparison of different surface modifications for dental implants. The International Journal of Oral \& Maxillofacial Implants. 2008;23(6):1037-46.

[70] Boyan BD, Hummert TW, Dean DD, Schwartz Z. Role of material surfaces in regulating bone and cartilage cell response. Biomaterials. 1996;17(2):137-46.

[71] Delgado-Ruiz RA, Gomez Moreno G, Aguilar-Salvatierra A, Markovic A, MateSanchez JE, Calvo-Guirado JL. Human fetal osteoblast behavior on zirconia dental implants and zirconia disks with microstructured surfaces. An experimental in vitro study. Clinical Oral Implants Research. 2015. doi:10.1111/clr.12585

[72] Calvo-Guirado JL, Aguilar-Salvatierra A, Gomez-Moreno G, Guardia J, Delgado-Ruiz RA, Mate-Sanchez de Val JE. Histological, radiological and histomorphometric evaluation of immediate vs. non-immediate loading of a zirconia implant with surface treatment in a dog model. Clinical Oral Implants Research. 2014;25(7):826-30. doi: $10.1111 /$ clr. 12145 
[73] Delgado-Ruiz RA, Markovic A, Calvo-Guirado JL, Lazic Z, Piattelli A, Boticelli D, et al. Implant stability and marginal bone level of microgrooved zirconia dental implants: a 3-month experimental study on dogs. Vojnosanitetski pregled. 2014;71(5):451-61.

[74] Jung YC, Han CH, Lee KW. A 1-year radiographic evaluation of marginal bone around dental implants. The International Journal of Oral \& Maxillofacial Implants. 1996;11(6): 811-8.

[75] Calvo-Guirado JL, Aguilar-Salvatierra A, Delgado-Ruiz RA, Negri B, Fernandez MP, Mate Sanchez de Val JE, et al. Histological and histomorphometric evaluation of zirconia dental implants modified by femtosecond laser versus titanium implants: an experimental study in fox hound dogs. Clinical Implant Dentistry and Related Research. 2015;17(3):525-32. doi:10.1111/cid.12162 
Chapter 8

\title{
The Effects of Surface Roughening Techniques on Surface and Electrochemical Properties of Ti Implants
}

\author{
Youssef Al Jabbari, Wolf Dieter Mueller, \\ Abdulaziz Al-Rasheed and Spiros Zinelis \\ Additional information is available at the end of the chapter \\ http://dx.doi.org/10.5772/62791
}

\begin{abstract}
This chapter deals with the effect of commonly used surface roughening techniques for rapid osseointegration on surface and electrochemical properties of dental implants. Dental implants prepared by smooth machining (MAC), double acid etching (DAE), sandblasting and acid etching (SLA), Ti plasma spray (TPS) and anodization (ANO) were included, and their electrochemical properties were compared to untreated commercially pure titanium (cpTi). The treated surfaces demonstrated great differences in surface roughness, morphology, elemental composition and oxide type. Open circuit potential $(\mathrm{OCP})$ and anodic scan potentiodynamic curves showed that electrochemical properties of treated surfaces are inferior to untreated $\mathrm{cpTi}$ in an original Ringer's solution and a Ringer's solution enriched with $\mathrm{NaF}$ except from the case of ANO where the electrochemical properties were enhanced. Galvanic action between dental implants and prosthetic superstructures and more importantly between the treated root and polished collar of dental implants is also discussed.
\end{abstract}

Keywords: dental implants, electrochemical testing, corrosion, surface roughness, SEM

\section{Introduction}

$\mathrm{Ti}$ and its alloys (Ti-6Al-4V, Ti-6Al-7Nb, Ni-Ti and others) have a long record of applications in dental field. [1-3]. Although Ti is well known for its biocompatibility and excellent corrosion resistance, there are still concerns for the ionic release of $\mathrm{Al}$ and $\mathrm{V}$ from $\mathrm{Ti}$ alloys as they are connected with adverse biological consequences [4-9]. To overwhelm this complica- 
tion, most dental implants are manufactured of commercially pure titanium (cpTi: grade II and IV), although a few implants are still produced by the stronger Ti-6Al-4V alloy.

In first place corrosion of dental implants is not a primary concern as the implant surface is not exposed to oral fluids. Ideally after the implant placement the collar will be covered by the soft tissue at cervical region while root region will be covered by the attached bone. However, under inflammatory conditions like peri-implantitis, the environment can be very acidic and thus much more aggressive. In general, peri-implantitis establishes two changes at the region. The first is a significant decrease in $\mathrm{pH}$ value at the region resulting in a more aggressive environment for Ti surfaces. Both cpTi and Ti6Al4 V alloys showed inferior corrosion resistance in lower $\mathrm{pH}$ while the corrosion rate and kinetic is accelerated [10]. The second is the direct contact of collar and root regions with oral fluids due to the resorption of soft and hard tissues has to be considered. Under these conditions, different corrosion mechanisms can be activated:

Uniform corrosion: Ti surfaces cannot withstand the corrosive action of oral fluids and a uniform regular removal of metal from implant surface is occurred [11].

Pitting corrosion: A form of localized corrosion, where small surface fissures are developed on the metal surface.

Crevice corrosion: Corrosion takes place between two close metallic surfaces as in the case of implant and abutment [12]. Crevice corrosion can be also developed on a deep surface crevice where stagnant conditions of the solution are achieved and oxygen exchange between surface and environment is impossible.

Galvanic corrosion: A galvanic couple is developed when dissimilar metallic materials are placed in contact.

Microbial corrosion: Microbial corrosion or microbiologically-influenced corrosion is the corrosion form caused or promoted by the metabolic actions of microorganisms which reduce the $\mathrm{pH}$ levels.

Fretting corrosion: Fretting corrosion is caused due to micro movements of mechanically connected parts of an implant structure.

Recently, a research study claims that corrosion of dental implants might be not the result but the triggering factor for peri-implantitis [13]. In 2009, Alberkston et al [13] claimed that corrosion along with the presence of aggressive bacteria, lesion of peri-implant attachment and excessive mechanical loading, among the four triggering factors of peri-implantitis. They concluded that "peri-implantitis is a general term dependent on a synergy of several factors, irrespective of the precise reason for first triggering of symptoms" and thus corrosion resistance might be associated with the failure of dental implants.

Although Ti oxide can be instantly rebuilt after an unexpected damage, a recent study has pointed out that the breakdown of the oxide film is followed by a dissolution process which finally deteriorates the corrosion resistance if this happens repeatedly [14]. In a retrieval analysis study, the corrosion and pitting potential of an intra-oral aged implants were found lower compared to unused ones. The retrieved implants showed lower passivation range and 
polarization resistance, indicating that in vivo aging deteriorates the electrochemical properties of Ti implants [15]. Moreover, a retrieval study of four failed dental implants showed that all had been corroded during intra-oral service [16]. The authors concluded that surface oxidation of dental implants might be changed due to the acidic environment developed by bacteria biofilms and/or the inflammatory conditions at the region. This process may permanently breakdown the oxide film facilitating the release of debris and metal ions around the implant. The latter might also hinders the re-integration of bone on implant surface. [16]

Given that corrosion has not yet considered among the risk factors of implant failure there are no specific guidelines to clinicians to minimize the possibility of in vivo corrosion (i.e minimize galvanic coupling between implant and supestructure alloys). Unfortunately, till today, there are no comparative studies on the electrochemical behavior of contemporary dental implants with different surface treatments. A few studies have employed advanced techniques such as electrochemical impedance spectroscopy to characterize the electrochemical properties of anodized and machined dental implants [17-19]. However, the diversity of the applied methods and solutions used for testing makes comparison between the surface treatments rather invalid. A few papers have studied the galvanic coupling of Ti with different dental alloys used for the preparation of implant-retained superstructures providing data for suitable and nonsuitable combinations [20-23]. However, the aforementioned results cannot be directly extrapolated in clinical practice as the experimental conditions are far from intra-oral environment.

\section{Effect of surface roughening techniques on morphology, roughness, composition and oxide type of modified Ti implant surfaces.}

The modification of implant surface in a way to accelerate the osseointegration process is a topic of intense research and competition among implant companies. A variety of surface roughening techniques have been implemented till today including Ti plasma spray (TPS), double acid etching (DAE), sandblasting with large grit and acid etching (SLA), anodization (ANO), machining (MAC) (Table 1), laser etching and others [24].

\begin{tabular}{lll}
\hline Implant (Manufacturer) & Surface treatment & Code \\
\hline Ice (3i, Palm Beach Gardens, FL, USA) & Smooth machining & MAC \\
IMZ TPS (Friedrichsfeld, Mannheim, GER) & Ti plasma-sprayed & TPS \\
OsseotiteFull (3i) & Double acid etched & DAE \\
SLA Active (Institute Straumann, Basel, CH) & Sandblasting, acid etching & SLA \\
Replace Select (Nobel Biocare, Göteborg, Sweden) & Anodized & ANO \\
\hline
\end{tabular}

Table 1. Dental implants, manufacturer, surface roughening technique and code for commercially available products. 
Today, products prepared with the aforementioned techniques are available in dental market as there is no clear evidence for the superiority of one surface modification over the others. The different surface roughening techniques provide characteristic surface patterns on $\mathrm{Ti}$ implant surfaces. MAC is characterized by parallel serrations with a rather smooth surface (Figure 1). TPS provides surfaces with a random distribution of small granules resemble to solidified droplets probably due to plasma spray process along with a random distribution of surface cracks (Figure 1). DAE and SLA depict some similarities due to the final step of acid etching, although SLA illustrates shallow grooves probably due to grit blasting before etching. ANO is characterized by valleys and open craters although the size, the shape and the distribution of these craters are significantly dependent on operational parameters during anodization.

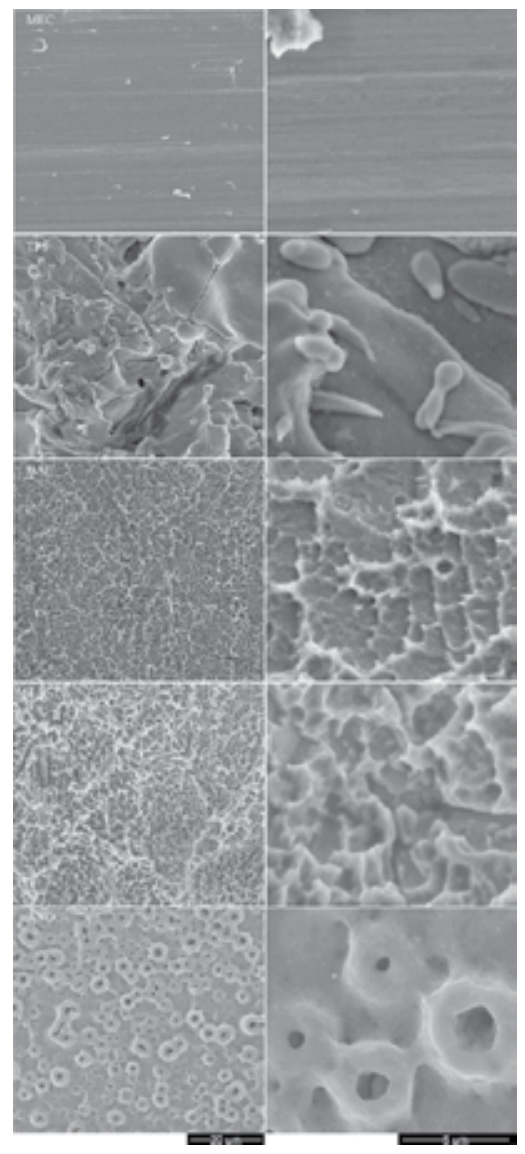

Figure 1. Secondary electron images from the root surface of dental implants in 4000 (left) and 24000 (right) nominal magnifications. Parallel serrations are shown on MAC surface due to surface grinding. TPS provides surfaces with a random distribution of small granules along with surface cracks. DAE and SLA illustrate some similarities due to the final step of acid etching although SLA demonstrates shallow grooves associated to grit blasting before etching. ANO is characterized by open craters and valleys. 
3D profilometric images (Figure 2) provide a better idea for the highest (red) and lowest (blue) areas of each surface. For MAC the highest points are the ridges of serrations while for TPS randomly distributed granular regions. The highest points for SLA are region surrounding valleys while the top of craters constitutes the highest points for ANO. Table 2 presents representative values for roughness parameters from dental literature. In general, the implants' surfaces are classified based on Sa (average roughness over the complete 3D surface) in smooth $(0.0-0.4 \mu \mathrm{m})$, minimally rough $(0.5-1.0 \mu \mathrm{m})$, moderately rough $(1.0-2.0 \mu \mathrm{m})$ and rough $(>2 \mu \mathrm{m})$ [25]. The first category includes the well-polished implant collars while MAC and DAE are classified as minimally rough surfaces. SLA and ANO belong to moderately rough surfaces and TPS to rough ones. Despite this general classification, it must be noted that manufacturers can modify the procedural parameters, and thus commercially available implants might have big differences in their surface roughness even if they are prepared by the same surface roughening technique.

From corrosion standpoint, this difference in surface roughness might trigger the crevice corrosion mechanism. In this mechanism, the surface can withstand the corrosive environment but the stagnant solution in the crevice changes the chemistry increasing the aggressiveness of solution.
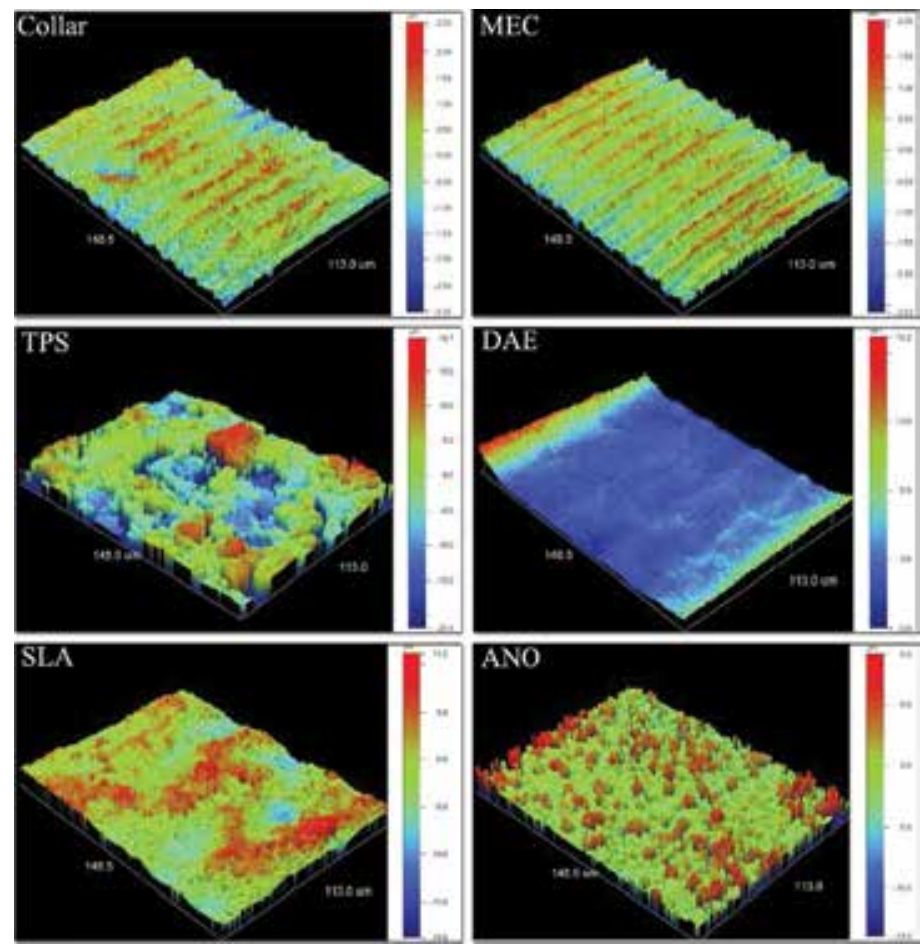

Figure 2. Representative 3D profilometric images from the collar (representative from all implants) and the surfaces of differently modified root surfaces. Red areas are the highest and blue the lowest areas of each surface. Note the difference in scale among 3D images. 


\begin{tabular}{llll}
\hline & Sa [26] & Sa [27] & Ra [24] \\
\hline Collar & & $0-0.4$ & \\
MAC & 0.9 & 0.5 & 0.2 \\
TPS & 5.2 & & 7.0 \\
DAE & 0.9 & 0.5 & 1.2 \\
SLA & 2.6 & 1.6 & \\
ANO & 1.7 & 2.0 & \\
\hline
\end{tabular}

Table 2. Sa (average roughness over the complete 3D surface) and Ra (average roughness along X or Y axes) values for collar and root regions of implants from dental literature.

Implant surfaces are further differentiated in elemental composition as appeared by EDX analysis (Figure 3). All spectra showed $\mathrm{C}$ and $\mathrm{N}$ which should be appended to surface contamination while $\mathrm{O}$ should be attributed to surface oxide film. For SLA, Na and Cl were also identified and might be appended to residues of $\mathrm{NaCl}$ solution where the implant is placed to avoid atmospheric contamination. $\mathrm{P}$ in ANO has been retained from the solution used during anodization.

Although Ti oxide is spontaneously formed when Ti is exposed to atmospheric oxygen, a recent study employing Raman analysis illustrated great differences among the oxide type developed on different surfaces [28]. According to the results of this study, MAC surface contains mainly

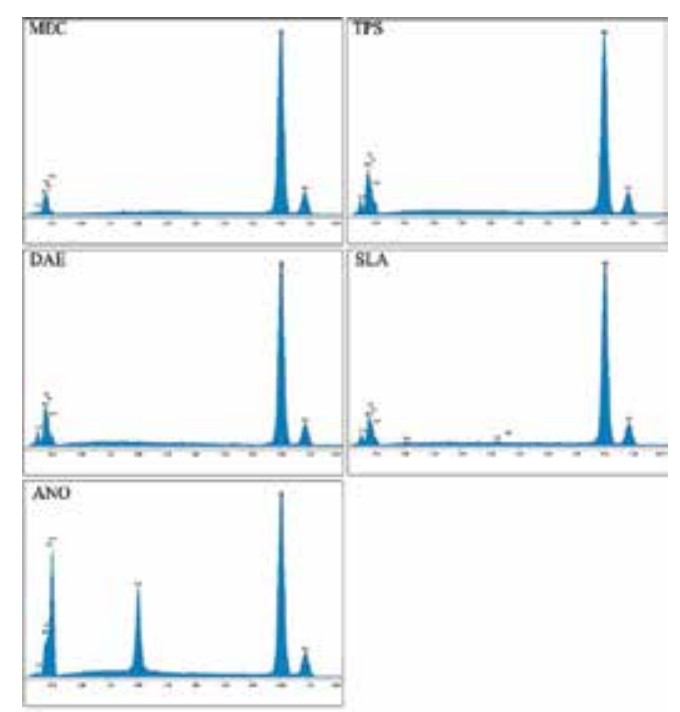

Figure 3. X-ray EDS spectra from the root surface of dental implants prepared by different surface roughening techniques. All surfaces illustrated the presence of Ti while $\mathrm{C}$ and $\mathrm{N}$ should be appended to surface contamination. The presence of $\mathrm{O}$ is involved with oxide film. $\mathrm{Na}$ and $\mathrm{Cl}$ were also identified for SLA and might be appended to residues of $\mathrm{NaCl}$ solution where the implant is stored. $\mathrm{P}$ in $\mathrm{ANO}$ has been retained from the solution used during anodization. 
amorphous Ti oxide and less anatase, TPS amorphous and less rutile, DAE mainly $\mathrm{Ti}_{2} \mathrm{O}_{3}$ and amorphous and less rutile, SLA mainly Brookite and lesser rutile and ANO anatase and less rutile. Given the big differences in all the aforementioned properties, different electrochemical properties are anticipated.

\section{Electrochemical properties}

All the surfaces show an almost steady open circuit potential (OCP) in Ringer's (Figure 4), indicating a rapid establishment of equilibrium between surface and solution. The OCP values range from -0.28 up to $-0.05 \mathrm{~V}$ while cpTi showed $-0.05 \mathrm{~V}$ close to previous reported values [29]. OCP curves illustrate that the potential of all surfaces is quickly stabilized. MAC and TPS showed values close to cpTi while SLA and ANO showed slightly lower OCP values. A few peaks at ANO curve might be appended to reactions taking place at the surface craters. However this is only a speculation and it needs further experimental verification. DAE showed the lowest OCP value. All the treated surfaces showed lower OCP values compared to cpTi a finding which has been also detected for sandblasting compared to reference Ti surface [30].

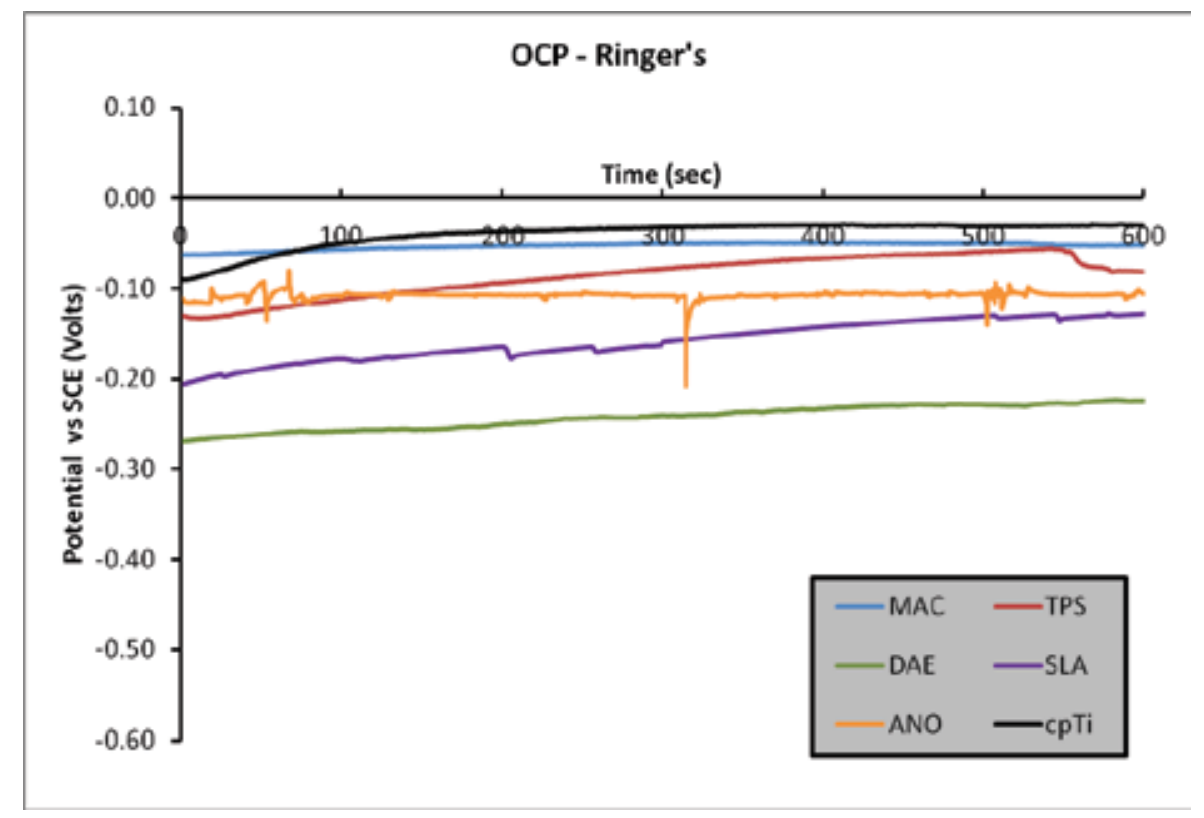

Figure 4. Open circuit potential (OCP) curves in Ringer's solution. All implants show an almost steady curve over the time, indicating a rapid establishment of equilibrium between surface and solution. The ionization tendency is increased towards lower OCP values.

Figure 5 illustrates representative anodic scan curves along with a small part of reverse scanning while the electrochemical data are presented in Table 3. SLA and TPS demonstrate a few oxidation peaks (pointed by the black arrows) while all curves show negative hysteresis implying that the oxide film can be reformed after an unexpected breakdown. Similar $\mathrm{E}_{\text {corr }}$ 
values have been reported in dental literature (-0.35 V [31], $-0.4 \mathrm{~V}$ [32] and $-0.18 \mathrm{~V}$ [29]). However, all $\mathrm{E}_{\text {corr }}$ values of treated surfaces moved cathodically denoting an increase tendency of surface to react. All surfaces show a passivation region and $\mathrm{E}_{\mathrm{pit}}$ of $\mathrm{cpTi}$ was found close to previously reported values $\left(0.45 \mathrm{~V}\right.$ [32]. ANO showed the highest $\mathrm{E}_{\text {pit }}$ (Table 3 ) compared to others.

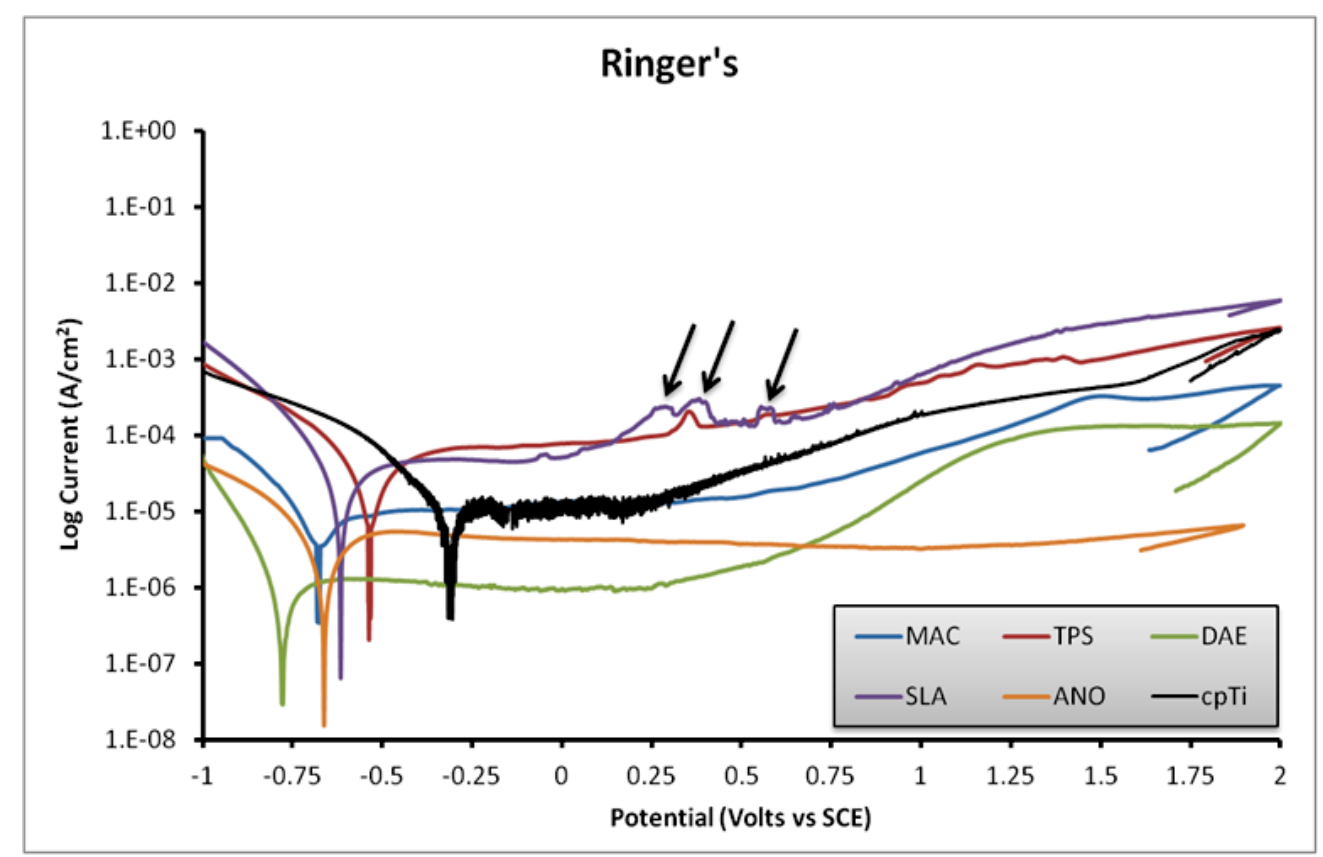

Figure 5. Anodic scans from dental implants with different surface modifications. Oxidation peaks (pointed by black arrows) were identified for TPS and SLA. All the surfaces showed a breakdown potential $\left(\mathrm{E}_{\mathrm{pit}}\right)$ and negative hysteresis in reverse scanning (a small part of reverse scanning curve at $2 \mathrm{~V}$ is appeared for all materials).

\begin{tabular}{lllll}
\hline & $\begin{array}{l}\mathrm{E}_{\text {corr }} \\
(\mathbf{V})\end{array}$ & $\begin{array}{l}\mathbf{I}_{\text {corr }} \\
\left(\mu \mathrm{A} / \mathbf{c m}^{2}\right)\end{array}$ & $\begin{array}{l}\mathrm{E}_{\text {pit }} \\
(\mathbf{V})\end{array}$ & Hysteresis \\
\hline cpTi & -0.27 & 3.8 & 0.22 & Negative \\
MAC & -0.84 & 3.6 & 0.55 & Negative \\
TPS & -0.52 & 20.3 & 0.43 & Negative \\
DAE & -0.79 & 7.4 & 0.29 & Negative \\
SLA & -0.62 & 39.4 & 0.04 & Negative \\
ANO & -0.68 & 3.4 & 1.26 & Negative \\
\hline
\end{tabular}

Table 3. $\mathrm{E}_{\text {corr }} \mathrm{I}_{\text {corr }} \mathrm{E}_{\text {pit }}$ and type of hysteresis from the anodic scan curves obtained in Ringer's solution. Higher $\mathrm{E}_{\text {corr }}$ and $\mathrm{E}_{\text {pit }}$ lower $\mathrm{I}_{\text {corr }}$ and negative hysteresis benefit the corrosion resistance. 


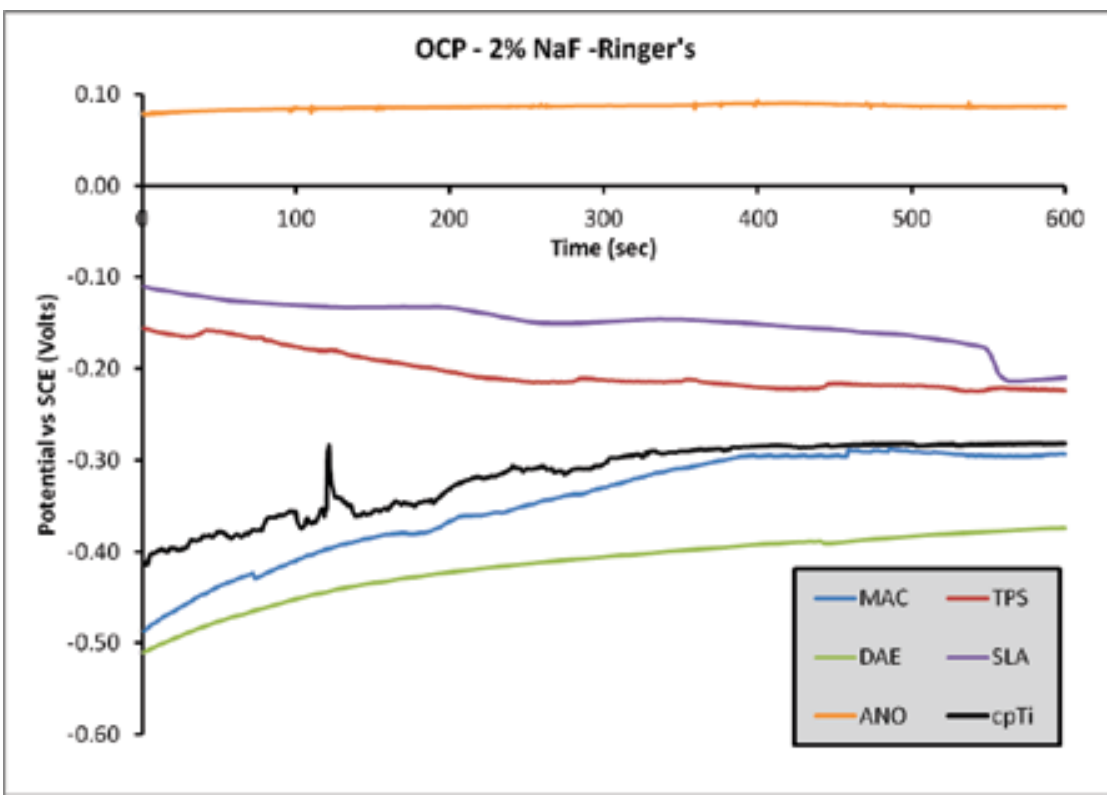

Figure 6. OCP curves in $2 \% \mathrm{NaF}+$ Ringer's solution. ANO showed an increase in OCP values compared to Ringer's solution. However, the OCP values of the rest implants moved cathodically although potential is again quickly stabilized as in the original Ringer's solution.

Many researchers have focused on the effect of fluoride ions on the corrosion resistance of dental implants as many dental products such as toothpastes, mouthwashes, prophylactics gels and others are proposed for the oral hygiene of patients with dental implants. However, Ti oxide is very vulnerable to fluoride ions and thus the corrosion resistance of dental implants is seriously compromised [33-35]. Generally, in $\mathrm{F}^{-}$containing media the surface of Ti showed a strongly bound complex $\mathrm{Na}_{2} \mathrm{TiF}_{6}$ followed by a huge increase in surface roughness [36] However, the presence of $\mathrm{F}^{-}$reduces the corrosion resistance of dental alloys too [37]. In Ringer's solution with $2 \% \mathrm{NaF}$ all OCP curves moved cathodically in a range from -0.4 to -0.2 V. Previous studies reported that OCP of cpTi in Ringer's solution is ranged between -0.08 [29] and $0.05 \mathrm{~V}$ [38], implying that the surface roughening techniques applied have moved the OCP cathodically. Surprisingly, ANO showed an increase in OCP in the $2 \% \mathrm{NaF}+$ Ringer's solution, while the OCP of the rest implants moved cathodically due to the more aggressive nature of this reagent. However, the potential is again quickly stabilized as in the original Ringer's solution.

Similar to Ringer's solution the anodic scan curves showed that surface roughening techniques move $\mathrm{E}_{\text {corr }}$ value to lower values while passive region was vanished for cpTi, MAC and SLA. In addition, DAE and MAC showed positive hysteresis denoting that in the case of oxide breakdown the reformation of the oxide film is impossible under these conditions (Figure 7). Again ANO showed the best corrosion resistance properties demonstrating the highest (1.32 V) $\mathrm{E}_{\text {pit }}$ value (Table 4). 


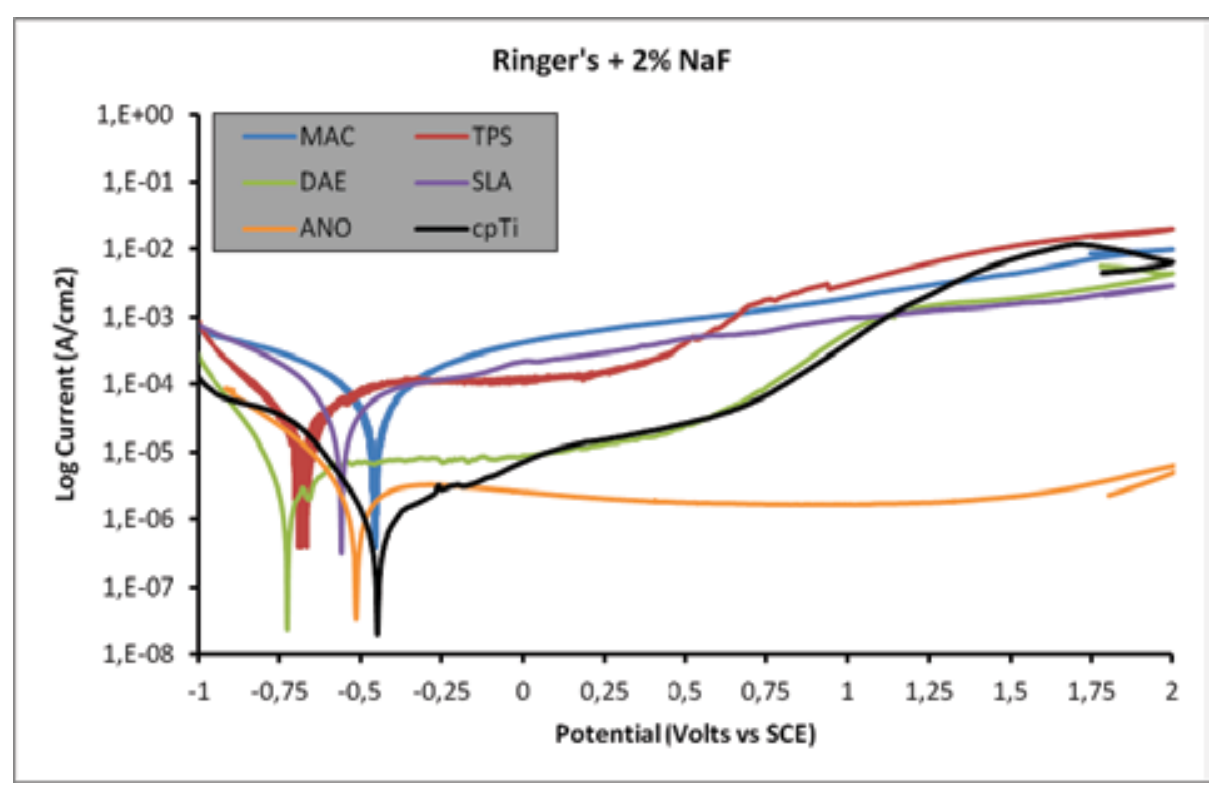

Figure 7. Representative anodic scans from dental implants with different surface modifications. All surfaces showed a breakdown potential while MAC and DAE demonstrated a positive hysteresis in reverse scanning (a small part of reverse scanning curve at $2 \mathrm{~V}$ is appeared for all materials).

\begin{tabular}{lllll}
\hline & $\begin{array}{l}\mathbf{E}_{\text {corr }} \\
(\mathbf{V})\end{array}$ & $\begin{array}{l}\mathbf{I}_{\text {corr }} \\
\left(\boldsymbol{\mu} \mathbf{A} / \mathbf{c m}^{2}\right)\end{array}$ & $\begin{array}{l}\mathbf{E}_{\text {pit }} \\
(\mathbf{V})\end{array}$ & Hysteresis \\
\hline cpTi & -0.42 & 1.7 & Without passive region & Negative \\
MAC & -0.47 & 46.2 & Without passive region & Positive \\
TPS & -0.69 & 19.1 & 0.20 & Negative \\
DAE & -0.72 & 4.0 & 0.18 & Positive \\
SLA & -0.68 & 83.8 & Without passive region & Negative \\
ANO & -0.56 & 1.8 & 1.32 & Negative \\
\hline
\end{tabular}

Table 4. $\mathrm{E}_{\text {corr }} \mathrm{I}_{\text {corr }} \mathrm{E}_{\text {pit }}$ and type of hysteresis from the anodic scan curves acquired in $2 \% \mathrm{NaF}+$ Ringer's solution. Higher $\mathrm{E}_{\text {corr }}$ and $\mathrm{E}_{\mathrm{pit}}$ lower $\mathrm{I}_{\text {corr }}$ and negative hysteresis benefit the corrosion resistance.

There is limited knowledge for the effect of surface roughening techniques on electrochemical properties of dental implants. OCP and anodic scans showed that sandblasting deteriorates the electrochemical properties of Ti surface, a finding that has already been reported by previous studies [30]. A speculation for this behavior is that the residual stresses developed in the subsurface during sandblasting have a detrimental effect on corrosion properties. The same trend was identified for both the Ti6Al4V and Ti6Al7Nb alloys after sandblasting in phosphatebuffered solution (PBS) [39]. However, all previous studies on ANO surfaces agreed that ANO has a positive effect on electrochemical properties. This has been tested in a variety of reagents 
including PBS and media with cells simulating inflammatory conditions [17], Ringer's [40], PBS [41] and $0.9 \% \mathrm{NaCl}$ [42]. Interestingly the same findings were found for Ti6Al4V and Ti6Al7Nb [42]. Recent data showed that no correlation was identified between roughness parameters and electrochemical properties in both the aforementioned solutions meaning that surface roughness cannot affect the corrosion resistance and thus the electrochemical properties are not dependent on how rough the surface is [26].

\section{The galvanic aspect}

Galvanic coupling can be easily developed in the oral cavity between dental implants and implant-retained superstructures especially under peri-implantitis conditions. Concerning the galvanic couple of Ti with dental alloys, a few studies have been conducted employing different reagents. Tables 5, 6 and 7 illustrate potential differences of various galvanic couples between $\mathrm{Ti}$ and dental alloys. The values are sorted in descending order from the highest positive value towards the lower negative value. In most cases, the precious alloys show positive values implying that Ti will be under anodic control. In this scenario if the galvanic corrosion is triggered, then the alloy under cathodic control (precious alloys) remains immune while $\mathrm{Ti}$ will be dissolved. In contrast $\mathrm{Ti}$ is in cathodic control with all base $\mathrm{Co}-\mathrm{Cr}$ and $\mathrm{Ni}-\mathrm{Cr}$ alloys which means that Ti will be protected while the base alloys will be corroded under the galvanic action [21]. Given that galvanic action is triggered when the difference in potential is above $0.2 \mathrm{~V}$ the couples with minimal difference to $\mathrm{Ti}$ is ideal to avoid galvanic action and corrosion of one of the two alloys. As implant-retained superstructures are replaced easier than implants themselves, it is recommended that dental implants should be under minimal cathodic control.

\begin{tabular}{ll}
\hline Couple & $\begin{array}{l}\text { Potential } \\
\text { (V) }\end{array}$ \\
\hline (Ti)/(60Pd-28Ag-6Sn-6In) & 0.067 \\
(Ti)/(40Au-35Ag-7.9Pd-7Cu-5In-3.5Zn) & 0.002 \\
(Ti)/(63.5Co-30Cr30-5Mo-1Si) & -0.027 \\
(Ti)/(61Ni-26Cr-11Mo-1.5Si) & -0.031 \\
(Ti)/(61Co-25Cr-7Mo-5W-1.5Si) & -0.107 \\
\hline
\end{tabular}

Table 5. Difference in potential between Ti and dental alloys in modified artificial saliva with pH 7.2 [20].

However, all previous values used smoothly machined or polished Ti surfaces which achieved great difference in OCP values with treated root surfaces (Figures 4 and 6). DAE have almost $0.2 \mathrm{~V}$ difference with MAC surface which can be representative of collar. This means that the exposure of DAE surface and collar to Ringer's solution is close to galvanic threshold. Differences with MAC surface (collar) is even higher in the case of $\% \mathrm{NaF}+$ Ringer's solution denoting that galvanic corrosion is still possible between collar and root of the implant itself 
in some cases. Of course, the presence of superstructure facilitates the galvanic phenomena more. However there is limited knowledge on this matter and definitely further research is required in this topic while the development of guidelines for clinicians to minimize intraoral corrosion of dental implants might have a beneficial effect on longevity of implant-retained restorations.

\begin{tabular}{ll}
\hline Couple & $\begin{array}{l}\text { Potential } \\
\text { (V) }\end{array}$ \\
\hline$(\mathrm{Ti}) /(68.9 \mathrm{Ag}-26 \mathrm{Pd} 26-4 \mathrm{Cu}-0.9 \mathrm{Au}-0.1 \mathrm{In}-0.1 \mathrm{Zn})$ & -0.09 \\
$(\mathrm{Ti}) /(76.5 \mathrm{Au}-12 \mathrm{Ag}-8 \mathrm{Cu}-2 \mathrm{Pd}-1.5 \mathrm{Pt})$ & -0.14 \\
$(\mathrm{Ti}) /(66.5 \mathrm{Ni}-22 \mathrm{Cr}-9 \mathrm{Mo}-1.6 \mathrm{Si} 0.5 \mathrm{Fe}-0.4 \mathrm{Ce})$ & -0.22 \\
$(\mathrm{Ti}) /(67 \mathrm{Co}-28.5 \mathrm{Cr}-4.5 \mathrm{Mo})$ & -0.31 \\
\hline
\end{tabular}

Table 6. Difference in potential between Ti and dental alloys in artificial saliva at $37^{\circ} \mathrm{C}$ [12].

\begin{tabular}{ll}
\hline Couple & $\begin{array}{l}\text { Potential } \\
\text { (V) }\end{array}$ \\
\hline$(\mathrm{Ti}) /(60 \mathrm{Au}-24 \mathrm{Pt}-15 \mathrm{Pd})$ & 0.210 \\
$(\mathrm{Ti}) /(85.5 \mathrm{Au}-6.5 \mathrm{Pt}-4.8 \mathrm{Pd}-1.5 \mathrm{Ag})$ & 0.175 \\
$(\mathrm{Ti}) /(51.5 \mathrm{Au}-38.4 \mathrm{Pd}-8.5 \mathrm{In}-1.5 \mathrm{Ga})$ & 0.148 \\
$(\mathrm{Ti}) /(65 \mathrm{Ag}-23 \mathrm{Pd}-6.4 \mathrm{Cu}-2 \mathrm{In})$ & 0.099 \\
$(\mathrm{Ti}) /(68.5 \mathrm{Au}-11.7 \mathrm{Cu}-11 \mathrm{Ag}-3.8 \mathrm{Pd}-3.5 \mathrm{Pt}-1.5 \mathrm{Zn})$ & 0.097 \\
$(\mathrm{Ti}) /(71 \mathrm{Au}-14.5 \mathrm{Cu}-9 \mathrm{Ag}-2 \mathrm{Pd}-2 \mathrm{Pt}-1.5 \mathrm{Zn})$ & 0.088 \\
$(\mathrm{Ti}) /(63 \mathrm{Ni}-21.7 \mathrm{Cr}-10.8 \mathrm{Mo}-1.8 \mathrm{Fe}-1.5 \mathrm{Si}-1 \mathrm{~W})$ & -0.132 \\
$(\mathrm{Ti}) /(65.2 \mathrm{Ni}-21.6 \mathrm{Cr}-10.5 \mathrm{Mo} 1.3 \mathrm{Si}-0.7 \mathrm{Fe}-0.5 \mathrm{Mn}-0.2 \mathrm{Yt})$ & -0.167 \\
$(\mathrm{Ti}) /(79.2 \mathrm{Ni}-14.5 \mathrm{Cr}-6 \mathrm{Mo}-0.3 \mathrm{Co})$ & -0.191 \\
$(\mathrm{Ti}) /(77.5 \mathrm{Ni}-13.3 \mathrm{Cr}-3.1 \mathrm{Mo}-2 \mathrm{Ti}-1.5 \mathrm{Be}-1 \mathrm{Si}-0.5 \mathrm{Co})$ & -0.229 \\
$(\mathrm{Ti}) /(78.4 \mathrm{Ni}-13 . \mathrm{Cr}-4.5 \mathrm{Mo}-3.4 \mathrm{Al}-0.6 \mathrm{Fe})$ & -0.274 \\
\hline
\end{tabular}

Table 7. Difference in potential between Ti and dental alloys in Fusayama reagent with $\mathrm{pH} 5$ at $37^{\circ} \mathrm{C}$ [21].

\section{Conclusions}

- Surface roughening techniques significantly affect the roughness, morphology, elemental composition, oxide type and electrochemical properties of Ti implants.

- Electrochemical properties of dental implants are inferior compared to untreated cpTi apart from that of ANO where the electrochemical properties are enhanced. 
- Galvanic action might be seriously implicated in corrosion under clinical conditions, a factor associated recently to peri-implantitis.

- Extensive research must be exerted in order to minimize the galvanic phenomena among treated root, polished collar and implant-retained superstructure.

- ANO of Ti surface significantly increases the electrochemical properties of dental implants but these findings must be verified by clinical data.

\section{Acknowledgements}

This chapter was supported financially by Vice Deanship of scientific research and research chairs, King Saud University, Riyadh, Saudi Arabia

\section{Author details}

Youssef Al Jabbari1 ${ }^{1,2^{*}}$, Wolf Dieter Mueller ${ }^{3}$, Abdulaziz Al-Rasheed ${ }^{2,4}$ and Spiros Zinelis ${ }^{5,2}$

*Address all correspondence to: yaljabbari@ksu.edu.sa

1 Prosthetic Dental Sciences Department, School of Dentistry, King Saud University, Riyadh, Saudi Arabia

2 Dental Biomaterials Research and Development Chair, School of Dentistry, King Saud University, Riyadh, Saudi Arabia

3 Dental and Biomaterial Research Group, Dental School, “Charite” Medical University of, Berlin, Germany

4 Periodontics and Community Dentistry Department, School of Dentistry, King Saud University, Riyadh, Saudi Arabia

5 Department of Biomaterials, School of Dentistry, National and Kapodistrian University of Athens, Athens, Greece

\section{References}

[1] Zinelis S, Eliades T, Eliades G. A metallurgical characterization of ten endodontic NiTi instruments: assessing the clinical relevance of shape memory and superelastic properties of Ni-Ti endodontic instruments. Int. Endod. J. 2010;43:125-134. 
[2] Gioka C, Bourauel C, Zinelis S, Eliades T, Silikas N, Eliades G. Titanium orthodontic brackets: structure, composition, hardness and ionic release. Dent. Mater. 2004;20:693700 .

[3] Zinelis S. Effect of pressure of helium, argon, krypton, and xenon on the porosity, microstructure, and mechanical properties of commercially pure titanium castings. J. Prosthet. Dent. 2000;84:575-582.

[4] Steinemann SG. Metal implants and surface reactions. Injury 1996;27 Suppl 3:SC16SC22.

[5] Steinemann SG. Titanium--the material of choice? Periodontol 2000. 1998;17:7-21.

[6] Buser D, Broggini N, Wieland M, Schenk RK, Denzer AJ, Cochran DL, et al. Enhanced bone apposition to a chemically modified SLA titanium surface. J. Dent. Res. 2004;83:529-533.

[7] Zreiqat H, Valenzuela SM, Nissan BB, Roest R, Knabe C, Radlanski RJ, et al. The effect of surface chemistry modification of titanium alloy on signalling pathways in human osteoblasts. Biomaterials 2005;26:7579-7586.

[8] Okazaki Y, Gotoh E, Manabe T, Kobayashi K. Comparison of metal concentrations in rat tibia tissues with various metallic implants. Biomaterials 2004;25:5913-5920.

[9] Okazaki Y, Gotoh E. Comparison of metal release from various metallic biomaterials in vitro. Biomaterials 2005;26:11-21.

[10] Barao VA, Mathew MT, Assuncao WG, Yuan JC, Wimmer MA, Sukotjo C. Stability of cp-Ti and Ti-6Al-4V alloy for dental implants as a function of saliva $\mathrm{pH}$ - an electrochemical study. Clin. Oral Implants Res. 2012;23:1055-1062.

[11] Chaturvedi TP. An overview of the corrosion aspect of dental implants (titanium and its alloys). Indian J. Dent. Res. 2009;20:91-98.

[12] Oh KT, Kim KN. Electrochemical properties of suprastructures galvanically coupled to a titanium implant. J. Biomed. Mater. Res. B Appl. Biomater. 2004;70:318-331.

[13] Mouhyi J, Dohan Ehrenfest DM, Albrektsson T. The peri-implantitis: implant surfaces, microstructure, and physicochemical aspects. Clin. Implant. Dent. Relat. Res. 2012;14:170-183.

[14] MarinoCu EB, Mascaro LH. EIS characterization of a Ti-dental implant in artificial saliva media: dissolution process of the oxide barrier. J. Electroanal. Chem. 2004;568:115-120.

[15] Chung C-H, Kim H-J, Jeong Y-T, Son M-K, Jeong Y-H, Choe H-C. Electrochemical behavior of dental implant system before and after clinical use. Trans. Nonferrous Metals Soc. China 2009;19:846-851. 
[16] Rodrigues D, Valderrama P, Wilson T, Palmer K, Thomas A, Sridhar S, et al. Titanium corrosion mechanisms in the oral environment: a retrieval study. Materials 2013;6:5258-5274.

[17] Messer RL, Seta F, Mickalonis J, Brown Y, Lewis JB, Wataha JC. Corrosion of phosphateenriched titanium oxide surface dental implants (TiUnite) under in vitro inflammatory and hyperglycemic conditions. J. Biomed. Mater. Res. B Appl. Biomater. 2010;92:525534.

[18] Yu WQ, Qiu J, Xu L, Zhang FQ. Corrosion behaviors of TiO2 nanotube layers on titanium in Hank's solution. Biomed. Mater. 2009;4:065012.

[19] Bozzini B, Carlino P, D’Urzo L, Pepe V, Mele C, Venturo F. An electrochemical impedance investigation of the behaviour of anodically oxidised titanium in human plasma and cognate fluids, relevant to dental applications. J. Mater. Sci. Mater. Med. 2008;19:3443-3453.

[20] Taher NM, Al Jabab AS. Galvanic corrosion behavior of implant suprastructure dental alloys. Dent. Mater. 2003;19:54-59.

[21] Reclaru L, Meyer JM. Study of corrosion between a titanium implant and dental alloys. J. Dent. 1994;22:159-168.

[22] Grosgogeat B, Reclaru L, Lissac M, Dalard F. Measurement and evaluation of galvanic corrosion between titanium/Ti6A14V implants and dental alloys by electrochemical techniques and auger spectrometry. Biomaterials 1999;20:933-941.

[23] Cortada M, Giner L, Costa S, Gil FJ, Rodriguez D, Planell JA. Galvanic corrosion behavior of titanium implants coupled to dental alloys. J. Mater. Sci. Mater. Med. 2000;11:287-293.

[24] Le Guehennec L, Soueidan A, Layrolle P, Amouriq Y. Surface treatments of titanium dental implants for rapid osseointegration. Dent. Mater. 2007;23:844-854.

[25] Albrektsson T, Wennerberg A. Oral implant surfaces: Part 1--review focusing on topographic and chemical properties of different surfaces and in vivo responses to them. Int. J. Prosthodont. 2004;17:536-543.

[26] Zinelis S. Surface and electrochemical characterization of contemporary Ti implants with different surface modifications. Athens: National and Kapodistrian University of Athens; 2016.

[27] Albrektsson T, Wennerberg A. Oral implant surfaces: Part 2--review focusing on clinical knowledge of different surfaces. Int. J. Prosthodont. 2004;17:544-564.

[28] Gaintantzopoulou M, Zinelis S, Silikas N, Eliades G. Micro-Raman spectroscopic analysis of $\mathrm{TiO}(2)$ phases on the root surfaces of commercial dental implants. Dent. Mater. 2014;30:861-867. 
[29] Robin A, Carvalho OAS. Influence of $\mathrm{pH}$ and fluoride species on the corrosion behavior of Ti-xNb-13Zr alloys in Ringer's solution; 2013. p. 10.

[30] Aparicio C, Gil FJ, Fonseca C, Barbosa M, Planell JA. Corrosion behaviour of commercially pure titanium shot blasted with different materials and sizes of shot particles for dental implant applications. Biomaterials 2003;24:263-273.

[31] Li J, Zhou L, Li Z. Corrosion behaviors of a new titanium alloy TZNT for surgical implant application in Ringer's solution. Rare Metals 2010;29:37-44.

[32] Alkhateeb E, Virtanen S. Influence of surface self-modification in Ringer's solution on the passive behavior of titanium. J. Biomed. Mater. Res. A 2005;75:934-940.

[33] Anwar EM, Kheiralla LS, Tammam RH. Effect of fluoride on the corrosion behavior of $\mathrm{Ti}$ and Ti6Al4V dental implants coupled with different superstructures. J. Oral Implantol. 2011;37:309-317.

[34] Nakagawa M, Matsuya S, Shiraishi T, Ohta M. Effect of fluoride concentration and $\mathrm{pH}$ on corrosion behavior of titanium for dental use. J. Dent. Res. 1999;78:1568-1572.

[35] Rodrigues AV, Oliveira NT, dos Santos ML, Guastaldi AC. Electrochemical behavior and corrosion resistance of Ti-15Mo alloy in naturally-aerated solutions, containing chloride and fluoride ions. J. Mater. Sci. Mater. Med. 2015;26:5323.

[36] Stajer A, Ungvari K, Pelsoczi IK, Polyanka H, Oszko A, Mihalik E, et al. Corrosive effects of fluoride on titanium: investigation by X-ray photoelectron spectroscopy, atomic force microscopy, and human epithelial cell culturing. J. Biomed. Mater. Res. A 2008;87:450-458.

[37] Reclaru L, Meyer JM. Effects of fluorides on titanium and other dental alloys in dentistry. Biomaterials 1998;19:85-92.

[38] Popa MV, Demetrescu I, Suh SH, Vasilescu E, Drob P, Ionita D, et al. Monitoring of titanium base alloys-biofluids interface. Bioelectrochemistry 2007;71:126-134.

[39] Burnat B, Walkowiak-Przybylo M, Blaszczyk T, Klimek L. Corrosion behaviour of polished and sandblasted titanium alloys in PBS solution. Acta Bioeng. Biomech. 2013;15:87-95.

[40] Singh A, Singh BP, Wani M, Kumar D, Singh J, Singh V. Effect of anodization on corrosion behaviour and biocompatibility of $\mathrm{Cp}$-titanium in simulated body fluid. Bull. Mater. Sci. 2013;36:931-937.

[41] Kim K, Lee BA, Piao XH, Chung HJ, Kim YJ. Surface characteristics and bioactivity of an anodized titanium surface. J. Periodontal Implant. Sci. 2013;43:198-205.

[42] Song H-J, Kim M-K, Jung G-C, Vang M-S, Park Y-J. The effects of spark anodizing treatment of pure titanium metals and titanium alloys on corrosion characteristics. Surf. Coat. Technol. 2007;201:8738-8745. 


\section{Section 4}

Non Autogenous Grafting Healing Pattern 

Chapter 9

\title{
Biodegradation of Injectable Calcium Phosphate Bone Cements: A Dental Perspective
}

\author{
Volkan Arısan \\ Additional information is available at the end of the chapter
}

http://dx.doi.org/10.5772/62789

\begin{abstract}
The prevalence of tooth loss and edentulism is among the most ubiquitous diseases of human history. Dental implants have been widely used for the treatment of any type of edentulism. However, the absence of sufficient bone volume usually limits the placement of implants. Many techniques and materials have been developed to restore an adequate volume of bone for future implant placement, but the process of biodegradation and replacement with new bone tissue is still under debate for all grafting materials. Among the available biomaterials, calcium phosphates (CaP) have been under the spot light for their advantages such as the ease of production and lack of disease transfer. The preparation of the material in two phases allowed self-hardening and subsequent space maintenance where it applied. This was of critical importance in load-bearing implants and joint prosthesis where rapid and strong healing is required. The injectability also allowed a better handling and manipulation in compromised areas such as the oral cavity. A novel form of injectable calcium phosphate cement (iCaP) with two distinct formulations was tested on dog tibiae. Healing and ossification at 4 and 12 weeks were assessed by histologic and histomorphometric analysis. No adverse reactions or negative consequences were noted. Mean new bone formation was 22.12 (SD, 15.68), 18.62 (SD, 13.11), and 9.56 (SD, 11.11)\% in the groups 1,2 , and the control, respectively. Statistically, significant higher new bone formation was evident in the groups 1 and 2 as compared to the control group $(\mathrm{p}<0.01)$. However, these differences were no more discernable after 12 weeks of healing. The results of the present investigation showed excellent in vivo biocompatibility but insufficient biodegradation of the $\mathrm{iCaP}$ in the center of the defect area. Further attempts are required to expedite the biodegradation of the iCaP.
\end{abstract}

Keywords: Calcium phosphate, dental implant, dentistry, bone graft, bone defect, bone regeneration, histology, biomaterial 


\section{Introduction}

Calcium phosphate is the group name of minerals consisting of diverse ions. The fundamental ion group calcium $\left(\mathrm{Ca}_{2}^{+}\right)$is coupled by the orthophosphates-a basic ion of distinctive atoms and molecules within varying organisms to form many different compounds essential to vitality [1]. Metaphosphates and pyrophosphates and occasionally hydroxide or hydrogen ions also contribute this family forming various combinations of crystalline configurations [2]. Mineralization of these ions and molecules constitutes the main frame of multicellular residents (the bone) including the human [3]. Some of the important subcategories of the calcium phosphates are as follows:

\subsection{Mono calcium phosphate}

Monocalcium phosphate is an inorganic compound mainly found as monohydrate salts. Monocalcium phosphates are widely used in the food industry to enhance baking, rising, and longevity issues. One of the main ingredients in baking powder is monocalcium phosphate. It is also used as a leavening agent in various processes. Phosphoric acid is used to treat the monocalcium phosphates to sustain their purity. Together with the fluorapatite, it can be converted to superphosphates, which are used in fertilizers [3].

\subsection{Di-calcium phosphates}

This form of the calcium phosphates mainly consists of the "brushite"-type calculus and could be formulated as monohydrate dihydrate and anhydrous crystalline structures. They are used as a dietary supplement in many of the low-calorie foods [4].

\subsection{Tri-calcium phosphates}

The calcium phosphate of phosphoric acid is named as tri-calcium phosphate and mainly derived from inorganic substances such as whitlockite mineral rocks. Tri-calcium phosphates are one of the main metabolic products of bone tissue and - the beta tri-calcium phosphatesespecially have been under serious investigation by many researchers. With the evolution of sophisticated techniques and controlled sinterization methods, a biphasic form was supplied and termed as "biphasic calcium phosphate." This final form provided significant benefit, especially in bone surgery. A powder and liquid form which could be provided in a small physical carrier could be mixed and injected to the desired area like a tool paste. The material can be shaped and contoured in situ, and a hardening process takes place within $10 \mathrm{~min}$. This is of utmost importance in bone defects requiring space maintenance. A semi-permeable membrane could be played over the hardened biphasic calcium phosphate body for further osteogenesis [5].

\subsection{The calcium apatite}

It forms the hydroxyapatite by a hexagonal crystalline system which $70 \%$ of the body bone mass is made of. Accordingly, hydroxyapatite can be considered as a principal component of 
the human skeleton, including the teeth dentin and enamel. The carbonated calcium-deficient hydroxylapatite which is a modified form of the hydroxyapatite is the foremost mineral in teeth tissues. Regarding the importance of the material, many synthesis methods were proposed including wet chemical deposition, sol-gel route (wet-chemical precipitation), electrodeposition, and biomimetic deposition. Hence, many studies yielded an enhanced response of the bone tissues when the hydroxyapatite is implanted. Consequently, many modern joints or hip prostheses are coated by hydroxyapatite to facilitate healing and osseointegration (direct bone deposition on the titanium surface). This approach was also used in the dental implants, but higher production costs and relatively lower bone-contact surface of dental implants did not justify its feasible use. Blocks of porous hydroxyapatite are also used for the restoration of the bone defects and local drug delivery [4].

Besides the mentioned types of calcium phosphates, there are other crystalline configurations such as octacalcium phosphate, tetracalcium phosphate, and amorphous calcium phosphate [6].

\subsection{CaP cement}

It is defined as a powder or a mixture of powders which following the mixing into water or an aqueous medium to a paste, reacting in room or normal body temperature by the formation of a precipitate containing of one or more calcium phosphate crystals and sets by the entanglement of the crystals of that precipitate. In the hardening phase, the material can be injected into any desired area. This greatly improves the manipulation [7].

\subsection{Self-hardening injectable iCaP}

The self-setting forms of $\mathrm{CaP}$ were introduced by Brown and Chow [8]. The material gained high popularity and interest due to its mechanical and biologic properties [8]. When used as a grafting material, its application promoted a higher level of bone repairing with some noted problematic issues. The difference of the crystalline composition and final amorphous form was found to be not favorable in terms of biocompatibility [9]. This was overcome by different sintering and preparation techniques leaving a higher percentage of organic form in the latest setting.

In almost all clinical and experimental studies, the material was accepted and healed rapidly [3]. However, histologic sections revealed limited biodegradation of the material. This was especially critical when a functional implant is to be placed on the area. Any load-bearing functional implant is expected to be surrounded by living bone tissue, which is called as osseointegration [10]. Upon the use of alloplastic materials around load-bearing implants, the replacement of the grafting material was not of a concern. The inert behavior of the materials was favored rather than the bone replacement (creeping substitution). The widespread use of dental implants then yielded the need of bone replacement of any graft material applied for the treatment of the lost bone volume. Up until then, the term "resorption" was being used to define the dissolution of the grafting materials. However, this was rather associated with a pathologic response so "biodegradation" was used instead of resorption [11]. 


\subsection{Biodegradation}

Occasionally defined as "resorption" can be defined as the dissolution of the graft material by the body biology [1]. Specifically, when used in bone defects, the CaP are expected to be removed by polymorph nucleated cells and simultaneously replaced by bone deposition by osteoblasts and other bone-inducing cells. In the description of this process, the "resorption" term was being used to define a group of inflammatory cells and subsequent tissue repair. In contrast to the repair process, biodegradation was then found appropriate for defining the dissolution of organic materials for a regeneration result [12]. Biodegradation is especially used in product packing when environmental issues are considered [7]. The biodegradation potential is distinct in different graft materials (Table 1).

\begin{tabular}{|c|c|c|c|c|}
\hline \multirow{3}{*}{$\begin{array}{l}\text { Type of graft transfer } \\
\text { Within the same species } \\
\text { (autografts) }\end{array}$} & \multicolumn{2}{|c|}{ Bone-inducing effect (osteoinductive) } & \multirow{2}{*}{$\begin{array}{l}\text { Space maintenance } \\
\text { (osteoconductivity) }\end{array}$} & \multirow{2}{*}{$\begin{array}{l}\text { Vital cell } \\
\text { proliferation } \\
\text { (osteogenesis) } \\
\text { レレレ }\end{array}$} \\
\hline & Potency & $v v$ & & \\
\hline & $\begin{array}{l}\text { Biodegradation } \\
\text { characteristic }\end{array}$ & Surface resorption & & \\
\hline Between the different & Potency & $\checkmark$ & $\checkmark v$ & $\checkmark$ \\
\hline species (allografts) & $\begin{array}{l}\text { Biodegradation } \\
\text { characteristic }\end{array}$ & $\begin{array}{l}\text { Inconsistent and/or } \\
\text { incomplete }\end{array}$ & & \\
\hline Transfer from non-vital/ & Potency & $\checkmark$ & レレレ & Not applicable \\
\hline $\begin{array}{l}\text { synthetic sources } \\
\text { (alloplasts) }\end{array}$ & $\begin{array}{l}\text { Biodegradation } \\
\text { characteristics }\end{array}$ & Incomplete & & \\
\hline
\end{tabular}

Table 1. Biodegradation and osteogenesis potential in various types of bone grafts.

\subsection{The relevance of the biodegradation in oral reconstruction}

The skeleton constitutes the principal internal framework that allows the structural integrity of the organs. It also provides many biomechanics aspects of mobility [13]. More than 200 different types of bones create a critical support for many of the organs and elements. Among these, the face and jawbones that are embriogenetically derived from the pharyngeal arch to have unique features from rest of the body bone that is constructed via the endochondral ossification. The neural crest that the skull is originating attains its particular characteristics for specific purposes such as the protection of the brain tissue and formation of the first digestion component: the jaws and teeth. Any loss or damage in the jaws or teeth was one of the major health problems that the humanity faced upon the early ages. Due to its accessibility, the calcium phosphates-based materials were the first choice in the repair and restoration of jawbones [14]. Initial application of the raw material was not practical due to the powder form. Following particulate forms, improved the outcomes. However, they yielded difficulty in the 
contention of the defect area in the presence of bleeding [15]. Especially in the oral cavity, the conceded are may be subjected to forces and irritating factors resulting with the geometric violation of the graft area and a poor outcome (Table 2).

\begin{tabular}{ll}
\hline Name & Characteristics and biodegradation \\
\hline Calcium phosphates (CaP) & Constitute the inorganic matrix of the bone \\
Resorbable hydroxyapatite (HA) & Rapid biodegradation. Small particles may lead foreign body reaction \\
Tri-calcium phosphate (TCP) & High biocompatibility and moderate biodegradation \\
Dense HA & Resistant to biodegradation. Long-term space maintainer \\
Porous HA & Faster biodegradation than dense HA \\
Bioglass & Non-degradable. High biocompatibility in bone \\
Calcium carbonate & Inconsistent biodegradation \\
Calcium sulfates (the Paris plaster) & Rapid biodegradation \\
\hline
\end{tabular}

Table 2. Classification of CaP materials and their biodegradation characteristics.

\subsection{Injectable $\mathrm{CaP}$ in clinical dentistry}

Amorph and hydrous forms opened a new horizon with the cement-like setting feature. In this form, a powder (amorph component) and liquid (hydrous form) component is mixed to create a reaction of hardening just like a cement. While in its hardening stage, the material is in a "flowable" state allowing easy transfer and shaping according to the defect-site-specific conditions. This feature is then used as "inject ability" for enhancing the practical aspect of the calcium phosphate-based bone-grafting sequence. The primary results were favorable except one phenomenon present in almost all histologies. The core of the material was found intact in situ despite the abundant bone formation in the graft-to-host bone border. Initial observations revealed that the material was highly biocompatible but lacked porosity yielding a bulky end product. As a result, the body fluids could penetrate the material only from the surface but did not reach to the core of the material. This aspect may of course be advantageous in some specialties of dentistry such as endodonty. The material applied to the root of the natural teeth after the removal of the vital structures known as the root canal therapy. The material successfully sealed the canals (even the side canals known as the isthmus) hermetically and caused no foreign material reaction the tooth-apex. The resistance of the material to resorption and biodegradation allowed long-term stability and success of the treatment known as the root canal therapy. However, in the restoration of the lost bone volume, the lack of complete translation of the injectable calcium-phosphate-bone cement (iCaP) into the bone tissue was a challenge [16]. Especially in oral implantology where a titanium fixture is expected being surrounded by living bone tissue (osseointegration) and any intact form of graft material was undesirable (Figure 1). 


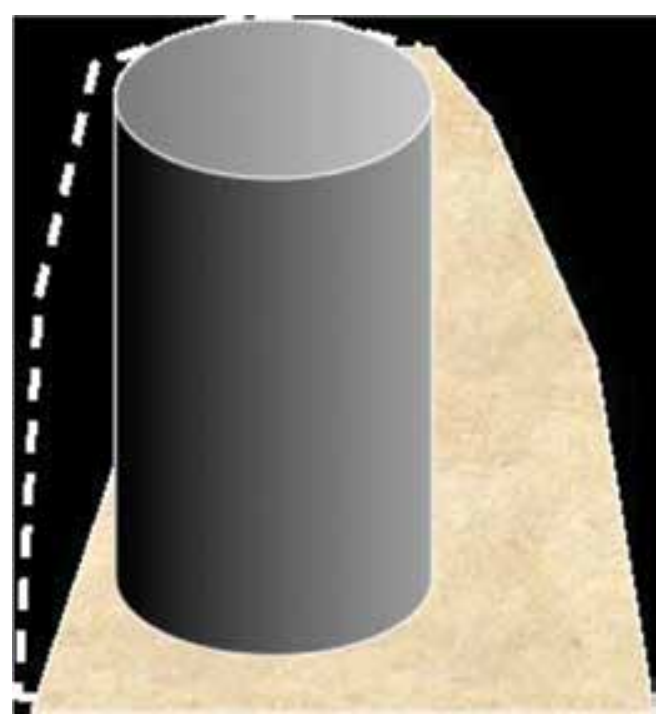

Figure 1. A dental implant placed into the alveolar crest should be surrounded by living bone tissue. Any lack of bone that is described as the dehiscence defects (intermittent lines) should be covered by a graft material with an osteogenesis potential.

\subsection{Biodegradation of injectable CaP}

Many attempts have been undertaken to overcome the issues related to biodegradation of the iCaP. A series of powder and mixture settings was formulated and experimented on animal models to reveal the best configuration. The hydrous component allowed fine-tuning of the setting time and flowability characteristics, while the powder component was mainly related with the final hardness of the cement. Concomitantly, a porous character was obtained for gaining better flow and penetration by bodily cells and fluids. A delicate balance of the setting time, ease of injectability, and the final setting hardness was a constant challenge in the development stage in many previous studies [17].

\section{Experimental study}

In order to optimize the biodegradation of the injectable $\mathrm{CaP}$, three different formulations were deduced be tested experimentally to achieve an objective comparison. In this respect, a dog model was chosen due to the available bone volume. The tibia was the choice of defect creating since the oral cavity may pose significant infection and mastication forces risks. After the retrieval of an ethical approval, six beagle dogs were housed for the experiment, and the tibias were exposed after the general anesthesia. Three standard bone defects were created in the proximal tibia of animals, and the mentioned $\mathrm{iCaP}$ formulations were mixed and injected into the defects. One defect was left empty to serve as control. All animals were injected with fluorochrome labels in the first and last week of healing to discriminate the pattern of healing 
on the histology. The animals were sacrificed after 4 weeks, and bone biopsies were obtained from the defect sites. The samples were processed according to the non-decalcified histology protocol. The histologic slices were obtained and subjected to histomorphometric analysis for objective comparison.

\subsection{The injectable CaP cements}

The cements were founded as powder and liquid components in a capsule carrier and are readily available for mixing (Figure 2).

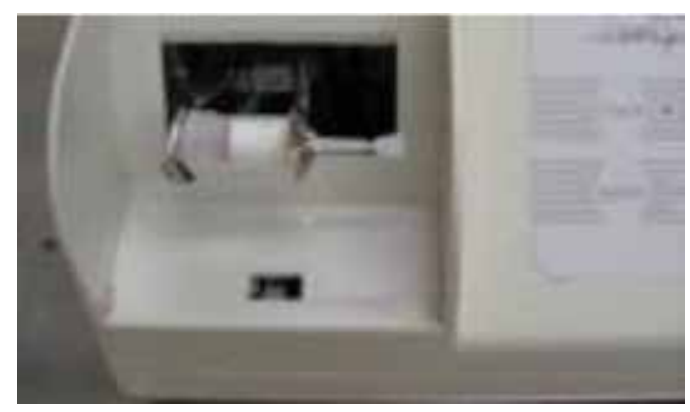

Figure 2. The injectable CaP was provided in a ready-to-mix tube. The powder and liquid form is separated by a plastic barrier. Prior to the placement to the shaker (i.e., amalgamator), the barrier plastic is removed thereby allowing the mixing of the components. The material is shaken for $30 \mathrm{~s}$ for proper viscosity.

After mixing, the iCaP cement can be injected to the defect and cured in a similar manner to others cement materials.

Tetracalcium phosphate (TTCP: $\left.\mathrm{Ca}_{4}\left(\mathrm{PO}_{4}\right)_{2} \mathrm{O}\right)$ and an hydrous di-calcium phosphate $\mathrm{CaHPO}_{4}$ are mixed 2:5 molar and obtained the $\mathrm{Ca}\left(\mathrm{H}_{2} \mathrm{PO}_{4}\right)_{2} \cdot \mathrm{H}_{2} \mathrm{O}+\mathrm{Ca}_{2} \mathrm{NaK}\left(\mathrm{PO}_{4}\right)_{2}$. The mixture is diluted with $0.5 \mathrm{ml}$ distilled water. The powder was sterilized via $27 \mathrm{kGy}$ gamma radiation. The hydrous part of cements was divided into two groups. In the group 1, the hemi-hydrate part excluded. In group 2, the hemi-hydrate part was included but the concentrations were 5 .

The powder and liquid form was provided in an application tube ready to be inserted in to a mixer. The separator is removed, and the power and liquid forms are mixed for $20 \mathrm{~s}$.

\subsection{Surgical procedures}

All surgical procedures were performed under general anesthesia. The left tibia of the dog was shaved and disinfected with povidone-iodine. During all surgical procedures, the animals were pre-anesthetized with Xylazine (Rompun/ Bayer, Germany) $1.5 \mathrm{mg} / \mathrm{kg}$ intramuscularly [i.m.] and anesthetized by Ketamine (Ketanest/ Alfasan, Holland) $10 \mathrm{mg} / \mathrm{kg}$ i.m. and maintained by isoflurane 3.5\% (volume/volume) (Forane, Abbott Laboratories, Rungis Cedex, France). They were administered through an endotracheal tube. Ten, the bone surface in the proximal tibia region was exposed by an incision followed by skin and periosteal elevation. 
Three recipient sites were prepared, using a drill of $3.8 \mathrm{~mm}$ in diameter to a depth of $13 \mathrm{~mm}$ to obtain standard defect sites. A minimum of $1.5 \mathrm{~mm}$ was sustained between defects to provide adequate healing conditions for the defects.

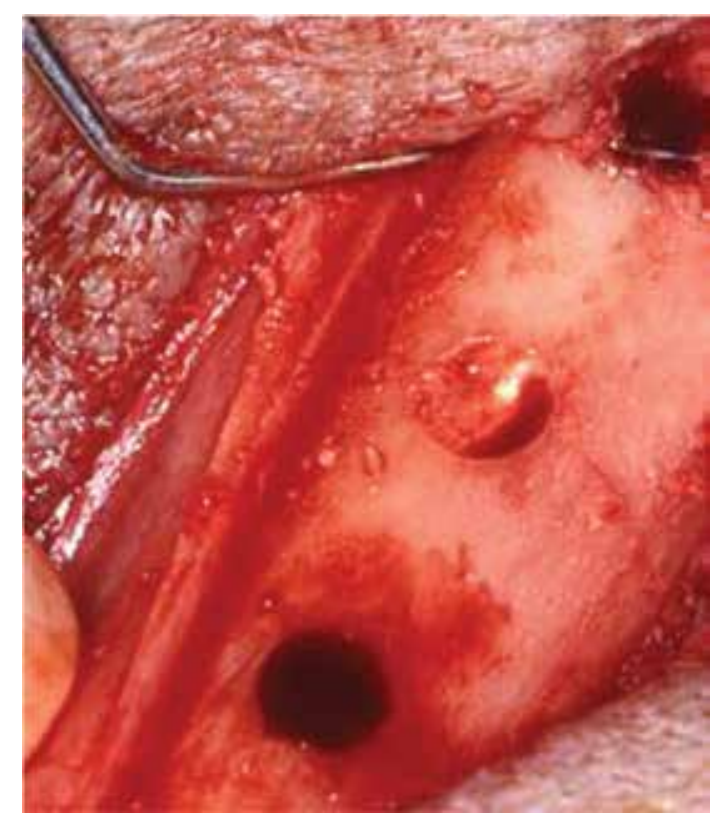

Figure 3. Two standard bone defects (a diameter and depth of 3.8 and $13 \mathrm{~mm}$ respectively) were prepared for the injection of groups 1 and 2 (middle and the right defect). One defect (on left side) was left empty to serve as control.

After achieving bleeding control, iCaP cement capsule placed in amalgamator for $20 \mathrm{~s}$, after that iCaP cement injected in all defect except one defect for each animal left empty (Figure 3).

After the removal of the residual cement, 10 min time was exceeded for the setting of the material. Then, the periost and dermis sutured with vicryl 3-0 suture material (Ethicon, Polyglactin 910, Chicago, A.B.D). In order to monitor patterns of bone formation, hydrochloric tetracycline (at the 4th week (Tetra, Mustafa Nevzat İlaç Sanayı, Istanbul, Turkey) and Alizarin complexone (Sigma-Aldrich, Bonn, Germany); (at the 11th week) were injected intravenously (I.V.). The animals were fed with standard diet throughout the 12-week recovery period. At the end of the 12 weeks, the animals were sacrificed by an overdose of sodium pentobarbital (Abbot Lab. Chicago A.B.D).

\subsection{Histologic preparation and analysis}

The block biopsies taken from the proximal tibias, stored in phosphate-buffered solution and maintained at $4^{\circ} \mathrm{C}$. The blocks were dehydrated with a series of alcohols and put into a transparent flask filled with methyl methacrylate. This was essential for the non-decalcified histologic sections. Following the polymerization, the blocks were removed from the flask and using the Donath technique, $395 \mu \mathrm{m}$ non-decalcified sections were obtained. A total of three 
sections were taken from each defect. The first two sections stained with methylene blue and basic fuchsin, and the third section with the thickness of $390 \mu \mathrm{m}$ was taken without staining for fluorescence analysis. For the analysis, the sections were magnified under $\times 100$ light magnification of a stereo microscope. The new bone and residual area was calculated manually using dedicated software (Olympus Image Analyzer, Tanaka, Japan). The percentage of new bone and the residual graft area was calculated.

\subsection{Statistical analysis}

The normality of the results was controlled by the Shapiro-Wilk Normality test. Student t-test was used for the statistical analysis. All analyses were performed by the GraphPad Prism software (San Diego, California, USA).

\section{Results}

The injection and the manipulation of the CaP were easy, and the material was set in almost $15 \mathrm{~min}$. However, this period of time can be considered long for the clinical work. Also, in the presence of bleeding, the setting of the material was compromised and particles washed away by the blood. After the self-hardening, the manipulation of the soft tissues for suturing was rather easy.

Throughout the healing period (up to12 weeks), no local or general problems or complications were observed in the animals. The surgical area healed quickly in all dogs without any signs of a developed pathology. Radiographic examination showed no pathological changes at the surgical zone.

\subsection{Light microscopic examination}

All the histological cross-section views of the CaP graft material have showed bone integration. A dense trabecular bone structure was also noticed around the grafted area. A thin cortical bone layer surrounded a trabecular woven bone. In this layer, the particles of the CaP cement were in the center of the defect and substituted by a thick layer of trabecular bone tissue. Almost in all the histological sections, the coronal aspect of the injectable $\mathrm{CaP}$ graft was surrounded by a layer of cortical bone. At high magnification, the Howship lacunae (osteoclast resorption lacunae) were seen at the zone adjacent to the graft material. A continuous layer of osteoid deposition followed biodegradation of the graft material. The outer part of the graft core was replaced with new bone, but the core part (inner part) of the cement was not biodegraded. In contrary to the outer part (the sections in contact with the native bone), the center section was still intact. The graft material was strictly placed into the defect which was in a complete contact with the surrounding bone tissue, and no fibrous tissue or inflammatory reaction was observed in any of the histological sections. At the early stage of healing active angiogenesis and osteogenesis have been shown, and no inflammatory symptoms were seen. (Figures 4 and 5) 


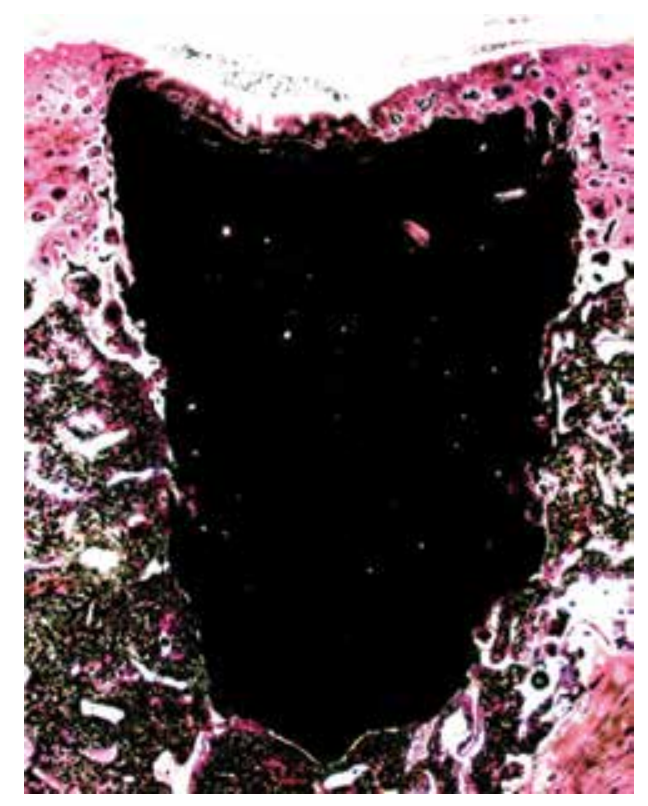

Figure 4. Group 1. Four weeks healing. Basic fuchsin and toluidine staining. Original magnification $\times 10$. The un-resorbed bulk material can be seen in the middle of the defect. Osteoid deposition is evident in the borders of the material. No inflammatory evidence is visible.

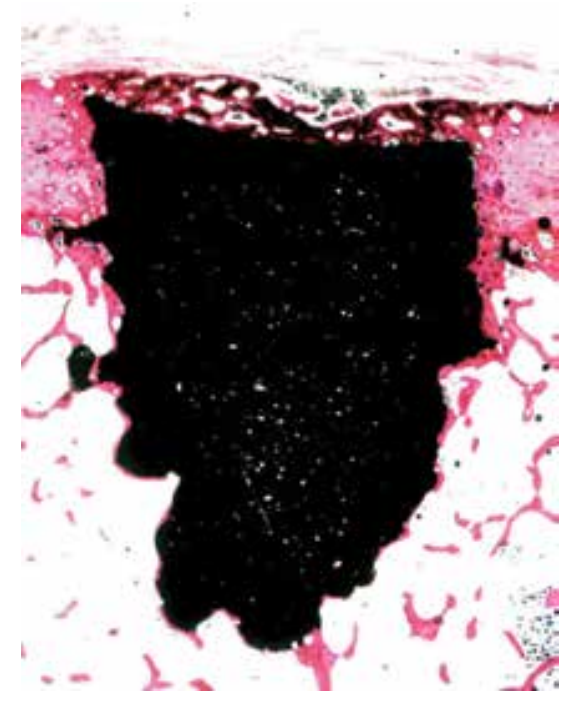

Figure 5. Group 2. Four weeks healing. Basic fuchsin and toluidine staining. Original magnification $\times 10$. The apical portion of the material has been replaced by living bone tissue characterized by large trabecular zones. The material is not biodegraded completely as marked by the dark area. However, the iCaP shows excellent integration with the host bone. 
At 12th week, the process of new bone apposition and mineralization was still visible. Moreover, the graft found at the base of the defect and next to the cortical bone has been degraded by osteoclast-like cells. At higher magnification, both dense trabecular area and unlimited osteoblast like cells, primary, and secondary osteons were found in the space between the vessels at the regenerated bone. In this time frame, it was evident that the formation of osteoid tissue began growing from the defect walls and continues toward the center (Figures 6 and 7).

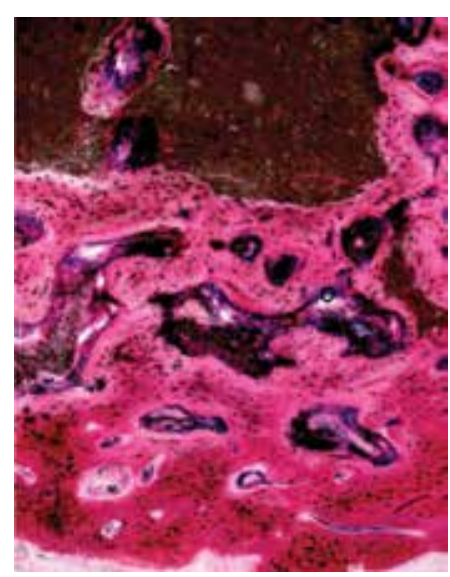

Figure 6. Group 1. Twelve weeks healing. Basic fuchsin and toluidine staining. Original magnification, $\times 100$. The floor of the defect is focused. High magnification in the apical portion reveals direct contact the living bone tissue with vital cells and ongoing ossification. Osteoid deposition is characterized by osteocytes (small dots) lines at the iCaP border. The iCaP material is being penetrated by small indentations (Howship lacuna) derived from the host bone tissue.

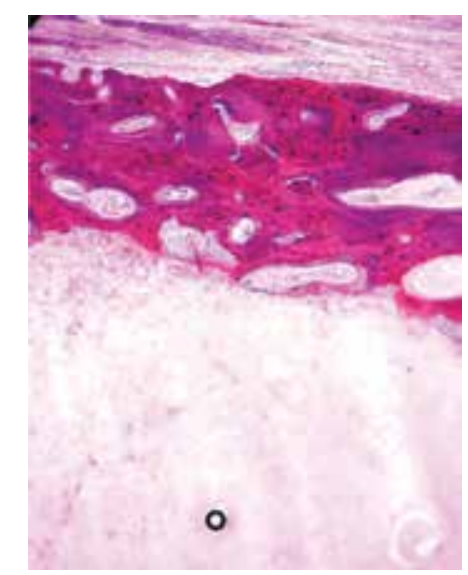

Figure 7. Group 2. Twelve weeks healing. Basic fuchsin and toluidine staining. Original magnification, $\times 100$. Coronal part of the defect is focused. In the coronal aspect, the iCaP material is covered with new bone tissue. Despite the fragments of small ossification points, the iCaP material has not biodegraded (white bulk in the lower aspect of the image). 
In the control defect, the cervical part of the defect was filled with soft tissue. On the contrary, the apical part was filled with mature bone. Low-mineralized primary osteoid was also seen especially at the borders of the defect in both the control and test groups.

\subsection{Fluorescence microscopic examination}

The use of fluorochrome labels allowed observation of the bone growth and the position of the new bone that occupied the grafted space in relation with the time frame. The tetracycline HCL applied in the 4th week stains the mineralization by green color (Native bone in dark green and new bone in light green). The alizarin complexone applied in the 11th week stains the mineralized tissues in orange color (Native bone dark orange/red/brown and new bone in light orange). Accordingly, tetracycline HCL stain was seen at borders of the defect at the 4th week sections. This indicates that the formation of this bone started shortly after CaP placement. The histological cross-section of the CaP-grafted area at the 12th week showed a continuous formation of bone and remodeling. It was evident that a bone turnover was ongoing throughout both the intervals. The rate of new bone formation was within normal physiology limits. The formation of the bone initiated from the borders of the defect towards the center (Figures 8 and 9).

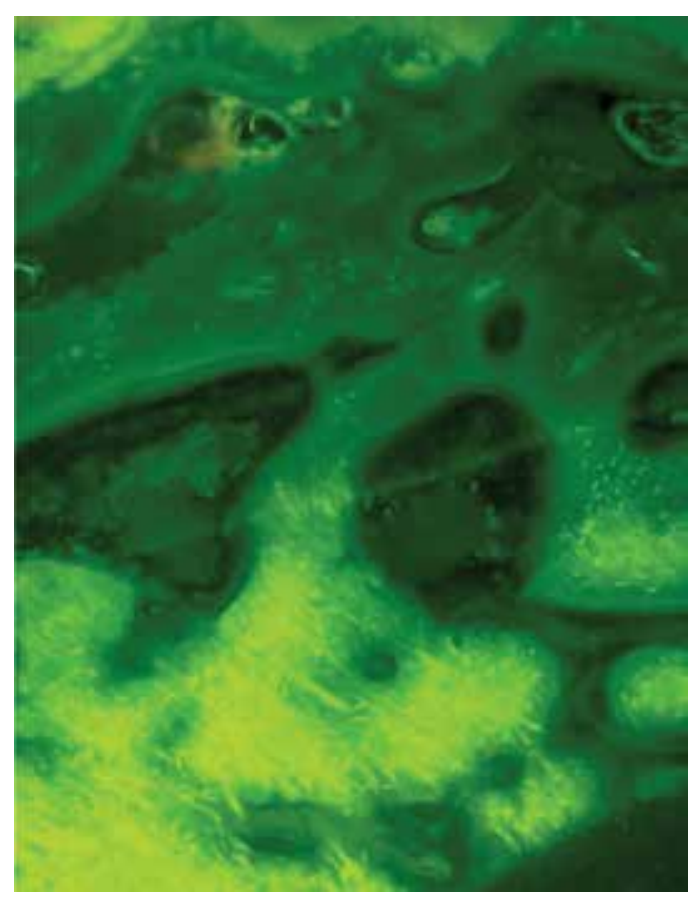

Figure 8. Fluorescence microscopy view of the 4 weeks healed defect in group 1 . Light green staining reveals new bone formation. Original magnification, $\times 200$. Coronal side of the defect is focused. Light green areas depicting ongoing osteogenesis around the iCaP area (right bottom corner). It is obvious that the osteogenic activity started soon after the placement of the iCaP. 


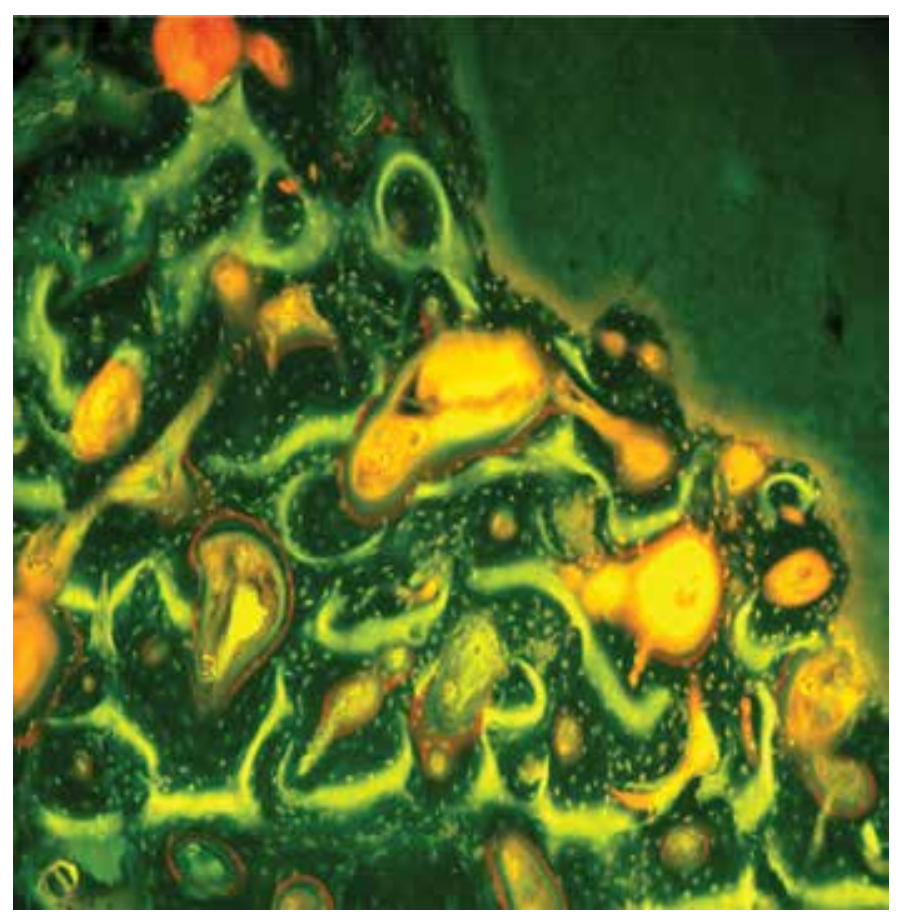

Figure 9. Fluorescence microscopy view of the 12 weeks healed defect in group 2. Light green and orange staining reveals new bone formation. Original magnification, $\times 150$. Apical side of the defect is focused. Orange circles and lines reveal bone active remodelation and formation in the 11th week. The iCaP is being replaced by trabeculas of new bone. The bone formation that is evident on the 4th week (light green staining) is being deposited by osteocyte lamellas (orange color) in the 11th week.

\subsection{Histomorphometric analysis}

Mean new bone formation was 22.12 (SD, 15.68), 18.62 (SD, 13.11), and 9.56 (SD, 11.11)\% in the groups 1, 2, and the control, respectively. Statistically, significant higher new bone formation was evident in the groups 1 and 2 as compared to the control group $(\mathrm{p}<0.01)$. However, these differences were no more discernable after 12 weeks of healing (Figure 8).

The rate of residual iCaP was similar in both time intervals. In the 4 weeks healing group, almost half of the iCaP was still present in both groups and there were no statistically significant differences between the groups 1 and 2. After 12 weeks, the biodegradation was evident. However, complete biodegradation of the iCaP was not evident in any groups 45.44 (SD, 22.16) and $41.20(21.20) \%$ for groups 1 and 2, respectively; (Figure 9).

Cellular evaluation of the histologic slices in the groups yielded no inflammatory response or foreign body reaction. Histomorphometry taken together with the fluorescence sections reveals that new bone formation initiated right after the surgery at the $\mathrm{iCaP}$ and host bone border. In both groups, the staining in the 4 th and 11th weeks was similar. It is obvious that the cells involved in bone turnover infiltrate the $\mathrm{iCaP}$ body by small indentations and the 
biodegradation was sparsely conducted in the roots of these indentations. The bulk and nonporous nature of $\mathrm{iCaP}$, unfortunately, inhibited the infiltration of cells responsible in the biodegradation. This was characterized by orange stains in the 11th week, and there were not visible differences between the groups (Table 3).

\begin{tabular}{|c|c|c|c|}
\hline & Group 1 & Group 2 & Control \\
\hline $\begin{array}{l}\text { 4th week } \\
\text { (tetracycline } \\
\text { staining) }\end{array}$ & $\begin{array}{l}\text { Osteoid deposition and new bone } \\
\text { formation visible in all histologic } \\
\text { sections. Major mass of the } \mathrm{iCaP} \text { is } \\
\text { visible }\end{array}$ & $\begin{array}{l}\text { Osteoid deposition and new bone } \\
\text { formation visible in all histologic } \\
\text { sections. No significant } \\
\text { biodegradation is visible }\end{array}$ & $\begin{array}{l}\text { Osteoid deposition and new } \\
\text { bone formation visible at } \\
\text { bottom side of the defect. The } \\
\text { coronal aspect of the defect is } \\
\text { lacking bridging }\end{array}$ \\
\hline 11th week & $\begin{array}{l}\text { New bone formation is evident in } \\
\text { all sections. A thin layer of new } \\
\text { bone tissue is bridging over the } \\
\text { iCaP. No sections reveal complete } \\
\text { biodegradation of the iCaP }\end{array}$ & $\begin{array}{l}\text { New bone formation and lamellar } \\
\text { formation is evident in all sections. A } \\
\text { thin layer of new bone is bridging the } \\
\text { top of the defect. iCaP was not } \\
\text { biodegraded and left intact, } \\
\text { especially in the center of the defect }\end{array}$ & $\begin{array}{l}\text { The bone defect is being } \\
\text { filled with trabecular bone. } \\
\text { The amount of new bone } \\
\text { formation is less than the } \\
\text { group } 1 \text { and } 2\end{array}$ \\
\hline
\end{tabular}

Table 3. Evaluation of biodegradation in groups 1 and 2 as compared to the control group.

\section{Discussion}

The restoration of the lost bone volume would be one of the most concerned topics in the future of dentistry. Given the prevalence of edentulism and tooth loss, more people are likely to apply for a fixed prosthetic restoration approach. Dental implant is an excellent base for such purposes. Unfortunately, the bone volume rapidly decreases due to the atrophy in lack of the functional stimulus [16].

In the restoration of an alveolar bone defect, the autogenous bone transfers are regarded as the golden standard. However, they are difficult manage and prone to many complications in the short and long term. Hence, extensive surface resorption, especially in the iliac grafts, questions their effective use. Nevertheless, the contents of living bone cells are critical for rapid healing [3]. The iCaP lacks any living cells and does not incorporate relevant growth factors or boneinducing elements. Therefore, its application and efficacy fundamentally depend on the vascularization of the native bone [18]. Moreover, the open nature of the iCaP allows integration of any desired elements, cells, or components that may be tailored according to the sitespecific needs. The results of the present investigation are promising, and the iCaP seems suitable for further development for efficient and inexpensive bone regeneration purposes (Figures 10 and 11). 


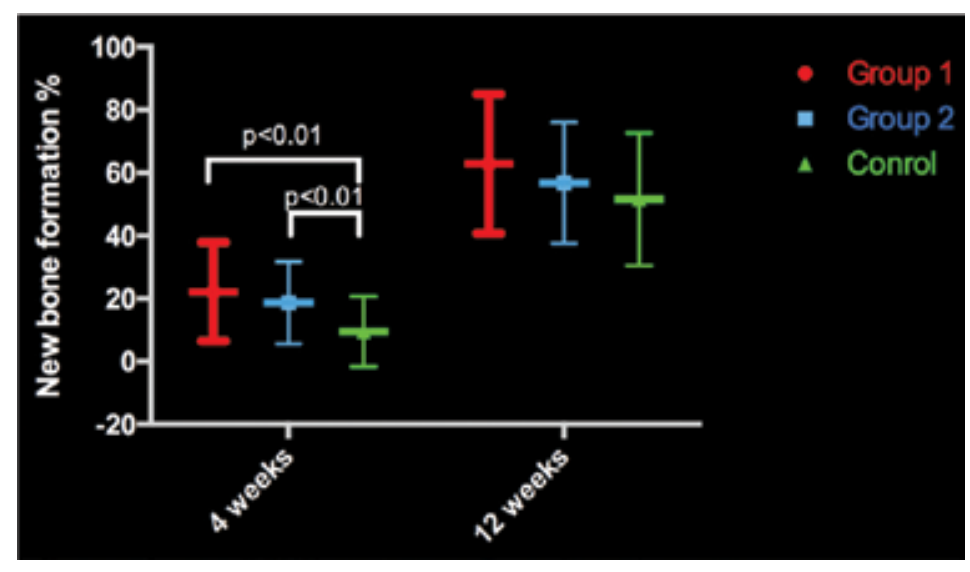

Figure 10. New bone formation measured in the time intervals.

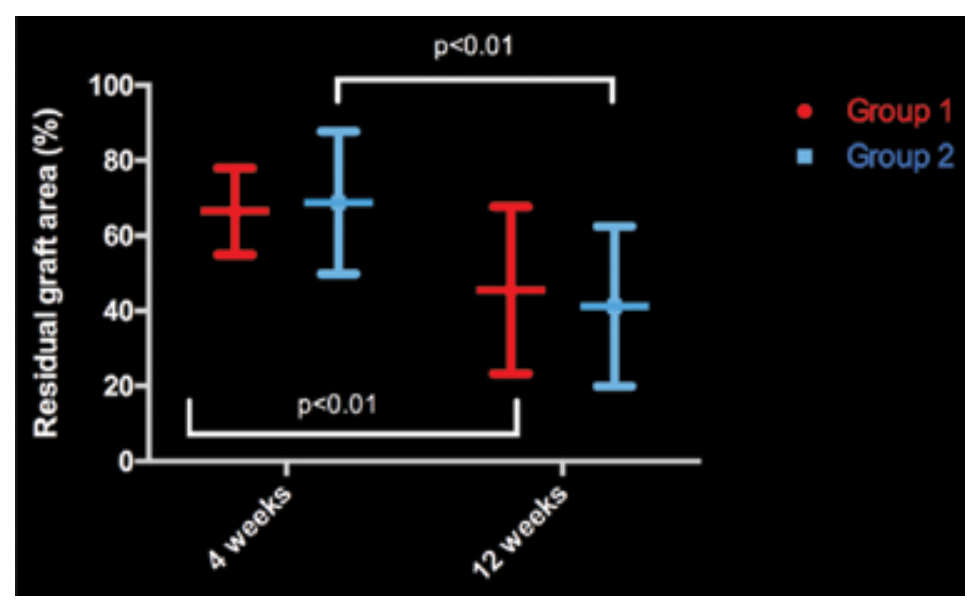

Figure 11. Residual graft area measured in the time intervals.

After 4 weeks of healing, a considerable amount of new bone was evident in both groups as compared to the control defect. Nevertheless, there were no statistically significant differences in between these two groups. This may render that the inclusion of hemi-hydrate groups did not yield any positive influence in terms of new bone formation.

After 12 weeks of healing, the level of new bone was above $50 \%$ in all the defects and there were no statistically significant differences in the groups or the control defect. This may point the long healing period or the insufficient dimensions of the graft. Even so, there is no consensus on the critical size defects of the tibia in terms of a dental implant osteotomy.

The residual graft was also investigated to corroborate the results of new bone formation. In the 4 weeks, more than $60 \%$ of the injectable $\mathrm{CaP}$ material was still present in the defects. After 12 weeks, the rate of residual $\mathrm{CaP}$ decreased below $40 \%$ in group 2 . The difference was 
statistically significant in none of the time intervals. Histologic section yielded a core material was left non-resorbed right at the center of the defect. Ooms et al. [19] in a study on dog, placed an injectable porous form $\mathrm{CaP}$ graft material into the standardized defects in combination with an experimental titanium implant and found that this material was highly ossified in the whole area, especially in infection cases or in case of few walled bony defects, and also he found out that the material outcome might be high if vascularization is supported. It may be proposed that further porosity is required around the iCaP to allow vascularization and body-fluid penetration.

Many different attempts and experiments have been performed in a purpose to increase the biodegradation of $\mathrm{CaP}$ cement. It is thought that increasing the solubility of $\mathrm{CaP}$ inside the bone results in accelerating the period of biodegradation. Solubility increases in direct proportion to the surface area [20]. The body fluids and their contents such as phagocytic cells expedite the resorption period of the graft when the contact area between the fluids and the graft material increases. As a result, the hardened graft material porosity is expanded so to rise the infiltration of fluids and blood between the graft. Daculsi et al. [21] produced a porous $\mathrm{CaP}$ cement with interporous distance ranges between 100-500 micrometer to introduce a good environment for cell growth.

In the present experimental model, new bone regeneration was ascertained without any complications that might occur thereby of using a barrier membrane such as exposure of the soft tissue and infection. This may be attributed to site of the tibia as the area of the defect. Nonetheless, applying the graft into the oral bone might also have good prognosis with no complications as it was observed in the tibia. Some researchers reported that the use of membrane may be unnecessary as the material acts as a space maintainer. In this study, the four-walled bony defect was involved so that no barrier membrane was used. Hence, new bone formation was occurred in both groups.

\section{Conclusions}

The injectable $\mathrm{CaP}$ cement has an excellent biocompatibility and a good space maintaining ability. No pathologic findings encountered during the period of the present and similar other studies. Injectable from of the $\mathrm{CaP}$ greatly improves the applicability of the material. However, the biodegradation of the present iCaP was similar to those of previous observations. The application of the $\mathrm{CaP}$ yielded better new bone formation as compared to the empty control defects. The center of the graft seen intact at the end of 12 weeks. The inclusion of a hemihydrate component did not effect effected neither the new bone formation nor the residual graft. In both groups and time intervals, in the injectable $\mathrm{CaP}$ was not degraded completely at the end of 12 weeks of recovery time. Supplementary methods are required to fasten the biodegradation process. 


\section{Acknowledgements}

The author thanks Dr. Ata Anıl and Dr. Jakob Wenz for the preparation of the iCaP. Dr. Joop Wolke is acknowledged for the histologic assessment. Dr. Sevda Özel is acknowledged for the statistical analysis of this study. This study was supported by the Turkish Society of Oral Implantology and Istanbul University Research Fund.

\section{Author details}

\section{Volkan Arısan}

Address all correspondence to: varisan@istanbul.edu.tr

Department of Oral Implantology, Faculty of Dentistry, Istanbul University, Çapa, Istanbul, Turkey

\section{References}

[1] Bellucci D, Sola A, Lusvarghi L, Cannillo V. Hydroxyapatite-tricalcium phosphatebioactive glass ternary composites. Ceramics International. 2014;40(2):3805-8.

[2] Habibovic P, Barralet J. Bioinorganics and biomaterials: bone repair. Acta Biomaterialia. 2011;7(8):3013-26.

[3] Labres XR, Camps AR, Salas EJ, Albuquerque R, Ortega EV, Lopez-Lopez J. Graft materials in oral surgery: revision. Journal of Biomimetics Biomaterials and Tissue Engineering. 2014;19(124):1-7

[4] Suzuki O. Octacalcium phosphate: osteoconductivity and crystal chemistry. Acta Biomaterialia. 2010;6(9):3379-87.

[5] Kolk A, Handschel J, Drescher W, Rothamel D, Kloss F, Blessmann M, et al. Current trends and future perspectives of bone substitute materials - from space holders to innovative biomaterials. Journal of Cranio-Maxillofacial Surgery. 2012;40(8):706-18.

[6] Wang J, Qiao P, Dong L, Li F, Xu T, Xie Q. Microencapsulated rBMMSCs/calcium phosphate cement for bone formation in vivo. Biomedical Materials and Engineering. 2013;24(1):835-43.

[7] von Rechenberg B, Génot OR, Nuss K, Galuppo L, Fulmer M, Jacobson E, et al. Evaluation of four biodegradable, injectable bone cements in an experimental drill hole model in sheep. European Journal of Pharmaceutics and Biopharmaceutics. 2013;85(1): $130-8$. 
[8] Brown WE, Chow LC. Effects of neutral salts in a bench-scale caries model. Journal of Dental Research. 1986;65(9):1115-20.

[9] Liu W, Zhang J, Rethore G, Khairoun K, Pilet P, Tancret F, et al. A novel injectable, cohesive and toughened Si-HPMC (silanized-hydroxypropyl methylcellulose) composite calcium phosphate cement for bone substitution. Acta Biomaterialia. 2014;10(7): 3335-45.

[10] Mishra R, Kumar A. Osteocompatibility and osteoinductive potential of supermacroporous polyvinyl alcohol-TEOS-Agarose- $\mathrm{CaCl}_{2}$ (PTAgC) biocomposite cryogels. Journal of Materials Science: Materials in Medicine. 2014;25(5):1327-37.

[11] Wang J, Tian X, Wu S, Meng X, Wen G. Accelerated healing by composites containing herb epimedium for osteoinductive regeneration. Biomedical Materials. 2014;9(3): 035013.

[12] Dorozhkin SV. Bioceramics of calcium orthophosphates. Biomaterials. 2010;31(7):146585.

[13] Oryan A, Alidadi S, Moshiri A, Maffulli N. Bone regenerative medicine: classic options, novel strategies, and future directions. Journal of Orthopaedic Surgery and Research. 2014;9(1):18.

[14] Yang Y-L, Chang C-H, Huang C-C, Kao W, Liu W-C, Liu H-W. Osteogenic activity of nanonized pearl powder/poly (lactide-co-glycolide) composite scaffolds for bone tissue engineering. Bio-medical Materials and Engineering. 2013;24(1):979-85.

[15] Jansen J, Ooms E, Verdonschot N, Wolke J. Injectable calcium phosphate cement for bone repair and implant fixation. Orthopedic Clinics of North America. 2005;36(1):8995.

[16] Lopez-Heredia MA, Bongio M, Bohner M, Cuijpers V, Winnubst LA, van Dijk N, et al. Processing and in vivo evaluation of multiphasic calcium phosphate cements with dual tricalcium phosphate phases. Acta Biomaterialia. 2012;8(9):3500-8.

[17] Li R, Nauth A, Li C, Qamirani E, Atesok K, Schemitsch EH. Expression of VEGF gene isoforms in a rat segmental bone defect model treated with EPCs. Journal of Orthopaedic Trauma. 2012;26(12):689-92.

[18] Dorozhkin SV. Biphasic, triphasic and multiphasic calcium orthophosphates. Acta Biomaterialia. 2012;8(3):963-77.

[19] Ooms EM, Verdonschot N, Wolke JG, Van de Wijdeven W, Willems MM, Schoenmaker $\mathrm{MF}$, et al. Enhancement of initial stability of press-fit femoral stems using injectable calcium phosphate cement: an in vitro study in dog bones. Biomaterials. 2004;25(17): 3887-94. 
[20] Arısan V, Anıl A, Wolke J, Özer K. The effect of injectable calcium phosphate cement on bone anchorage of titanium implants: an experimental feasibility study in dogs. International Journal of Oral and Maxillofacial Surgery. 2010;39(5):463-8.

[21] Daculsi G, Uzel A, Weiss P, Goyenvalle E, Aguado E. Developments in injectable multiphasic biomaterials. The performance of microporous biphasic calcium phosphate granules and hydrogels. Journal of Materials Science: Materials in Medicine. 2010;21(3):855-61. 




\section{Edited by Mazen Ahmad Jawad Amin Almasri}

The discipline of dental implantology is one of the scientific medical/dental fields that are moving dynamically very fast. Not to mention the multiple specialties involved in managing the service as well as the research production. As much as it is necessary to have books to review the basics of bone healing, cellular biology, and implant rehabilitation planning, it is very critical to have more focused books to link the dots and elevate the benchmark of success even higher, especially when facing the reality of more advanced case challenges nowadays. "Dental Implantology and Biomaterial" presents four main sections covering topics of clinically applied "tips and tricks", the reality of transmucosal implant surface, the future of ceramic implants, the revolution of implant surface treatment, and finally the application of nonautogenous graft in the treatment process. The aim is updating the practitioners, researchers, and postgraduate trainees in the field with up-to-date clinically applied topics focused on reducing the gap between research and clinical application. Doing so will not only optimize the practice but also advance it with evidence-based maneuvers and technical details. 